\title{
MSTER \\ Preliminary Geochemical And \\ Physical Testing Of Materials For \\ Plugging Of Man-Made Accesses \\ To A Repository In Basalt
}

\author{
Charles L. Taylor \\ Gary J. Anttonen \\ John E. O'Rourke \\ Daniel Allirot
}

Prepared for the United States

Department of Energy

Under Contract DE-AC06-77RL01030

Rockwell International

Rockwell Hanford Operations Energy Systems Group

Richland, WA 99352 


\section{DISCLAIMER}

This report was prepared as an account of work sponsored by an agency of the United States Government. Neither the United States Government nor any agency Thereof, nor any of their employees, makes any warranty, express or implied, or assumes any legal liability or responsibility for the accuracy, completeness, or usefulness of any information, apparatus, product, or process disclosed, or represents that its use would not infringe privately owned rights. Reference herein to any specific commercial product, process, or service by trade name, trademark, manufacturer, or otherwise does not necessarily constitute or imply its endorsement, recommendation, or favoring by the United States Government or any agency thereof. The views and opinions of authors expressed herein do not necessarily state or reflect those of the United States Government or any agency thereof. 


\section{DISCLAIMER}

Portions of this document may be illegible in electronic image products. Images are produced from the best available original document. 


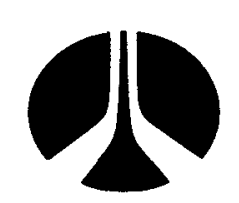

\title{
Rockwell International
}

\author{
Rockwell Hanford Operations \\ Energy Systems Group \\ Richland, WA 99352
}

\begin{abstract}
DISCLAIMER
This report was prepared as an account of work sponsored by an agency of the United States Government Neither the United States Government nor any agency thereof, nor any of their employees, makes any warranty, express or implied, or assumes any legal liability or responsi bility for the accuracy, completeness, or usefulness of any information, apparatus, product, or process disclosed, or represents that its use would not infringe privately owned rights Refer ence hereın to any specific commercial product, process, or service by trade name, trademark, manufacturer, or otherwise, does not necessarily constitute or imply its endorsement, recom mendation, or favoring by the United States Government or any agency thereof The views and opinions of authors expressed herein do not necessarily state or reflect those of the United States Government or any agency thereof
\end{abstract}


PRELIMINARY GEOCHEMICAL AND PHYSICAL TESTING OF MATERIALS FOR PLUGGING OF MAN-MADE ACCESSES TO A REPOSITORY IN BASALT

\author{
by \\ Charles L. Taylor \\ Gary J. Anttonen \\ John E. O'Rourke \\ Daniel Allirot
}

April 1980

\begin{abstract}
Prepared for Rockwell Hanford Operations
A Prime Contractor to the U.S. Department of Energy, Under Contract Number DE-AC06-77RL01030
\end{abstract}

NOTICE

This report was prepared as an account of work sponsored by an agency of the United States Government. Neither the United States Government, nor any agency thereof, nor any of their employees, makes any warranty, express or implied, or assumes any legal liability or responsibility for the accuracy, completeness, or usefulness of any information, apparatus, product or process disclosed, or represents that its use would not infringe privately owned rights. Reference herein to any specific commercial product, process, or service by trade name, trademark, manufacturer, or otherwise, does not necessarily constitute or imply its endorsement, recommendation, or favoring by the United States Government or any agency thereof. The views and opinions of authors expressed herein dc not necessarily state or reflect those of the United states Government or any agency thereof.

WOODWARD-CLYDE CONSULTANTS

Consulting Engineers, Geologists, and Environmental Scientists Three Embarcadero Center, Suite 700

San Francisco, California 94111 
PRELIMINARY GEOCHEMICAL AND PHYSICAL TESTING OF MATERIALS FOR PLUGGING OF MAN-MADE ACCESSES TO A REPOSITORY IN BASALT

TABLE OF CONTENTS

$\underline{\text { PAGE }}$

LIST OF TABLES

$\mathrm{x}$

LIST OF FIGURES

xiii

ACKNOWLEDGMENTS

xviii

0 EXECUTIVE SUMMARY

1

0.1 INTRODUCTION

0.2 CHARACTERIZATION OF THE PLUG ENVIRONMENT AND MAN-MADE ACCESSES

0.3 SELECTION OF CANDIDATE PLUG MATERIALS 3

0.4 GEOCHEMICAL TESTING PROGRAM 5

0.5 PHYSICAL TESTING PROGRAM 7

0.6 SUITABILITY OF MATERIALS FOR USE IN PRECONCEPTUAL PLUG SYSTEMS

0.7 LIMITATIONS OF THE RESULTS 11

0.8 CONCLUSIONS AND RECOMMENDATIONS 12

1 INTRODUCTION 16

1.1 BACKGROUND 16

$\begin{array}{lll}1.2 & \text { SCOPE OF WORK } & 19\end{array}$

1.3 ORGANIZATION OF REPORT 21

2 CHARACTERIZATION OF THE PLUG ENVIRONMENT AND MAN-MADE ACCESSES 
2.2 THE PLUG ENVIRONMENT 23

2.3 TABULATION PROCEDURE 24

2.4 DISCUSSION 25

3 SELECTION OF CANDIDATE PLUG MATERIALS 26

3.1 INTRODUCTION 26

3.2 DEVELOPMENT AND RATIONALE FOR THE MATERIALS SELECTION PROCESS 28

3.2.1 GENERAL OBJECTIVES OF THE PROCESS 28

3.2.2 STRUCTURE AND OBJECTIVES OF THE DECISION ANALYSIS 31

3.2.2.1 STRUCTURING THE PROBLEM 31

3.2.2.2 DETERMINING EVALUATION

FUNCTIONS 32

3.2.2.3 ESTIMATING ATTRIBUTE LEVELS 33

3.2.2.4 EVALUATING ALTERNATIVES 33

3.3 THE MATERIALS SELECTION PROCESS 35

3.3.1 DEVELOPMENT OF AN INITIAL LIST OF MATERIALS (STEP 1) 35

3.3.2 PRELIMINARY SCREENING (STEP 2) 41

3.3.3 FUNCTION CLASSIFICATION (STEP 3) 41

3.3.4 DATA AVAILABILITY SCREENING

$\begin{array}{ll}\text { (STEP 4) } & 43\end{array}$

3.3.5 DETERMINATION OF MATERIAL PROPERTIES (STEP 5) 44

3.3.5.1 PROPERTIES OF MATERIALS TO INH IBIT FLUID FLOW 46

3.3.5.2 PROPERTIES OF MATERIALS TO INHIBIT RADIONUCLIDE MIGRATION 47

3.3.5.3 PROPERTIES OF MATERIALS TO PROVIDE STRUCTURAL INTEGRITY 
3.3.5.4 DETERMINATION OF ATTRIBUTE

LEVE'LS

3.3.6 EVALUATION OF PHYSICAL AND CHEMICAL PROPERTIES OF MATERIALS (STEP 6)

3.3.7 CONSIDERATION OF OTHER FACTORS (STEP 7)

4 GEOCHEMICAL TESTING PROGRAM 56

4.1 INTRODUCTION 56

4.1.1 BACKGROUND AND OBJECTIVES 56

4.1.2 SCOPE OF THE GEOCHEMICAL TESTING

PROGRAM $\quad 57$

4.2 MATERIALS 60

4.2 .1 COMPONENTS 60

4.2.2 DESIGN OF MIXTURES 66

4.3 TYPE OF TESTS $\quad 68$

$4.3 .1250^{\circ} \mathrm{C}$ STATIC TEST 68

$4.3 .2150^{\circ} \mathrm{C}$ STATIC TEST 70

4.3.3 STATIC HIGH PRESSURE $34.5 \mathrm{MPa}$ TESTS 70

4.3.4 $250^{\circ} \mathrm{C}$ STIRRED TESTS 72

4.4 TESTING PROCEDURES

4.4.1 SAMPLE PREPARATION 73

4.4.1.1 GRINDING 73

4.4.1.2 POLISHING 73

4.4.1.3 TEST WATER PREPARATION 73

4.4.1.4 ENCAPSULATION 74

4.4.1.5 PREPARATION OF HYDRAULIC

CEMENT MORTARS $\quad 75$

4.4.2 PRE-TEST EXAMINATION AND SAMPLE

CHARACTERIZATION $\quad 76$

4.4.2.1 X-RAY POWDER DIFFRACTION

ANALYSIS $\quad 76$ 
4.4.2.2 BRUNAUER, EMMETT, AND TELLER ANALYS IS

4.4.2.3 FISHER SUBSIEVE ANALYSIS

4.4.2.4 PETROGRAPHIC ANALYSIS

4.4.2.5 SCANNING ELECTRON

MICROSCOPY

4.4.3 POST-TEST EXAMINATION AND SAMPLE CHARACTERIZATION

4.4.3.1 SOLUTION ANALYSIS BY ATOMIC ABSORPTION (AA) $S$ SECTROSCOPY

4. 5 RESULTS

4.5.1 GENERAL OBSERVATIONS

4.5.2 SINGLE NATURAL MATERIALS

4.5.3 MIXTURES OF NATURAL MATERIALS

4.5.4 MIXTURES CONTAINING CEMENTS

4.6 DISCUSSION AND SUMMARY

4.6.1 GENERAL CONSIDERATIONS

4.6.2 DISCUSSION OF SINGLE NATURAL MATERIALS

4.6.3 MIXTURES OF MATERIALS

4.6.4 SUMMARY

4.7 CONCLUSIONS AND RECOMMENDATIONS

4.7.1 PREFERRED MATERIALS

4.7.2 FU'PURE WORK

5 PHYSICAL 'PESTING PROGRAM

5.1 INTRODUCTION

5.2 CEMENTITIOUS MIXTURES - SCREENING TESTS

5.2.2 MATERIALS AND MIXTURES USED IN CEMENTS

5.2.3 TESTING PROGRAM AND PROCEDURES

5.2.4 DISCUSSION OF SCREENING TESTS ON CEMENTITIOUS MIXTURES 
5.2.4.1 THE EFFECT OF TEMPERATURE ON THE COMPRESSIVE STRENGTH OF CEMENT MORTARS

5.2.4.2 THE EFFECT OF ALUM INUM POWDER ON PORTLAND CEMENT MIXTURES

5.2.4.3 EFFECT UF A WATER-REDUCING RETARDER AGENT (WRA) ON PURTLAND CEMENT MIXTURES

5.2.4.4 PERFORMANCE OF CANDIDATE SAINDS

5.2.5 RESULTS OF SCREENING TESTS ON CEMENTITIOUS MIXTURES

3 COMPACTEDD EARTH MATERIALS - SCREENING TESTS

5.3 .1 BACKGROUND

5.3.2 CANDIDATE EARTH MATERIALS AND MIXTURES

5.3.3 TESTING PROGRAM AND PROCEDURES

5.3.3.1 MAXIMUM/MINIMUM DENSITY OF NON-COHESIVE GRANULAR MATERIAL

5.3.3.2 IMPACT COMPACTION

5.3.4 DISCUSSION OF SCREENING TESTS ON CANDIDATE CLAYEY SOILS FROM NEAR THE HANFORD SITE

5.3.4.1 INDEX TESTS AND FIELD RECONNA ISSANCE

5.3.4.2 MECHANICAL PROPERTIES

5.3.5 DISCUSSIUN OF SCREENING TEST ON CANDIDATE NON-COHESIVE GRANULAR MATERIALS 
5.3.6 DISCUSSION OF SCREENING TESTS ON THE INDEX PROPERTIES OF CANDIDATE CLAYS

5.3.7 EVALUATION OF THE MECHANICAL PROPERTIES OF CANDIDATE SAND/CLAY MIXTURES

5.3.7.I COMPACTION OF CANDIDATE SAND/CLAY MIXTURES

5.3.7.2 SWELLING PRESSURE OF CANDIDATE BENTONITE MIXTURES 150

5.3.7.3 RIGIDITY AIND COHESION OF CANDIDATE SAND/CLAY MIXTURES

5.3.8 DESIGN AND EVALUATION OF SKIP-GRADED AGGREGATE/CLAY MIXTURES

5.3.8.1 DESIGN OF SKIP-GRADED AGGREGATE/CLAY MIXTURES

5.3.8.2 EVALUATION OF THE MECHANICAL PROPERTIES OF SKIP-GRADED AGGREGATE/CLAY MIXTURES

5.3.y RESULTS OF SCREENING TEST ON COMPACTED EARTH MATERIALS

5.4 CLAY SLURRIES - SCREENING TESTS 160

5.4 .1 CANDIDATE MATERIALS 160

5.4.2 TESTING PROGRAM AND PROCEDURES 160

5.4.3 PRELIMINARY TEST RESULTS AND

DISCUSSION

5.4.3.1 SLURRY DENSITIES 163

5.4.3.2 FLOW PROPERTIES OF SLURRIES 160

5.4.3.3 THIXOTROPIC PROPERTIES

OF SLURRIES

167

5.4.4 RESULTS OF SCREENING TESTS FOR

CLAY SLURRIES

5.5 CEMENTITIOUS GROUTS AND CONCRETES PERFORMANCE TESTS 
5.5.2 MIXTURE DESIGNS

5.5.2.1 GROUT MIXTURES

5.5.2.2 CONCRETE MIXTURES

5.5.3 TESTING PROGRAM AND PROCEDURES

5.5.3.1 SAMPLE PREPARATION AND CURING OF A PLUG/BASALT (HOST ROCK) MODEL

5.5.3.2 BOND STRENGTH OF A CEMENT

PLUG/BASALT (HOST ROCK) MODEL

AT AMBIENT TEMPERATURE

5.5.3.3 BOND STRENGTH OF A CEMENT PLUG/BASALT (HOST ROCK) MODEL AT HIGH TEMPERATURE

5.5.3.4 PERMEABILITY OF CEMENT PLUG/BASALT (HOST ROCK) MODEL AT AMBIENT TEMPERATURE

5.5.4 TEST RESULTS AND DISCUSSION

5.5.4.1 GROUT PERFORMANCE

180

5.5.4.2 CONCRETE PERFORMANCE

5.6 COMPACTED EARTH MATERIAL - PERFORMANCE TESTS

5.6.1 MATERIALS AND MIXTURES

5.6.2 TESTING PROGRAM AND PROCEDURES

5.6 .2 .1 COMPACTED SOIL'PLUG MODEL PREPARATION

5.6.2.2 PERMEABILITY MEASUREMENTS OF COMPACTED SOIL PLUG/BASALT (HOST ROCK) MODELS

5.6.3 TEST RESULTS AND DISCUSSION

5.6.3.1 BOND STRENGTH OF COMPACTED SOIL PLUG

5.6.3.2 PERMEABILITY OF COMPACTED SOIL PLUG/BASALT (HOST ROCK) MODELS 
5.6.3.3 CONSOLIDATION TESTS ON COMPACTED SAND/CLAY MIXTURES 202

5.7 SOIL/CLAY SLURRIES - PERFORMANCE TESTS 205

5.7 .1 DESIGN OF MATERIALS AND MIXTURES 206

5.7 .2 TESTS AND PROCEDURES 209

5.7 .3 TEST RESULTS AND DISCUSSION 210

5.7.3.1 BOND STRENGTH FOR SLURRIES 211

5.7 .3 .2 COMPRESSIBILITY OF CLAY SLURRIES 212

5.7.3.3 PERMEABILITY OF CLAY SLURRIES 213

5.7.3.4 SUMMARY OF RESULTS FOR CLAY SLURRIES 214

5.8 SUMMARY OF THE PHYSICAL TESTING PROGRAM 214

5.8.1 PREFERRED MATERIALS 214

5.8.1.1 CEMENTS PLUS CEMENT ADDITIVES 215

5.8.1.2 COHESIVE MATERIALS 219

5.8 .1 .3 NON-COHESIVE GRANULAR MATERIALS 220

5.9 CONCLUSIONS AND RECOMMENDATIONS 220

6 SUITABILITY OF MATERIALS FOR USE IN PRECONCEPTUAL PLUG SYSTEMS 223

6.1 INTRODUCTION 223

6.2 SUITABILITY OF MATERIALS BASED ON TESTING PROGRAMS

6.3 MATERIALS PREFERRED FOR PRECONCEPTUAL $\begin{array}{ll}\text { DESIGN AND FURTHER TESTING } & 226\end{array}$

7 LIMITATIONS OF THE RESULTS $\quad 229$

7.1 DATA CHARACTERIZ ING THE ENVIRONMENT OF MAN-MADE ACCESSES 229

7.2 THE MATERIALS SELECTION PROCESS 230

7.3 THE MATERIALS TESTING PROGRAMS 230 

7.3.1 LIMITATIONS OF THE GEOCHEMICAL TESTING PROGRAM

7.3.2 LIMITATIONS OF THE PHYSICAL TESTING PROGRAM

8 CONCLUSIONS AND RECOMMENDATIONS

8.1 CONCLUSIONS

235

8.2 RECOMMENDATIONS

APPENDIX A SELECTED PRECONCEPTUAL DESIGN CONDITIONS OF THE PLUG ENVIRONMENT

APPENDIX B THE MODIFIED MATERIALS SELECTION PROCESS

APPENDIX C DETAILED DATA FROM GEOCHEMICAL TESTING PROGRAM 


\section{LIST OF TABLES}

Table No. Title

$\underline{\text { Page }}$

PREFERRED CANDIDATE PLUG MATERIALS

29

I I

DECISION ANALYSIS AND THE SELECTION

OF CANDIDATE PLUG MATERIALS

MATERIALS AND MATERIALS MIXTURES FOR

PRELIMINARY SAMPLE PREPARATION

62

IV

SPECIMENS USED IN THE GEOCHEMICAL

TESTING PROGRAM

63

$\mathrm{V}$

CHARACTERISTICS OF STARTING MATERIALS

(GROUND TO $-200 \mathrm{MESH}$ )

VI OPERATING CONDITIONS FOR ATOMIC

ABSORPTION ANALYSIS

CANDIDATE MATERIALS USED IN SCREENING

TESTS ON CEMENT MIXTURES

VIII

COMPONENTS AND PROPORTIONING DATA FOR CANDIDATE CEMENTITIOUS MIXTURES

IX

CEMENT CURING PROCEDURES

TESTING PROCEDURES APPLIED TO

CEMENTITIOUS MIXTURES 
SUMMARY OF TEST RESULTS FOR CEMENT

MORTARS CURED AT ELEVATED TEMPERATURES

XI I

SUMMARY OF TEST RESULTS FOR CALCIUM

ALUM INATE CEMENT MORTARS

XI I I

SUMMARY OF TEST RESULTS FOR PORTLAND

CEMENT MORTARS CONTAINING UNPOLISHED

ALUMINUM POWDER

118

XIV

SUMMARY OF TEST RESULTS FOR PORTLAND

POZZOLAN CEMENT MORTARS CONTAINING

DIFFERENT AGGREGATE TYPES

$\mathrm{XV}$

NATURAL MATERIALS USED IN SCREENING

TESTS ON COMPACTED EARTH MATERIALS

$X V I$

TESTING PROCEDURES APPLIED TO COMPACTED

EARTH MATERIALS

XVII

INDEX PROPERTIES OF CANDIDATE

NON-COHESIVE GRANULAR MATERIALS

XVIII

MATERIALS USED IN SCREENING TESTS

ON CLAY SLURRIES

$\mathrm{XIX}$

QUALITATIVE RESULTS OF THIXOTROPY

TESTS ON CLAY SLURRIES

162

$\mathrm{XX}$

MATERIALS USED IN PERFORMANCE TESTS

FOR CEMENTITIOUS MIXTURES 
XXI PERFORMANCE TEST PROCEDURES USED

FOR CEMENTITIOUS MIXTURES

XXI I

SUMMARY OF BOND-STRENGTH DATA FOR

SELECTED CLAY/SAND MIXTURES

$X X I I I$

SUMMARY OF PERMEABILITY TESTS ON

COHESIVE PLUG/BASALT (HOST ROCK)

MODELS

XXIV

SUMMARY OF DATA AND TEST RESULTS FOR PREPLACEMENT AND SLURRY INJECTION

OF AGGREGATE

207

$\mathrm{XXV}$

SUMMARY OF DATA AND TEST RESULTS FOR

PREMIXED SLURRY AND AGGREGATE

208

$\mathrm{XXVI}$

SUITABILITY OF CEMENTS AND ADDITIVES

BASED ON PHYSICAL TESTING

216

XXVII

SUITABILITY OF COHESIVE MATERIALS

BASED ON PHYSICAL TESTING

217

XXVII I

SUITABILITY OF NON-COHESIVE

MATERIALS, BASED ON PHYSICAL TESTING

$\mathrm{XXIX}$

PREFERRED MATERIAL MIXTURES FROM THE RESULTS OF PHYSICAL TESTING

225

$\mathrm{XXX}$

MATERIALS DETERMINED TO BE MOST SUITABLE FOR FURTHER STUDY 


\section{LIST OF FIGURES}

Figure No. Title

$\underline{\text { Page }}$

1

MATERIAL SELECTION PROCESS

36

2

X-RAY DIFFRACTION SPECTRA OF BASALT TESTED UNDER $250^{\circ} \mathrm{C}$ STATIC CONDITIONS

PHOTOMICROGRAPHS OF THE SURFACE OF A BASALT CUBE AFTER 3 MONTHS IN $250^{\circ} \mathrm{C}$ STATIC SOLUTION

PHOTOGRAPHS OF MATERIALS FROM AUTOCLAVE STIRRED TESTS

X-RAY DIFFRACTION SPECTRA OF BASALT FROM STIRRED $250^{\circ} \mathrm{C}$ TESTS

6

X-RAY DIFFRACTION SPECTRUM OF BASALT FROM STATIC, $34.5 \mathrm{MPa}, 250^{\circ} \mathrm{C}, 2$-WEEK TEST

COMPRESSIVE STRENGTH OF CEMENT MORTAR MIXTURES AT ELEVATED CURING TEMPERATURES

EFFECT OF ALUMINUM POWDER ON THE STRENGTH AND VOLUME CHANGE PROPERTIES OF WET CEMENT MOR'TARS

9

THE EFFECT OF TWO TYPES OF ALUM INUM POWDER ON THE EXPANSION CHARACTERISTICS OF FRESH GROUTS 
10

11

12

13

14

15

16

17

18

19
THE EFFECT OF INCREASING THE CONTENT OF A -325 MESH POLISHED, LEAF ING-TYPE ALUM INUM POWDER ON THE EXPANSION CHARACTERISTICS OF FRESH GROUT 123

COMPRESSIVE STRENGTH OF CEMENT MIXTURES CONTAINING A WRA (PLASTIMENT) AND ALUMINUM POWDER AT ELEVATED CURING TEMPERATURES

INDEX PROPERTIES OF CANDIDATE SANDS

PERFORMANCE OF CEMENT MIXTURES CON-

TAINING PORTLAND TYPE $V$, SILICA FLOUR

AND THREE TYPES OF FINE AGgREGATE

129

INFLUENCE OF THE MOLD DIAMETER SIZE

ON IMPACT COMPACTION

SELECTION CRITERIA AND DATA RESULTS

FOR THE CANDIDATE RINGOLD CLAYEY SOILS

MECHANICAL BEHAVIOR OF CANDIDATE RINGOLD CLAYS

GRAIN SIZE DISTRIBUTION OF THE COARSE-CRUSHED BASALT

INDEX PROPERTIES OF VARIOUS CLAY MINERALS

145

COMPACTION CURVES FOR CANDIDATE

SAND/CLAY MIXTURES

148 
THE RELATIONSHIP BETWEEN MAXIMUM DRY

DENSITY AND CLAY CONTENT

SWELLING PRESSURE OF BENTONITE/SAND

MIXTURES

UNCONFINED COMPRESSIVE STRENGTH OF CLAY/SAND MIXTURES

VARIATIUN OF SOLIDS CONTENTS ( $2 \%$ AND $4 \%$ ) OF CLAY SLURRIES

SUMMARY OF GROUT PERFORMANCE: FOR HIGH TEMPERATURE LOCATION ( $\left.\mathrm{T} \geq 100^{\circ} \mathrm{C}\right)$ 
SUMMARY OF GROUT PERFORMANCE: EXPANSIVE GROUT FOR RELATIVELY LOW TEMPERATURE LOCATIONS $\left(\mathrm{T} \leq 50^{\circ} \mathrm{C}\right)$

SUMMARY OF CONCRETE PERFORMANCE: FOR HIGH TEMPERATURE LOCATION $\left(T \geq 100^{\circ} \mathrm{C}\right)$

SUMMARY OF CONCRETE PERFORMANCE: FOR MODERATE TEMPERATURE LOCATIONS $\left(\mathrm{T}<100^{\circ} \mathrm{C}\right)$

SUMMARY OF CONCRETE PERFORMANCE: EXPANSIVE CONCRETE FOR RELATIVELY LOW TEMPERATURE LOCATIONS $\left(T \leq 50^{\circ} \mathrm{C}\right)$ BOND STRENGTH OF CLAY/SAND MIXTURES AT AMBIENT TEMPERATURE COHESIVE BEHAVIOR OF BENTONITE/ SAND MIXTURES

BOND STRENGTH-SLIDING STRAIN CURVES FOR SAND/CLAY MIXTURES CONTAINING WYOMING BENTONITE AND GLACIOFLUVIAL SAND

CONSOLIDATION CURVE OF CLAY/SAND MIXTURES CONTAINING $10 \%$ OREGON BENTONITE AND $90 \%$ GLACIOFLUVIAL SAND 
$$
\text { . }
$$ 


\section{ACKNOWLEDGMENTS}

The authors wish to thank fellow Woodward-Clyde Consultants colleagues Craig Kirkwood, Kenneth Weaver, Marvin Niccum, and Kevin O'Connor, who supplied portions of the text and valuable critical review during report preparation. Additional peer review of the completed first draft was supplied by the Project Director, Dr. Hans Ewoldsen.

Additional text was supplied by Dr. Ronald Loehman of SRI, International, Menlo Park, California. Laboratories at this facility carried out the geochemical testing program. Dr. Loehman was assisted in this effort by Sharon Wing, Rosalie Lespade, Eldon Farley, and Lorraine Watson.

For the physical testing program, the following wCC personnel provided assistance: Mr. Kevin o'Connor, Mr. Don Poulter, and Ms. Carol Ries; and at the WCC Laboratory, Mr. Jim Wilson (Laboratory Director), Mr. Clyde Caffs (Laboratory Supervisor), Mr. Robert Russel (Technician), Mr. Roger Taraya (Technician), and Mr. Chuck Wason (Technician). Mr. Oliver Gilbert reviewed the physical testing program and provided constructive criticism of the physical testing and suitability drafts.

For the laboratory testing at Testing Engineers, Inc., the cement and concrete testing were performed by Dr. Dushyant Manmohan, Dr. Vaughn Peters, Ray Catlette, and Crokett Gordon. Dr. Manmohan also provided useful suggestions and guidance throughout the testing of cement mixtures.

The Technical Review Board for this project, whose members include Mr. Douglas Moorhouse, Mr. Lloyd Cluff, and Dr. Ulrich Luscher of WCC; Dr. Konrad Krauskopf, Stanford University: 
Dr. James Mitchell, University of California, Berkeley; and Tyman Fikse, Fikse Engineering, Seattle, Washington, reviewed the progress of work leading to this preliminary report. Each of these individuals supplied many helpful suggestions and comments during the course of the work. In addition, Dr. Krauskopf supplied many useful suggestions on the geochemical program conducted by SRI and provided ongoing review of that effort.

Cecil van Til, WCC, performed Quality Assurance audits of the work performed by WCC and provided much useful information on the maintenance of project files and Quality Assurance documentation. He also monitored SRI's adherance to Quality Assurance procedures.

Special thanks are due to wCC staff who prepared this report. These individuals include: Heidi Horten, editor; Terrie Bullock, Patricia Martin, and Rose Sayao, secretaries; and Leo Germano and his graphics staff of illustrators. 


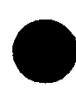




\section{O EXECUTIVE SUMMARY}

\subsection{INTRODUCTIUN}

The objective of the Basalt Waste Isolation Project (BWIP) borehole plugging effort, which is carried out under the direction of Rockwell Hanford Operations (Rockwell) at Richland, Washington, is to locate sites and assess the feasibility for developing a repository for terminal nuclear waste storage at depth in the Columbia River basalts beneath the Hanford site. As part of this effort, woodward-Clyde Consultants (WCC) has been contracted by Rockwell to provide a preconceptual design for a plug system in man-made openinys (boreholes, shafts, and tunnels excavated during repository construction) that will assure containment of radioactive waste products after closure of the repository. The specific purpose of the plug system will be to prevent the migration of harmful amounts of radioactive waste to the biosphere.

The specific objectives of the physical and geochemical testing effort conducted to date by WCC were to: (1) characterize manmade accesses to a repository in basalt, tabulate available information on physical and chemical parameters, and design considerations that help define the plug environment; (2) modify the selection process that was used to verify the list of preferred candidate plug materials identified during the preliminary Borehole Plugging Materials Selection Process ('Taylor and others, 1279); (3) conduct laboratory investigations on the physical and chemical behavior of candidate materials and present the results of the testing programs; and (4) assess the suitability of the various preferred candidate plug materials that might qualify for further testing and consideration in preconceptual plug design 
schemes on the basis of the results of the preliminary yeochemical and physical testing programs, the materials selection process, and expected environmental factors (both natural and man-made).

The scope of work for the study conducted to date by WCC included: (1) the characterization of man-made accesses to a repository in basalt; (2) laboratory tests and evaluation of materials to assess their suitability to plug man-made accesses to a repository in basalt; (3) a description of the results of a modified materials selection process and the application of the decision analysis technique used in this program; (4) development of a quality assurance program, program plan and schedule, and work plans; and (5) the preparation of this report.

\subsection{CHARACTERIZATION OF THE PLUG ENVIRONMENT AND MAN-MADE ACCESSES}

The physical and chemical characteristics of the anticipated plug environment will greatly influence the choice of potential plug materials. The selected plug materials will, in turn, influence the selection of plug placement equipment and will also ultimately determine plug system design. Thus, characterization of the plug environment and man-made accesses to plug seats and the repository are of critical importance. The plug environment includes: (1) the inherent components of the geologic environment at the Hanford Site; (2) the proposed location and depth of the repository; and (3) alteration of the natural environment due to both the excavation of the repository and the storage of radioactive waste. 
As an extension of the initial description and characterization of the plug environment presented by Taylor and others (1979), available pertinent data were tabulated in a single table Appendix A, (Table A-I). Any such preliminary, comprehensive tabulation of data is, of course, subject to revision. Many values quoted in Table A-I reflect a limited data base. As subsurface exploration proceeds at the Hanford Site, this data base will be enlarged, and new average values and ranges of values will undoubtedly be established. Many aspects of the geometric parameters included in the table are also preliminary in nature and reflect current thinking on possible overall repository design at the Hanford Site.

\subsection{SELECTION OF CANDIDATE PLUG MATERIALS}

It was recognized at an early stage of the basalt borehole plugging study that materials to be used in plugs vill greatly influence the selection of potential placement equipment and overall plug designs. Thus, the list of preferred candidate materials has a strong impact on the direction of the entire program. The original objective of the materials selection process was to identify candidate materials that (1) have a high probability for successful use in plugs; (2) have a high probability of acceptance based on NRC criteria; and (3) can be used in this and subsequent physical and geochemical testing programs. The selection process should also provide a documented defensible method for the logical selection of a small number of preferred materials for initiating testing programs and preconceptual design schemes. The selection process described in Taylor and others (1979) essentially accomplished several of these objectives. Preferred candidate materials, which are thought to have a high probability for successful use in plugs, were ideitified by that process. Also, these 
preferred materials formed the basis for initiation of physical and geochemical testing and preconceptual plug design.

A review of the original materials selection process presented in Taylor and others (1979) suggested the need for a reevaluation of the process and the possible need for a new approach; it was decided to extend the work effort in materials selection and to make improvements on the initial selection process. Because the selection of materials for inclusion in preconceptual plug design schemes and testing programs is a decision problem, the review and evaluation of the original screening process indicated that the application of decision analysis would help overcome the drawbacks of the initial selection scheme.

The primary objectives of continued evaluation of the selection process and of the application of decision analysis to the problem were: (1) to correct deficiencies in logic in the original selection schemes; (2) to develop a method that avoids the use of weighting and rating factors and cut-off values; (3) to re-examine the initial comprehensive list of materials with a different approach; and (4) to more completely document, the steps of the process (specifically the steps used in the decision analysis).

In general, the approach presented in this report helps to clearly determine and organize those factors which are most significant to the final outcome of the selection process and documents the process in a more complete fashion. Reorganization of function classifications and more complete definition of attributes in this new approach make possible the comparison of materials that will have like applications in plug design while maintaining the capability to discriminate among and rank 
them using established criteria. The list of preferred candidate materials developed in the selection process described by Taylor and others (1979) was verified by reevaluation as described in Chapter 3 of this report. This 1 ist was the basis for the physical and geochemical testing programs of preferred candidate materials.

\subsection{GEOCHEMICAL TESTING PROGRAM}

The primary objectives of the geochemical testing program were: (1) to help define the behavior of candidate plug materials in the plug environment; (2) to provide data on the relative stability and reactivity of candidate plug materials; and (3) to identify the most promising materials for consideration in future studies involving plug system design and advanced testing programs. Even though candidate plug materials are considered to be extremely stable and durable, slow chemical reactions not detected in earlier studies could be cumulative over time and could eventually lead to a loss in plug integrity. The need to make reliable predictions of plug behavior for periods of thousands of years places severe demands on any chemical testing program because long-term experiments may be necessary to obtain sufficiently accurate data on which to base these predictions. The geochemical testing program described here is a series of initial screening tests that were intended to permit an evaluation of the suitability of materials based on their short-term chemical reactivities. These tests determined a lower boundary on the level of reactivity to be expected over the useful life of the plug. 
Tests for the geochemical testing program were selected by estimates of environmental conditions to which the plug will ultimately be subjected. Preliminary ranges of temperature, pressure, $\mathrm{pH}$, and ground-water composition have been established; chemical degradation mechanisms for the plug Inaterials were hypothesized; and experiments were designed to detect the potential occurrence of reactions under these postulated environmental conditions. Additional constraints on the selection of test procedures were: (1) the length of time available to do the tests; (2) the anticipated low reactivity of plug materials; and (3) the availability of pressure vessels. The potential alteration mechanisms of plug materials are: (1) chemical reactions between plug materials; (2) cheinical reactions between the plug materials and the surrounding rock; (3) chemical reactions between the groundwater and the plug materials (dissolution, selective leaching, solution-mediated phase changes or recrystallization); and (4) pressure-induced phase changes. Tests were conducted under static conditions (no agitation) at $250^{\circ} \mathrm{C}$ and $150^{\circ} \mathrm{C}$ under the saturated steam pressure of water at $3.9 \mathrm{MPa}$ and at $250^{\circ} \mathrm{C}$ at high pressure $(34.5 \mathrm{MPa})$. Stirred tests were conducted at $250^{\circ} \mathrm{C}$ under saturated steam pressure. These tests were. performed at the laboratories of SRI, International in Menlo Park, California, on multiple samples of 39 materials and mixtures of materials selected from the results of previous work.

The original procedures used to select the materials for geochemical testing included chemical stability as a major criterion. Consequently, nearly all of the materials that were tested exhibited only slight reactivities, even at elevated temperature. As expected, the geochemical tests did not show major differences among the materials selected for study. 
Therefore, these tests do not rule out any of the candidate materials, and all materials appear to be suitable for further study and potential use in plug designs based on these results. Self-cementing characteristics were observed in stirred basalt samples; this is considered a positive, beneficial result which could enhance its performance in potential plug designs. The cementing action appears to reflect chemical reactions and the growth of new mineral phases in crushed basalt samples. An understanding of the reaction and the ability to promote it under static conditions could result in a replacement of manufactured cements by natural materials capable of self-cementation in plug designs requiring structural support.

\subsection{PHYSICAL TESTING PROGRAM}

The physical testing program was designed: (1) to heip select individual materials and mixtures from the list of preferred candidate materials for further testing and use in preconceptual design schemes to plug boreholes, shafts, and tunnels leading to a repository in basalt; and (2) to provide quantitative experimental data on the thermomechanical response of selected mixtures under silnulated repository conditions. Candidate materials for physical testing included natural cohesive and non-cohesive granular earth materials, portland cements, hydrothermal cements, and some standard cement additives. These materials are the same as those tested during the concurrent geochemical testing program.

For the purpose of the physical testing program, mixtures made from the candidate materials are classified into three main generic categories: (1) cementitious mixtures; (2) compacted natural earth materials; and (3) clay slurries. These mixtures 
were tested in two phases during this program. During an initial phase of screening tests, all preferred candidate materials and mixtures that fell into one of the three generic categories were examined, and the most promising mixtures were selected for further examination in the subsequent phase of the program -- preliminary tests. During the preliminary tests, specific, promising candidate materials and mixtures (selected by the screening phase) were examined in greater detail.

On the basis of this testing program, concrete, grout, compacted earth materials, and clay slurries are all considered feasible materials for sealing man-made accesses to a repository in basalt. Tests conducted during this study evaluated the permeability and bond strength of miniature plug/basalt (host rock) models at low and high temperatures. These tests indicate that it is possible to design mixtures of candidate plug materials that have permeabilities of less than $10^{-8} \mathrm{~cm} / \mathrm{sec}$ and will form an acceptable bond strength with the host rock. Other major conclusions are: (1) the addition of finely ground silica flour greatly improves the structural and bond strength of portland cement cured at elevated temperature; it also reduces shrinkage of portland cement mixtures cured at standard temperature; (2) compaction test results for bentonite/sand mixtures indicate that compaction to produce a relatively impervious clayey mixture is feasible by standard compactive methods; (3) significant time is required for a miniature, simulated compacted bentonite/sand plug to hydrate (on the basis of test data, the time required to saturate a 7-m diameter compacted bentonite/sand plug with a clay content of 50 percent may be more than 1,000 years.); (4) consolidation test results for bentonite/sand mixtures with a clay content of 50 percent indicate an expansive behavior in these mixtures for unloading pressures less than $2.2 \mathrm{MPa}$ (These results suggest a 
high swelling potential and self-healing properties for plugs composed of these materials; the results also suggest that tight contact between the emplaced plug and basalt (host rock) will be maintained even after cyclic thermal loading); and (5) mud contamination of simulated borehole walls during model testing was found to substantially decrease the bond strength of miniature cement and soil plugs with the basalt (host rock), which strongly suggests that drilling mud should be flushed from boreholes before plugging.

Materials preferred for further testing and use in preconceptual plug design schemes and selected on the basis of the physical testing program results are: (1) portland cement Type V, glaciofluvial sand and gravel, and crushed basalt in various cementitious mixtures and grouts containing an assortment of additives, such as aluminum powder (to promote expansion), a water-reducing retarder agent (to reduce water demand in cements and improve workability), finely ground silica (to reduce shrinkage and improve thermal stability and structural strength at high temperature), and a natural highsilica pozzolan (to reduce shrinkage, increase workability, improve impermeability, and increase stability at low to moderate temperature); (2) Wyoming and Oregon bentonites and glaciofluvial sand in compacted natural earth materials; and (3) processed bentonite, precompacted bentonite pellets, and crushed basalt in clay slurry mixtures.

\subsection{SUITABILITY OF MATERIALS FOR USE IN PRECONCEPTUAL PLUG SYSTEMS}

Both the physical and geochemical testing programs used essentially the same set of samples prepared from the list of preferred candidate materials. The geochemical program 
examined reaction rates of individual materials in simulated ground water (similar to that expected to exist at the depths of plug seats on the Hanford site) and the reaction rates of mixtures of candidate materials in simulated ground water. The tests were performed under a variety of temperatures and pressures designed to maximize potential reactivity between the various components. The physical testing program combined the candidate plug materials (using various grain size proportions) in mixtures that are precursors to actual plug designs. These tests were, again, designed as a screening step to select those individual materials and mixtures that exhibited the most desirable performance when submitted to a wide variety of mechanical and physical test sequences. On the basis of geochemical testing, all preferred candidate plug materials are considered suitable for further testing and use in preconceptual plug design. Small differences in relative reactivity were noted for the various samples, but the reactivities of all test samples were so low that all test materials are considered acceptable. The self-cementing characteristics of basalt under hydrothermal test conditions give this material an added degree of desirability at this stage of evaluating plug materials. On the basis of the physical testing program, seven preferred material mixtures that were designed and tested during the physical testing program for preconceptual plugging systems were selected as suitable for sealing man-made accesses to a nuclear waste repository in basalt.

The combined results of both testing programs indicate that the materials considered suitable for further testing and use in preconceptual design schemes are various combinations of compacted natural materials, grouts, and concretes. Geochemical testing shows that the materials are generally 
non-reactive or have very low reactivities in the hydrothermal test conditions employed during laboratory testing at SRI, which suggests stability in the proposed plug environment. Physical testing indicates that mixtures with the requisite mechanical properties can be designed into plugs from these materials.

\subsection{LIMITATIONS OF THE RESULTS}

In each of the previous sections, significant steps in establishing design limits and selecting materials for preconceptual plugs and systems are discussed. However, limitations exist on the uses of the data and results presented in this report. Many of the values for physical and chemical parameters presented in Chapter 2 are based on only a limited number of measurements and/or tests. Design conditions (such as borehole diameters, hydraulic gradients, lithostatic stress, etc.) are preliminary in nature and are subject to future revision. Thus, the total characterization of man-made accesses and the plug-seat environment will undergo constant review, and information in this report should be used with these 1 imitations in mind.

It should be noted that the list of preferred candidate plug materials developed by the present selection process is by no means a final selection of materials for all future plug testing and design. The list is not intended to limit the number of materials that can be considered in plug design and testing programs. Materials that have not yet been considered in selection processes and may have potential application in various plug functions could be added in a reprocessing of the initial, comprehensive list of potential materials. Also, the number of material properties used to rank materials may be 
expanded, thus requiring nodification of the details of the decision analysis performed during this study. Another limitation of the materials selection process is that only materials to be used as major plug components were considered; additives (materials added to plugs in small amounts to produce certain desirable conditions) were not included in the screening. However, the laboratory testing programs have already begun to rectify this last limitation. Various additives (particularly to cements) were investigated as the testing programs proceeded.

The results of the geochemical and physical testing programs represent the first major steps in further examining and screening candidate plug materials. Materials determined as suitable for future testing and preconceptual design work as a result of these testing programs will require detailed examination before final preconceptual design schemes can be adopted. The results of the materials testing programs are used in preliminary, preconceptual design and for the selection of plug placement equipment; subsequent reports will describe this preconceptual design work. Detailed design work will require advanced geochemical and physical laboratory testing, in-situ borehole testing of plug designs, computer modeling of various plug designs and schemes, and the incorporation of many additional physical and chemical parameters in order to refine the selection of materials, machines, and plug designs.

\subsection{CONCLUSIONS AND RECOMMENDATIONS}

Work recently completed for the engineered barriers effort of the BWIP is described in this report. The primary objectives of the study have been met during this phase of work: 
- Man-made accesses to a repository in basalt and details of the plug environment have been characterized. This characterization is in the form of a lengthy tabulation, and known and postulated conditions for these accesses and the environment are referenced;

- The materials selection process developed earlier was reviewed and modified. The modified selection process utilized a recognized decision analysis technique. The list of preferred candidate materials developed by the modified selection process confirmed the general validity of the list of preferred materials developed earlier;

- Geochemical and physical testing programs for evaluating the chemical stability and physical properties of candidate plug materials were completed during this phase of the work and are reported here; and

- The results of the testing programs were used to evaluate the suitability of materials from the preferred candidate list for use in preliminary preconceptual plug designs.

The major conclusions from the work described in this report are:

- The preconceptual plug system design is based on the available data for environmental conditions (both natural and man-made) at the Hanford site. (Final plug design may require additional data.);

- The results of the geochemical testing program indicated that the candidate plug materials selected are chemically non-reactive during laboratory tests that simulated some 
of the expected environmental conditions. Agitated, crushed-basalt samples and mixtures containing basalt were found to be self-cementing under the hydrothermal conditions of the laboratory tests. This ability is considered a positive finding for this material because natural materials that have the capability of selfcementation may replace manufactured cements in some plug applications requiring structural support;

- On the basis of physical test results, those materials considered most suitable for consideration in future test programs and preconceptual plug design are mixtures of natural materials (basalt, clay, glaciofluvial sand, gravel, and zeolite) and processed natural materials (portland cement Type $\mathrm{V}$ and grouts plus additives); and

- On the basis of results from both geochemical and physical testing programs, those materials considered most suitable for future test programs and preconceptual plug design are combinations of natural and processed natural materials, most of which are readily available at or near the Hanford Site. Most importantly, all of these. materials exhibit chemical stability under conditions that approximate the expected plug environment, and all can be combined and engineered under laboratory conditions to produce mixtures that have low permeabilities and/or requisite structural strength and other behavioral characteristics desirable in preconceptual plug designs. 
The following recommendations appear appropriate in view of the above:

- A comprehensive program should be developed for the advanced testing of chemical stability factors critical to the performance of borehole plug materials used in plug systems;

- An advanced physical testing program should be developed which will support repository backfill and borehole plugging needs during field testing, demonstration, licensing, and repository construction;

- Analytical modeling of borehole plug design and systems should be undertaken to serve several functions in the design/construction process;

- A program should be undertaken to evaluate the impact on the design and performance of borehole plugs of natural fractures in basalt flows and the effects of disturbed rock and rock fracturing that may accompany tunnel and shaft excavations and related repository borings;

- A preliminary field test of shallow borehole plugging technique should be performed at the Hanford Site. This field testing should examine leading candidate plug materials and plug placement schemes and should incorporate data and results from the laboratory effort and programs described in the other recommendations above; and

- Additional and more reliable data need to be acquired at the Hanford site in order to better evaluate plug materials and systems for final selection. 


\section{INTRODUCTION}

\subsection{BACKGROUND}

In 1976, the U.S. Department of Energy (DOE) established the National Waste Terminal Storage Program (NWTS). The objective of this program is to provide regional nuclear waste storage facilities in various deep geologic formations within the United States. The Office of Waste Isolation (OWI) at Oak Ridge National Laboratory was established to provide program management for the terminal storage program. In 1978, the functions of this office were superseded by the office of Nuclear Waste Isolation (ONWI) at Battelle in Columbus, Ohio.

The NWTS program includes the investigation of a number of rock types and geologic environments to determine their suitability for terminal storage of radioactive waste. The Columbia River basalts, which underlie a large portion of eastern washington State and adjacent portions of Oregon and Idaho in the Pacific Northwest, were identified as a possible repository rock. In 1976, Rockwell was given the responsibility of investigating these basalts as a potential site for terminal storage of commercial nuclear waste. Within Rockwell, this study is the BWIP.

In order to construct a subsurface repository in basalt, manmade openings will be required for exploration, access shafts and tunnels, and storage areas. The diameters of these manmade openings, which are collectively referred to as boreholes, may range from $5 \mathrm{~cm}$ for existing vertical exploration holes to 6 or $7 \mathrm{~m}$ for shafts and tunnels (upper limits of 9 to $10 \mathrm{~m}$ are 
expected). When the repository is decommissioned, these boreholes will be sealed, or plugged, to preserve the integrity of the repository.

Woodward-Clyde Consultants (WCC) has been contracted by Rockwell to help achieve the objectives of the BWIP. The objective of the wCC study is to devise a plug system (materials, machines, placement techniques, and instrumentation) to seal boreholes, shafts, and tunnels leading to a radioactive waste repository 900 to $1,500 \mathrm{~m}$ below the surface of the Columbia Plateau.

The materials and systems (integration of plug materials, plug emplacement machines, and monitoring) selected for the borehole plug must be compatible (stable) with the physical and chemical properties of the surrounding repository rock and its geologic environment. The plug system will be emplaced by machines and techniques that will provide a high degree of confidence in the security and durability of the plugs.

The purpose of the plug system is to prevent the migration of harmful amounts of radioactive waste to the biosphere. To prevent this migration along man-made openings, it is likely that a variety of materials and a series of multiple plug barriers will be used. The materials under consideration include hard rock, portland cernent concretes, chemical cements, grouts, clay, sand, gravel, and mixtures of these. Each inaterial or mixture of materials will contribute one or more favorable attributes to complement and preserve the integrity of the repository flow. 
The WCC investigation consists of three tasks: Task I (Planning and Procurement); Task II (Testing and Preconceptual Systems); and Task III (Borehole Plugging Field Tests and Preconceptual Design of Plugging Systems). Initial work was completed in fiscal year 1979 and is described in the report "Borehole Plugging of Man-Made Accesses to a Basalt Repository: A Preliminary Study" (Taylor and others, 1979) published by Rockwell as RHO-BWI-C-49. This present report describes a portion of the work completed in fiscal year 1979 - 1980. Subsequent reports will describe the remainder of work completed during this same period.

The objectives of the Task I study included: (1) the preparation of a preliminary list of candidate plug materials; (2) a description of available machinery capable of placing candidate plug materials; and (3) the development of physical and geochemical testing programs to help evaluate the chemical stability and physical properties of candidate plug materials.

The most significant finding from work to date is that, given reasonable regulatory criteria, nothing has been identified which would prevent the design of a plug system to seal manmade openings leading to a nuclear waste repository in columbia River basalt for significantly long periods of time (on the order of thousands of years). Work accomplished to date indicates that this plug system can be designed using both natural and manufactured materials and can be emplaced with existing placement machinery and modifications of that machinery. Other important findings are:

- Potential candidate plug materials appear to be compatible with the chemical and physical properties of the plug environment; 
- These candidate plug materials have characteristics that will tend to sorb or otherwise inhibit the inigration of radionuclides;

- Although gaps and uncertainties are present in existing data concerning the plug environment, sufficient information has been identified to initiate preconceptual plug design; and

- Geochemical and physical testing programs can be developed and used to help define potential plug behavior parameters in an initial laboratory simulation of the plug environment.

\subsection{SCOPE OF WORK}

The fiscal year 1979-1980 work is presented in two parts: preliminary testing of materials for plugging of man-made accesses to a repository in basalt, which is described in this report, and preconceptual systems and equipment for plugging of man-made accesses to a repository in basalt, which is described in a separate report.

The scope of the preliminary materials testing work (described in this report) included the following areas:

- A characterization of man-made accesses to a repository in basalt;

- Laboratory tests and evaluations of materials to assess their suitability to plug man-made accesses to a repository in basalt; 
- A description of the results of a modified materials selection process and the application of decision analysis in this process;

- A quality assurance program, program plan and schedule, and work plans; and

- Preparation of a report.

The technical work was initiated by the collection of additional data to characterize boreholes. A geochemical testing program and a physical testing program were conducted to evaluate selected materials and their suitability to plug manInade accesses to a repository in basalt. SRI, International of Menlo Park, California conducted the geochemical testing prograin as a subcontractor to wCC. The physical testing program was conducted at the WCC laboratory in Oakland, California.

Decision analysis was utilized to review, modify, and supplement the materials selection process. Materials that were utilized in the geochemical and physical testing programs and in the preconceptual plugging schemes, and that were identified as preferred candidate materials by the selection process developed during Task I, were verified by the Task II modified selection process utilizing decision analysis.

Quality assurance and project management are also considered indispensable parts of this project because they provide a mechanism for conducting the program in a logical, traceable, and documented manner. The identification of required procedures, scheduling, and cost control were the elements of quality assurance and project management in this work. Monthly 
progress reports were made to Rockwell, and periodic progress Ineetings were held either at the WCC offices in San Francisco, California, or at the Rockwell offices in Richland, Washington. The progress of the program was also discussed and reviewed at two meetings of the project Technical Review Board, which includes: Mr. Douglas Moorhouse, WCC; Mr. Lloyd Cluff, WCC; Dr. Ulrich Luscher, WCC:; Dr. James Mitchell, University of California, Berkeley; Dr. Konrad Krauskopf, Stanford University; and Mr. Tyman Fikse, Fikse Engineering, Seattle, washington. The program was also supplemented by telephone conversations between the WCC project manager and the technical liaison for Rockwell.

\subsection{ORGANIZATION OF REPORT}

The remaining chapters of this report include Chapter 2--a description of the plug environment, Chapter 3--a discussion of the modified process for selecting candidate plug materials, Chapters 4 and 5--descriptions of the geochemical and physical testing programs and the analytical results of those programs, Chapter 6--a discussion of the suitability of preferred candidate plug materials for further testing and consideration in preconceptual plug schemes, Chapter 7--1initations on the results and data of present work, and Chapter 8 -- conclusions and recommendations.

Appendices contain: (1) a detailed tabulation of the characteristics of the plug environment (Appendix A); (2) further discussion of the selection of candidate plug materials (Appendix B); and (3) a tabulation of data and results of the geochemical testing program (Appendix C). 


\section{CHARACTERIZATION OF THE PLUG ENVIRONMENT AND MAN-MADE ACCESSES}

\subsection{INTRODUCTION}

An essential part of the BWIP(and the primary objective of IVCC's participation in the BINIP) is to devise a plug system to seal boreholes, shafts, and tunnels leading to a high-level nuclear waste repository located 900 to $1,500 \mathrm{~m}$ deep in a basalt flow of the Columbia River Basalt Group. The physical and, chemical characteristics of the plug environment will greatly influence the choice of potential plug materials, which will, in turn, influence the selection of plug placement equipment and will ultimately determine plug system design. Thus, characterization of the plug environment and man-made accesses to plug seat locations and the repository are of critical importance.

The description of the plug environment presented in Chapter 2 and Appendix A of Taylor and others (1979) focused on those aspects of the natural environment (geotectonic, physical, and chemical) that will most likely affect plug design, plug systems, and plug stability. That description was based on a review of available literature, Rockwell reports, relevant reports from other private investigations, drilling logs, core samples, hydrogeologic records, geochemical studies, geologic maps, and lithologic, petrologic, and stratigraphic studies. That review was supplemented by conversations with knowledgeable individuals at Rockwell and various universities, including Stanford, The Pennsylvania State University, and the University of California, Berkeley. 


\subsection{THE PLUG ENVIRONMENT}

The plug environment includes: (1) the natural components of the geologic environment at the Hanford site; (2) the proposed location and depth of the repository; and (3) alteration of the natural environment due to both the excavation of the repository and the storage of radioactive waste. Conditions important to borehole plugging include the chemistry, mineralogy, and petrology of the host rock; rock strength of basalt; bedding attitudes; the position of aquifers; permeabilities of flows and interflow units; lithostatic pressure; potential maximum hydrostatic pressure; regional subsidence and related stresses; the parameters of potential earthquakes; general joint and fracture patterns within flows (flow top, entablature, and colonnade); temperature of the host rock; geochemistry of the ground water; and secondary minerals filling basalt fractures, joints, and other natural openings.

Some characteristics of the plug environment will be greatly influenced by the excavation of tunnels, shafts, and the repository itself and by placement of spent fuel, backfill, plugs, and other engineered barrier components. These characteristics are dependent on the design of the repository and the plug system and can only be discussed in terms of potential configurations of the system and the repository. For example, relief of accumulated stress during excavation, or the accumulation of stress following plugging, may conceivably affect the integrity of the repository by either inducing new fractures or opening existing fractures within the repository flow, thus increasing the permeability of the rock mass. The orientation of the repository and plugs, existing fracture orientations, and induced fractures may be influenced by the 
magnitude and orientation of the stress field. Permeabilities of various units within the plug environment may be increased or decreased by excavation methods or injection grouting.

Previous work indicated the strong need for a tabulation of all environmental conditions that might affect the selection of plug materials and the preconceptual plug design. Such a tabulation would provide workers within WCC and Rockwell with a common source of accepted, current values for a host of environmental conditions. In addition, by listing the many conditions, definition of the total environment at plug seats could be initiated, and workers would be able to more readily detect and address deficiencies in currently available data. Thus, as an extension of the initial description and characterization of the plug environment, available pertinent data were tabulated in a single document and appropriately referenced. This tabulation is presented in Table A-I of Appendix A, located at the back of this report.

\section{3 TABULATION PROCEDURE}

Table A-I in Appendix A was an outgrowth of the documentation of parameters presented throughout Taylor and others (1979); particularly Chapter 2 and Appendix A. These data and other information collected during the present study and relating to the natural environment and projected changes to this environment are included in Table A-I. In addition, available data on the anticipated geometry of man-made accesses (hole diameters, depth, etc.) to be superimposed on the natural environment are also included in Table A-I. Multiple data sets are available for many of the values quoted for chemical and physical parameters. Where appropriate, multiple values for the same parameters have been listed in Table A-II of 
Appendix $A$ and have been completely referenced. The introduction to Appendix A describes the method used to select a value or range of values included in Table A-I for cases where multiple measurements are 1 isted in Table A-II.

Data in Table A-I are tabulated with respect to four postulated borehole sub-environments: vertical boreholes that start at the surface; horizontal boreholes that start in the subsurface; tunnels; and shafts. Many additional environmental parameters were added and quantified where possible during the preparation of Tables A-I and A-II.

\subsection{DISCUSSION}

Any such preliminary, comprehensive tabulation of data is, of course, subject to revision. Many values quoted in Table A-I reflect a limited data base. As subsurface exploration proceeds at the Hanford Site, this data base will be enlarged, and new average values and ranges of values will undoubtedly be established. Many aspects of the geometric parameters included in the table are also preliminary in nature and reflect the most current thinking on possible overall repository design at the Hanford Site.

In spite of its preliminary nature, Table A-I has already proven very useful. It is the source for defining some of the attribute scales assigned to properties that are used in ranking materials during the materials selection process described in Chapter 3 and Appendix B of this report. Table A-I also lists many of the assumed preconceptual design conditions that were applied to the initial plug system designs and machinery selection schemes developed during this study. 


\section{SELECTION OF CANDIDATE PLUG MATERIALS}

\subsection{INTRODUCTION}

A preliminary scheme for selecting candidate plug materials for man-made accesses at the Hanford site was presented in Chapter 3 and Appendix B of Taylor and others (1979). It was recognized at an early stage of this study that materials to be used in plugs will greatly influence the selection of potential placement equipment and overall plug designs. Thus, the list of preferred candidate materials has a strong impact on the direction of the entire program.

A review of the original selection process presented in Taylor and others (1979) suggested the need for a re-evaluation of the materials selection process and the possible need for a new approach. This review indicated that in the preliminary scheme: (1) the scales of several evaluation measures were not completely defined; (2) a rationale was not presented for the evaluation measures that were used; (3) the use of weighting and rating factors and of specific cut-off values in various screens was not explained; and (4) the organization and use of the successive screens were not explained. In addition, the ranking of the materials examined during this initial selection process was found to be highly sensitive to some of these factors (particularly to the use of rating and weighting values and the relative organization of the screens used in the process).

It was decided to extend the work effort in materials selection and make improvements on the initial selection process during this study. Because the selection of materials for inclusion in a preconceptual design and testing program is a decision 
problem, the selection process can be appropriately viewed as a decision analysis. The concept of dominance in decision analysis (also referred to as efficiency) used in this modified materials selection process dates back to the classic work of Pareto (1897) on welfare economics. This work has been utilized successfully in a variety of evaluation problems involving multiple attributes (for example, Ford and others, 1979; Keeney, 1973). The interested reader is referred to Holloway (1979) for an elementary discussion of dominance, or Keeney and Raiffa (1976) for a more advanced presentation. Other relevant work is presented in Zeleny (1973).

Within a formal decision analysis, the following four steps need to be carried out:

- Structuring the problem: includes determining what objectives are being pursued, what alternatives might potentially meet those objectives, and what the constraints on the problem are;

- Determining the evaluation (utility) function: includes determining what evaluation measures (attributes) will be used to measure how well' each objective is met and determining how the various attributes will be combined to arrive at a single overall measure of the desirability of each alternative;

- Estimating attribute levels: includes an estimation, based on data or expert judgment, of the level of each attribute that each alternative will achieve. If appropriate, a quantification of uncertainties in these estimates is made; and 
Evaluation of alternatives: includes an integration of the results of the previous steps to evaluate the relative desirability of each alternative. In some situations there are disagreements about the estimated attribute levels or the evaluation function. In such cases, a sensitivity analysis is conducted to determine how these disagreements affect the evaluation results.

The review and evaluation of the original screening process indicated that the application of decision analysis would help overcome the drawbacks of the initial selection scheme discussed above.

The remainder of this chapter briefly reviews (1) the development and rationale of the modified materials selection process, and (2) the application of the process to select a list of preferred candidate plug materials for use in preconceptual design and testing. This list (Table I) verifies the results of the original selection process (Taylor and others, 1979). (See Chapter 3 and Appendix B of Taylor and others [1979] for a complete description of the original selection process.) Additional details of the modified process developed during the present study are presented in Appendix $B$ of this report.

\subsection{DEVELOPMENT AND RATIONALE FOR THE MATERIALS SELECTION PROCESS}

\subsubsection{General Objectives of the Process}

The original objectives of the selection process were to identify candidate materials that: (1) have a high probability for successful use in plugs; (2) have a high probability of 
TABLE I

PREFERRED CANDIDATE PLUG MATERIALS *

Material

Basalt

Quartz (only as a solid plug for

small boreholes)

Smectite clays

Clinoptilolite

Steatite fonly as a solid plug for

small boreholes)

Grouts

portland cements

hydrothermal cements

Concretes

portland cements and aggregate

hydrothermal cements and aggregate
Desirable Attributes

Relatively impermeable as a solid plug

Good strength for engineering purposes

Low (but some) ion exchange potential and moderate sorption capacity

Low cost, high availability

Impermeable

Good strength

Chemically stable

Low cost

Very impermeable

High ion exchange potential and sorption capacity

Chemically stable

Low cost, readily available

High ion exchange potential and sorption capacity Chemically stable

Low cost, readily available

Low permeability

Good strength

Low cost

Low permeability

High adaptability

Low cost, readily available

Good strength

Low permeability

High adaptability

Low cost, readily available

* Selected by the modified materials selection process described in this report. 
acceptance based on U.S. Nuclear Regulatory Commission (NRC) criteria; and (3) can be used in the physical and geochemical testing programs. The selection process should also provide a documented defensible method for logically arriving at a small number of preferred materials for initiating testing programs and preconceptual design schemes. The most promising plug materials from a vast array of potential candidates were selected at an early stage in the development of the program. Because many methods of selection are possible, one important objective was to clearly document the rationale underlying the selection process used in this study.

The selection process described in Taylor and others (1979) essentially accomplished several of these objectives. Preferred candidate materials, which are thought to have a high probability for successful use in plugs, were identified by that process. Also, these preferred materials formed the basis for initiation of physical and geochemical testing and preconceptual plug design.

The primary objectives of continued evaluation of the selection process and of the application of decision analysis to the problem are: (1) to correct deficiencies in logic in the original selection scheme; (2) to develop a method that avoids the use of weighting and rating factors and cut-off values; (3) to re-examine the initial comprehensive list of materials with a different approach; (4) to more completely document the steps of the process (specifically the steps used in the decision analysis); and (5) to develop an analytical approach that can be generalized and applied to materials selection problems pertaining to backfill and canister hole plugs. Thus, the re-evaluation of the original materials selection process 
and the application of a decision analysis to materials selection made possible the attainment of all objectives discussed above.

\subsubsection{Structure and Objectives of the Decision Analysis}

As discussed above, the modified selection process is a decision analysis, and therefore, the four steps of a decision analysis outlined in section 3.1 must be addressed.

\subsubsection{Structuring the Problem}

The constraints on the selection of materials are substantial because a plugging system must maintain its functional capabilities for thousands of years without human intervention. In addition, this study was restricted to considexing materials which do not require the collection of substantial amounts of new data.

These considerations resulted in the following objectives for the materials selection process:

- Selected materials must be compatible with the natural environment expected in the repository shafts, tunnels, and boreholes;

- Selected materials must have a documented history of survival for a period of time on the order of that expected for the containment lifetime of the repository;

- Selected materials must be sufficiently documented so that relevant physical and chemical properties can be specified; 
Selected materials should provide, in a superior manner, at least one of the three functions (inhibit fluid flow, inhibit radionuclide migration, or provide structural integrity, as discussed in section 3.3.3) needed in a plugging system; and

- Selected materials should be practical to use. This requires consideration of a variety of concerns, including cost, availability, ease of placement, etc.

Note that the first three objectives must be met by any selected material. If either of the first two objectives are not met by a material, conservative engineering practice dictates that the material not be used. If the third objective is not met, consideration of the material is outside the scope of the study. The last two objectives differ from the first three in that materials might meet these objectives to differing degrees and still be acceptable as potential plug materials.

\subsubsection{Determining Evaluation Functions}

In choosing appropriate material properties for measuring how well a material meets the fourth objective listed above, it is necessary to keep in mind that materials will be evaluated with respect to three different potential functions in plugs. Obviously, the properties used to measure how well materials inhibit fluid flow are different than those used to measure how well they provide structural integrity.

Multiple properties are needed to completely assess the ability of a material to perform one of these functions, and all of these properties are considered together when evaluating the 
overall ability of a material to perform one of the functions. Because the relative importance of the various properties will depend to some extent on details of plug system design (not yet determined), specific statements of a property's relative importance are avoided as much as possible when carrying out the evaluation.

\subsubsection{Estimating Attribute Levels}

One step in the process is to evaluate the numerical ranges of values quoted in the literature (or from other sources) for the material properties being used in the evaluation. These ranges of values are then broken into attribute scales by assigning numerical attribute levels to incremental parts of the range of values. Because much variation exists for the reported values of many properties of materials under consideration, the range of values quoted for properties is summarized in fairly broad categories in the attribute scales rather than in specific, exact levels. Attribute levels are then determined for a specific material based on the numerical levels in the attribute scales (which represent ranges of values quoted for the material properties) and information on published values for the properties of that material. This step is discussed in detail in Section 3.3.5.

\subsubsection{Evaluating Alternatives}

The first four objectives listed in Section 3.2.2.1 are qualitatively different and are considered to be more significant than the last objective (which is that materials should be practical to use). There are two reasons for this: (1) it is difficult to judge now what will become "practical" over the 50 to 100 years that are likely to elapse before a 
repository in basalt is permanently sealed; and (2) "practicality" is very relative. In some people's views, large scale use of nuclear power cannot occur until the terminal waste isolation problem is solved, and without such use of nuclear power there may be severe dislocations in the economy of the United States. If the latter is correct, cost and availability become secondary factors in selecting candidate plug materials.

For this reason, the overall evaluation of a material in the modified selection process has three sequential parts:

- Assurance that the three mandatory objectives are met;

- Determination of how well the physical and chemical properties suit the capability of a material to carry out one or more of the three plug functions (discussed earlier); and

- Qualitative consideration of the various practicality issues to determine whether these issues have sufficient importance to alter the evaluation based only on physical and chemical properties (carried out under the second part above).

In this three-part process, the initial evaluation of the desirability of a material is based only on physical and chemical properties. Thus, if anyone should disagree with the assessment as to what is "practical", he would still be able to use much of the analysis. 


\subsection{THE MATERIALS SELECTION PROCESS}

The considerations discussed in Sections 3.1 and 3.2 led to the development of a seven-step materials selection process during this study. This process is outlined in Figure 1, and the relationship of these seven steps to the four steps of a formal decision analysis (discussed in section 3.2.2) is illustrated in Table II. A detailed explanation of the selection process discussed in this chapter is presented in Appendix B.

\subsubsection{Development of an Initial List of Materials (Step 1)}

The initial list of materials (Taylor and others, 1979); to be considered in the modified selection process was assembled by WCC personnel.* This list was reviewed by Dr. Hans Ewoldsen, Project Director, and Mr. Charles Taylor, Project Manager. In assembling any such list, a vast array of potential plug materials could be included. The list used in Taylor and others (1979), which is not exhaustive, reflects the professional judgment of the authors. Obviously, another group of scientists might develop a somewhat different, specific group of materials. However, several guidelines were used in assembling the initial list, and adherence to them by other professionals should produce a similar list:

- Materials included on the list are considered to be potential major plug components. Additives (materials present in plugs in small amounts to serve specific functions) were not included in this screening process;

Dr. Gary Anttonen and Messrs. Marvin Niccum, Jack O'Rourke and Marc McGovern. 


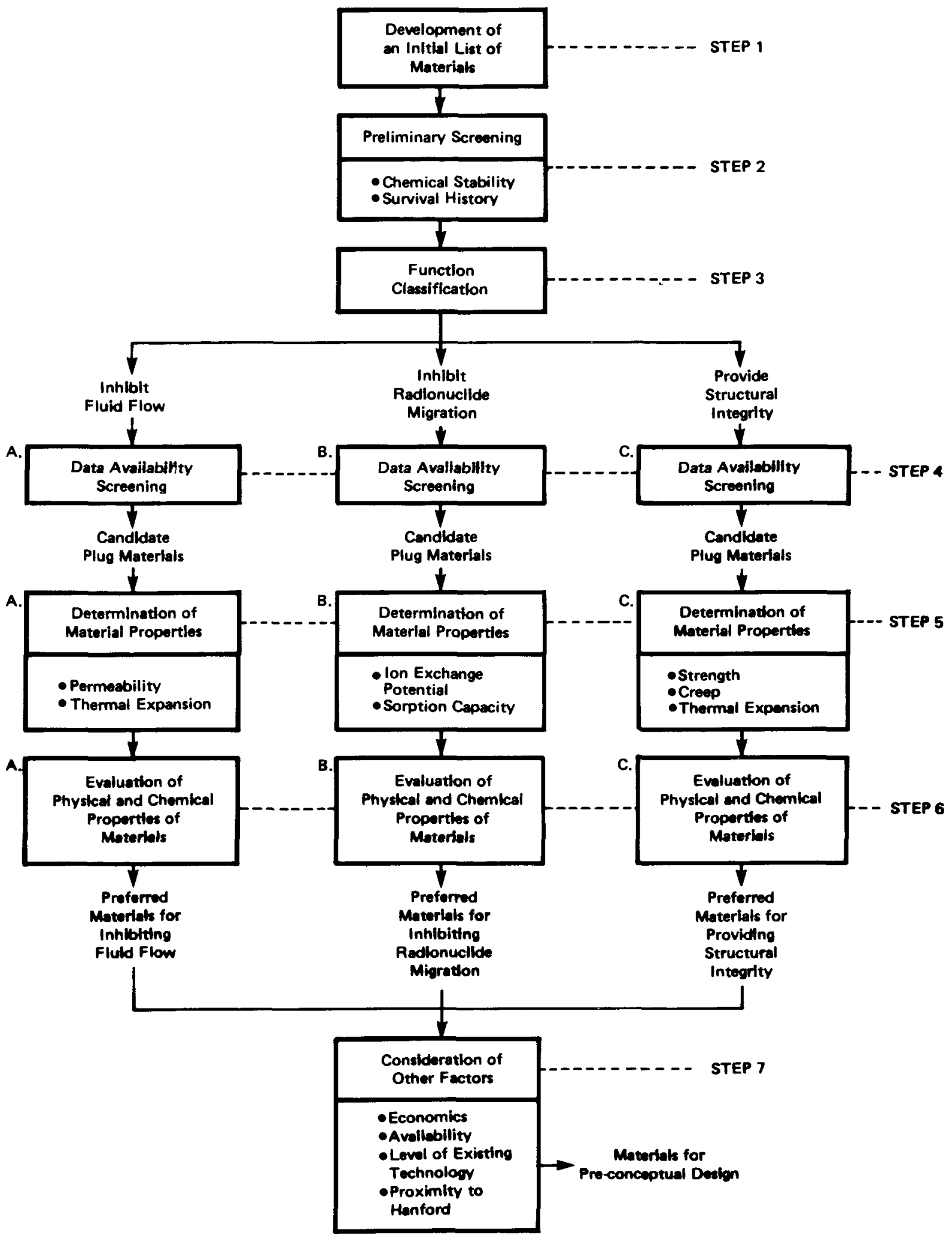

FIGURE 1 
TABLE II

DECISION ANALYSIS AND THE SELECTION OF CANDIDATE PLUG MATERIALS

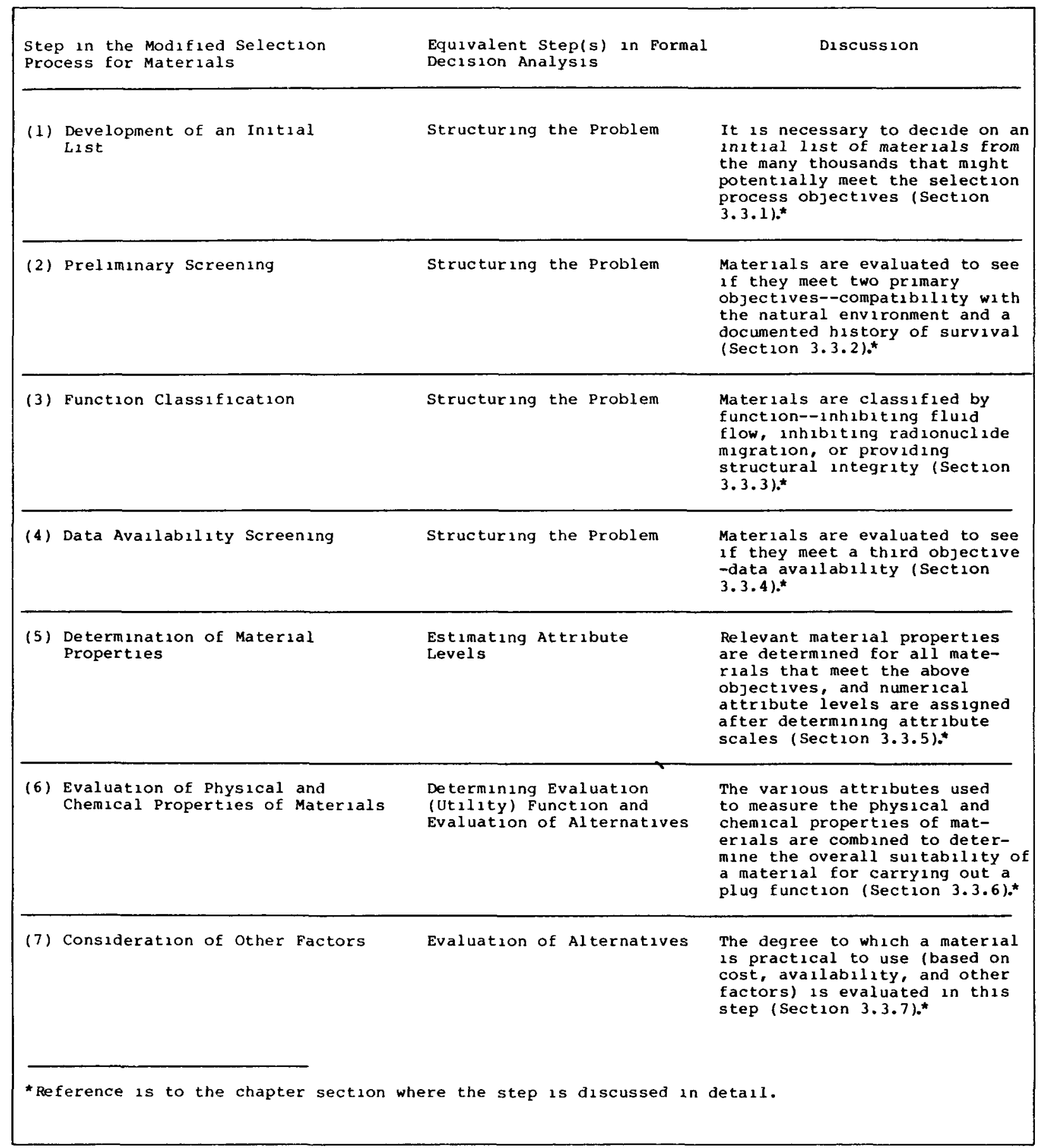


- The list is, in part, a sampling of material types rather than a complete list of every conceivable candidate material under a given classification;

- In general, the materials should appear to be compatible with the natural geologic environment at repository depths and with projected changes in this environment produced by drilling boreholes and excavating shafts and tunnels. Some history of a material's use in engineering applications and investigations was also considered desirable;

- The list of materials is based on desirable physical and chemical properties a material may potentially bring to a plug design; and

- Cost and availability of a given material were not considered when the list was assembled.

With respect to the first guideline, note that additives are best evaluated once major plug components, design, and environmental parameters are better known. Each additive can then be assessed on an individual basis with respect to the specific function it might serve. The screening process discussed in Taylor and others (1979), and the modified one described in this chapter and in Appendix B, evaluate the relative desirability of potential major plug components using a set of evaluation measures (attributes). These attributes are applied to the entire list in a sequential manner in order to eliminate less desirable candidates and eventually produce a preferred list of materials. Materials on the list are evaluated individually with respect to their chemical and physical properties. They are not considered in mixtures 
during the screening process because the number of possible permutations and combinations is too large. The range of attribute values of chemical and physical properties for mixtures would also become too large.

With respect to the second guideline, the authors used their professional experience and judgment to make the list an appropriate sampling of material types. For instance, various natural materials on the list, such as the zeolite, clinoptilolite, or the crystalline rock (granite), are representative of groups of minerals or rocks possessing particular properties. Likewise, manufactured items, such as concretes, are representative of a class of man-made materials that include many alternate choices. Various factors, such as availability and cost, may ultimately make an alternate possibility in any classification more desirable than the specific one currently listed. However, listing representatives from these groups and comparing their characteristics in the screening process suffices to discriminate between their relative desirability at the present time and at the present level of study and plug design.

The third and fourth guidelines used in assembling the list are considered in more detail during the screening process itself because the range of values for many material properties used in the process reflects both the natural environment at the Hanford site and the projected changes to that environment produced by excavation of the repository. However, in assembling the initial list, these guidelines generally helped eliminate obviously incompatible or non-durable materials from the 1 ist. 
The fifth guideline eliminated cost and availability as factors in assembling the initial 1 ist. These two factors are treated in a final step of the screening process itself to help distinguish the relative desirability of the most preferred candidate materials. The importance of designing successful plugs and the importance of the physical and chemical properties of materials used in plug construction outweigh economic considerations at this early stage of the materials selection process. Because creation of the initial list is the first step in the process, a comprehensive list of potentially desirable candidate plug materials that are listed without deference to cost and availability was considered essential. As a result, some rare and costly materials (especially precious metals), having potentially desirable physical and chemical properties, appeared on the initial list. Application of the cost factor to all materials at the same point later in the selection process will eliminate certain costly materials. However, for the sake of a uniform application of logic during the process, all materials on the initial list were screened in the same way.

The initial list of candidate plug materials used by Taylor and, others (1979) was reviewed during the present study and was found to be generally satisfactory. This list, with the elimination of some materials that were reclassified upon detailed re-evaluation as additives rather than potential major plug components, and with other minor modifications, was used as the initial list (Appendix B, Table B-I) for the analysis described in this chapter. 


\subsubsection{Preliminary Screening (Step 2)}

The original materials selection process described in Taylor and others (1979) was found to be highly sensitive to several major factors. In the original selection process, one of these factors, chemical stability, was incorporated into the general weighting and rating scheme used in that process. In the current approach, these major factors are consolidated into an initial screening procedure that eliminates materials found to be unacceptable on the basis of one or both of the following criteria:

- The material is chemically unstable in the repository environment with respect to expected $\mathrm{pH}$ and Eh conditions; and/or

- The material has an insufficiently documented history of survival to assure its stability for periods on the order of thousands of years.

This screen assesses the fundamental chemical compatibility of materials with the repository and geologic environment. It also assesses their documented history of survival through time and their ultimate acceptability as plug materials in plugs that must demonstrate, to a high degree of assurance, their capability for lasting thousands of years. The latter constraint greatly diminishes the acceptability of many man-made materials.

\subsubsection{Function Classification (Step 3)}

In step 3, the remaining materials are classified by three major functions: (1) to inhibit fluid flow; (2) to inhibit 
radionuclide migration; and (3) to provide structural integrity. Materials that can serve more than one function are classified under all relevant categories. Note that the function classification used here is different from that defined by Taylor and others (1979), which separates materials into potential major plug components and additives. In the current selection process, only potential major plug components are considered. Additives are not included in this process because the objective is to select candidate materials for testing that are potential major components for preconceptual plug designs. Additives will be present only in small amounts and will be tailored to highly specific conditions; they will fulfill a separate, special function and are best evaluated at a later date after major plug components, design, and environmental parameters are better known.

The function classification is necessary because the evaluation process must be somewhat different for each class of materials. In particular, the relevant material properties that need to be considered during evaluation of a material depend on the function for which the material will be used. For example, the ion exchange potential of a material is not important if the material is to be used to inhibit fluid flow; however, if its function is to inhibit radionuclide migration, then ion exchange potential is very important.

This classification of materials anticipates plug design to some extent because materials are categorized according to their projected ability to perform a certain function in the plug. However, such a classification at this stage in the selection process overcomes a major problem of the original screening process developed in Taylor and others (1979). In that process, the relative merits and properties of materials 
that are to serve fundamentally different functions in a plug had to be compared in a series of complex screens. As a result, the serious problem of comparing "apples" with "oranges" was greatly increased.

Classification of materials according to the three functions outlined in this section, and the evaluation of each group separately under each classification, enable the selection of properties that measure the performance of a material with respect to a specific function. Thus, materials can be ranked under each classification in accordance with their ability to perform that function as defined by a list of properties relevant to that function. In general, like quantities are being compared by the process.

\subsubsection{Data Availability Screening (Step 4)}

This screen is individually applied to data available for the various attributes used to rank materials in each function classification in step 5 (described in the next section). Materials for which large data bases have been accumulated are more predictable than materials for which fewer data are available. It was not within the scope' of the present study to expand the data base with respect to specific properties of materials listed under each of the three function classifications. This would require new research and laboratory experimentation for those materials whose physical and chemical properties are little known.

The data availability screen eliminates materials for which data are judged inadequate. University and company libraries, textbooks, scientific journals, and professional reports were consulted to evaluate their relevant properties within the time 
constraints of the testing program. For a material to pass this screen does not require that every property discussed under each function classification in the next step (Section 3.3.5) be completely defined in the literature. Materials that are similar to other well-documented materials, or materials that have properties that are well-documented and similar to those discussed in the next section, are considered as having sufficient available information for assigning attribute values on the basis of professional judgment or analogy (as discussed in Section 3.3.5.4). However, those materials that lack sufficient pertinent data on properties of concern (see section 3.3.5) or lack well-documented analogs are eliminated by this screen.

Obviously, as new data become available, the evaluation produced by this screen may change. It should be re-emphasized that the evaluation is made with respect to data considered pertinent to the basalt borehole plugging problem and to material properties (discussed in the section 3.3.5). Thus, some materials (particularly man-made ones) are eliminated even though they have relatively large, but inappropriate, data bases with respect to their known properties.

\subsubsection{Determination of Material Properties (step 5)}

A wide variety of chemical and physical properties are potentially relevant for evaluating the desirability of a material for use in borehole, shaft, or tunnel plugs. Selecting the appropriate material properties requires that the primary purpose of the materials selection process (i.e,, to select materials for inclusion in programs of continued evaluation and testing) be kept clearly in mind. The present objective is not to define the large number of properties for 
each material, as will be required in the selection of final designs for plugs. Many properties of a material will be important in deciding on a specific plug design that best utilizes that material. However, during the initial evaluation of whether a material should be considered for use in a plug, only a few critical material properties that will be important regardless of the exact design of the plug should be considered. The following questions were pertinent in developing the procedures used in steps 5 and 6:

- What material properties should be considered?

- What attributes (evaluation measures) should be used to measure each important material property?

- How should the attribute levels be determined for each material property?

- How should the different attributes be combined to arrive at a single overall evaluation of the chemical and physical properties of each material?

The first three questions are addres̀sed below; the fourth is discussed in Section 3.3.6.

The number and type of material properties considered should be limited to those that will fundamentally characterize the suitability of materials under each function classification. The list of selected material properties under each classification is based on parameters for which adequate data exist in the literature and for which the material's impact on potential plug design can be directly evaluated. Ambiguity surrounds the impact of certain properties on the final 
performance of a plug. These properties were not used in the evaluation of materials under each function classification.

3.3.5.1 Properties of Materials to Inhibit Fluid Flow

Permeability is the primary measure of the ability of a material to inhibit fluid flow. Many factors affect permeability, and a range of values for permeability is commonly cited in the literature for any given material. In addition, other physical properties of a material can directly affect the bulk permeability of a plug. One of these, thermal expansion, is included on the list of properties used to evaluate the ability of a material to inhibit fluid flow. Materials with coefficients of thermal expansion similar to that of basalt are more suitable for plugs than materials that have greatly different coefficients of thermal expansion. Separation at the plug/wall rock interface and induced fracturing of the plug or basalt should be less likely to occur during the heating and cooling cycles of the containment period of a repository where the plug has a coefficient of thermal expansion similar to that of basalt. Fracturing induced by materials having thermal expansion coefficients greatly different froln basalt could. drastically and adversely affect the bulk permeability of the plugs.

Other potentially relevant factors, such as modulus of elasticity and plasticity index, were considered for use as evaluation measures, but the significance of these factors is difficult to determine unless a specific plug design is being evaluated. For instance, high elasticity could either be detrimental or beneficial in a plug material, depending on the plug's proposed use. Both properties could influence the longterm ability of a plug to restrict fluid flow; however, because 
the impacts of these factors are unclear (high plasticity, for example, may be desirable in some plug designs to maintain impermeability and undesirable in others), they are not used to evaluate and rank materials. These factors, of course, will be considered once actual plug design is underway.

The two selected factors (permeability and thermal expansion) along with chemical stability assessed in step 2 (pH and Eh compatibility with the environment), are the bases for determining the overall potential of a material for inhibiting fluid flow in this evaluation.

\subsubsection{Properties of Materials to Inhibit Radionuclide Migration}

Under this function classification, the suitability of those materials which will inhibit the migration of radionuclides (although not necessarily a fluid containing them) was evaluated. In addition to low permeability, a large capacity to exchange ions with the environment is the most important mechanisin by which plug material can help control the migration of radionuclides in solution; ion exchange potential and sorption capacity are two primary indicators of this ability.

Ion exchange potential is a measure of the ability of a material to set free and replace ions in its structure with ions in solution in contact with the material. Materials with high ion exchange potentials may have the capacity for setting free ions from their lattice structure and replacing them with (and thus immobilizing) migrating radionuclides.

Sorption capacity is a measure of the general ability of a material to entrap ions migrating in solution; the actual 
sorption mechanism for any given material can reflect several phenomena, including van der Waals bonding, the filling of vacant lattice spaces in crystal structure, the entrapment of ions by the host due to unsatisfied bonds along crystal edges (edge effects), as well as actual ion exchange (as described above). Generally, the distribution coefficient ( $k_{d}$ value), which gives a relative measure of the sorption capacity of a material, is a collective, somewhat qualitative assessment of these various phenomena.

Both ion exchange potential and sorption capacity are temperature dependent; for most materials, these factors decrease with increasing temperature. However, thermal stability is not included as a third attribute under this function classification because the temperature at plug seats is expected to be less than $100^{\circ} \mathrm{C}$ (see Table A-I, Appendix A). Within this expected temperature range, the ion exchange potentials and sorption capacities for most materials are not greatly affected, and thermally induced changes in their properties that might affect ion exchange potential or sorption capacity are expected to be minor. Chemical changes could also adversely alter the ability of a material to block. migrating radionuclides. (Step 2 eliminated materials that are chemically unstable in the anticipated environment).

Chemical precipitation, another possible mechanism for inhibiting radionuclide migration, was also considered. However, in general, materials that have the ability to precipitate migrating radionuclides and to form stable mineral products are not candidates as major plug components. They would be present in plugs in small amounts as additives and, therefore, are not considered in this selection process. Thus, ion exchange potential and sorption capacity, in conjunction 
with chemical stability (evaluated in step 2 of the selection process), are the basis for determining the overall ability of a material for inhibiting radionuclide migration in this evaluation.

3.3.5.3 Properties of Materials to Provide Structural Integrity

Structural integrity of the plug will be provided primarily by its ability to resist or accommodate deformation over time. Because materials that provide other important functions of inhibiting fluid flow and radionuclide migration may be rather easily deformed, it is necessary to separately evaluate materials suitable for providing the plug with requisite structural integrity during the containment period of the repository. While deformable, plastic materials will provide some physical continuity, enyineering practice indicates that in large openings (shafts and tunnels) such materials will need to be buttressed by more rigid pluy components capable of transmitting the various loads that may be imposed on large plugs. Thus, the factors for evaluating the ability of a material to provide structural integrity include strength (in unconfined compression), creep (as a measure of a material's long-term behavior), and its coefficient of thermal expansion. The last factor measures the compatibility of the candidate plug material with host rock and the natural environment. Materials that have thermal expansion properties similar to basalt are preferred. Again, note that chemical compatibility with the environment is evaluated during step 2 of this selection process.

Other properties that might help measure a material's ability to provide structural integrity (such as consolidation, 
compressibility, plasticity, and elasticity) are, in part, design dependent. Under differing circumstances, high or low values of each may be desirable or undesirable. Thus, these properties can not be used in the present phase of materials selection.

3.3.5.4 Determination of Attribute Levels

In order to determine and record material properties in a consistent and easily understandable way, numerical evaluation measures (attributes) are used to summarize the properties of each material. The numerical ranges assigned to the various attribute scales are based on actual data from the natural environment at projected repository depths (e.g., the attribute scale for permeability) or are scaled from published data (e.g., the attribute scale for ion exchange potential).

Assignment of attribute levels to the properties of materials on each list of the three function classifications is made primarily on the basis of published data. Because each level of the attribute scale for each material property was bracketed by a rather broad range of values, uncertainty as to the appropriate attribute levels for particular materials is minimized. In most cases, ranges in published data for the properties of a given material fall within the range of a single defined level for each attribute scale.

Not every property 1 isted as an attribute has been measured for every material (or the pertinent data could not be located in the available time); where necessary, attribute levels are assigned on the bases of analogy with similar materials for which data are available. In other cases, attribute levels were assigned on the basis of judgment and the expected 
behavior of a given material. The primary objective of the materials selection process is to select promising materials for future study, and judgmental assignments of attribute levels are accurate enough to meet this objective and still allow comparisons with attribute levels assigned on the basis of data collected from the literature.

\subsubsection{Evaluation of Physical and Chemical Properties of Materials (Step 6)}

In order to evaluate the physical and chemical properties of materials under each function classification, all attributes of the material are considered together in step 6. To the extent possible, the desirability of candidate pluy materials would be evaluated without assigning specific relative importance to each of the various attributes. This procedure is desirable because the importance of the different factors depends in part on features of plug design that have not yet been determined. For example, the importance that should be attached to having high ion exchange capacity depends on the degree to which this mechanism will be used to trap radionuclides in the plug. This has not yet been determined. In addition, the approach used herein avoids the weighting factors and cut-off values applied in the original selection process described in Taylor and others (1979).

The evaluation procedure used here is dominance analysis, which does not require any assignment of relative importance to the various properties. Appendix B, Section B.7, describes in detail the application of dominance analysis to the current materials selection process; this application resulted in a list of materials ranked from most to least preferred in each function classification. This list categorizes materials by 
the relative desirability of their physical and chemical properties. However, all materials in each function classification are not precisely rank-ordered for two reasons: (1) because each attribute scale has only a few different levels, several materials have the same levels for all attributes. Thus, these materials will always rank the same, regardless of what procedure is used to combine the various attributes; and (2) because only dominance concepts are used in the evaluation and no statements are made about the exact relative importance of the various material properties, the decision of which of any two materials in question has the most desirable physical and chemical properties is not always possible.

In most cases, the first of these two reasons resulted in materials being ranked as equally preferable. There are only two situations in the set of three lists (one for each of two function classifications) for which additional information about the relative importance of attributes could lead to a more detailed ranking of the materials. Both of these situations involve materials that are ranked relatively low, and hence, a more detailed evaluation that would require. assessment of the relative importance of each attribute was not necessary.

\subsubsection{Consideration of Other Factors (Step 7)}

In addition to chemical and physical properties, several other factors are important in determining the final list of preferred candidate materials to be used in testing programs and preconceptual plug design schemes. These factors include economic availability, compatibility with various borehole diameters (ranging from several centimeters to as much as $10 \mathrm{~m})$, and in the case of natural materials, proximity to the Hanford site. 
Each material ranked on the three lists derived from step 6 for the three function classifications is evaluated in Step $7 \mathrm{with}$ respect to these other factors. A final list of preferred candidate materials (Table $I$ ) is based on the physical and chemical properties evaluated in step 6 and these other factors.

From the beginning of the selection process through Step 6, the evaluation procedure considered the physical and chemical properties of the materials on the original list and also considered the potential for determining these properties. Step 7 addresses limitations (such as cost or potential plug volume dependent on hole diameter) of the uses to which materials can be put. For example, certain materials that have desirable chemical and physical properties for performing certain plug functions may be costly (the precious metals are a good example). In other instances, materials that have desirable physical and chemical properties may only be appropriate for consideration as plugs in certain diameter holes (for example, the use of machined quartz or ceramic plugs for small dianeter boreholes).

With the exception of Step 4 , step 7 is more qualitative and judgmental than the other steps in the evaluation. This subjectivity is necessary because questions of cost and availability are dependent on factors of plug environment and design that are not yet determined. In addition, the mearing of these terms is relative and depends on available alternatives at the time of actual plug placement. While it is almost certainly out of the question to use gold to plug a shaft or tunnel, it might be feasible to use it as part of a plugging system for a small borehole. Whether gold is, in 
fact, too costly for this application depends partly on what alternatives to its use are available. If, for example, no other material had physical and chemical properties that were as suitable for a particular plugging function in a borehole, and if the plugging program required the function performance, then it is conceivable that a costly material would be used. In step 7, the assessment that the cost will preclude the use of an expensive material is essentially an assessment that the hypothetical chain of events discussed above will not come to pass.

\subsection{DISCUSSION}

The final list of preferred candidate, materials (Table I) derived from the approach described here is very similar to the 1 ist developed from the original selection process described in Taylor and others (1979). However, the approach presented in this chapter and in Appendix $B$ is considerably different from the original process.

In general, the approach presented in this report helps clearly determine and organize those factors that are most significant to the final outcome of the selection process and documents the process in a more complete fashion. The reorganization of function classifications and more complete definition of attributes in this new approach makes it possible to compare materials that will have like applications in plug design and to discriminate between and rank them on common grounds.

The restructuring of the selection process also provides a framework for this type of analysis during future work on materials selection for repository backfill and canister hole plugs. New initial lists of materials for backfill and 
canister hole plug problems could be developed, and the various attribute scales can be adjusted to reflect the more extreme physical and chemical conditions that may exist in the nearfield environment of the waste storage canisters. It would probably be necessary to expand the list of material properties under the various function classifications if the selection scheme was modified to evaluate potential backfill and canister hole plug materials. For example, the thermal stability ranyes of various materials may be a critical property in the nearfield environment.

The list of preferred candidate materials developed by the selection process described by Taylor and others (1979) was verified by re-evaluation during the present study, as described here. This list is the basis for the physical and geochemical testing programs of preferred candidate materials presented in the next two chapters. This list is not intended to be a final list of potential candidate plug materials. In fact, additions and minor modifications were made as the two testing programs proceeded. However, materials on the list do represent the types of materials that are considered to have the greatest potential for successful use in plugs and for meeting the many other restrictions that may eventually be applied to plug design and to the entire borehole plugging problem. 


\subsection{INTRODUCTION}

\subsubsection{Background and Objectives}

Materials used in plugging boreholes must be stable in the plug environment over time periods that are long (many thousands of years) by any human standard of comparison. When engineered into plugs, these materials must block radionuclide migration to the biosphere as part of the overall containment function of the repository. One process that could lead to unacceptable levels of radionuclide migration to the biosphere during the containment period of the repository is chemical deterioration of plug materials due to reactions between the materials themselves or reactions with their surroundings.

The primary objectives of the geochemical testing program were to:

- Help define the behavior of candidate plug materials in the plug environment;

- Provide data on the relative stability and reactivity of candidate plug materials; and

- Identify the most promising materials for consideration in future studies involving plug system design and advanced testing programs.

Even though candidate plug materials from Table I are considered to be extremely stable and durable, slow chemical reactions not detected in earlier studies could eventually lead 
to a loss in plug integrity. The need to make reliable predictions on behavior for periods of thousands of years or more places severe demands on any chemical testing program because long-term experiments may be necessary to obtain sufficiently accurate data on which to base these predictions.

However, given the large number of mixtures of candidate materials, which are of potential interest and could be designed from the list in Table $I$, and the need to reach early decisions on plug design, such long-term experiments are not practical at this stage of the program. Instead, the geochemical testing program described here is a series of initial screening tests that were intended to permit an evaluation of the suitability of materials based on their short-term chemical reactivities. These tests determined a lower bound on the level of reactivity to be expected over the useful life of the plug.

The results of these geochemical screening tests (described in this chapter) are combined with test results from the physical testing program (described in Chapter 5) to select a group of preferred plug materials (Chapter 6). This group of materials will be used in preconceptual design schemes to be described in a separate report. These materials should be subjected to more extensive chemical and physical testing in order to make the necessary long-term predictions on the behavior of materials in the plug environment.

\subsubsection{Scope of the Geochemical Testing Program}

Selection of tests for the present geochemical testing program was determined by estimates of environmental conditions to which the plug will ultimately be subjected. Preliminary ranges of temperature, pressure, $\mathrm{pH}$, and ground-water 
composition have been established (see Table A-I, Appendix A), and chemical degradation mechanisms for the plug materials were hypothesized and experiments were designed to detect the potential occurrence of reactions under these postulated environmental conditions.

Additional constraints on the selection of test procedures were: (1) the length of time available to do the tests; (2) the anticipated low reaction rates of plug materials; and (3) the availability of reaction vessels. The potential alteration mechanisms of plug material are: (1) chemical reactions between plug materials; (2) chemical reactions between the plug materials and the surrounding rock; (3) chemical reactions between the ground water and the plug materials (dissolution, selective leaching, solution-mediated phase changes or recrystallization); and (4) pressure-induced phase changes.

The rates of these reactions are likely to be extremely slow at plug seats, where temperatures are projected to range from the ambient wall rock temperature of $65^{\circ} \mathrm{C}$ to less than $100^{\circ} \mathrm{C}$ after closure of the repository (see Table A-I, Appendix A). Therefore, it was decided to run most tests at as high a temperature as was experimentally feasible to take advantage of the approximate doubling of reaction rates for every $23^{\circ} \mathrm{C}$ rise in temperature. A temperature of $250^{\circ} \mathrm{C}$ was selected for reasons discussed below. The assumption of a water-saturated repository required the tests to be done wet, which dictated the use of pressure vessels to contain the reactants. Equiliorium between the chromium in the stainless steel pressure vessel and oxygen in the test water maintained highly reducing conditions in the pressure vessels. 
Thus, one of the major components of this program was a screening test for chemical reactivity of potential plug materials in contact with simulated ground water. Chemical alteration of the plug materials was detected by analysis of the solid and of the solution in contact with it after fixed periods at $250^{\circ} \mathrm{C}$ under saturated steam pressure.

Other experiments were designed to determine the effects of variables not tested in the procedure just described. For example, the solutions in all individual capsules were static, and a separate set of tests was run in a stirred pressure reactor on duplicate samples of some materials and mixtures to assess the effect of agitation on reaction rates. Likewise, the influence of hydrostatic pressure on reaction rates and phase transitions was evaluated for a selection of materials at $250^{\circ} \mathrm{C}$ and $34.5 \mathrm{MPa}(5,000 \mathrm{psi})$. Some potential plug materials were tested under static saturated steam pressure at $150^{\circ} \mathrm{C}$ to examine the effects of temperature change on reaction rates. In general, the tests reflect extreme pressure, temperature, and moisture conditions at projected plug locations. In particular, temperatures at plug locations are not expected to exceed $100^{\circ} \mathrm{C}$ (see Appendix A, Table A-I), and any movement will be very slow and restricted. Thus, the laboratory tests reflect worst-case repository conditions with respect to several variables.

A further constraint was the need to evaluate approximately 40 samples for several reaction times. Physical limits on laboratory space and availability of pressure vessels necessitated that most materials be tested simultaneously in only a few vessels. This was accomplished by separately encapsulating the components of each individual test and placing all the capsules to be tested in the same vessel at a given temperature, 
pressure, and length of time. Early in the process of designing the experiments, it was decided to encapsulate in PTFE (poly-tetrafluoroethylene) cells rather than to bear the cost of the more commonly used gold for a large number of tests. PTFE is chemically inert in contact with all anticipated reactants and is reportedly stable to $300^{\circ} \mathrm{C}$. A test temperature of $250^{\circ} \mathrm{C}$ was chosen to provide the maximum acceleration of reaction rates consistent with the thermal stability of PTFE. The need to cool the entire autoclave to room temperature before sampling is an unavoidable consequence of any closed-tube experiment.

\subsection{MATERIALS}

\subsubsection{Components}

Materials used in both the geochemical and physical testing programs were selected from the list of preferred candidate plug materials developed during Task I work (Taylor and others, 1979). Chapter 3 describes a review and modification of the selection process that led to this list of preferred materials. The list of preferred plug materials presented in. Table I resulted from this modified selection process and essentially confirms the original selection.

Appendix C of Taylor and others (1979) described a preliminary sample preparation scheme using preferred candidate plug materials (singly and in mixtures) that will serve specific functions in various parts of preconceptual plug systems. Materials from the preferred list (Taylor and others, 1979; Table I, this report) that are contemplated for use in solid, crystalline machined plugs (such as fitted crystalline quartz plugs or ceramic plugs) for small boreholes were not tested in 
either the physical or the geochemical testing program. Materials tested in the initial programs (described in this chapter and Chapter 5) have potential use in multi-phase plugs designed from granular, natural materials and/or cements and concretes. The various samples constructed from these materials have potential application in all sizes of man-made accesses (small boreholes, shafts, and tunnels).

The sample descriptions presented by Taylor and others (1979) were derived with both the physical and geochemical testing programs in mind. The preliminary selection of samples described in that report (Taylor and others, 1979) is shown in Table III. The overall selection and design of samples in Table III were based on the projected or known engineering capabilities of materials from the preferred list of candidate materials.

Based on the list of preferred candidates (Taylor and others, 1979), 14 different materials were supplied by WCC for testing at SRI facilities. These final 14 materials were selected by preliminary screening tests performed at the WCC laboratory in Oakland, California, during the initial phases of the physical testing program; these tests are described in chapter 5. Table IV presents the list of samples that were prepared from these materials and used by SRI in the geochemical testing program. Note the similarity between Tables III and IV; specific cements, cement additives, and the last category of eight unspecified samples (shown in Table III) were defined and acquired during the early part of this study.

Because it is difficult to detect the occurrence of chemical alterations without establishing an unreacted reference state, all 14 materials were thoroughly characterized using techniques 
TABLE III

MATERIALS AND MATERIALS MIXTURES FOR PRELIMINARY SAMPLE PREPARATION (DETERMINED BY TASK I WORK)

\author{
Basalt Samples \\ Bulk Basalt \\ Coarse-Grained Basalt \\ Fine-Grained Basalt \\ Basalt/Sand
}

Soil Materials

Oregon Bentonite ${ }^{c}$
Wyoming Bentonite
Ringold Clayc
Oregon Zeolite
Processed Bentonite

Soil Materials Mixtures

Oregon Bentonite/Sand

Wyoming Bentonite/Sand

Ringold Clay/Sand

Oregon Bentonite/Zeolite

Wyoming Bentonite/Zeolite

Basalt/Soil Materials Mixtures

Basalt/Oregon Bentonite

Basalt/Wyoming Bentonite

Basalt/Ringold Clay

Basalt/Sand/Oregon Bentonite

Basalt/Sand/Wyoming Bentonite

Basalt/Sand/Ringold Clay

Basalt/Zeolite/Oregon Bentonite

Basalt/Zeolite/Wyoming Bentonite

Basalt/zeolite/Ringold Clay

Cement/Soil Materials/Basalt Mixtures

Portland Cement Type II/Sand/Basalt Portland Cement Type V/Sand/Basalt

Portland Pozzolan Cement/Sand/Basalt

Hydrothermal Cement (1)/Sand/Basalt

Hydrothermal Cement (2)/Sand Basalt

Portland Cement Type II/Zeolite/Basalt

Portland Cement Type V/Zeolite/Basalt

Portland Pozzolan Cement/Zeolite/Basalt

Hydrothermal Cement (1)/Zeolite/Basalt

Hydrothermal Cement (2)/Zeolite/Basalt

Eight Unspecified Combinations of Materials (From Table B-XVI, Appendix B) in Water

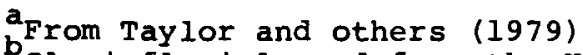

${ }_{c}$ Glaciofluvial sand from the Hanford Site

dPrimarily smectite clay

derimarily the mineral clinoptilolite 
TABLE IV

SPECIMENS USED IN THE GEOCHEMICAL TESTING PROGRAM

Sample

ID No. Composition

Basalt

Basalt

Basalt

Basalt/sand

Basalt/Oregon bentonite

Basalt/Wyoming bentonite

Basalt/Shurgel

Basalt/Aquagel

Basalt/Ringold clay ${ }^{C}$

Basalt/sand/Oregon bentonite

Basalt/sand/Wyoming bentonite

Basalt/sand/Ringold clay

Basalt/zeolite/Oregon bentonite

Basalt/zeolite/Wyoming bentonite

Basalt/zeolite/Ringold clay

Oregon bentonite

Wyoming bentonite

Oregon bentonite/sand

wyoming bentonite/sand $\underline{\text { Proportions }}^{a}$

Description $^{b}$

Single piece, polished face $-10 /+40$ mesh

$1: 1$

$1: 1$

$1: 1$

$1: 1$

$1: 1$

$1: 1$

$1: 1: 1$

$1: 1: 1$

$1: 1: 1$

$1: 1: 1$

$1: 1: 1$

$1: 1: 1$

$1: 1$

$1: 1$
Bentonite -325 mesh

Bentonite -325 mesh

Shurgel -325 mesh

(processed bentonite)

Aquagel -325 mesh

Clay -325 mesh

Bentonite -325 mesh

Bentonite -325 mesh

zeolite, bentonite -325 mesh

Zeolite, bentonite -325 mesh

zeolite, clay -325 mesh

-325 mesh

-325 mesh

Bentonite -325 mesh

Bentonite -325 mesh (processed bentonite)

Clay -325 mesh 
TABLE IV (continued)

\begin{tabular}{|c|c|c|c|}
\hline $\begin{array}{l}\text { Sample } \\
\text { ID No. }\end{array}$ & Composition & Proportions $^{a}$ & Description $^{\mathrm{b}}$ \\
\hline 20 & Oregon bentonite/zeolite & $1: 1$ & Both -325 mesh \\
\hline 21 & Wyoming bentonite/zeolite & $1: 1$ & Both -325 mesh \\
\hline 22 & Oregon zeolite & & -325 mesh \\
\hline 23 & Ringold clay & & -325 mesh \\
\hline 24 & Ringold clay/sand & $1: 1$ & Clay -325 mesh \\
\hline 25 & Fondu/sand/basalt & $1: 1: 1$ & $\begin{array}{l}\text { Fondu }=\text { hydrothermal cement } \\
\text { (brand name) }\end{array}$ \\
\hline 26 & Secar/sand/basalt & $1: 1: 1$ & $\begin{array}{l}\text { Secar }=\text { hydrothermal cement } \\
\text { (brand name) }\end{array}$ \\
\hline 27 & (Portland pozzolan cement + sand)/basalt & $1: 1$ & \\
\hline 28 & (Portland Type II cement + sand)/basalt & $1: 1$ & \\
\hline 29 & (Portland Type $V$ cement + sand)/basalt & $1: 1$ & \\
\hline 30 & $($ Fondu + zeolite) $/$ basalt & $1: 1$ & \\
\hline 31 & (Portland pozzolan cement + zeolite)/basalt & $1: 1$ & \\
\hline 32 & (Portland Type II cement + zeolite)/basalt & $1: 1$ & \\
\hline 33 & (Portland Type $V$ cement + zeolite)/basalt & $1: 1$ & \\
\hline 34 & (Portland Type $V$ cement + silica flour)/basalt & $1: 1$ & \\
\hline 35 & Basalt core + concrete & & $\begin{array}{l}\text { Bulk specimen supplied by } \\
\text { Rockwell }\end{array}$ \\
\hline
\end{tabular}


TABLE IV (continued)

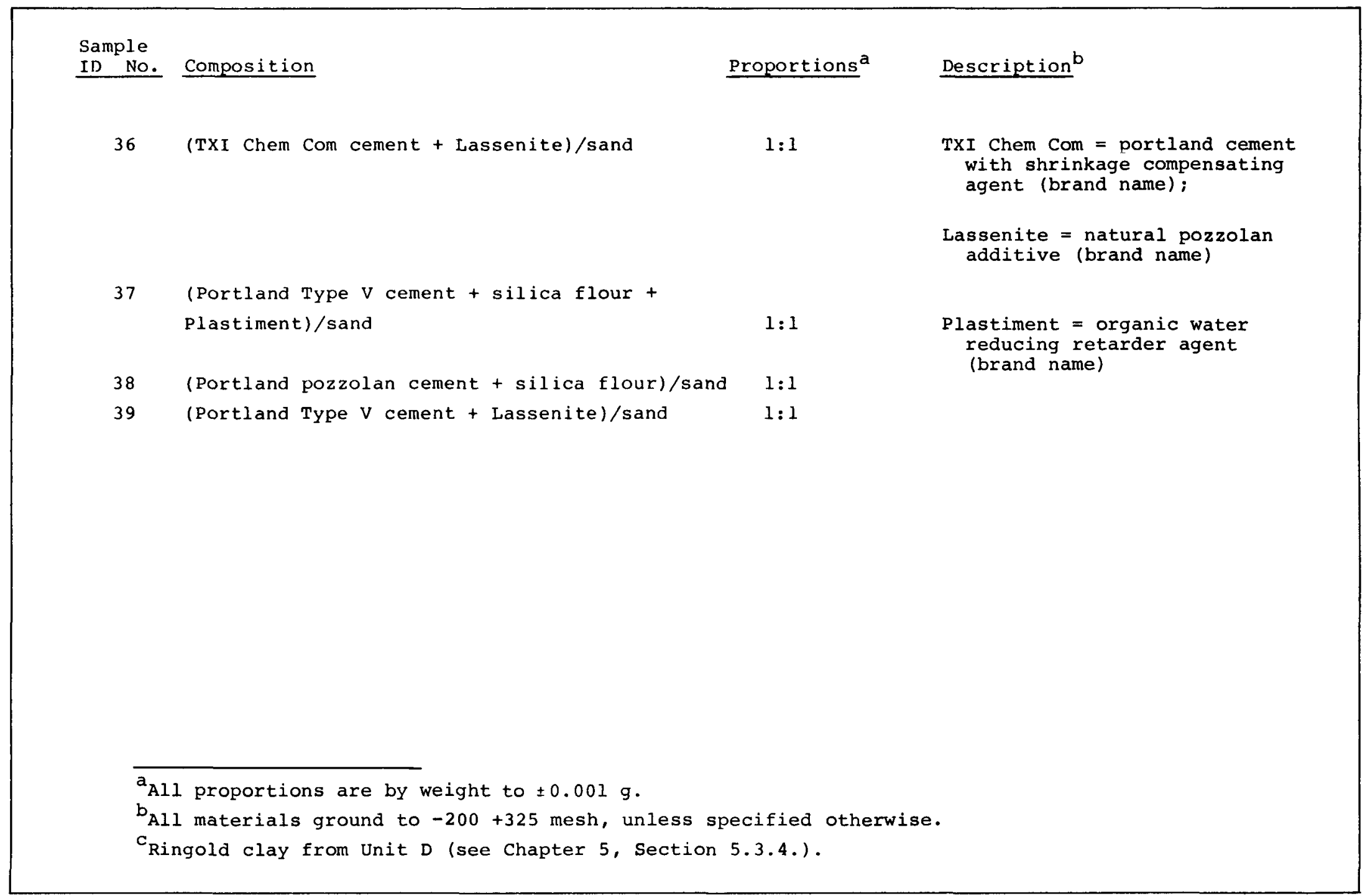


described in Section 4.4.2. The list of materials and the results of the analysis are given in Table $V$.

\subsubsection{Design of Mixtures}

Even though the same materials and mixtures. of materials tested for physical properties in WCC's laboratory facility were tested at the SRI facility in Menlo Park, California, the specifics of sample preparation, sample size, and exact proportions of materials used in mixtures varied between the two laboratories in accordance with variations in testing equipment requirements and testing program objectives. The physical testing program examined a range of proportions of components in samples containing two or more of the materials listed in Table IV. This examination was done to help select the best proportions for optimum mechanical response of a given mixture. However, the geochemical program generally used simple mixtures with equal parts for two-, three-, and fourcomponent systems. Chemical reactivities are generally not dependent on the percentage amount of a component present; one of the requirements of the chemical testing program at this stage was that only sufficient quantities of each component be present in order to prevent complete consumption of one of the components during the duration of the test runs.

Grain size also differed between samples used in the two testing programs. The physical testing program was designed to examine a range of grain sizes for most of the materials being tested. However, material for the geochemical testing program was finely ground $(-200$ to +325 mesh) in most, but not all samples, in order to maximize reaction rates between the small quantities being tested. 
TABLE V

CHARACTERISTICS OF STARTING MATERIALS (GROUND TO -200 MESH)

\begin{tabular}{|c|c|c|c|c|c|c|c|}
\hline Material & WCC No. & $\underline{a}$ & $\mathrm{~b}$ range & $\begin{array}{c}\text { Average } \\
\text { Particle Size } \\
\end{array}$ & BET $\left(m^{2} / g\right)^{d}$ & Color & Mineral Phasese \\
\hline Basalt & $A-76$ & 2.88 & 2.68 to 2.72 & -- & & Dk.Gray & $L, A, M$ \\
\hline $\begin{array}{c}\text { Bentonite } \\
\text { Oregon } \\
\text { Oregon } \\
\text { Wyoming } \\
\text { Shurgel } \\
\text { Aquagel }\end{array}$ & $\begin{array}{l}A-60 \\
A-61 \\
A-04 \\
A-03 \\
A-05\end{array}$ & $\begin{array}{l}2.70 \\
2.67 \\
2.44 \\
2.47 \\
2.46\end{array}$ & $\begin{array}{l}2.2 \text { to } 2.7 \\
2.2 \text { to } 2.7 \\
2.2 \text { to } 2.7 \\
2.2 \text { to } 2.7 \\
2.2 \text { to } 2.7\end{array}$ & $\begin{array}{l}2.9 \\
2.9 \\
7.3 \\
5.9 \\
4.9\end{array}$ & $\begin{array}{l}90 \\
90 \\
25\end{array}$ & $\begin{array}{l}\text { Brown } \\
\text { Brown } \\
\text { Lt.Gray } \\
\text { Lt.Gray } \\
\text { Lt.Gray }\end{array}$ & $\begin{array}{l}\text { Mt } \\
\text { Mt } \\
\text { Mt }\end{array}$ \\
\hline $\begin{array}{l}\text { Clay } \\
\quad \text { Ringold }\end{array}$ & $\begin{array}{l}\text { A-77 } \\
\text { Rin-D }\end{array}$ & 2.71 & 2.6 to 2.7 & 2.6 & 45 & Brown & \\
\hline $\begin{array}{l}\text { Sand } \\
\text { Glaciofluvial }\end{array}$ & $A-79$ & 2.64 & -- & - & & Dk.Gray & $L, A, Q$ \\
\hline $\begin{array}{l}\text { Quartz } \\
\text { Silica Flour }\end{array}$ & $A-84$ & 2.68 & 2.65 & 3.1 & & White & $\mathbf{Q}$ \\
\hline $\begin{array}{l}\text { zeolite } \\
\text { Oregon } \\
\text { Oregon }\end{array}$ & $\begin{array}{l}A-59 \\
A-73\end{array}$ & $\begin{array}{l}2.30 \\
2.20\end{array}$ & $\begin{array}{l}2.0 \text { to } 2.4 \\
2.0 \text { to } 2.4\end{array}$ & $\begin{array}{l}2.6 \\
2.6\end{array}$ & 40 & $\begin{array}{l}\text { Lt. Brown } \\
\text { Lt. Brown }\end{array}$ & $\mathrm{C}$ \\
\hline $\begin{array}{l}\text { Portland Cements } \\
\text { Type II } \\
\text { Type V } \\
\text { Pozzolan }\end{array}$ & $\begin{array}{l}A-75 \\
A-01 \\
A-02\end{array}$ & $\begin{array}{l}3.26 \\
3.16 \\
3.15\end{array}$ & $\begin{array}{r}3.15 \\
3.15 \\
-\end{array}$ & $\begin{array}{l}4.2 \\
5.7 \\
3.2\end{array}$ & & $\begin{array}{l}\text { Gray } \\
\text { Gray } \\
\text { Gray }\end{array}$ & \\
\hline $\begin{array}{l}\text { Hydrothermal Cements } \\
\text { Fondu } \\
\text { Secar }\end{array}$ & $\begin{array}{l}A-74 \\
A-83\end{array}$ & $\begin{array}{l}3.34 \\
3.06\end{array}$ & -- & $\begin{array}{l}4.1 \\
3.3\end{array}$ & & $\begin{array}{l}\text { Dk. Brown } \\
\text { White }\end{array}$ & \\
\hline $\begin{array}{l}\text { a Measured experiment } \\
b_{\text {From literature }(\mathrm{g} /} \\
\mathrm{C}_{\mathrm{Fisher}} \text { Subsieve Ana } \\
\mathrm{d}_{\text {Surface area measur }} \\
\mathrm{e}_{\text {Found by powder } \mathrm{x}-\mathrm{r}} \\
\mathrm{L}=\text { Labradorite }(\mathrm{Ca} \\
\mathrm{Mt}=\text { Montmorillonite }\end{array}$ & $\begin{array}{l}\text { ally with } \\
\mathrm{cm}^{3} \text { ) } \\
\text { lysis (mi } \\
\text { ement (se } \\
\text { ay diffra } \\
\text {, Na) Si }{ }_{2}^{\mathrm{Al}} \\
; Q=\text { Qua. }\end{array}$ & $\begin{array}{l}\text { the } \\
\text { crons) } \\
\text { e sect } \\
\text { ction } \\
2 \mathrm{O}_{8} ; \\
\mathrm{rtz}\end{array}$ & $\begin{array}{l}\text { eter }\left(\mathrm{g} / \mathrm{cm}^{3}\right) \\
4.2 .1) \\
\text { sis (using st } \\
\text { gite (Ca,Mg, F } \\
=\text { Clinoptilo }\end{array}$ & $\begin{array}{l}\text { andards) } \\
\text { e) } \mathrm{SiO}_{2} ; \mathrm{M}=\mathrm{Ti}- \\
\text { lite }(\mathrm{Ca}, \mathrm{Na}, \mathrm{K}) \mathrm{Al}\end{array}$ & $\begin{array}{l}\text { Magnetite } \\
{ }_{7} \mathrm{O}_{8} \cdot{ }^{6 \mathrm{H}}{ }_{2} \mathrm{O}\end{array}$ & $\mathrm{Ti}) \mathrm{Fe}_{2} \mathrm{O}_{4}$ & \\
\hline
\end{tabular}


Thus, mixtures for geochenical testing were prepared by combining materials in equal proportions by weight. For example, the basalt/sand mixture was half sand and half basalt, and the basalt/sand/zeolite mixture was one-third basalt, one-third sand, and one-third zeolite. Materials, such as basalt and sand, that were received by SRI in a relatively coarse state were ground, and the -200 to +325 mesh fraction was used for making the mixtures. Other components, such as clay, bentonite, and zeolite, occur naturally as fine particles. These were ground to break up agglomerates, and the -325 mesh fraction was then used in the mixtures being tested. Specimens containing cement were prepared by separately casting and curing the specified cement/aggregate compositions. They were then ground to -200 to +325 mesh and combined with equal proportions of the other ingredients. Some of the cements were supplied as pre-cast cubes by the WCC laboratory in Oakland, California. Several one- and twocomponent specimens were tested, even though they are not candidates for plug systems; such testing was done to understand better the potential alterations and reactions in more complex mixtures and to help simplify the analysis of complex mixtures. The list of starting materials used in. mixtures for geochemical testing is given in Table $V$. This table also gives some of the characteristics of these individual starting materials.

\subsection{TYPES OF TESTS}

\subsection{1 $250^{\circ} \mathrm{C}$ Static Test}

The geochemical test involving the largest number of samples was a $250^{\circ} \mathrm{C}$, static experiment conducted in a 11.4-1iter stainless steel autoclave. Three identical sets of the 39 
samples listed in Table IV were tested in the autoclave, with a complete group being removed after one-, two-, or three-month exposures to the hydrothermal conditions. Temperature control was achieved by external strip heaters powered by a HoneywellBrown controller. The test temperature in the interior of the autoclave was monitored continuously by two thermocouples connected to a two-pen strip-chart recorder. One thermocouple was adjusted so that its junction was at top center on the central axis of the vessel; the other was placed about $2.5 \mathrm{~cm}$ from the bottom, near the vessel wall. Temperature control was maintained at $250^{\circ} \pm 3^{\circ} \mathrm{C}$ during the three-month duration of the test. The two thermocouples agreed within $4^{\circ} \mathrm{C}$, indicating the temperature gradient in the autoclave was very small. During operation, the pressure inside the autoclave was equal to the pressure of water in equilibrium with its vapor at that temperature, or about $3.9 \mathrm{MPa}$ at $250^{\circ} \mathrm{C}$, as indicated by a pressure yage connected to the vessel.

The specimen bottles were arranged in tiers on stainless steel racks in the autoclave so that when it was cooled at the end of each one-, two-, or three-month test period, all the bottles from a given group could be easily removed without disturbing the others. Synthetic ground water was prepared (as described in section 4.4 .1 .3 ) and added to the autoclave in the space surrounding the specimen bottles. Sufficient head space was left in the vessel to allow for thermal expansion of the water. The autoclave was brought to temperature at a rate of about $60^{\circ} \mathrm{C}$ per hour at the beginning of each run, whereas the natural cooling rate (when the runs were terminated) was approximately $15^{\circ} \mathrm{C}$ per hour due to the large thermal mass of the autoclave. 


\subsection{2 $150^{\circ} \mathrm{C}$ Static Test}

The $150^{\circ} \mathrm{C}$ tests were conducted in a 2-liter Parr Instruments Corporation general purpose autoclave with associated heater, temperature controller, and pressure gage. The autoclave is constructed of Hastelloy $C$, which gives it a somewhat higher pressure capability than the standard 304 stainless steel alloy. The temperature of the autoclave was monitored near its central axis about a third of the way up from the bottom, using the unit's built-in thermocouple well. The temperature was held constant to within $\pm 2^{\circ} \mathrm{C}$ over the duration of the test. The pressure was equal to the steam-saturated vapor pressure of water at $150^{\circ} \mathrm{C}$, or about $0.5 \mathrm{MPa}$. The autoclave was filled with the simulated ground water used in other tests. Because of the smaller size of this autoclave, only 18 specimen bottles could be accommodated for the test run. Accordingly, samples $12,13,21,25,27$, and 29 (mixtures of basalt and other natural materials and various cements plus basalt as an aggregate) were selected from the list in Table IV and prepared in three identical sets. One set was removed from the autoclave after each of the one-, two-, and three-month test periods.

\subsubsection{Static High Pressure $34.5 \mathrm{MPa}$ Tests}

A Parr Instruments Corporation l-liter high pressure autoclave was used to determine the effects of high pressure on the reactivities of plug materials in a hydrothermal environment. Except for its smaller capacity and higher pressure capability, the autoclave is similar to the one used for the $150^{\circ} \mathrm{C}$ static tests in that they both are constructed of Hastelloy $C$ and have similar heaters, controllers, thermocouple placement, and pressure gages. 
Only one specimen at a time could be tested in the highpressure autoclave. By contrast, it was possible to run multiple samples simultaneously in the $150^{\circ} \mathrm{C}$ and $250^{\circ} \mathrm{C}$ tests just described, because under the conditions of those experiments, there was no pressure difference between the interiors and the exteriors of the PTFE bottles in which the samples and solutions were sealed. In a high-pressure experiment, a sealed PTFE bottle containing water would have an internal pressure equal to the steam-saturated vapor pressure at the reaction temperature, whereas the external pressure would be that set for the experiment, which in this case was 34.5 MPa. If gold cells had been used, they would have deformed under the external pressure without failing; however, as discussed earlier, gold cells were not used in this research for reasons of cost. Such a pressure difference would crush a PTFE sample bottle, causing it to leak and to mix with the water in the autoclave. (The more commonly used gold cells do not have this problem because the ductile metal can deform under an external pressure without failing.) without encapsulation to isolate the samples, it is not possible to test more than one sample at a time.; Therefore, for the high pressure tests, single specimens chosen from the list in Table IV were placed in the autoclave with the standard test solution (Section 4.4 .1 .3 ). The ratio of $40 \mathrm{~g}$ solid per $400-\mathrm{ml}$ test solution was used to keep the solid-to-liquid ratio identical for all the tests.

After the autoclave was sealed, it was heated to $250^{\circ} \mathrm{C}$ without applying any external pressure. Once the temperature stabilized, the vessel was pressurized with argon to $34.5 \pm 0.34 \mathrm{MPa}$ using an external intensifier system. Invariably, a minor drop in pressure of about $1.4 \mathrm{MPa}$ occurred over the first 12 hours 
of operation, at which time the system was repressurized to 34.5 $\mathrm{MPa}$. No further pressure drops were observed during the remainder of the two-week test period.

\section{$4.3 .4 \quad 250^{\circ} \mathrm{C}$ stirred Tests}

The effect of continuous sample agitation on sample reactivities was tested using a Pressure Products Industries l-liter, 304 stainless steel, magnetically coupled, stirred autoclave. The design of the autoclave precluded testing several samples simultaneously. Hence, $40 \mathrm{~g}$ of a given solid was placed in the autoclave with $400 \mathrm{ml}$ of test solution (simulated ground water) and run at $250^{\circ} \pm 3^{\circ} \mathrm{C}$ and $3.9 \pm 0.2 \mathrm{MPa}$ for two weeks with continuous stirring at about $500 \mathrm{rpm}$. The temperature was monitored using a strip chart recorder connected to a thermocouple inserted in the vessel's integral well. Heating was provided by a mantle that fastened around the autoclave; the temperature was controlled with a Norton unit.

\section{4 TEST ING PROCEDURES}

A brief description of sample preparation, testing, and analytical procedures is included here. Further details are available in project files at the SRI facilities in Menlo Park. The various procedures applied by SRI generally reflect the standard laboratory practice. Equipment operation and calibration is based on descriptions provided by the manufacturer and experience of the technical personnel performing the analyses. Special procedures, such as sample preparation and encapsulation, are discussed here and were also included in the project file of procedures in SRI. 


\subsubsection{Sample Preparation}

\subsubsection{Grinding}

Some of the materials provided to SRI, such as the oregon bentonite, zeolite, and silica flour, were -325 mesh. Others, such as the basalt, glaciofluvial sand, Ringold clay, and Wyoming bentonite, required grinding to reduce the particle size or to break up agglomerates. Those substances were ground by hand in an alumina mortar and pestle and then screened to collect the -200 to +325 mesh fraction. The sized powders were dried in a $60^{\circ} \mathrm{C}$ oven where they were stored until needed.

\subsubsection{Polishing}

The bulk basalt specimens (Sample No. 1, Table IV) were made by slicing with a diamond saw to form cubes approximately $1 \mathrm{~cm}$ on a side. One face of each specimen was polished by standard metallographic procedures using a series of progressively finer abrasive grits, finishing with 0.3 micron diamond paste. Optical and scanning electron micrographs (Section 4.4.2.5) were taken of the polished surfaces.

\subsubsection{Test Water Preparation}

The test water was synthesized as a single 50-1iter batch according to a recipe supplied to WCC by Rockwell. This recipe is based on Ames (1978). Appropriate amounts of the following salts were dissolved in deionized water in a polyethylene carboy to give the indicated concentrations: hydrated calcium chloride $\left(\mathrm{CaCl}_{2} \cdot 2 \mathrm{H}_{2} \mathrm{O}\right), 23.0 \mathrm{mg} / \mathrm{l}$; hydrated magnesium chloride $\left(\mathrm{MgCl}_{2} \cdot 6 \mathrm{H}_{2} \mathrm{O}\right), \quad 8.3 \mathrm{mg} / 1$; sodium bicarbonate $\left(\mathrm{NaHCO}_{3}\right)$, $109.6 \mathrm{mg} / 1$; and potassium sulfate $\left(\mathrm{K}_{2} \mathrm{SO}_{4}\right), 20 \mathrm{mg} / 1$. The $\mathrm{pH}$ of 
the resulting simulated groundwater was found to be 8.12 . Cations were analyzed by atomic absorption spectroscopy when the solution was first prepared and at l-month intervals afterward. The cationic concentrations at 1 -month intervals proved to be the same as those measured in the initial analysis of the simulated ground water.

\subsubsection{Encapsulation}

During the initial stages of the program, several Rockwell scientists expressed concern that, if the solids were freely in contact with test solutions, it would be impossible to distinguish between species that precipitated out of a supersaturated solution on cooling and those that formed at a higher temperature due to reaction with the solution. Accordingly, solids were encapsulated in a semipermeable membrane that would allow dissolved species to exchange with the test solution while retaining any solids. A commercially available filter membrane that met the necessary requirements was used in lieu of perforated gold foil.

The solid specimens were bagged in pieces of a porous, PTFE filter membrane (Zitex, Chemplast, Inc., Wayne, New Jersey) tied with $0.25-\mathrm{mm}$ platinum wire. For all specimens, $1.50-\mathrm{g}$ total weight of solids was used. The zitex membranes are chemically inert toward any of the substances used in this test program and are made with a variety of pore sizes. The ones used here had pores in the 10 to 20 micron range. Zitex is hydrophobic; water will not pass through it at room temperature in the absence of a pressure differential. In the hydrothermal experiments, however, the contents of the Zitex bags were always wet when they were analyzed at the conclusion of each experiment, indicating that water did pass through. 
The zitex bays were placed with $15 \mathrm{ml}$ of the test solution in 30-ml (nominal), screw-top bottles made of perfluoroalkoxy (PFA)-substituted PTFE (Cole-Parmer Instrument Company, Chicago, Illinois). That quantity of solution gave sufficient head space to accommodate the thermal expansion of water between room temperature and $250^{\circ} \mathrm{C}$. PFA-substituted PTFE, unlike conventional Teflon, is thermoplastic and can be deformed and molded with sufficient application of heat. Special tubular resistance heaters were constructed with an inner diameter a few millimeters larger than the outer diameter of the bottle caps. These heaters were set at $350^{\circ}$ to $375^{\circ} \mathrm{C}$, at which temperature the PFA-substituted polymer is fairly fluid. Before the lids could be heat-sealed to the bottles, however, the surface contacts had to be treated with a proprietary etching agent used in the plastics industry (Tetraetch, R.S. Hughes Company, Sunnyvale, California) to enhance the bonding of the two surfaces. To minimize evaporation of the test solution, the bottle and its contents were frozen in dry ice before the lids were sealed. The frozen bottles were inserted so that just their lids were in the hot zone of the heater. Within about 5 minutes, the 1 id and top of the bottle were hot enough to form a seal when pressure was applied by screwing down the lid further and then pressing a steel plate on top. Many trials were required to establish the technique, but eventually SRI technicians were able to reliably seal the bottles.

\subsubsection{Preparation of Hydraulic Cement Mortars}

ASTM method C-log (American Society of Testing and Materials [ASTM], 1977a) was followed to prepare the cubic cement specimens. Because of the small quantity (5 to $10 \mathrm{~g}$ ) of material 
needed (one cube of each was more than sufficient), the European standard hand-mixing procedure was used in place of the ASTM mechanical mixing method, which is more appropriate for mixing larger volumes of cement. The weight ratios used in mixing were:

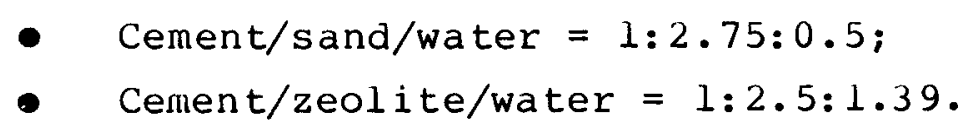

The cement and sand were premixed and spread on a flat surface, and the water was placed in a shallow depression formed in the powder surface. The wet mortar was vigorously mixed with a spatula following the ASTM C-109 procedure (ASTM, 1977a). The samples were allowed to set in air under wet towels for 4 hours. They were then submerged in a water bath at $95^{\circ} \mathrm{C}$ for a period of 36 to 42 hours to accelerate their aging. The cubes were crushed in a Baldwin press and reauced to -7 mesh with a steel mortar and pestle. Final portions, weighing $25 \mathrm{~g}$ each, were then ground to -200 mesh.

\subsubsection{Pre-Test Examination and Sample Characterization}

\subsubsection{X-Ray Powder Diffraction Analysis}

A thin layer of each specimen, ground to -200 mesh or finer, was spread on a piece of two-sided Mylar tape, which was supported by a glass slide. X-ray diffraction patterns were generated on a Phillips x-ray diffraction unit employing a high intensity copper tube, a compensating theta slit, a vertical goniometer, and a pyrolytic graphite monochrometer. The x-ray data were processed through a Canberra solid state manipulation and data reduction system. Each sample was scanned from 3 to 90 degrees two theta at 10 degrees per minute. Stereoscans of 
significant two-theta areas were recorded at 1 degree per minute. Patterns could be obtained for crystalline species present in amounts of at least 1 percent by volume, which is the detection linit of the particular apparatus used in these tests. A major limitation on analyzing x-ray data from mixtures containing many components is that frequently, a significant number of diffraction lines are superimposed and cannot be resolved.

\subsubsection{Brunauer, Emmett, and Teller Analysis}

Surface area measurements were made by the dynamic Brunauer, Emmett, and Teller (BET) method (Brunauer and others, 1938) in which nitrogen ( $\mathrm{N}_{2}$ ) gas, diluted about 10 to 1 in a helium (He) carrier, adsorbs on the surface of the solid at low temperatures. Monolayer coverage is assumed, and the surface area can be estimated by measuring the quantity of $\mathrm{N}_{2}$ desorbed on heating from $-196^{\circ}$ to $127^{\circ} \mathrm{C}$. Comparison standards of carbon (surface area approximately equal to $100 \mathrm{~m}^{2} / \mathrm{g}$ ) and titanium oxide (Tio2; surface area approximately equal to $10 \mathrm{~m}^{2} / \mathrm{g}$ ) were run to calibrate the instrument. The smallest surface area that can be measured using this technique is $1 \mathrm{~m}^{2} / \mathrm{g}$.

\subsubsection{Fisher Subsieve Analysis}

Average particle sizes of the powders were also measured on a Fisher Subsieve Sizer, which operates on the principle that a plug of coarse powder is more permeable to diffusion of a gas than is a plug of fine powder. This measurement requires that the densities of the solid particles be known; such densities were obtained using a Micrometrics (Model 1303) helium-air pycnometer. Average particle sizes in the range 0.2 to 50 microns can be determined by this method. 


\subsubsection{Petrographic Analysis}

Thin sections of bulk basalt were cut and polished in the petrographic laboratory at Stanford University, Stanford, California. These sections were then analyzed at SRI using a Leitz petroyraphic inicroscope.

\subsubsection{Scanning Electron Microscopy}

A Cambridge Stereoscan scanning electron microscope (SEM) was used to examine some of the solids tested in this program. One of the main advantages of the SEM is its ability to produce high magnification inages with good depth of field. This allows study of microstructural features, such as grain sizes, porosity, etc. Color rendition is impossible because the inage is produced by electrons rather than photons. Polished faces or, occasionally, acid-etched polished faces of bulk specimens (such as basalt) were examined using this method. Powdered materials were analyzed without further preparation. A Kevex energy-dispersive $x-r a y$ analyzer accessory on the SEM permitted semiquantitative analyses for elements of atomic number 12 or greater.

\subsubsection{Post-Test Examination and Sample Characterization}

Because one of the objectives of this test program was to evaluate changes occurring as a result of hydrothermal exposure, solid materials recovered after the tests were subjected to the same analyses that were described in Section 4.4.2. 
4.4.3.1 Solution Analysis by Atomic Absorption (AA) Spectroscopy

Specimen bottles removed from the autoclaves were opened by drilling a small hole through each cap. A hypodermic syringe was inserted through the hole, and a 3-ml aliquot portion of solution was removed and injected into a polyethylene bottle containing $57 \mathrm{ml}$ of deionized water acidified with two drops of nitric acid $\left(\mathrm{HNO}_{3}\right)$. The remainder of the liquid was removed volumetrically and transferred to another container for storage. The bottle caps were cut off with a hot wire loop and the solid contents were placed in a $60^{\circ} \mathrm{C}$ oven for drying prior to further analysis.

The collected sample solutions were analyzed for sodium, potassium, magnesium, calcium, iron, aluminum, and silicon ( $\mathrm{Na}, \mathrm{K}$, $\mathrm{Mg}, \mathrm{Ca}, \mathrm{Fe}, \mathrm{Al}$, and $\mathrm{Si}$ ) according to ASTM Method D 2576-76 (ASTM, 1978b). This method depends on the fact that metallic elements in their ground states absorb light of the same wavelength as they emit when excited. When radiation from a yiven excited element passes through a flame containing ground state atoms of that element, the intensity of the transmitted radiation decreases in proportion to the amount of the ground state element in the flame. Because the wavelength of the light beam is unique to the metal being determined, the radiant energy absorbed by the flame is a measure of the concentration of that metal in the sample. Radiation was provided by a lamp with a hollow cathode constructed from the element to be determined. The sample is aspirated into an oxidant-fuel flame through which the beam passes. A monochromator isolates the characteristic radiation from the hollow cathode lamp, and a photo-sensitive device measures the attenuated transmitted radiation. 
Calibration curves were constructed according to ASTM Method D 2576-76 (ASTM, 1978b) for each of the elements to be analyzed by preparing a series of standard solutions, each with a known concentration of the particular species. The concentrations were chosen to span the range expected for the unknowns. The absorbance of each solution was then measured, and a curve was constructed relating the experimetally determined value to the concentration of the solution. The calibration curves were linear. In a similar way, the absorbance of each test solution was measured, and only a single measurement was made for a particular element in a given sample. The concentrations of each of the sought-for elements were then calculated using the calibration curves.

A Varian-Pechtron AAG atomic absorption spectrophotometer was used to analyze for $\mathrm{Na}, \mathrm{K}, \mathrm{Mg}, \mathrm{Ca}$, and $\mathrm{Fe}$. An accessory graphite furnace CRA-90 atomizer was used for the $A l$ and $\mathrm{Si}$ analysis because those elements were present in concentrations too low for detection with the standard flame burner. From past experience with many similar analyses, SRI technicians know that the precision of the AA spectrophotometer operating in the conventional flame mode is about 1 percent ( 2 sigma), whereas with the graphite furnace it is about 20 percent (2 sigma). The operating conditions used during experiments are shown in Table VI.

\subsection{RESULTS}

Results and detailed data from the geochemical testing program are tabulated in Appendix C, Tables C-I to C-XIII. 
TABLE VI

\section{OPERATING CONDITIONS FOR ATOMIC ABSORPTION ANALYSIS}

\begin{tabular}{|c|c|c|c|c|}
\hline Metal & Wavelength $\left(10^{-9} \mathrm{~m}\right)$ & $\begin{array}{c}\text { Fuel (Acetylene)/ } \\
\text { Oxidant } \\
\end{array}$ & $\begin{array}{l}\text { Standard } \\
\text { Concentration } \\
\text { Range }(\mathrm{ppm})^{\mathrm{a}} \\
\end{array}$ & $\begin{array}{l}\text { Detection } \\
\text { Limit }^{\mathrm{b}}\end{array}$ \\
\hline Sodi um & 589.0 & $\mathrm{C}_{2} \mathrm{H}_{2} / \mathrm{air}$ & 0.1 to 0.5 & $0.025 \mathrm{ppm}^{\mathrm{a}}$ \\
\hline Potassium & 766.5 & $\mathrm{C}_{2} \mathrm{H}_{2} / \mathrm{air}$ & 0.25 to 2.00 & $0.01 \mathrm{ppm}$ \\
\hline Magnesium & 285.2 & $\mathrm{C}_{2} \mathrm{H}_{2} / \mathrm{air}$ & 0.05 to 0.4 & $0.01 \mathrm{ppm}$ \\
\hline Iron & 248.3 & $\mathrm{C}_{2} \mathrm{H}_{2} / \mathrm{air}$ & 0.5 to 10 & $0.2 \mathrm{ppm}$ \\
\hline Calcium & 422.7 & $\mathrm{C}_{2} \mathrm{H}_{2} / \mathrm{air}$ & 0.25 to 2.0 & $0.05 \mathrm{ppm}$ \\
\hline Al uminum ${ }^{C}$ & 309.3 & $\mathrm{C}_{2} \mathrm{H}_{2} / \mathrm{air}$ & 5 to 40 & $\begin{array}{l}2 \mathrm{ppm}(\mathrm{f} 1 \mathrm{ame}) \\
0.02 \times 10^{-9} \mathrm{~g} \\
\text { (graphite) }\end{array}$ \\
\hline Silicon ${ }^{c}$ & 251.6 & $\mathrm{C}_{2} \mathrm{H}_{2} / \mathrm{N}_{2} \mathrm{O}$ & 0.5 to 20 & $\begin{array}{l}5 \mathrm{ppm}(\mathrm{flame}) \\
0.02 \times 10^{-9} \mathrm{~g} \\
\text { (graphite) }\end{array}$ \\
\hline \multicolumn{5}{|c|}{$\begin{array}{l}{ }_{\text {parts per million }(m g / l) \text {. }} \\
\mathrm{b}_{\text {The detection limit is usually considered to be equal to twice the }} \\
\text { maximum variation of the background. } \\
\mathrm{c}_{\text {Graphite furnace temperature program: }}\end{array}$} \\
\hline \multicolumn{5}{|c|}{$\begin{array}{l}\text { dry temperature: } 125^{\circ} \mathrm{C} ; 50 \text { seconds. } \\
\text { ash temperature: } 500^{\circ} \mathrm{C} ; 20 \text { seconds. } \\
\text { atomize temperature: } 2,600^{\circ} \mathrm{C}: \text { hold time } 1.5 \text { seconds, ramp rate } 600^{\circ} \mathrm{C} / \mathrm{sec} \text {. }\end{array}$} \\
\hline
\end{tabular}




\subsubsection{General Observations}

When the 11.4-liter autoclave was opened after the l-month test at $250^{\circ} \mathrm{C}$, some of the PTFE bottles used to encapsulate the samples had failed. Each of those bottles was characterized by one or two longitudinal cracks and a quantity of test solution different from the $15 \mathrm{ml}$ it originally contained. Although the mechanism of bottle failure has not been proved, a plausible explanation has been developed. When the temperature in the autoclave first was raised to $250^{\circ} \mathrm{C}$, the solutions in each of the bottles expanded to fill the head space that had been left, compressing in the process the air that had originally been sealed in the bottles. It is well known that at high temperatures, PTFE is permeabie to aiffusion of molecular gases, and it is likely that at $250^{\circ} \mathrm{C}$ the compressed air diffused out of the bottles during the test runs. Later, when the autoclave cooled, a partial vacuum was created in the bottles as the solutions underwent thermal contraction. Backdiffusion of air was not rapid enough to fill the evacuated space. Moreover, because PrFE, like all thermoplastics, softens at elevated temperature, the bottle walls would have collapsed inward. This hourglass shape due to wall collapse was observed in many of the bottles after testing. The cracks resulted from deformation that exceeded the failure strength of the material.

Whether the surrounding test solution entered or was expelled from a particular bottle depended on the temperature at which the crack occurred and the position of the bottle in the autoclave vessel. Because the necessary head space in the 11.4-liter autoclave was conservatively overestimated, the top tier of sample bottles was exposed only to saturated steam during the first month's test. Cracks in those bottles would 
have allowed solution to leak out. Those further down in the vessel were submerged in test solution, and they could have gained liquid after cracking as subsequent thermal contraction of the fluid created a partial vacuum in the bottles.

Apparently the likelihood of failure was also influenced by manufacturing variations in the sample bottles. Bottles were used from at least four separate shipments from the manufacturer, and some of them evidently were not as strong as others. Those obtained in the first two shipments were prone to failure, whereas none of the bottles from the last shipment failed, even though all batches experienced about the same degree of deformation after cooling. The bottles were not analyzed to verify this possible variation in properties. About one-third of the bottles tested at $250^{\circ} \mathrm{C}$ in the $11.4-1$ iter autoclave showed evidence of cracking. At lower temperatures there was no problem with PTFE encapsulation, as indicated by the absence of cracking in bottles used in the $150^{\circ} \mathrm{C}$ tests.

All the specimen bottles were exainined each time the autoclave was opened. All those destined for further testing and showing signs of failure were opened, and the contents were re-encapsulated in new PTFE bottles. Where less than the original $15 \mathrm{ml}$ of test solution was present, the new bottles were topped up to $15 \mathrm{ml}$, and the quantity of added test solution was recorded. Where a greater quantity of test solution was present, the excess was removed, the amount was recorded, and in some cases, it was submitted for AA analysis along with the other samples. The results of those analyses are given in Table $\mathrm{C}-\mathrm{V}$ of Appendix C. 


\subsubsection{Single Natural Materials}

The most comprehensive data on these materials (basalt, bentonite, zeolite, and Ringold clay: sample nos. 1, 2, 3, I6, 17, 22, and 23 from Table IV) were obtained from the $250^{\circ} \mathrm{C}$ static test in the 1l.4-liter autoclave. The results of AA analysis of the solutions are given in Tables C-II, C-III, and C-IV of Appendix $C$. The results of qualitative $x$-ray phase analysis of the solids remaining after testing are given in Table C-VIII, and the quantities of solids recovered from the Zitex filter bags after drying are listed in Table C-XI. As shown oy AA data, the leaching behavior of all these materials is similar. Ionic concentrations in the solutions fall generally in the ranges: Na equal to 50 to 150 ppin (parts per inillion); $K$ equal to 2 to $20 \mathrm{ppm}$; $\mathrm{Mg}$ less than or equal to 2 ppm; total $\mathrm{Fe}$ less than or equal to $10 \mathrm{ppm}$; Ca equal to 2 to 40 $\mathrm{ppm}$; Al less than or equal to $5 \mathrm{ppm}$; and $\mathrm{Si}$ equal to 50 to 200 ppill. There are some anomalous data, most of which are explained by solution loss from cracked bottles. Except for Al, there seems to be little effect from increased time at temperature. Overall, the concentrations are low and show that the solids are fairly stable under the given test conditions.

In any closed-tube experiment, such as those discussed here, there is the possibility that species will precipitate out of solution when the autoclave is cooled so that subsequent solution analysis inaccurately portrays conditions at temperature and pressure. Recent experiments at stanford University, conducted by Mr. Raynald Gillemette, show that for the basalt-water system any quench taking longer than 20 to 30 minutes will cause precipitation. It was in partial recognition of this phenomenon that individuals from Rockwell recommended wrapping the solids in porous 
membranes. It was stated that phases precipitating during the quench could be readily identified by their distinctive morphologies and from the fact that they would be found predominantly outside the membrane. Quench phases of that sort were not observed in any of the experiments discussed here.

The behavior of silica in hydrothermal systems has been studied extensively and it is instructive to consider it at this point, since all the materials tested contained $\mathrm{SiO}_{2}$ in one form or another. The maximum $\mathrm{Si}$ concentration in solution at equilibrium is given by the known solubility of amorphous silica. Data from the literature (Fournier and Truesdale, 1973) are: $250^{\circ} \mathrm{C}:\left[\mathrm{SiO}_{2}\right]=1,200 \mathrm{mg} / 1 ; 50^{\circ} \mathrm{C}:\left[\mathrm{SiO}_{2}\right]=200 \mathrm{mg} / 1$; $25^{\circ} \mathrm{C}:\left[\mathrm{SiO}_{2}\right]=100 \mathrm{mg} / 1$. In terms of elemental concentrations, as used in this report, the concentrations are: $250^{\circ} \mathrm{C}:[\mathrm{Si}]=561 \mathrm{mg} / 1 ; 50^{\circ} \mathrm{C}:[\mathrm{Si}]=93 \mathrm{mg} / 1 ; 25^{\circ} \mathrm{C}:$ [Si] $=47 \mathrm{mg} / 1$. It can be seen by reference to the tables in Appendix $C$ that in almost all cases the silicon concentrations fall between those given by amorphous silica solubility at $250^{\circ} \mathrm{C}$ and $25^{\circ} \mathrm{C}$. The most notable exceptions are the $\mathrm{Si}$ concentrations of 540 and $580 \mathrm{mg} / \mathrm{l}$ found for two of the stirred tests (Appendix $\mathrm{C}$, Table C-VII). Given that the cooling rate of the stirred autoclave was almost as slow as that of the 11.4-liter autoclave, these concentrations, which are near the $250^{\circ} \mathrm{C}$ amorphous $\mathrm{SiO}_{2}$ solubility, indicate that the lower values from the static tests are due to low reactivities rather than precipitation during the cool-down period. This also is consistent with results from Stanford University reported by Mr. Raynald Gillemette.

One consistent finding is the presence of high-calcium concentrations in solutions containing oregon bentonite. Agitation greatly accelerates the leach rates, as can be seen 
from the data in Table C-VII of Appendix C. By contrast, the $34.5 \mathrm{MPa}, 250^{\circ} \mathrm{C}$ static test produced only a modest enhancement in leaching rates. There is no significant temperature effect on leaching rates, as indicated by the overlap of solution concentrations for the $250^{\circ} \mathrm{C}$ and $150^{\circ} \mathrm{C}$ tests (Tables $\mathrm{C}-\mathrm{II}$, C-III, C-IV and C-VI; Appendix C).

The results of $x$-ray diffraction analyses indicated that the solid phases remaining in the PTFE membrane bags are only slightly changed as a result of hydrothermal exposure at $250^{\circ} \mathrm{C}$. Reference to Figure 2 and to Table C-VIII of Appendix C shows that a small amount of montmorillonite formed in the basalt over time, probably from the glassy fraction, because the ratios of the other crystailine phases remained the same. SEM examination of the surfaces of basalt cubes also showed the presence of montinorillonite (Figure 3). The tabular crystals in the photo micrograph are an aluminum silicate present in concentrations too low for $x$-ray diffraction analysis. Figure $3(a)$ also shows that the basalt surface has been etched by the test solution to a slightly roughened state from its originally polished condition. All the basalt phases were attacked to about the same extent, although labradorite may have been slightly more resistant.

The two-week, stirred test at $250^{\circ} \mathrm{C}$ showed that there is a strong tendency for powdered basalt to cement and form a rigid mass. About half the sample recovered from the autoclave after testing was in a single, strong, dense piece (Figure 4). The remainder was still in its original, finely-divided state. $x$-ray diffraction analysis (Figure 5) shows that cemented material has a broad diffuse halo centered around 25 degrees two theta. This indicates that amorphous or microcrystalline quartz has formed, probably by reprecipitation of material 


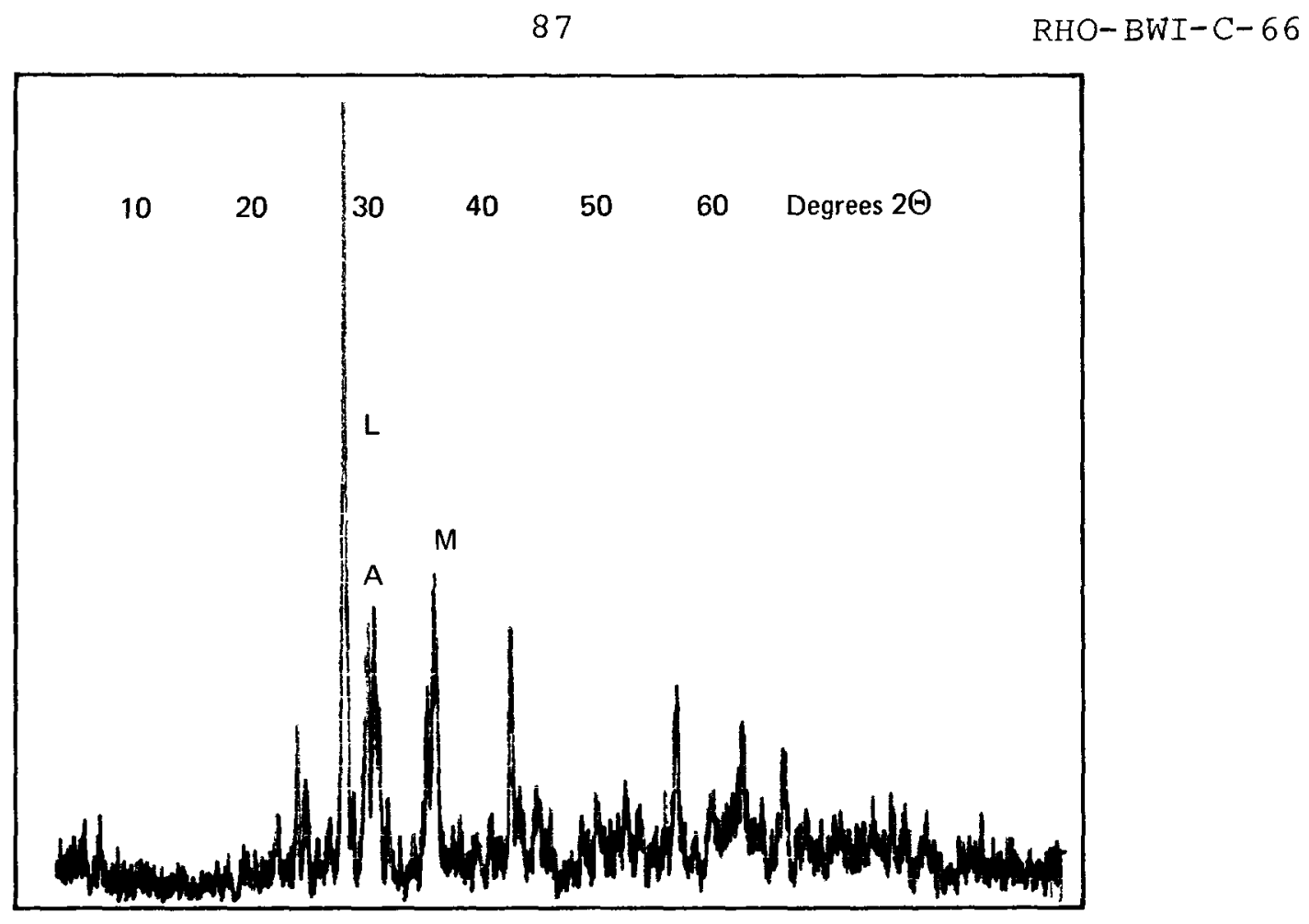

(a) STARTING MATERIAL

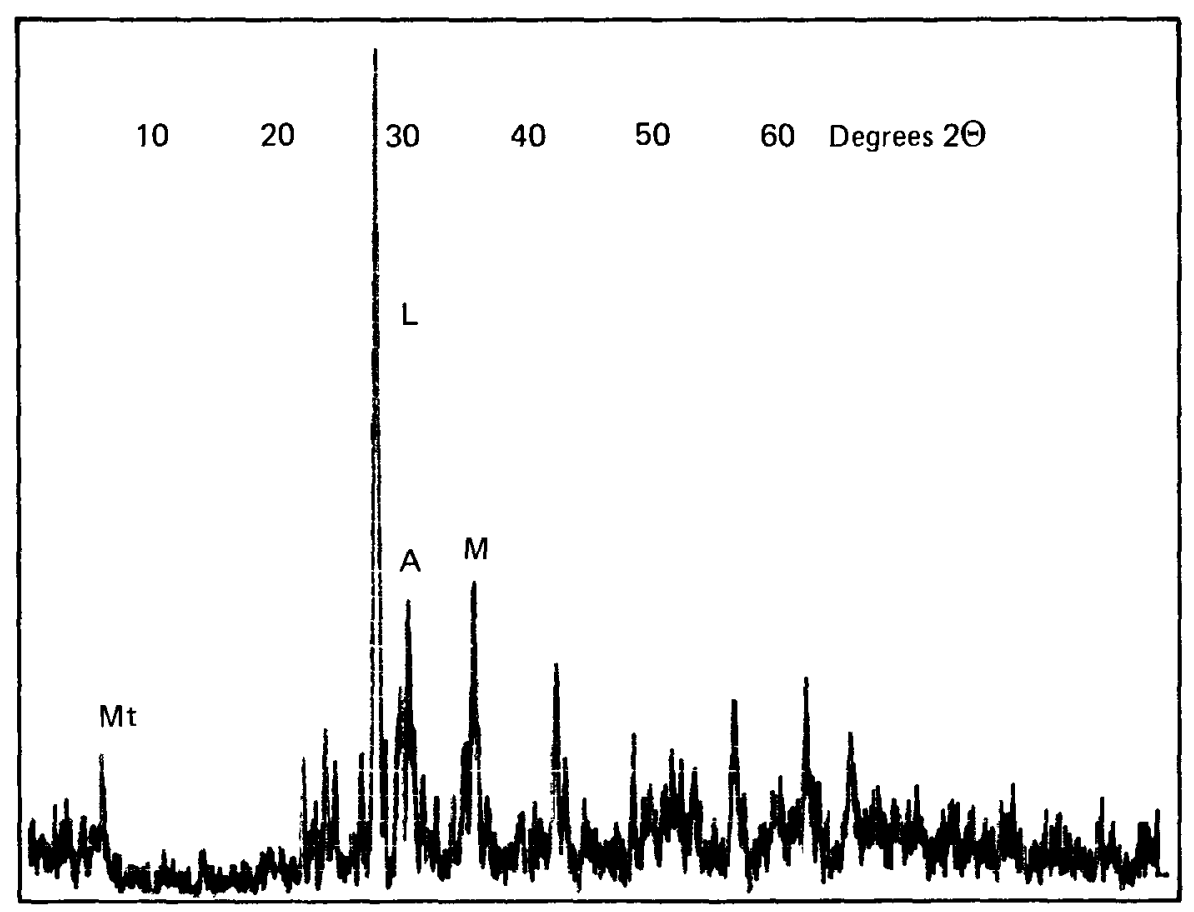

(b) SAMPLE 3C, 1 MONTH

NOTES: $A=$ Augite $;=$ Labradorite; $M=$ Magnetite; $M t-$ Montmorillonite

FIGURE 2

$X$-RAY DIFFRACTION SPECTRA OF

BASALT TESTED UNDER $250^{\circ} \mathrm{C}$, STATIC CONDITIONS 


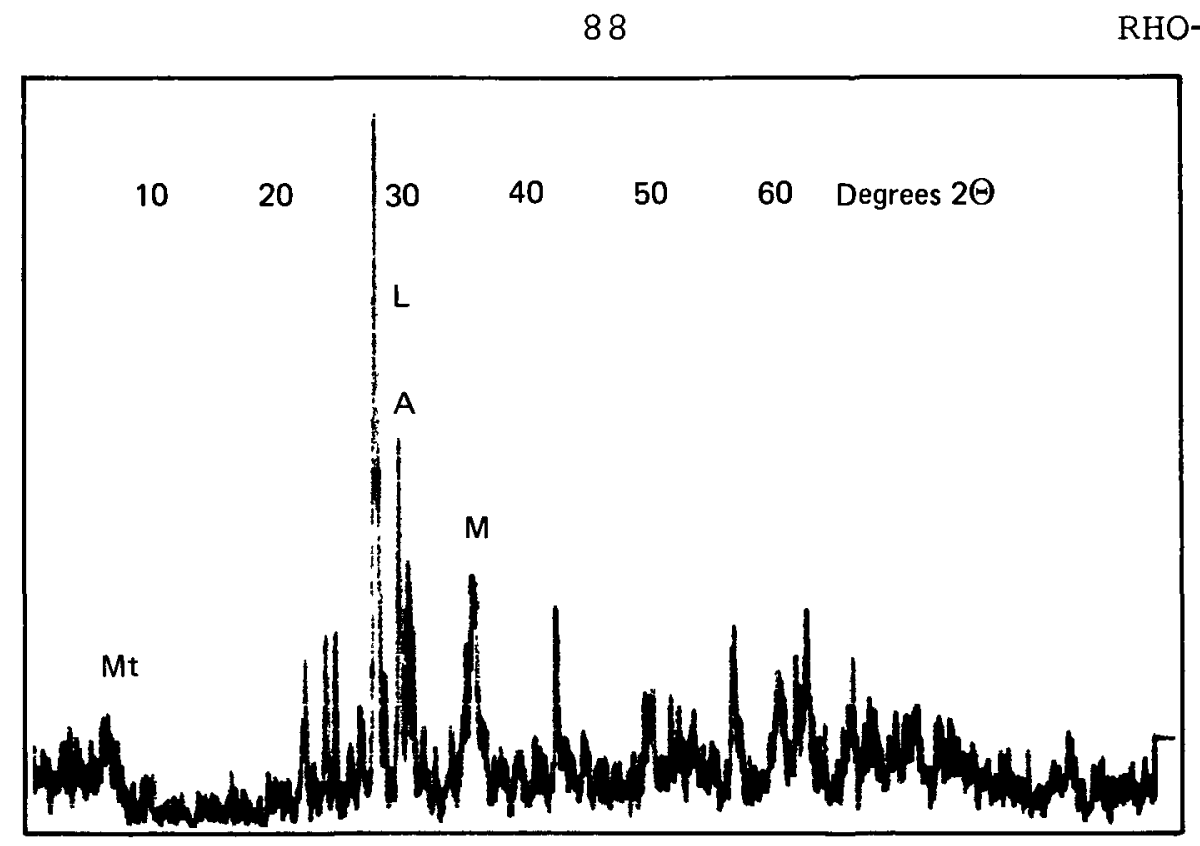

(c) SAMPLE 3B, 2 MONTHS

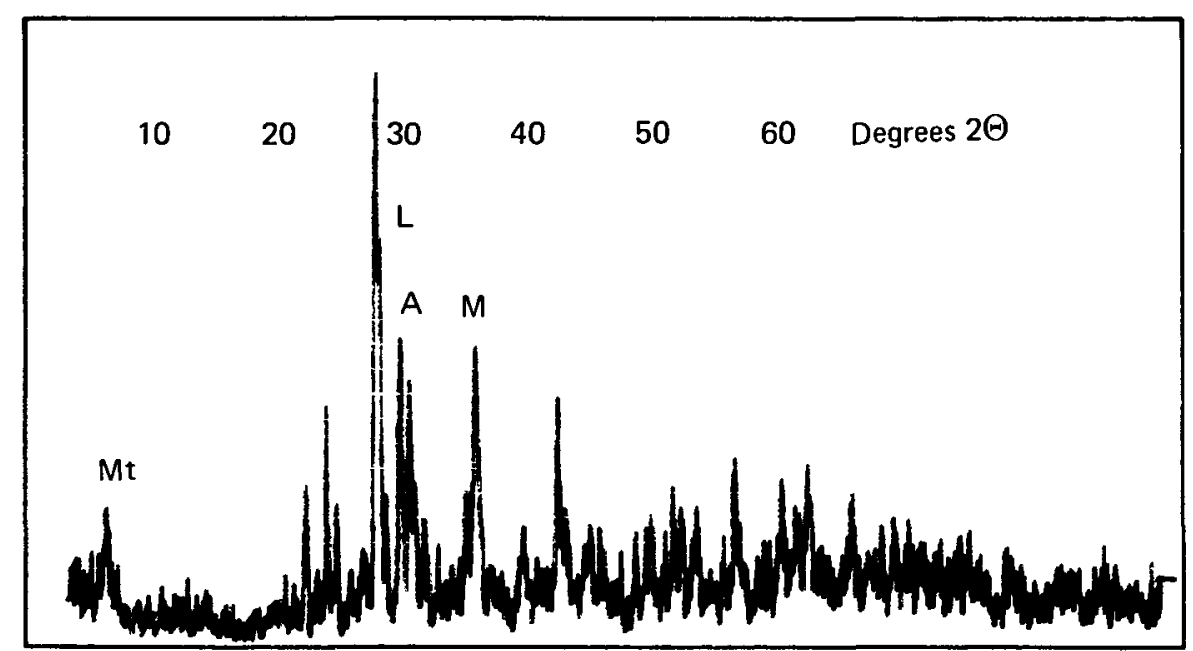

(d) SAMPLE 3A, 3 MONTHS

NOTES: $A=$ Augite; $L=$ Labradorite; $M=$ Magnetite; $M t-$ Montmorillonite 
POLISHED SURFACE

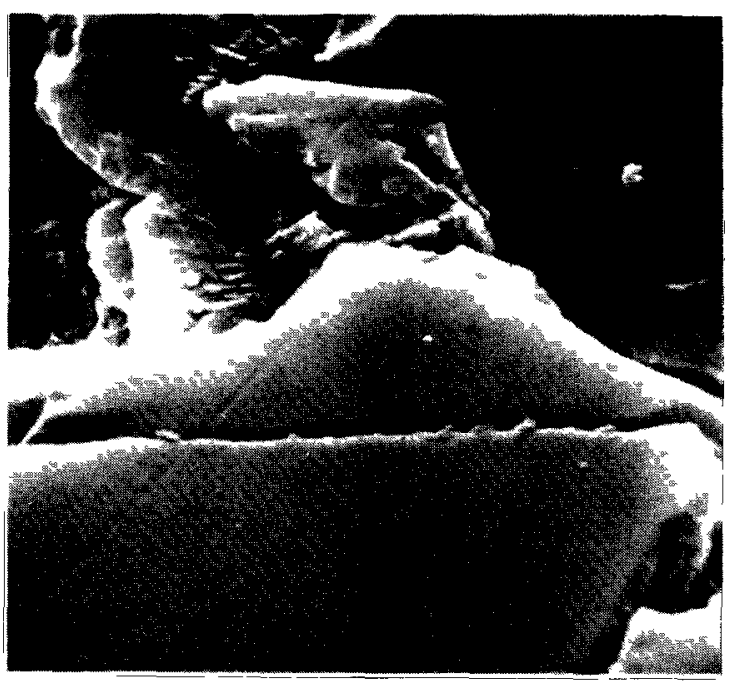

BEFORE
ETCHED SURFACE

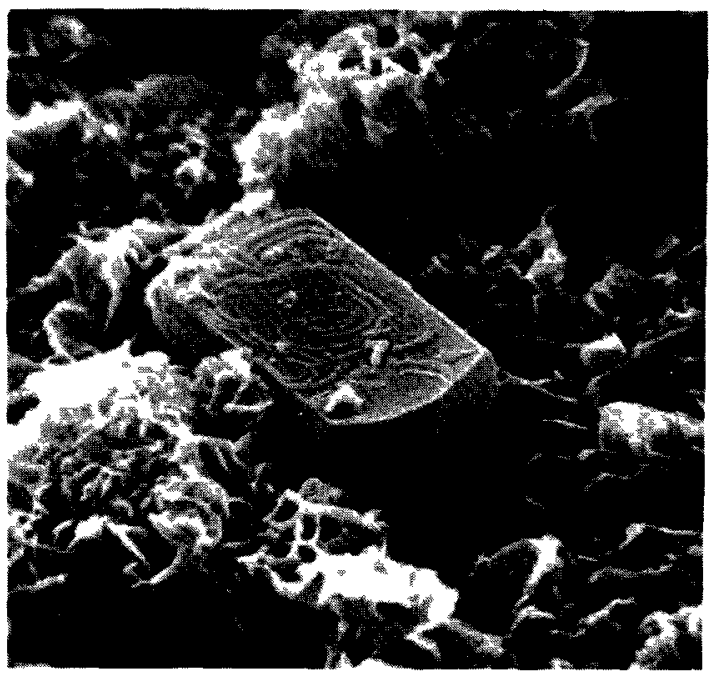

AFTER

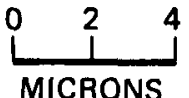

POLISHED SURFACE

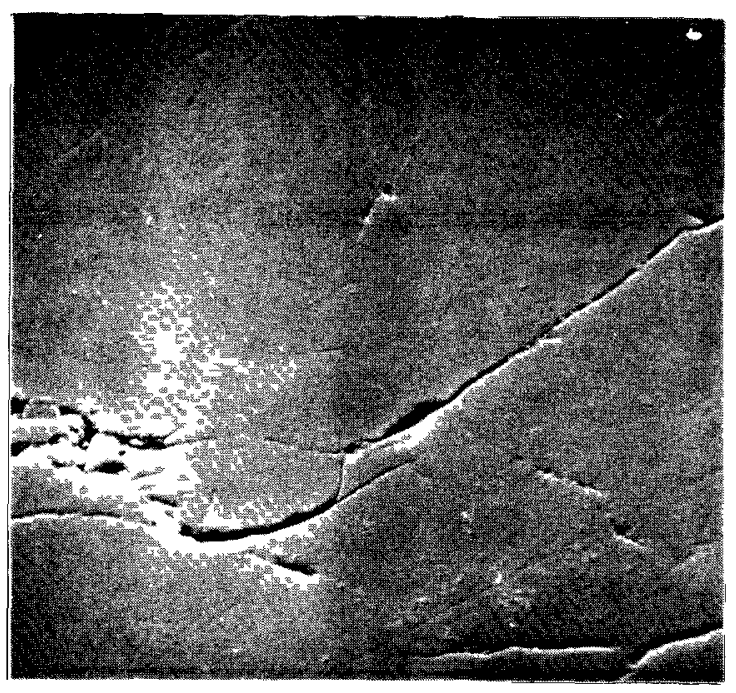

BEFORE
ETCHED SURFACE

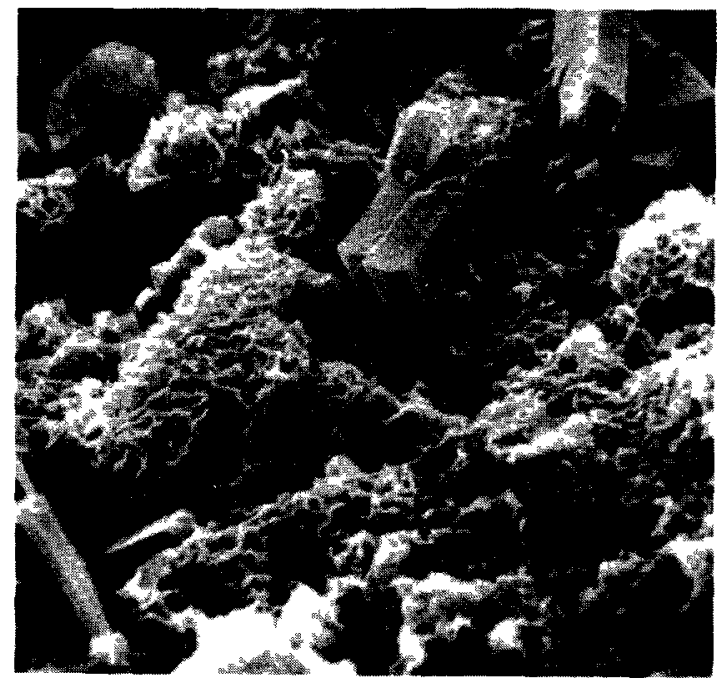

AFTER

$\underbrace{0}_{\text {MICRONS }} \underbrace{10}$

\section{FIGURE 3}

PHOTOMICROGRAPHS OF THE SURFACE

OF A BASALT CUBE BEFORE AND AFTER

3 MONTHS IN $250^{\circ} \mathrm{C}$ STATIC SOLUTION 

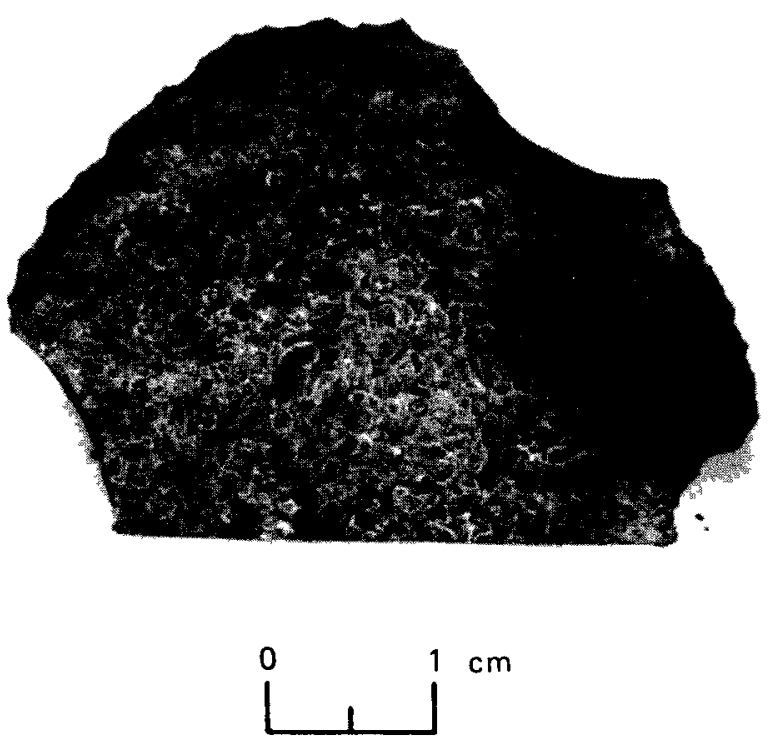

(a) CEMENTED BASALT

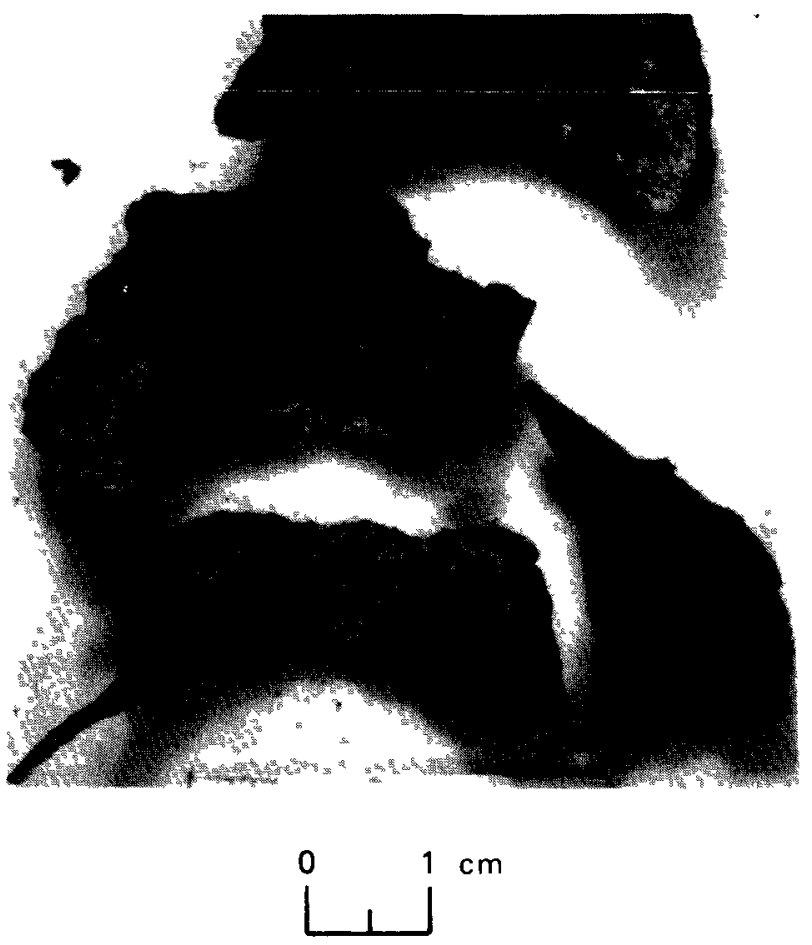

(b) CEMENTED BASALT AND BENTONITE

\section{FIGURE 4}

PHOTOGRAPHS OF MATERIALS FROM

AUTOCLAVE STIRRED TESTS 


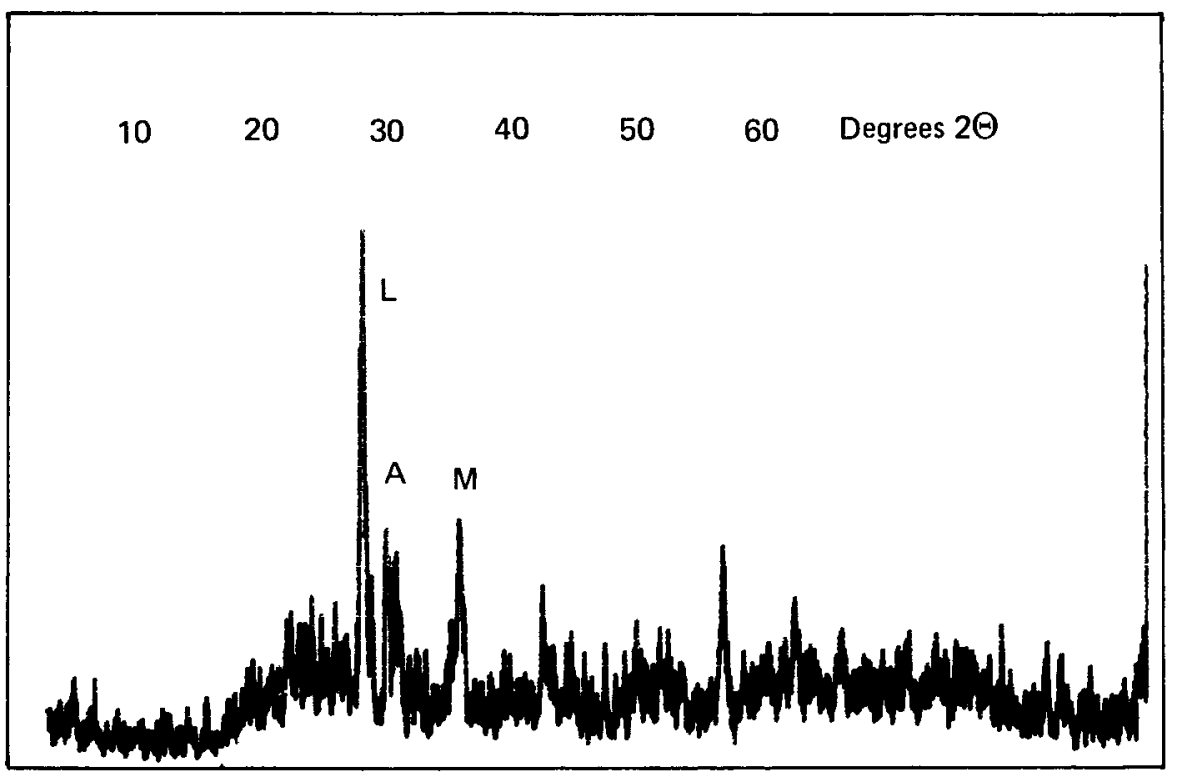

(a) CEMENTED BASALT

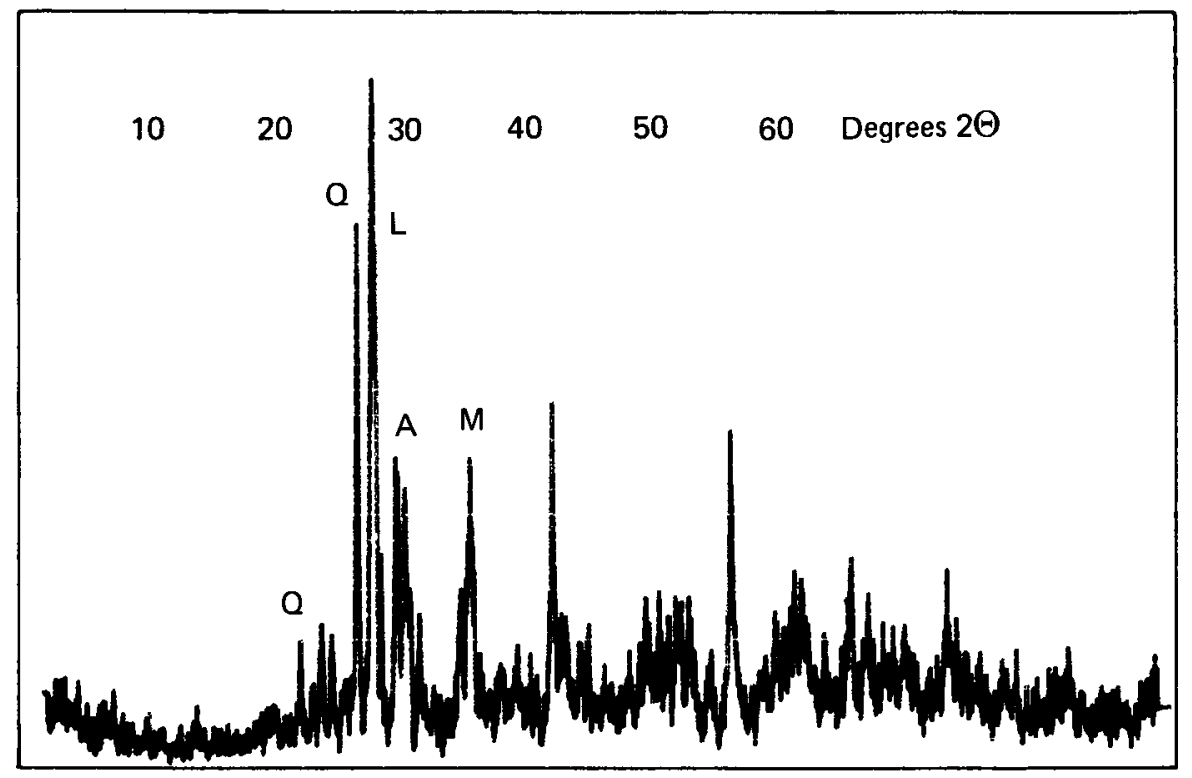

(b) UNCONSOLIDATED MATERIAL

NOTES: $A=$ Augite; $L=$ Labradorite; $M=$ Magnetite; $Q=$ Quartz 
dissolved from the glassy fraction. SEM analysis shows intergranular regions containing silica $\left(\mathrm{SiO}_{2}\right)$, which inay be responsible for the cementing action. The unconsolidated residue gives an $x$-ray spectrum similar to that of powdered basalt (Sample 3) after one-month exposure (Table C-VIII of Appendix C). The $x$-ray spectrum of material from the high pressure test (Figure 6) is very similar to the spectrum of inaterial from the stirred test (Figure 5).

Uther $x$-ray analyses show that the quartz in the Oregon Dentonite decreases in concentration as a small quantity of montinorillonite forms. The $x$-ray spectra for the wyoming bentonite and the Ringold clay tested for three months at $250^{\circ} \mathrm{C}$ under static conditions contain, in addition to the expected patterns, a single unidentified large peak with a d-spacing of 3.18 angstroms. Apparently a species has formed with a high degree of preferred orientation that accentuates a single peak in its $x$-ray spectrum. The 100-percent peak in the $x-r a y$ spectrun of labradorite falls at 3.18 angstroms; however, there is no obvious structural reason it should form with such a high degree of preferred orientation. Without the presence of other peaks, identification by $x$-ray diffraction cannot be made. As with the solution analyses, the $x$-ray data show only a modest reactivity for these materials under the test conditions.

\subsubsection{Mixtures of Natural Materials}

Most of the data on mixtures of natural materials (basalt plus sand, clay and/or zeolite, and mixtures of clay with sand or zeolite: Sample Nos. 4 to 15,18 to 21 , and 24 from Table V) were obtained from the $250^{\circ} \mathrm{C}$ static, hydrothermal test. Results were very similar to those discussed in the preceding section. Atomic absorption (AA) analysis of solutions 


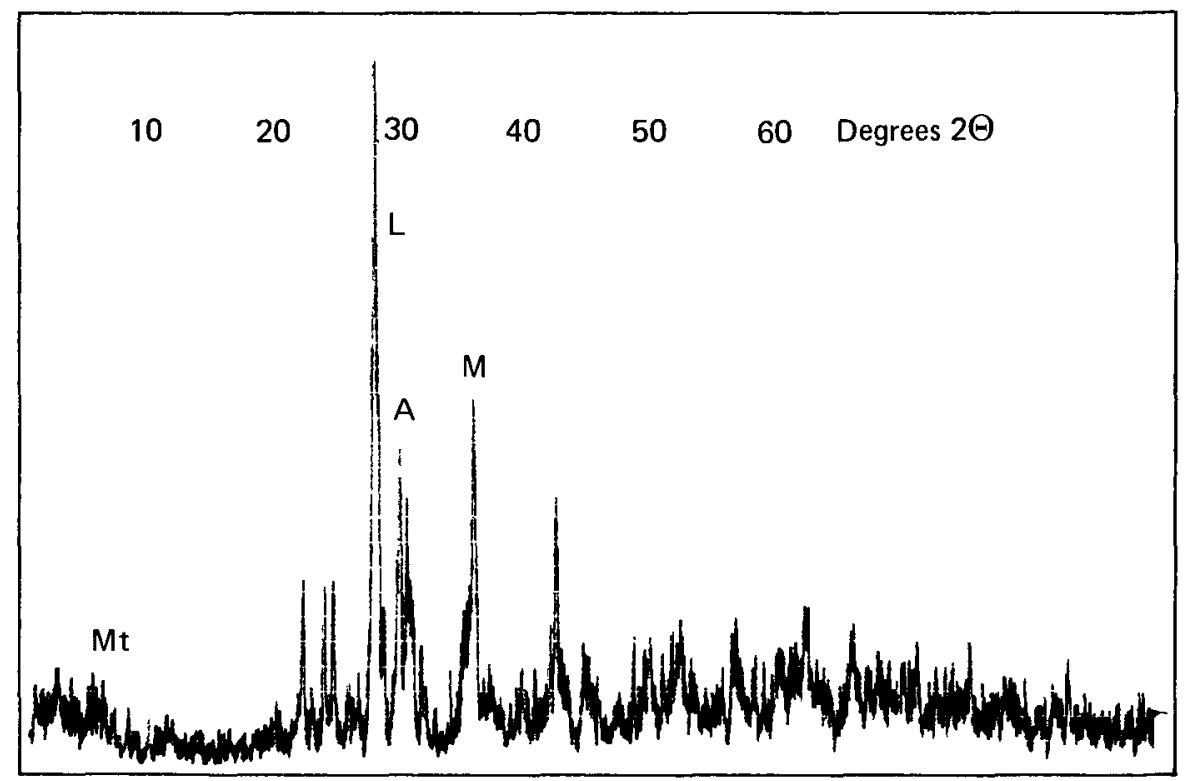

NOTES: $A$ - Augite; $L-$ Labradorite; $M=$ Magnetite; $M t=$ Montmorillorite

\section{FIGURE 6}

X-RAY DIFFRACTION SPECTRUM OF

BASALT FROM STATIC, $34.5 \mathrm{MPa}$,

$250^{\circ} \mathrm{C}, 2-$ WEEK TEST 
recovered from the test bottles generally fell into the same ranges found for the single components, with $\mathrm{Na}$ equal to 50 to $150 \mathrm{ppm} ; \mathrm{K}$ equal to 2 to $20 \mathrm{ppm}$ i Mg less than or equal to 2 $\mathrm{ppm}$; total $\mathrm{Fe}$ less than or equal to $10 \mathrm{ppm}$; $\mathrm{Ca}$ equal to 2 to 40 ppin; Al less than or equal to $5 \mathrm{ppm}$; and $\mathrm{Si}$ equal to 50 to 200 ppm. Mixtures containing oregon bentonite showed the highest leaching rates and were above the levels just quoted. Under the conditions of these tests, there is little or no effect on leaching behavior due to time at temperature (Tables C-II, C-III, and C-IV, Appendix $C$ ), change in temperature (Tables C-II, C-III, C-IV, and C-VI) or increased pressure (Table C-VII). There is a significant acceleration of leaching rates as a result of agitation (Table C-VII). For example, powdered basalt shows more than a ten-fold increase in leaching rates in the stirred experiments, based on a comparison of the silicon concentrations in solution for a sample of powdered basalt run under static conditions at $250^{\circ} \mathrm{C}$ for one month (Appendix C, Table C-II) and for stirred basalt.

$x$-ray diffraction analysis of these rnixtures is more complicated than for the single component specimens. The general conclusion is that any little change occurs in the solid nixtures as a result of hydrothermal exposure. Because the spectrum for each mixture is a superposition of the spectra for each of its components, many peaks are present, and there is considerable overlap among them. As a result, evidence for low concentrations of alteration products is often obscured, and the detection limit for the appearance of new phases is close to 3 to 5 volume percent rather than the one volume percent for pure materials. The one consistent observation is that small amounts of montmorillonite formed in mixtures containing basalt under the $250^{\circ} \mathrm{C}$ static test conditions (Table C-IX, Appendix C). With a few exceptions, Fisher 
subsieve particle size analyses show a modest decrease in particle size in the powders over the 3 -month test at $250^{\circ} \mathrm{C}$ and a slight decrease in porosity as the bagged powder compacts. The latter result probably is due to particle re-arrangement, which produces higher packing densities.

\subsubsection{Mixtures Containing Cements}

Atomic absorption (AA) analysis of solutions from $250^{\circ} \mathrm{C}$ static tests of these materials (various cements with sand or zeolite and basalt as aggregate, and cements with these ingredients plus additives: Sample Nos. 25 to 39 from Table IV) gave results that differed very little from those obtained from the other specimens in this program. Test solutions from mixtures containing cements generally had the lowest $\mathrm{Na}$ concentrations of all those tested. Ionic concentrations for some specimens after a l-month exposure to hydrothermal conditions were higher than tests that ran for two and three months, possibly due to incomplete curing before the start of the autoclave experiments. This is borne out by the $x$-ray results (Table $c-x$, Appendix $C$ ) which show differences in the spectra between the untested and the 1-month specimens, with little or no change thereafter. Due to the multiplicity of phases and extensive overlap of peaks, the $x$-ray spectra are difficult to interpret in greater detail. The particle sizes and porosities follow the same trends as for all the other materials tested, (i.e., both decrease slightly with time at temperature).

\subsection{DISCUSSION AND SUMMARY}

\subsubsection{General Considerations}

All of the materials examined during testing were relatively stable under test conditions. Analysis of solutions resulting 
from exposure to hydrothermal conditions gave the following ranges of ionic concentrations for most materials: $\mathrm{Na}$, 50 to $150 \mathrm{ppm} ; \mathrm{K}$, 2 to $20 \mathrm{ppm}$; $\mathrm{Mg}$, less than or equal to $2 \mathrm{ppm}$; $\mathrm{Fe}$, less than or equal to $10 \mathrm{ppm}$; $\mathrm{Ca}, 2$ to $40 \mathrm{ppm}$; $\mathrm{Al}$, less than or equal to $5 \mathrm{ppm}$; and $\mathrm{Si}$, 50 to $200 \mathrm{ppm}$. For some specimens, higher $\mathrm{Na}$ and $\mathrm{K}$ solution concentrations may have resulted from soluble alkali compounds present as contaminants. Dissolved silicon and aluminum, on the other hand, could have originated only from breakdown of the aluminosilicate networks present in most rock-forming minerals. Solution concentrations of $\mathrm{Si}$ and Al are therefore considered to be of more significance as indicators of mineral reactivity than are concentrations of other ionic species.

Results from glass leaching experiments can put into perspective the degree of hydrothermal reactivity found in these geochemical tests. A soda-lime-silica glass composition (similar to window glass) exposed to a static volume of distilled water for seven days at $100^{\circ} \mathrm{C}$ gave a dissolved silica concentration of $600 \mathrm{ppm}$ (Clark and others, 1976). Fused silica similarly exposed for 10 days at $25^{\circ} \mathrm{C}$ gave a dissolved silica concentration of $60 \mathrm{ppm}$ (Wirth and Gieskes, 1979). Both glass tests were conducted under considerably less severe conditions than the hydrothermal experiments performed here. However, si concentrations up to an order of magnitude greater were reported for the experiments on glass. X-ray diffraction analysis of the solids performed after test runs during this geochemical testing program also showed that little reaction had occurred in the samples.

4.6.2 Discussion of Single Natural Materials

Basalt solution concentrations were in the ranges quoted above for the $250^{\circ} \mathrm{C}$ and $150^{\circ} \mathrm{C}$ static hydrothermal tests. Agitation 
in the 2-week stirred tests produced significantly higher ionic concentrations in solution. $x$-ray analysis of the solid residue from the static tests showed a limited formation of montmorillonite, and SEM examination showed that the montmorillonite was present as a platy surface layer on the basalt particles.

Agitation of basalt under hydrothermal conditions caused the powdered basalt particles to aggregate and eventually to cement together. The $x$-ray spectra from the cemented basalt contained a broad halo characteristic of an amorphous or microcrystalline structure superimposed on the normal basalt spectrum. SEM examination showed the basalt particles were surrounded by a fine-grained intergranular material which gave a KEVEX spectrum indicative of $\mathrm{SiO}_{2}$ or possibly a mixture of $\mathrm{SiO}_{2}$ and a small amount of an aluminum silicate.

Bentonite samples were somewhat more reactive in the static hydrothermal tests than were basalt samples. In particular, Oregon bentonite gave higher solution concentrations of $\mathrm{Na}$ and significantly higher $\mathrm{Ca}$ concentrations. Montmorillonite peaks in the $x$-ray spectrum of the oregon bentonite increased in intensity with increasing exposure time to hydrothermal conditions. The wyoming bentonite, on the other hand, was characterized by the appearance of a single, large, unidentified peak in its $x$-ray spectrum and a corresponding decrease in the intensity of the montmorillonite peaks with increasing exposure time under $250^{\circ} \mathrm{C}$ hydrothermal conditions.

Under static hydrothermal conditions, the zeolite samples also showed low reactivity in the synthetic ground water. X-ray analysis of the solids similarly showed little reactivity. However, solution concentrations resulting from the stirred 
test were as much as an order of magnitude greater than the average concentrations measured for other stirred samples, and of all materials studies, the enhancement of reactivity by agitation was greater for zeolite and mixtures containing zeolite.

\subsubsection{Mixtures of Materials}

In general, mixtures of materials gave solution reactivities that would be expected from a linear superposition of the reactivites of the individual components. For example, mixtures containing Oregon bentonite generally gave relatively high Ca concentrations in the test solutions. An exception to this linear superposition rule was found for mixtures of bentonite and zeolite in which the $\mathrm{Ca}$ concentrations in solution were lower than expected, perhaps due to ion exchange between the components. A somewhat surprising result was the relatively low reactivities in solution of the cementitious mixture. The accelerated ASTM cure given to the cements before hydrothermal testing may not have been sufficient to completely cure them. Exposure to hydrothermal conditions would promote the cementing reactions that might tend to tie up ions which otherwise would leach into the test solution. Whether the leach rates would increase for longer test periods is unknown.

$x$-ray analysis of the solid residues of the inixtures was limited by the complexity of the spectra. However, a weak trend toward montorillonite formation was noted for mixtures containing basalt.

\subsubsection{Summary}

To summarize these results, all the materials studied are very stable under the specified hydrothermal test conditions. 
Comparison of ionic solution concentrations for the candidate plug materials with those of stable glasses tested under less extreme hydrothermal conditions shows that candidate materials are considerably less reactive. For static hydrothermal tests, reactivities are about the same at both $150^{\circ} \mathrm{C}$ and $250^{\circ} \mathrm{C}$. Stirring the solution has the greatest effect on increasing candidate material reactivities. In mixtures containing basalt, this reactivity leads to cementing of the powders. Commercial cements were slightly less reactive than the average material tested, indicating that they should be included for further consideration at this time.

4.7. CONCLUSIONS AND RECOMMENDATIONS

\subsubsection{Preferred Materials}

No marked differences in chemical reactivities among any of the materials were identified by this test program. Under the described test conditions all samples proved stable, as might be expected given the criteria used in their original selection for testing. The only exceptions might be the oregon bentonite and, to a lesser extent, the Wyoming bentonite, which showed somewhat higher reactivities in the test solution than did other materials. The basalt showed a small degree of transformation to montmorillonite under hydrothermal conditions, and this was accelerated by agitation. In those experiments where agitation was performed, cementing apparently occurred by recrystallization of the glassy fraction in the basalt. The formation of montmorillonite and self-cementation reactions are considered beneficial and desirable results with respect to potential plug designs; these reactions would tend to enhance the ability of a plug to sorb radionuclide, to increase the strength of a plug, and also to lower its permeability with passing time. 
The mixtures containing cement were surprisingly unreactive under the yiven test conditions. This might be due to further curing of the cements even after the standard ASTM aging treatment. The crystal growth and phase changes that occurred during cement aging may have tied up the species being analyzed, lowering their solubilities in the test solution. Whether the anount of leaching would be enhanced by much longer rest times is unknown.

In summary, the original screening procedure used to select the materials for yeochemical testing included chemical stability as a major criterion. Consequently, nearly all of the materials that were tested exhibited only slight reactivities, even at elevated temperature, and tests did not show major differences among them. Such lack of distinction does not necessarily mean that all materials would be equally stable over millennia, but simply means that a 3 -month test may be too short to reveal differences that may exist. Therefore, the geochemical tests do not rule out any of the candidate materials, and all materials appear to be suitable for further study and potential use in plug designs based on the test results. The self-cementing action of agitated basalt samples is considered a positive, beneficial result, which could enhance its performance in potential plug designs.

\subsubsection{Future Work}

Candidate plug materials will need to be subjected to more extensive geochemical testing to determine their overall suitability in advanced plug designs. The present data allow only limited predictions of possible long-term chemical stability and durability of plugs constructed from the materials discussed here; nor are they sensitive enough to 
discriminate between the chemical stabilities of materials with nearly equal reactivities. Longer term experiments are needed, perhaps at slightly higher temperatures (temperatures that would accelerate reaction rates but would not exceed the thermal stability limits of the test materials) and with agitation to also provide a greater acceleration of reaction rates. Ideally, the mechanisms for plug degradation should be modeled mathematically and the model used as a guide in designing the experimental program. The data obtained from those experiments would then be put back into the model to attempt predictions of plug durability for periods of thousands of years.

One unanticipated result of these tests was the observation that powdered basalt and mixtures containing powdered basalt are rapidly self-cementing under stirred, hydrothermal conditions at $250^{\circ} \mathrm{C}$. This raises the prospect of designing plug systems in which basalt is the principal plug material. such systems are conceptually appealing because, in principle, the compositional and structural discontinuity produced by a borehole in basalt could be eliminated. Much more work needs to be done to study the factors that control basalt selfcementing, so that the feasibility of designing such a plug system can be determined. The effects of such variables as particle size, temperature, solid-water ratio, solution chemistry, $\mathrm{pH}$, and stirring rate on cementing reaction also need to be analyzed. Once the reaction is understood, bulk specimens can be produced, and their physical and mechanical properties can be determined for use in calculations leading to final plug design. 


\section{PHYSICAL TESTING PROGRAM}

\subsection{INTRODUCTION}

The physical testing program was designed: (1) to help select individual materials and mixtures from the list of preferred candidate materials (presented by Taylor and others, 1979; and confirmed by the work described in Chapter 3 and Table I of this report) for further testing and use in preconceptual design schemes to plug boreholes, shafts, and tunnels leading to a repository in basalt; and (2) to provide quantitative experimental data on the thermomechanical response of selected mixtures under simulated repository conditions. Candidate materials for physical testing included natural cohesive and non-cohesive granular earth materials, portland cements, hydrothermal cements, and some standard cement additives (see Chapter 4, Section 4.2). These materials are the same as those tested during the concurrent geochemical testing program, and Table IV presents a detailed listing of the various individual materials used in both testing programs. Various aspects of the physical testing program required different proportions of components in various test mixtures and different sample and particle sizes from the geochemical testing program. These variations in sample design for physical testing are discussed at appropriate intervals in the following sections.

For the purpose of the physical testing program, mixtures made from the candidate materials listed in Table IV are classified into three main generic categories: (1) cementitious mixtures; (2) compacted natural earth materials; and (3) clay slurries. These mixtures were tested in two phases during this program. During an initial phase of screening tests, all preferred candidate materials and mixtures that fell into one of the 
three generic categories were examined, and the most promising mixtures were selected for further examination in the subsequent phase of the program--preliminary tests. During the preliminary tests, specific, promising candidate materials and mixtures selected by the screening phase were examined in greater detail. In this chapter, the screening tests are described for cementitious mixtures (Section 5.2), compacted earth materials (Section 5.3), and clay slurries (Section 5.4). The following sections (5.5 to 5.7) discuss the parallel, preliminary tests for these categories of materials. Final sections in the chapter provide a summary (Section 5.8) and conclusions and recommendations (Section 5.9).

\subsection{CEMENTITIOUS MIXTURES - SCREENING TESTS}

\section{2 .1 Background}

Candidate cementitious mixtures for plugging man-made accesses to a repository in basalt should be characterized by good working ability, low permeability, good bonding properties, and long-term integrity and durability. In related research, portland cements were recommended by Eilers and Spangle (1973) as the primary sealant for boreholes because of portland cement's "proven permanence, low porosity, and good bond strength to formation material." Preferred portland cements included Types II and $V$ because of sulfate resistance, and Chem Com expanding cements because of their ability to provide a compressive self-stressing effect against confining walls, thus resulting in a higher bond strength to formation material. The best performing Chem Com cement was reported to be El Toro Chem Com from Southwestern Portland Cement Company; this cement is no longer available. TXI Chem Com made by Texas Industries was 
considered next best in performance characteristics, and it was evaluated in this study.

Boa (1978) included fly ash and natural high silica pozzolans in his selection of candidate grouts for plugging. These additives improve the impermeability of cement mixtures, and the addition of natural or artificial pozzolan in mixtures should also reduce bleeding and segregation, lower the heat of hydration and thermal shrinkage, and improve chemical resistance and long-term integrity and durability of the cementitious material. In this study, preference is given to natural, high-silica pozzolan because of its documented history of survival. In addition, natural high-silica pozzolan has been found to provide cementitious mixtures that have greater sulfate resistance than fly ash (Mather, 1977). Accordingly, this study includes: (1) premixed portland pozzolan cement containing 15 percent (by weight) expanded shale; and (2) a natural calcined, high-silica volcanic ash (Lassenite), which was added to various cement mixtures during the batching process.

To improve workability of fresh grout or concrete, several additives were used. One additive (Plastiment) was a waterreducing retarder agent (WRA) which, when introduced in very small quantities, causes a reduction of the required water and provided a stronger, denser product. Another additive was small amounts of finely ground aluminum powder which reacted with the alkaline constituents of portland cement to produce hydrogen gas. This resulted in an early expansion of cementitious mixtures prior to setting and improved the contact of fresh cement mixtures against irregular surfaces. 
Cement mixtures to be placed near the waste repository should also have enough thermal stability to withstand cyclic temperature increases caused by the storage of radioactive wastes. Conventional portland cement mixtures are reported to be unstable at elevated temperatures (Roy and others, 1976). Under elevated pressure and temperature conditions, the original highly cementitious calcium silicate hydrates into crystalline calcium oxide (lime) that has lower strength and higher permeability. A feasibility study by Roy and others (1976) on hydrothermal transport indicated that the addition of finely ground silica flour to conventional portland cement produces a thermodynamically stable phase, tobermorite, which results in a denser, stronger final product. To minimize deterioration of cement mixtures at elevated temperature, the following two alternatives were examined during this phase of the testing program: (1) the addition of finely ground silica to portland cements (both a -325 mesh silica flour and a high silica pozzolan); and (2) the use of calcium aluminate cements (Fondu and Secar). In the second case, the main component is calcium aluminate as distinguished from calcium silicate. in portland cements; no free lime is liberated either during hydration or heat exposure in calcium aluminate cements. Fine and coarse aggregates used in all cement mixtures were chosen for their ready availability and proximity to the Hanford site; they include crushed and naturally graded sands and gravels and crushed basalt.

\subsubsection{Materials and Mixtures Used in Cements}

Candidate materials in cement mixtures and the source of each material are listed in Table VII. The combination of components used in each mixture and data on the relative proportion of each component in a mixture are summarized in 
CANDIDATE MATERIALS USED IN SCREENING TESTS ON CEMENT MIXTURES

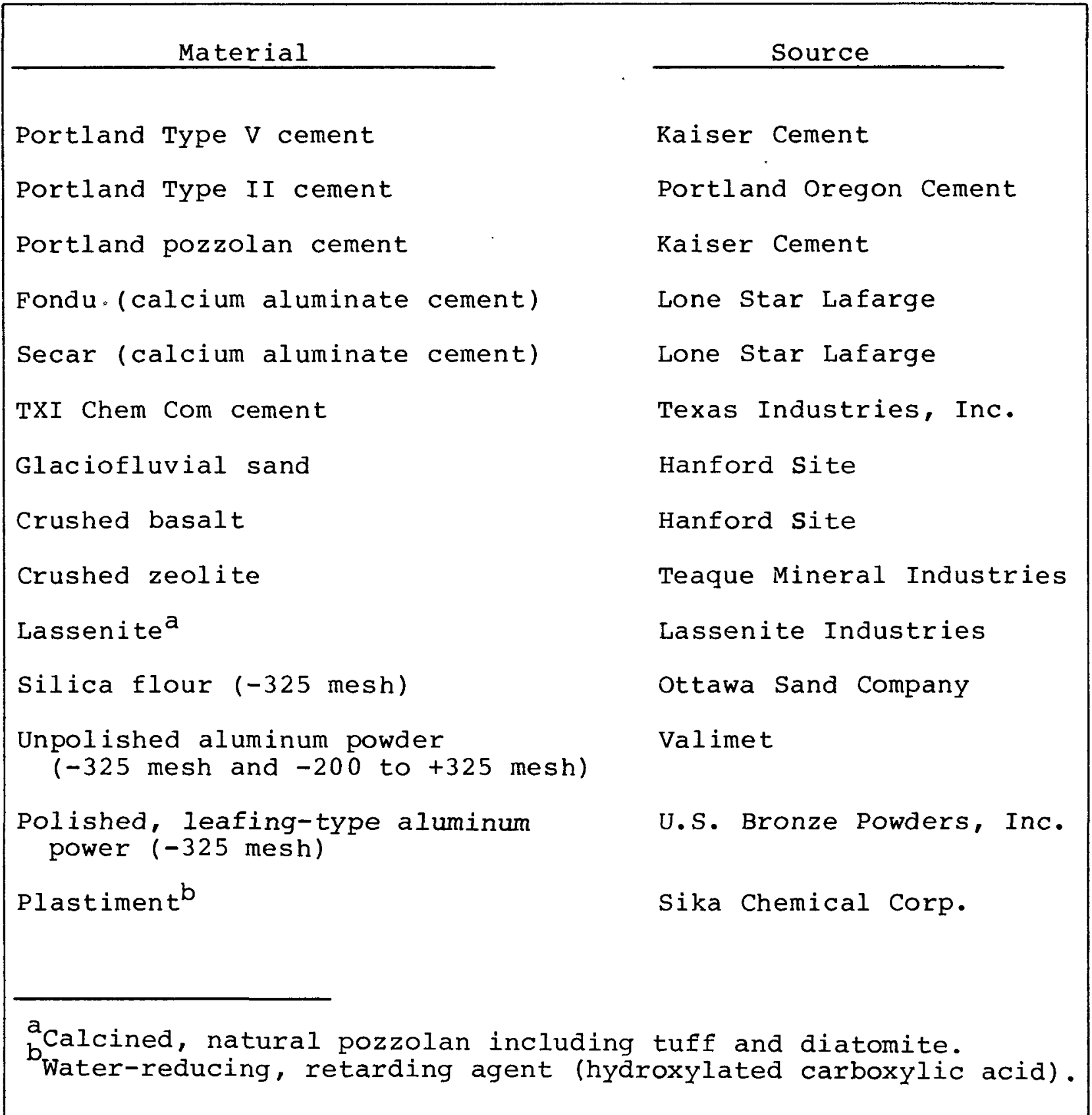


Table VIII for 22 cement mixtures. To simplify the screening process of candidate cements, the following guidelines were applied to each mixture, based on published standards and previous research:

- The water/cement ratio was selected to produce cement mortars of normal consistency, as determined at the flow table (ASTM, 1973);

- The ratio of aggregate (sand plus silica) to cement (cement plus pozzolan) was $2.5: 1$ (2.5 parts aggregate to 1 part cement), based on ASTM Cl09, adjusted;

- The ratio of silica to silica plus cement was equal to $0.35: 1$, based on work by Eilers and Spangle (1973);

- The ratio of pozzolan to cement was equal to 0.20:1, a standard practice, and

- The addition of $90 \mathrm{ml}$ of Plastiment per bag of cement (weighing $42.6 \mathrm{~kg}$ ) was made when a WRA was used in test mixtures, in accordance with general practice.

\subsubsection{Testing Program and Procedures}

Screening tests for cementitious materials included:

- The determination of unit weight, specific gravity, percentage of absorption, grain size distribution, and inorganic impurities content for candidate sands;

- The consistency and setting time of freshly mixed cementitious mixtures; 
TABLE VIII

COMPONENTS AND PROPORTIONING DATA FOR CANDIDATE CEMENTITIOUS MIXTURES

\begin{tabular}{|c|c|c|c|c|c|c|c|c|c|c|c|c|c|c|c|}
\hline $\begin{array}{l}\text { MIXTURE } \\
\text { NUMBER }\end{array}$ & $\begin{array}{c}\text { PORTLAND } \\
\text { TYPE V } \\
(0)\end{array}$ & $\begin{array}{c}\text { PORTLAND } \\
\text { TYPE II } \\
\text { (g) }\end{array}$ & $\begin{array}{c}\text { PORTLAND } \\
\text { POZZOLAN } \\
(0)\end{array}$ & $\begin{array}{c}\text { TXI } \\
\text { CEMENT } \\
(0)\end{array}$ & $\begin{array}{c}\text { FONDU } \\
\text { CEMENT } \\
(g)\end{array}$ & $\begin{array}{c}\text { SECAR } \\
\text { CEMENT } \\
(g)\end{array}$ & $\begin{array}{c}\text { GLACIO- } \\
\text { FLUVIAL } \\
\text { SAND } \\
(0)\end{array}$ & $\begin{array}{c}\text { CRUSHED } \\
\text { BASALT } \\
(0)\end{array}$ & $\begin{array}{l}\text { CRUSHED } \\
\text { ZEOLITE } \\
(0)\end{array}$ & $\begin{array}{c}\text { SILICA } \\
\text { FLOUR } \\
-325 \text { MESH } \\
\text { (g) }\end{array}$ & $\begin{array}{c}\text { LAS. } \\
\text { SENITE } \\
(g)\end{array}$ & $\begin{array}{c}\text { AL } \\
\text { POWDER } \\
(8)\end{array}$ & $\begin{array}{l}\text { PLASTI } \\
\text { MENT } \\
(\mathrm{ml})\end{array}$ & $\underset{\text { WATER }}{(\mathrm{ml})}$ & $\begin{array}{c}\text { FLow } \\
(x)\end{array}$ \\
\hline 612 & & & & & 500 & & 1250 & & & & & & & 200 & 115 \\
\hline 613 & & & & & & 500 & 1250 & & & & & & & 260 & 113 \\
\hline 614 & 500 & & & & & & 980 & & & 269 & & & & 286 & 115 \\
\hline 615 & & & 500 & & & & 981 & & & 269 & & & & 278 & 111 \\
\hline 616 & & & & 500 & & & 1250 & & & & & & & 235 & 116 \\
\hline 617 & & & 500 & & & & & 981 & & 269 & & & & 278 & 110 \\
\hline 618 & & & 500 & & & & & & 981 & 269 & & & & 676 & 112 \\
\hline 619 & 416 & & & & & & 1250 & & & & 84 & & & 243 & 105 \\
\hline 620 & & & & 416 & & & 1250 & & & & 84 & & 0.98 & 249 & 104 \\
\hline 621 & 500 & & & & & & 981 & & & 269 & & & & 246 & 113 \\
\hline 622 & 416 & & & & & & 1250 & & & & 84 & 0.2346 & 0.82 & 223 & 106 \\
\hline 623 & 500 & & & & & & 981 & & & 269 & & 0.2346 & 0.98 & 250 & 117 \\
\hline 624 & & 416 & & & & & 1250 & & & & 84 & & & 246 & 106 \\
\hline 625 & & & 500 & & & & 1250 & & & & & & & 227 & 105 \\
\hline
\end{tabular}

\begin{tabular}{|c|c|c|c|c|c|c|c|}
\hline $\begin{array}{c}\text { MIXTURE } \\
\text { NUMBER }\end{array}$ & $\begin{array}{c}\text { PORTLAND } \\
\text { TYPE } V \\
(g)\end{array}$ & $\begin{array}{c}\text { PORTLAND } \\
\text { POZZOLAN } \\
(g)\end{array}$ & $\begin{array}{c}\text { GLACIO } \\
\text { FLUVIAL- } \\
\text { SAND } \\
(\boldsymbol{g})\end{array}$ & $\begin{array}{c}\text { ALUMINIUM } \\
\text { POWDER } \\
-325 \text { MESH } \\
(\mathrm{g})\end{array}$ & $\begin{array}{c}\text { ALUMINIUM } \\
\text { POWDER } \\
\text { (200/325 MESH } \\
(\mathrm{M})\end{array}$ & $\begin{array}{c}\text { WATER } \\
(\mathrm{mI})\end{array}$ & $\begin{array}{c}\text { FLOW } \\
(\mathrm{X})\end{array}$ \\
\hline 601 & 500 & & 1250 & & & 222 & 107 \\
\hline 602 & 494 & & 1250 & & 0.117 & 221 & 110 \\
\hline 603 & 494 & & 1250 & 0.117 & & 215 & 114 \\
\hline 604 & 494 & & 1250 & 0.2346 & & 228 & 105 \\
\hline 606 & 494 & & 1250 & & 0.2346 & 228 & 107 \\
\hline 606 & 491 & & 1250 & & 0.3519 & 228 & 103 \\
\hline 607 & 491 & & 1250 & 0.3519 & & 231 & 115 \\
\hline 606 & & 494 & 1250 & 0.2346 & & 227 & 106 \\
\hline
\end{tabular}


- The early volume change and the restrained shrinkage or expansion of candidate mixtures; and

- The unconfined compressive strength at 7 days and 28 days of hardened 5-cm cubes of cement mortar, cured using one of the methods presented in Table IX.

The procedures used during physical testing included the ASTM and the Army Corps of Engineers standards and modified standard procedures, as described in the Quality Assurance program. The list of procedures is given in Table $x$, and procedures on file in the Quality Assurance program, for which no literature citation exists, are briefly discussed in the text.

\subsubsection{Discussion of Screening Tests on Cementitious Mixtures}

5.2.4.1 The Effect of Temperature on the Compressive Strength of Cement Mortars

Comparison of strength data for samples cured at ambient temperature, $100^{\circ} \mathrm{C}$, and $200^{\circ} \mathrm{C}$ are plotted in Figure 7 ( $a$ and $b$ ). Curing procedures for all samples are given in Table IX. There is a difference among samples for curing and testing at the ambient $\left(23^{\circ} \mathrm{C}\right)$ temperature. For example, Fondu and Secar samples follow procedure $A$ (2) requiring 7 days in the mold before removing and immediate testing. Other cement samples are removed in 24 hours and tested at 28 days. The reason is in the high early strength characteristics of Fondu and Secar cements. Curing for elevated temperature tests was the same for all samples and is given in Table IX (B). All elevated temperature testing was at 28 days. 
TABLE IX

\section{CEMENT CURING PROCEDURES}

A. Wet-curing at standard temperature $\left(23^{\circ} \mathrm{C}\right)$

(1) For non-expansive or quick-hardened, cement mortars, specimen wet-cured 24 hours within the mold, then removed and cured in a moist room before testing.

(2) For expansive cement mortar, specimen wet-cured 7 days within the mold, then removed and cured in a moist room before testing.

B. Wet-curing at elevated temperature, initial curing for 24 hours within the mold followed by one of the following curing alternatives:

(1) In boiling water for 72 hours at $100^{\circ} \mathrm{C}$.

(2) In an autoclave for 72 hours at $200^{\circ} \mathrm{C}$. 
TABLE X

TESTING PROCEDURES APPLIED TO CEMENTITIOUS MIXTURES

$$
\begin{aligned}
& \text { ASTM C }-29^{a} \\
& \text { ASTM } C-128^{a} \\
& \text { ASTM } C-40^{a} \\
& \text { ASTM D }-422^{b} \\
& \text { ASTM C }-230^{a} \\
& \text { ASTM C }-191^{C} \\
& \text { ASTM C }-827^{a} \\
& \text { CRD C }-588^{d}
\end{aligned}
$$

Modified ASTM C-109a
Unit weight of aggregate

Specific gravity and absorption of fine aggregate

Inorganic impurities

Particle size analysis of soil

Specification for flow table for use in test of hydraulic cement

Setting time by Vicat needle

Early volume change of cementitious mixtures

Restrained expansion of cement mortars: Corps of Engineers method

(1) Compressive strength of expansive or shrinkagecompensating cement mortars. (2) Compressive strength of non-expansive and rapidhardening cement mortars. (3) Effect of heat exposure on the compressive strength of wet cement mortars. Modifications include variations in curing procedures described in the text.

\footnotetext{
$\mathrm{a}_{\text {ASTM }}(1977 \mathrm{~b})$

b ASTM (1978b)

CASTM (1973)

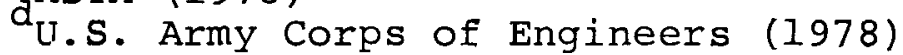




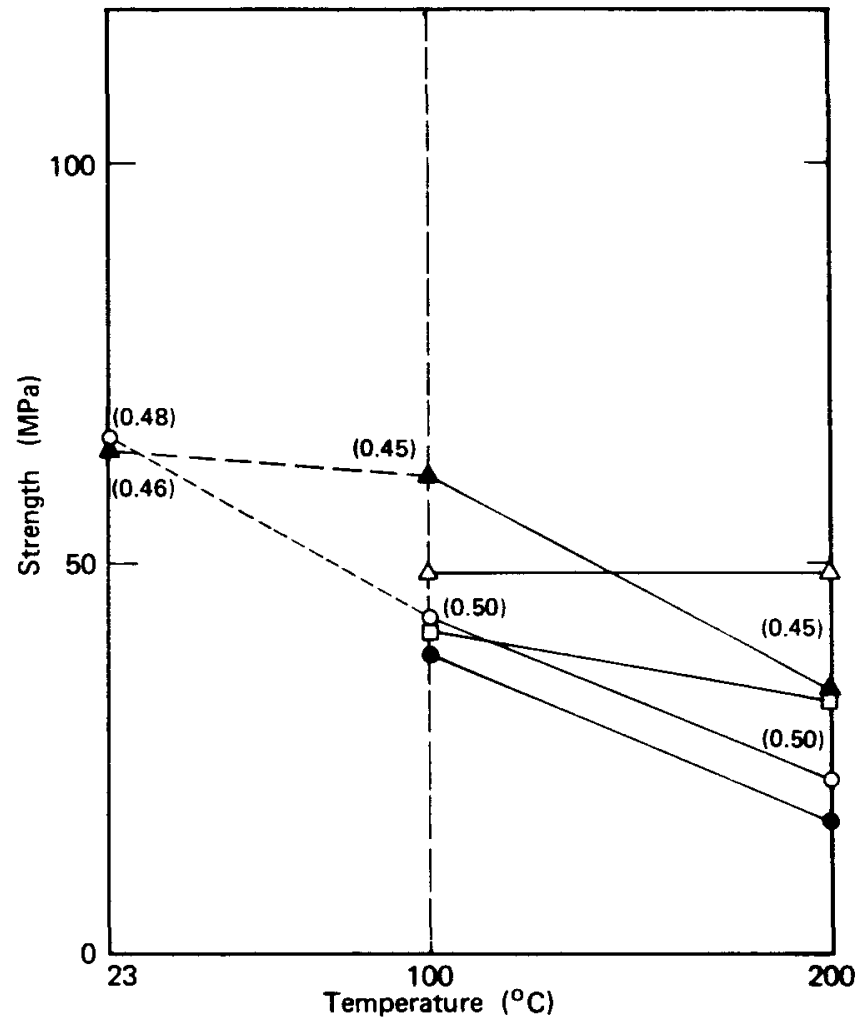

(a)

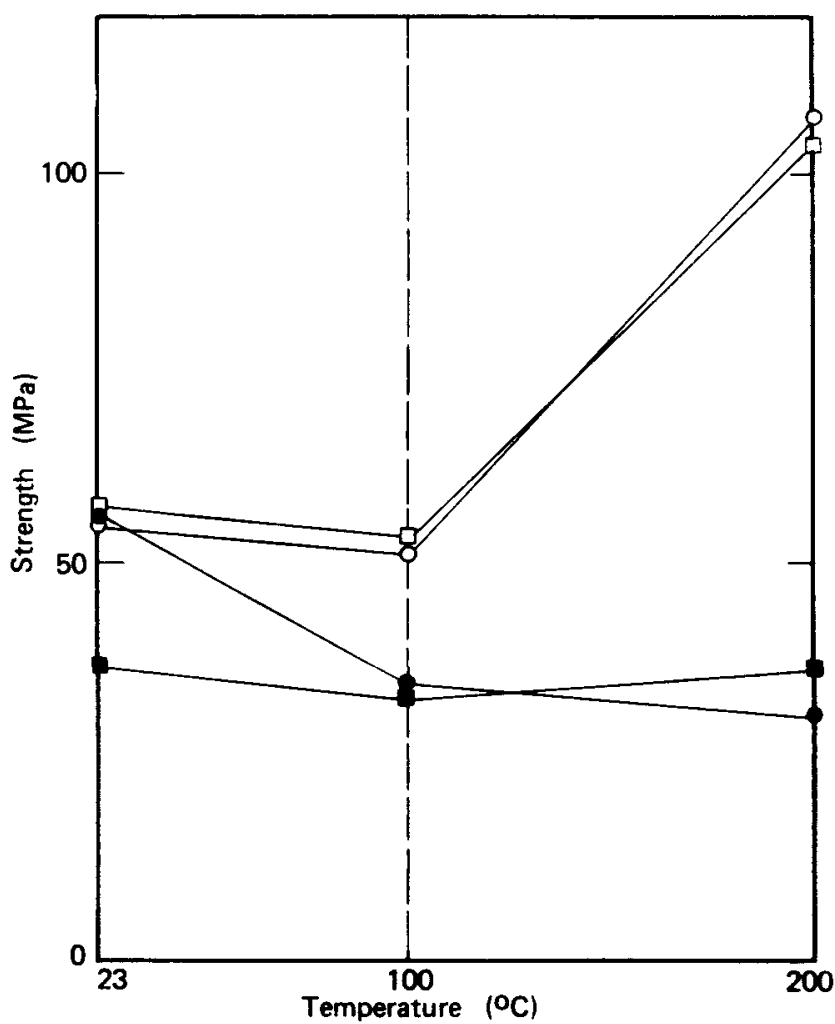

(b)

FIGURE 7

\section{EXPLANATION}

A Portland Pozzolan Cement

- TXI Chem Com plus Lassenite

- TXI Chem Com

$\checkmark$ Portland Cement Type II plus Lassenite $\triangle$ Portland Cement Type $V$ plus Lassenite

NOTE:

Water-cement ratios are plotted in parentheses near data point when not uniform for the same candidate mixture at different curing temperature.

\section{EXPLANATION}

- Fondu Cement

- Secar Cement

- Portland Cement Type V plus Silica

$\square$ Portland Pozzolan Cement plus Silica 
Descriptions of the mixture components, water/cement ratios, setting times, and compressive strengths are summarized in Table XI. Corresponding mixture descriptions, water/cement ratios, setting times, and shrinkage/expansion characteristics are given in Table XII.

Prior to discussing Figure 7 , it is useful to note that (1) property changes observed in specimens heated under a confined free moisture condition are primarily related to changes in the mineralogy of the cementitious phase (Lankard and others, 1970); and (2) the percent strength retained by portland cement (without additives and after autoclaving) has been observed to range from 76 percent at $115^{\circ} \mathrm{C}$ to 29 percent at $199^{\circ} \mathrm{C}$ (Akaiwa and Sudoh, 1966). The following results were considered most important for this screening phase of cementitious mortar mixtures with respect to temperature effects:

- TXI Chem Com (shrinkage compensating cement) showed a decrease in strength with increasing curing temperature. The addition of Lassenite to the mixture slightly increased the strength of the cementitious mixture, but the percent deterioration with temperature increase remained the same. Strength percent remaining after autoclaving ranged from 65 percent at $100^{\circ} \mathrm{C}$ to 35 percent at $200^{\circ} \mathrm{C}$ (Figure 7a);

- Portland pozzolan cement remained quite stable for curing temperatures less than $100^{\circ} \mathrm{C}$ but underwent a net strength decrease when cured at higher temperatures (Figure 7a);

- The addition of 20 percent Lassenite (by weight of cement) in mixtures of portland cement Type $V$ stabilized the structural properties of the mixture. Therefore, no 
TABLE XI

SUMMARY OF TEST RESULTS FOR CEMENT MORTARS

CURED AT ELEVATED TEMPERATURE

\begin{tabular}{|c|c|c|c|c|c|c|c|c|c|}
\hline \multirow{2}{*}{$\begin{array}{l}\text { MIXTURE } \\
\text { NUMBER }\end{array}$} & \multirow{2}{*}{$\begin{array}{c}\text { CEMENT } \\
\text { DESCRIPTION }\end{array}$} & \multirow{2}{*}{$\begin{array}{c}\text { SAND } \\
\text { DESCRIPTION }\end{array}$} & \multirow{2}{*}{$\begin{array}{l}\text { ADDITIVE } \\
\text { DESCRIPTION }\end{array}$} & \multicolumn{2}{|c|}{$\begin{array}{c}\text { WATER CEMENT } \\
\text { RATIO }\end{array}$} & \multicolumn{2}{|c|}{ SETTING TIME } & \multicolumn{2}{|c|}{$\begin{array}{l}\text { UNCONFINED STRENGTH } \\
\text { (MPa) }\end{array}$} \\
\hline & & & & $w_{/ C}$ & $\begin{array}{l}\text { W/C+ } \\
\text { SILICA }\end{array}$ & INITIAL & FINAL & $\begin{array}{c}\text { CURING AT } \\
t=100^{\circ} \mathrm{C}\end{array}$ & $\begin{array}{c}\text { CURING AT } \\
t=200^{\circ} \mathrm{C}\end{array}$ \\
\hline 612 & FONDU & $\begin{array}{l}\text { GLACIOFLUVIAL } \\
\text { SAND }\end{array}$ & NA* & 0.40 & NA & 2:00 & $3: 30$ & 33.9 & 24.6 \\
\hline 613 & SECAR & $\begin{array}{l}\text { GLACIOFLUVIAL } \\
\text { SAND }\end{array}$ & NA & 0.51 & NA & $1: 40$ & $2: 50$ & 32.4 & 35.6 \\
\hline 614 & $\begin{array}{l}\text { PORTLAND } \\
\text { TYPE V }\end{array}$ & $\begin{array}{c}\text { GLACIOFLUVIAL } \\
\text { SAND }\end{array}$ & SILICA FLOUR & 0.57 & 0.37 & $2: 45$ & $4: 00$ & 50.1 & 106.1 \\
\hline 615 & $\begin{array}{l}\text { PORTLAND } \\
\text { POZZOLAN }\end{array}$ & $\underset{\text { SAND }}{\text { GLACIOFLUVIAL }}$ & SILICA FLOUR & 0.56 & 0.36 & $2: 15$ & $3: 45$ & 53.3 & 101.7 \\
\hline 616 & $T \times 1$ & $\begin{array}{l}\text { GLACIOFLUVIAL } \\
\text { SAND }\end{array}$ & NA & 0.47 & NA & $1: 40$ & $3: 35$ & 38.3 & 16.7 \\
\hline 619 & $\begin{array}{l}\text { PORTLAND } \\
\text { TYPE V }+ \\
\text { LASSENITE }\end{array}$ & $\begin{array}{c}\text { GLACIOFLUVIAL } \\
\text { SAND }\end{array}$ & NA & 0.49 & NA & 3:15 & $5: 15$ & 48.3 & 47.8 \\
\hline 620 & $\begin{array}{c}\text { TXI + } \\
\text { LASSENITE }\end{array}$ & $\begin{array}{c}\text { GLACIOFLUVIAL } \\
\text { SAND }\end{array}$ & NA & 0.50 & NA & $1: 30$ & $3: 45$ & 43.6 & 22.2 \\
\hline 621 & $\begin{array}{l}\text { PORTLAND } \\
\text { TYPE V }\end{array}$ & $\begin{array}{c}\text { GLACIOFLUVIAL } \\
\text { SAND }\end{array}$ & $\begin{array}{l}\text { SILICA FLOUR } \\
\text { + PLASTIMENT }\end{array}$ & 0.49 & 0.32 & 3:00 & $6: 30$ & 53.0 & 116.3 \\
\hline 622 & $\begin{array}{l}\text { PORTLAND } \\
\text { TYPE V + } \\
\text { LASSENITE }\end{array}$ & $\begin{array}{c}\text { GLACIOFLUVIAL } \\
\text { SAND }\end{array}$ & PLASTIMENT & 0.45 & NA & & & 56.1 & 53.2 \\
\hline 623 & $\begin{array}{l}\text { PORTLAND } \\
\text { TYPE } V\end{array}$ & $\begin{array}{c}\text { GLACIOFLUVIAL } \\
\text { SAND }\end{array}$ & $\begin{array}{l}\text { SILICA FLOUR } \\
\text { + PLASTIMENT } \\
\text { + AL POWDER }\end{array}$ & 0.50 & 0.33 & & & 58.5 & 111 \\
\hline 624 & $\begin{array}{l}\text { PORTLAND } \\
\text { TYPE II+ } \\
\text { LASSENITE }\end{array}$ & $\begin{array}{c}\text { GLACIOFLUVIAL } \\
\text { SAND }\end{array}$ & NA & 0.53 & NA & $1: 50$ & $4: 20$ & 40.6 & 31.8 \\
\hline 625 & $\begin{array}{l}\text { PORTLAND } \\
\text { POZZOLAN }\end{array}$ & $\begin{array}{c}\text { GLACIOFLUVIAL } \\
\text { SAND }\end{array}$ & NA & 0.45 & NA & & & 60.9 & 33.1 \\
\hline
\end{tabular}

"Not applicable 
TABLE XII

SUMMARY OF TEST RESULTS FOR CALCIUM ALUMINATE CEMENT MORTARS

\begin{tabular}{|c|c|c|c|c|c|c|c|c|c|c|}
\hline \multirow{2}{*}{$\begin{array}{l}\text { MIXTURE } \\
\text { NUMBER }\end{array}$} & \multirow{2}{*}{$\begin{array}{l}\text { COMPONENTS } \\
\text { DESCRIPTION }\end{array}$} & \multirow{2}{*}{$\begin{array}{c}\text { ADDITIVE } \\
\text { DESCRIPTION }\end{array}$} & \multirow{2}{*}{$\begin{array}{c}\text { WATER/ } \\
\text { CEMENT } \\
\text { RATIO } \\
\text { W/C }\end{array}$} & \multicolumn{2}{|c|}{ SETTING TIME } & \multirow{2}{*}{$\begin{array}{l}\text { MAXIMUM EARLY } \\
\text { VOLUME CHANGE }\end{array}$} & \multicolumn{2}{|c|}{$\begin{array}{l}\text { RESTRAINED } \\
\text { VOL.CHANGE }\end{array}$} & \multicolumn{2}{|c|}{$\begin{array}{l}\text { UNCONFINED } \\
\text { COMPRESSION }\end{array}$} \\
\hline & & & & $\begin{array}{c}\text { INITIAL } \\
\text { hr:mn }\end{array}$ & $\begin{array}{l}\text { FINAL } \\
\text { hr:mn }\end{array}$ & & $\begin{array}{c}3 \\
\text { days }\end{array}$ & $\begin{array}{c}7 \\
\text { days }\end{array}$ & $\begin{array}{c}24 \\
\text { hours }\end{array}$ & $\begin{array}{c}7 \\
\text { days }\end{array}$ \\
\hline 612 & $\begin{array}{l}\text { FONDU CEMENT/ } \\
\text { GLACIOFLUVIAL } \\
\text { SAND }\end{array}$ & NONE & 0.40 & $2: 00$ & $3: 30$ & -0.11 & -0.02 & -0.03 & 47.6 & 56.2 \\
\hline 613 & $\begin{array}{l}\text { SECAR CEMENT/ } \\
\text { GLACIOFLUVIAL } \\
\text { SAND }\end{array}$ & NONE & 0.52 & $2: 50$ & $2: 50$ & -0.05 & 0.00 & +0.02 & 30.5 & 37.3 \\
\hline
\end{tabular}


decrease in strength was observed between a specimen cured at $100^{\circ} \mathrm{C}$ and a specimen cured at $200^{\circ} \mathrm{C}$ (Figure 7a);

- No such strength stabilization was observed in the mixture which included portland cement Type II plus Lassenite, where a 20-percent decrease in strength was observed between specimens cured at $100^{\circ} \mathrm{C}$ and at $200^{\circ} \mathrm{C}$ (Figure 7a);

- The calcium aluminate cement, Fondu, underwent a substantial decrease in strength when cured at elevated temperatures (Figure 7b);

- The calcium aluminate cement, Secar, appeared to be quite stable, and no significant change in strength was observed between a specimen cured in a moist room at ambient temperature and specimens cured at $100^{\circ} \mathrm{C}$, and $200^{\circ} \mathrm{C}$. However, the strength of a cement mixture fabricated with Secar was lower than the strength of a mixture made from portland cement when specimens cured at ambient temperature were compared (Figure 7b);

- The addition of 35 percent finely ground silica flour (by weight of cement plus silica) caused a strong hydrothermal reaction that greatly improved the structural strength of portland cement Type $V$ cured at elevated temperatures. Specimens containing silica flour and cured at $200^{\circ} \mathrm{C}$ developed a compressive strength twice as great as the same material cured at $100^{\circ} \mathrm{C}$. This result is noteworthy considering that portland cement without a silica additive showed a three-fold decrease in strength when submitted to the same comparative test (Figure 7b); and 
- Mixtures of portland pozzolan cement containing silica flour showed the same behavior as mixtures of portland cement Type $V$ plus silica flour, and structural strengths developed during the curing process were similar for the two cement types when silica was present (Figure 7b).

5.2.4.2 The Effect of Aluminum Powder on Portland Cement Mixtures

Table XIII summarizes test data (including water/cement ratios, setting times, maximum early volume changes, restrained volume changes, and 7-day and 28-day compressive strengths) for portland cements mixed with fine-grained, unpolished aluminum powders. Both -325 mesh and -200 to +325 mesh unpolished aluminum powder were tested in cement mixtures in quantities ranging from 0.023 to 0.070 percent by weight of the cementitious materials. Figure 8 ( $a$ and $b$ ) presents data on the variation in compressive strength (at 7 and 28 days) and in restrained shrinkage for increasing unpolished aluminum powder/cement ratios. The following observations were made with respect to increasing aluminum powder contents in cement mixtures:

- An increase in the water/cement ratio was necessary to obtain the same workability. This resulted in an increase in porosity of the cement mixture;

- There was a notable acceleration of setting times;

- Restrained shrinkage continuously decreased with increasing content of -325 mesh aluminum powder, which resulted in a non-shrink mortar for the largest aluminum powder content $(0.070$ percent) studied (Figure $8 \mathrm{~b})$; 
TABLE XIII

SUMMARY OF TEST RESULTS FOR PORTLAND CEMENT MORTARS CONTAINING UNPOLISHED ALUMINUM POWDER

\begin{tabular}{|c|c|c|c|c|c|c|c|c|c|c|}
\hline \multirow{2}{*}{$\begin{array}{l}\text { MIXTURE } \\
\text { NUMBER }\end{array}$} & \multirow{2}{*}{$\begin{array}{l}\text { COMPONENTS } \\
\text { DESCRIPTION }\end{array}$} & \multirow{2}{*}{$\begin{array}{l}\text { ADDITIVE } \\
\text { DESCRIPTION } \\
\text { (Weight \%) }\end{array}$} & \multirow{2}{*}{$\begin{array}{c}\text { WATER/ } \\
\text { CEMENT } \\
\text { RATIO } \\
\text { W/C }\end{array}$} & \multicolumn{2}{|c|}{ SETTING TIME } & \multirow{2}{*}{$\begin{array}{l}\text { MAXIMUM EARLY } \\
\text { VOLUME CHANGE }\end{array}$} & \multicolumn{2}{|c|}{$\begin{array}{l}\text { RESTRAINED } \\
\text { VOL. CHANGE }\end{array}$} & \multicolumn{2}{|c|}{$\begin{array}{l}\text { UNCONFINED } \\
\text { COMPRESSION }\end{array}$} \\
\hline & & & & $\begin{array}{c}\text { INITIAL } \\
\text { hr:mn }\end{array}$ & $\begin{array}{l}\text { FINAL } \\
\text { hr:mn }\end{array}$ & & $\begin{array}{c}3 \\
\text { days }\end{array}$ & $\begin{array}{c}7 \\
\text { days }\end{array}$ & $\begin{array}{c}7 \\
\text { days }\end{array}$ & $\begin{array}{c}28 \\
\text { days }\end{array}$ \\
\hline 601 & \begin{tabular}{|l|} 
PORTLAND \\
TYPE V/GLACIO- \\
FLUVIAL SAND \\
\end{tabular} & NONE & 0.44 & $2: 54$ & $5: 32$ & $-0.40 \%$ & $-0.55 \%$ & $-0.57 \%$ & 38.1 & 48.5 \\
\hline 602 & \begin{tabular}{|c|} 
PORTLAND \\
TYPE V/GLACIO- \\
FLUVIAL SAND \\
\end{tabular} & \begin{tabular}{|c|} 
AL POWDER \\
$-200 /+325 \mathrm{MESH}$ \\
$0.023 \%$ \\
\end{tabular} & 0.43 & 2:00 & $3: 15$ & $-0.34 \%$ & $-0.05 \%$ & $-0.05 \%$ & 45.7 & 49.3 \\
\hline 603 & \begin{tabular}{|l|} 
PORTLAND \\
TYPE V/GLACIO- \\
FLUVIAL SAND \\
\end{tabular} & \begin{tabular}{|c|} 
AL POWDER \\
$-325 \mathrm{MESH}$ \\
$0.023 \%$ \\
\end{tabular} & 0.44 & $2: 18$ & $4: 20$ & $-0.46 \%$ & $-0.23 \%$ & $-0.24 \%$ & 41.1 & 51.9 \\
\hline 604 & \begin{tabular}{|c|} 
PORTLAND \\
TYPE V/GLACIO- \\
FLUVIAL SAND \\
\end{tabular} & $\begin{array}{c}\text { AL POWDER } \\
-325 \mathrm{MESH} \\
0.047 \% \\
\end{array}$ & 0.46 & 2:05 & $3: 15$ & $-0.29 \%$ & $-0.05 \%$ & $-0.05 \%$ & 37.2 & 49.6 \\
\hline 605 & \begin{tabular}{|c|} 
PORTLAND \\
TYPE V/GLACIO- \\
FLUVIAL SAND \\
\end{tabular} & \begin{tabular}{|c|} 
AL POWDER \\
$-200 /+325 \mathrm{MESH}$ \\
$0.047 \%$ \\
\end{tabular} & 0.46 & $2: 10$ & 4:00 & $-0.50 \%$ & $-0.13 \%$ & $-0.15 \%$ & 36 & 53.8 \\
\hline 606 & \begin{tabular}{|c|} 
PORTLAND \\
TYPE V/GLACIO- \\
FLUVIAL SAND \\
\end{tabular} & $\begin{array}{c}\text { AL POWDER } \\
-200 /+325 \mathrm{MESH} \\
0.070 \% \\
\end{array}$ & 0.47 & $2: 00$ & 3:00 & $-0.34 \%$ & $-0.32 \%$ & $-0.29 \%$ & 36.8 & 52.4 \\
\hline 607 & \begin{tabular}{|c|} 
PORTLAND \\
TYPE V/GLACIO- \\
FLUVIAL SAND \\
\end{tabular} & $\begin{array}{l}\text { AL POWDER } \\
-325 \mathrm{MESH} \\
0.070 \% \\
\end{array}$ & 0.46 & $2: 20$ & $3: 45$ & $-0.32 \%$ & 0.00 & 0.00 & 38.3 & 50.7 \\
\hline 608 & $\begin{array}{c}\text { PORTLAND } \\
\text { POZZOLAN/ } \\
\text { GLACIO- } \\
\text { FLUVIALSAND }\end{array}$ & $\begin{array}{l}\text { AL POWDER } \\
-325 \mathrm{MESH} \\
0.023 \% \\
\end{array}$ & 0.46 & $2: 00$ & $3: 45$ & $-0.71 \%$ & $+0.02 \%$ & $+0.02 \%$ & 42.1 & 64.5 \\
\hline
\end{tabular}


a) Effect of aluminum powder on the compressive strength of wet cement mortars

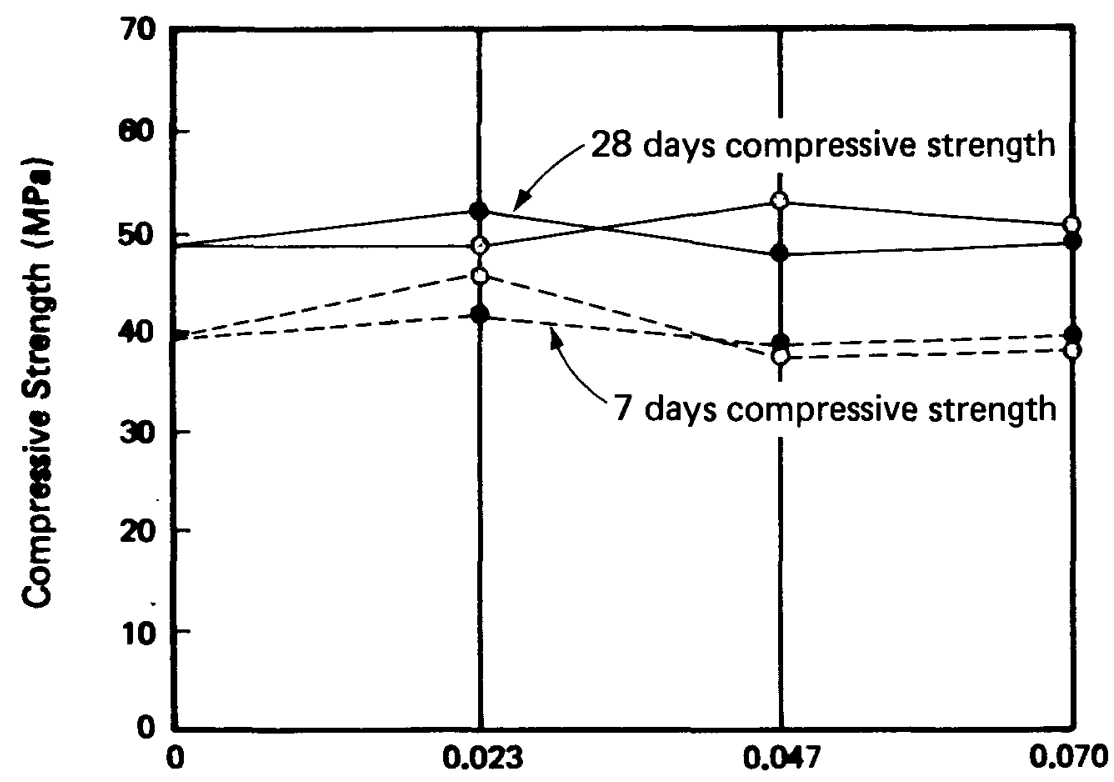

Aluminum Powder/Weight of Cement (percent)

b) Effect of aluminum powder on the early volume change of wet cement mortars

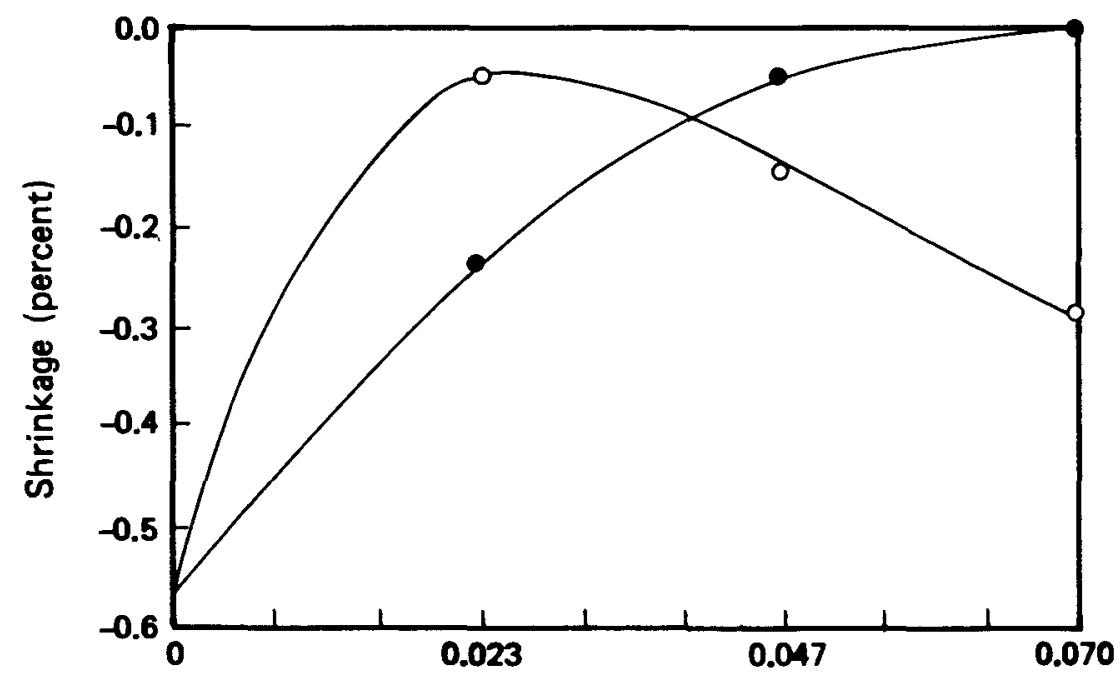

Aluminum Powder/Weight of Cement (percent)

EXPLANATION

- -325 mesh unpolished aluminum powder

o $-200 /+325$ mesh unpolished aluminum powder 
- An optimum, restrained shrinkage reduction was observed for samples containing 0.023 percent aluminum powder using the $-200 /+325$ mesh grain size. An increase in shrinkage was observed with further additions of aluminum powder with this grain size (Figure $8 \mathrm{~b}$ ); and

- No substantial changes in the compressive strength of cement specimens occurred with increasing powder content; at equal water/cement ratios, a slight increase in strength was noted (Figure 8 a).

Cement mixtures containing portland pozzolan cement and 0.023 percent -325 mesh unpolished aluminum powder were slightly expansive. The strength of a 28-day, moist-cured specimen of portland pozzolan cement was observed to be 30 percent higher than the strength of a specimen fabricated from portland cement Type V.

Those data on early volume changes produced by the addition of unpolished aluminum powders are difficult to interpret and somewhat contradictory. An expected early expansion of cement mortars (due to the reaction of aluminum powder with alkaline solutions) was not observed, even when using twice the amount of aluminum powder generally recommended (U.S. Bureau of Reclamation, 1975). This lack of expansion suggests that the commercial-grade unpolished aluminum powder used in these tests was poorly suited to react with the cement mixtures as a gasforming agent.

A -325 mesh polished, leafing-type aluminum powder was also investigated. The reactivity of this aluminum powder was determined by measuring the change in volume of a grout column 
from its original height and its height at the end of a specified period, following the C-681 standard method (U.S. Army Corps of Engineers, 1978). (The proportions of components used in grout mixtures during this part of the screening tests are presented in section 5.4.) Cement grouts used in comparing the relative reactivities of -325 mesh unpolished aluminum powder and -325 mesh polished, leafing-type aluminum powder were designed with identical components, and the proportions of those components (portland cement Type $V$, Lassenite, and glaciofluvial sand) were designed to provide the same flow, as determined with a Marsh funnel. Curves giving the early volume change of fresh grout per time elapsed for a control mixture without aluminum powder, a mixture containing 0.048 percent by weight of -325 mesh unpolished aluminum powder, and a mixture containing 0.048 percent by weight of -325 mesh polished, leafing-type aluminum powder are presented in Figure 9. These curves indicate a considerable difference in reactivity between the two grades of aluminum powder. Fresh grout with unpolished aluminum powder exhibited shrinkage of 0.068 percent. However, the grout with polished, leafing-type aluminum powder exhibited a strong, unrestrained expansion, reaching 14 percent in 4 hours. A study of the optimum content of polished, leafingtype aluminum powder (the results of which are presented in Figure 10) resulted in the selection of 0.03 percent aluminum powder in cement mixtures by weight, which produced about 8 percent of pre-expansion before set of the mixture.

5.2.4.3 The Effect of a Water-Reducing Retarder Agent (WRA) on Portland Cement Mixtures

Although organic components in cement mixtures may have a poorly documented history of survival and durability, their use in small amounts may prove to be highly desirable. Their 


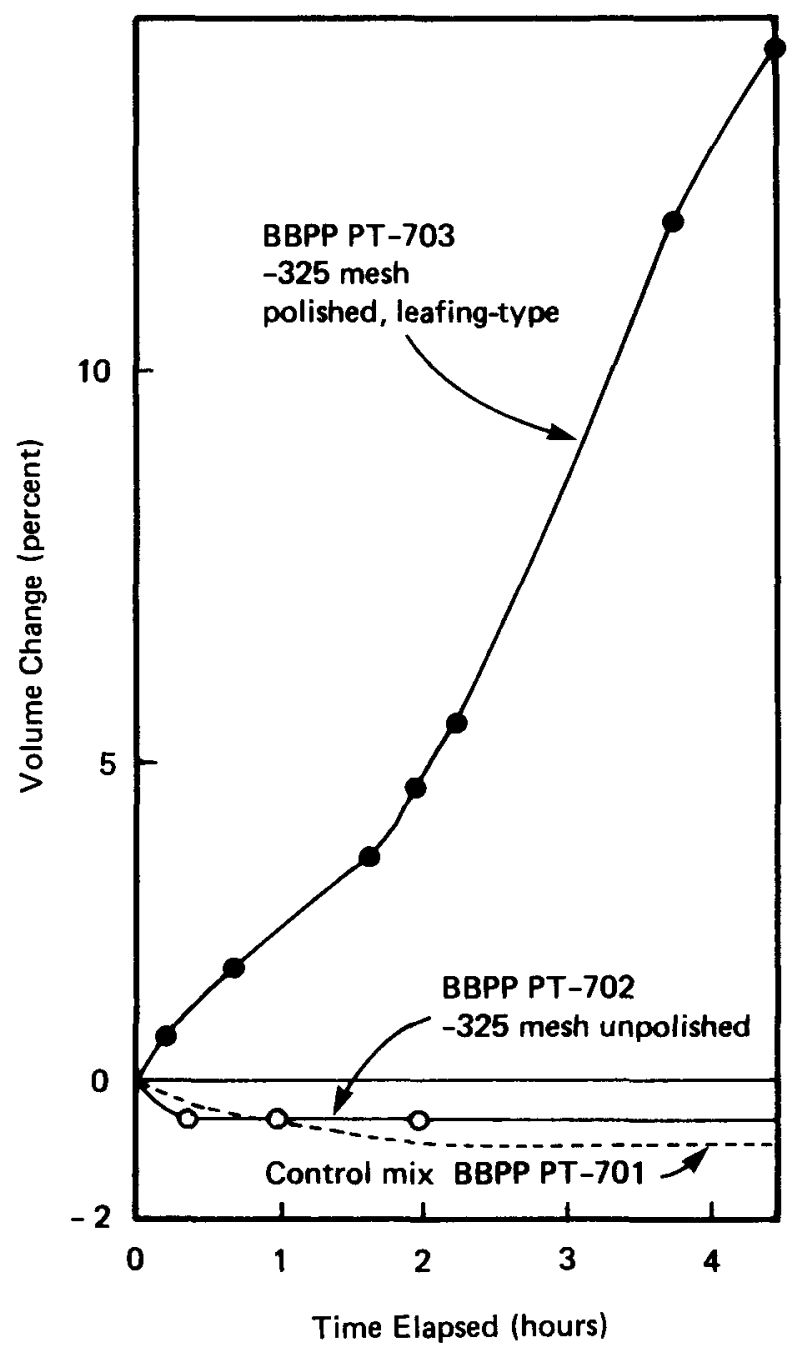

FIGURE 9 


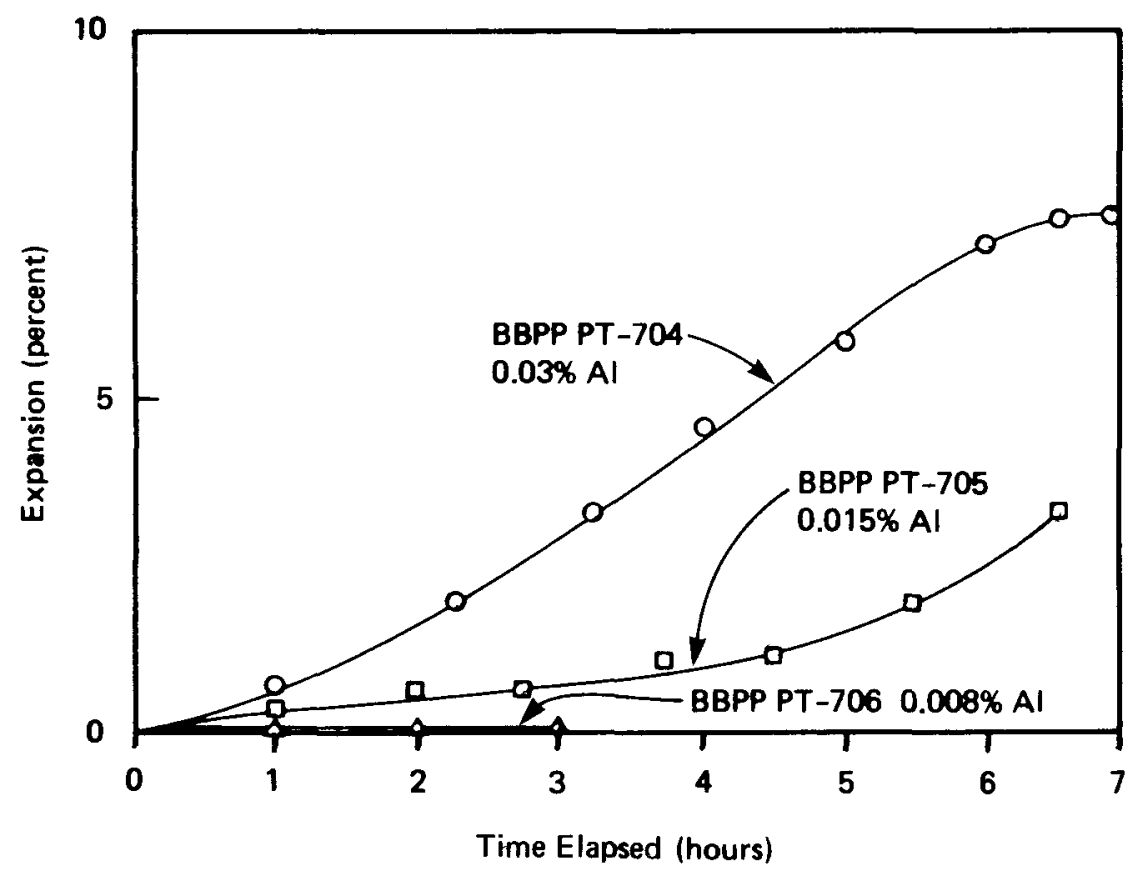

FIGURE 10 
addition to cement mortars improves plasticity, decreases mixing water requirements, lengthens the time of set, and avoids flash setting in moderate to high temperature environments. The thermal stability of cementitious mixtures containing a WRA, Plastiment, was examined during unconfined compressive strength tests on $5-\mathrm{cm}$ cement cubes cured in an autoclave at $100^{\circ} \mathrm{C}$ and $200^{\circ} \mathrm{C}$. A description of the mixtures, water/cement ratios, setting times, and strengths is presented in Table XI.

Strength values are plotted on Figure 11 for cement mortars containing portland cement Type $V$ plus Lassenite and portland cement Type $V$ plus silica flour. For both of these mixtures, the addition of $90 \mathrm{ml}$ of Plastiment per bag of cement $(42.6 \mathrm{~kg})$ slightly increased the strength of mortars cured at elevated temperature. Comparative values of compressive strengths for mortars containing portland cement Type $V$ plus Lassenite indicated a strength increase reaching 18 percent for a specimen cured at $100^{\circ} \mathrm{C}$ and 11 percent for a specimen cured at $200^{\circ} \mathrm{C}$ (with Plastiment added). For mixtures containing portland cement Type $V$ plus silica flour, the strength increase reached 6 percent for a specimen cured at $100^{\circ} \mathrm{C}$ and 10 percent for a specimen cured at $200^{\circ} \mathrm{C}$.

Strength tests were also performed on mixtures of portland cement Type $V$ plus silica flour which contained both Plastiment and aluminum powder. Data plotted on Figure ll show a slight increase in strength. Comparative values of strength obtained for mixtures containing both Plastiment and aluminum powder versus mixtures containing only plastiment indicated a 10 percent gain in strength for a specimen cured at $100^{\circ} \mathrm{C}$ and a 5 percent loss in strength for a specimen cured at $200^{\circ} \mathrm{C}$. These percentages of gain and loss are relatively small and are 


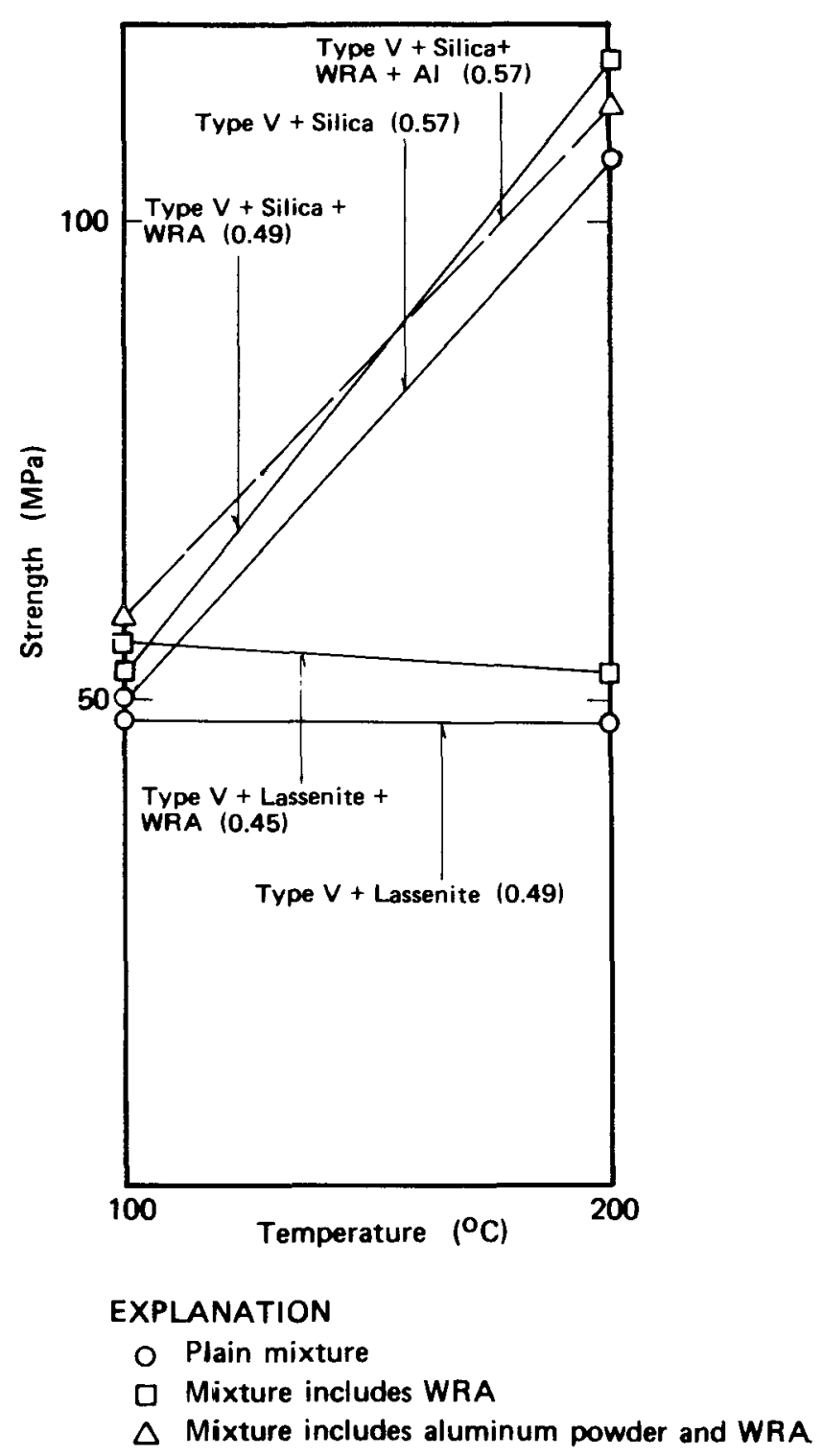

FIGURE 11 
within the range of accuracy to be expected from experimental strength values. Thus, no firm conclusion can be reached as to the effect of a WRA on strength.

\subsubsection{Performance of Candidate Sands}

Figure $12 \mathrm{a}$ gives values of unit weight, specific gravity, percentage of absorption, and inorganic impurities of glaciofluvial sand, crushed basalt, and crushed zeolite. Figure $12 b$ gives the grain size distribution curves of these three candidate sands relative to two grading limit curves proposed by ASTM C-33 (ASTM, 1977b) for sand used in mortar and concrete. The basalt and zeolite sands had to be crushed to conform to ASTM requirements. The glaciofluvial sand and the crushed-basalt sand have similar physical properties and are recommended for cement mixtures. Crushed zeolite appears to be a porous, weak aggregate. A large amount of breakdown was observed during blending of this material.

Comparative values for water/cement ratios and compressive strengths, together with mixture designs, are given in Table XIV. Three cement mixtures were cured at $100^{\circ} \mathrm{C}$ and at $200^{\circ} \mathrm{C}$ using the same cements and additives but containing different aggregates. Experimental strength values are plotted on Figure 13. Cement mortars mixed with glaciofluvial sand and crushed basalt developed similar strengths. Cement mortar mixed with crushed zeolite had an extremely weak structural strength. The amount of water used with crushed zeolite aggregate to maintain the same consistency was twice that used for either crushed basalt or glaciofluvial sand. This demand for water and weak strength suggests a porous cement mortar. 
(a)

\begin{tabular}{|c|c|c|c|c|c|}
\hline SAMPLE NUMBER & DESCRIPTION & $\begin{array}{c}\text { UNIT WEIGHT } \\
\left(\mathbf{K g} / \mathbf{m}^{3}\right)\end{array}$ & SPECIFIC GRAVITY & ABSORPTION & $\begin{array}{c}\text { INORGANIC } \\
\text { IMPURITY }\end{array}$ \\
\hline A-79 & GLACIOFLLUVIAL & 1824.5 & 2.75 & $1.83 \%$ & NONE \\
\hline A-82-SAND-R & SAND & 2.96 & $2.33 \%$ & NONE \\
\hline A-59-R & CRUSHED BASALT & 1853.3 & 1.73 & $34.3 \%$ & NONE \\
\hline
\end{tabular}

SIEVE ANALYSIS

HYDROMETER ANALYSIS

CLEAR SQUARE OPENINGS (inches)

TIME READINGS

(b)

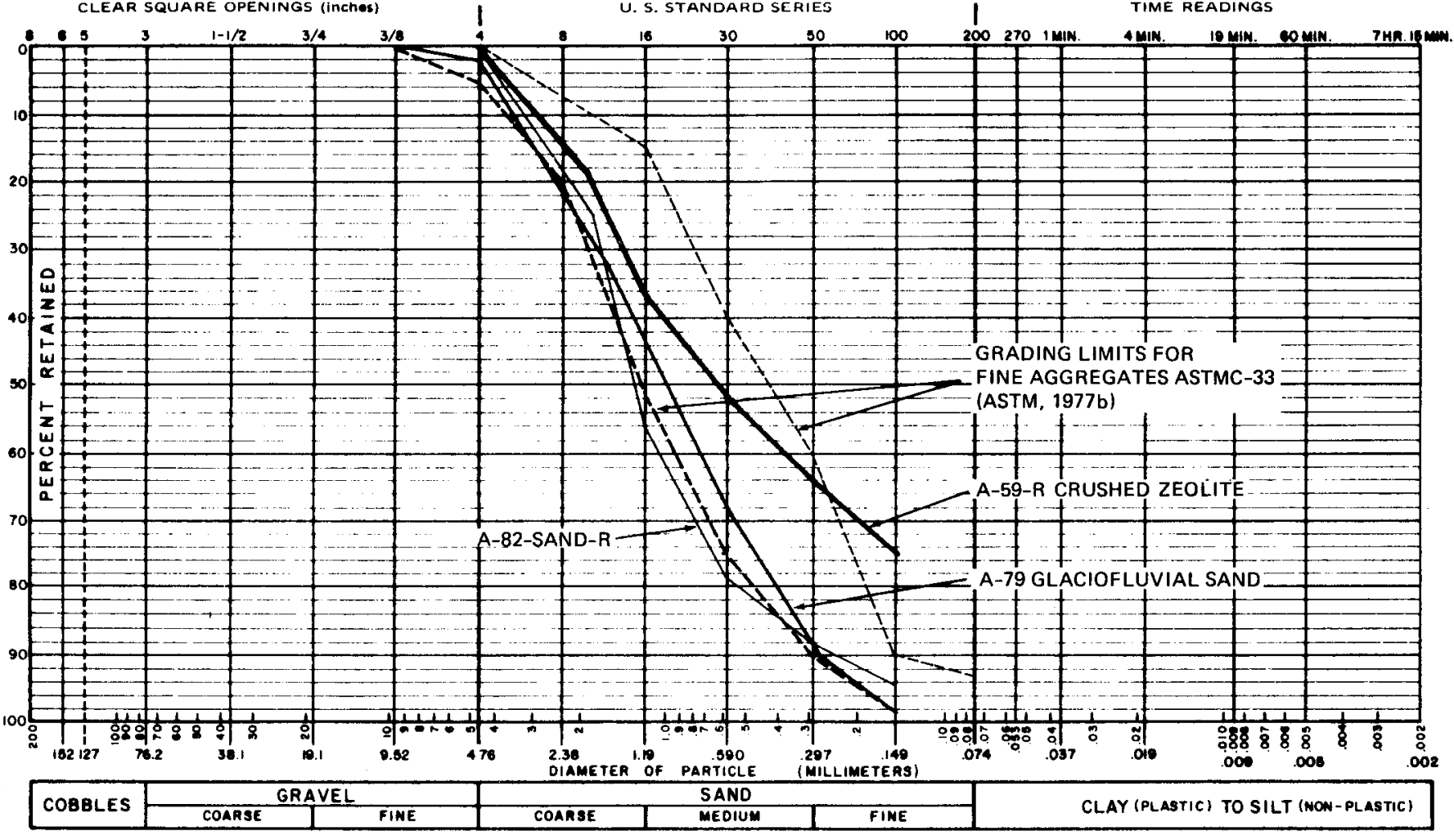

FIGURE 12

INDEX PROPERTIES OF CANDIDATE SANDS 
TABLE XIV

SUMMARY OF TEST RESULTS FOR PORTLAND POZZOLAN CEMENT MORTARS CONTAINING DIFFERENT AGGREGATE TYPES

\begin{tabular}{|c|c|c|c|c|c|c|}
\hline \multirow{2}{*}{$\begin{array}{l}\text { MIXTURE } \\
\text { NUMBER } \\
\text { BBPP-PT }\end{array}$} & \multirow{2}{*}{$\begin{array}{l}\text { COMPONENTS } \\
\text { DESCRIPTION }\end{array}$} & \multirow{2}{*}{$\begin{array}{l}\text { ADDITIVE } \\
\text { DESCRIPTION }\end{array}$} & \multicolumn{2}{|c|}{$\begin{array}{c}\text { WATER CEMENT } \\
\text { RATIO } \\
\end{array}$} & \multicolumn{2}{|c|}{$\begin{array}{l}\text { UNCONFINED } \\
\text { COMPRESSION (MPa) }\end{array}$} \\
\hline & & & W/C & \begin{tabular}{|r|} 
W/C \\
+ SILICA \\
\end{tabular} & $\begin{array}{c}\text { BOILING WATER } \\
\text { CURIING } \\
100^{\circ} \mathrm{C} \\
\end{array}$ & $\begin{array}{l}\text { AUTOCLAVE } \\
200^{\circ} \mathrm{C}\end{array}$ \\
\hline 615 & $\begin{array}{c}\text { PORTLAND } \\
\text { POZZOLAN } \\
\text { GLACIOFLUVIAL } \\
\text { SAND } \\
\end{array}$ & SILICA FLOUR & 0.56 & 0.36 & 53.3 & 101.7 \\
\hline 617 & $\begin{array}{c}\text { PORTLAND } \\
\text { POZZOLAN/ } \\
\text { CRUSHED BASALT }\end{array}$ & SILICA FLOUR & 0.56 & 0.36 & 54.3 & 98.1 \\
\hline 618 & $\begin{array}{c}\text { PORTLAND } \\
\text { POZZOLAN/ } \\
\text { CRUSHED ZEOLITE }\end{array}$ & SILICA FLOUR & 1.39 & 0.88 & 14.9 & 21.7 \\
\hline
\end{tabular}




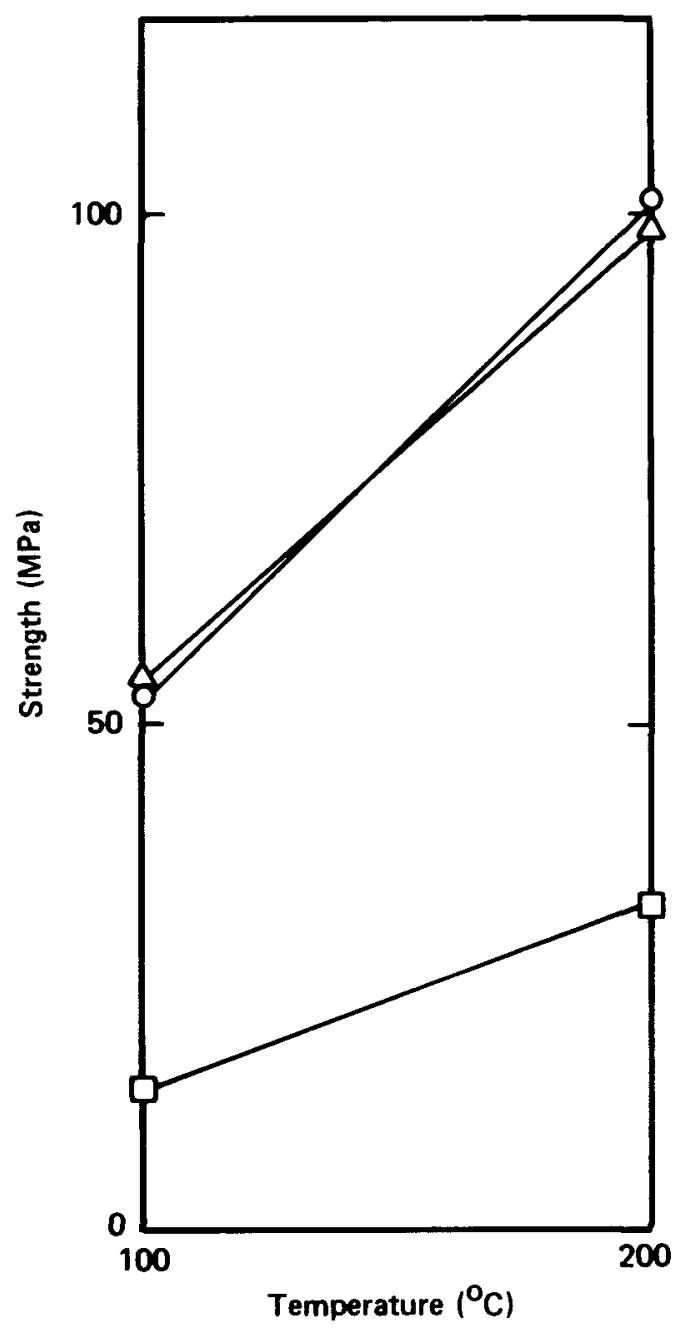

\author{
EXPLANATION \\ O Glaciofluvial sand \\ $\triangle$ Crushed basalt sand \\ $\square$ Crushed zeolite sand
}




\subsubsection{Results of Screening Tests on Cementitious Mixtures}

Calcium aluminate cement (Fondu), portland pozzolan cement, portland cement Type II with a natural pozzolan added, and TXI Chem Com cement (with or without pozzolan) show a substantial deterioration in structural strength when subjected to elevated temperature.

Portland cement Type $V$ mixed with a high-silica pozzolan (Lassenite) and Secar cement are stable and exhibit no significant change in strength with increasing curing temperature. However, strengths developed by mixtures of portland cement Type $V$ plus Lassenite are about 35 percent higher than strengths developed by mixtures of secar cement On the basis of data indicating high structural strength, the addition of finely ground silica powder to portland cements appears to be highly desirable in mixtures designed for use in high-temperature (greater than $100^{\circ} \mathrm{C}$ ) plug locations.

Large variations in reactivity were observed between the various grades of aluminum powder tested in this program. Whereas 0.070 percent -325 mesh unpolished aluminum powder by weight of cement was necessary to eliminate early shrinkage in portland cement Type $V$ mixtures, 0.03 percent of -325 polished, leafing-type aluminum powder was found to produce 8 percent free expansion in cement mixtures. Initial testing of cement mortars containing unpolished aluminum powder indicated that, for the same consistency, an increase in the aluminum powder ratio required: (1) an increase in the water/cement ratio (thus causing increased bleeding and segregation and a less dense mortar); and (2) an acceleration of the set of the mixture. The use of a WRA, Plastiment, which can reduce the amount of water required for a given cement consistency and 
also retard the rate of stiffening, is expected to improve significantly the expansive characteristics and structural behavior of mixtures containing aluminum powder. Experimental compressive strength values for specimens, which were cured at elevated temperatures and which contain both a WRA and aluminum powder, indicated that no additional deterioration was caused by either the addition of a WRA or aluminum powder. On the contrary, there was a slight increase in structural strength. The use of crushed zeolite in cement is not desirable, based on low strength results and high water demand for a given consistency. The results of tests on mortars made with either glaciofluvial or crushed basalt were similar and indicate a strong, dense, competent material.

\subsection{COMPACTED EARTH MATERIALS - SCREENING TESTS}

\section{3 .1 Background}

The feasibility of using compacted earth materials to plug boreholes has been examined by Martin (1975) for shale and montmorillonite/quartz sand mixtures. Buffer materials composed of quartz sand and bentonite and highly compressed bentonite blocks have been proposed by workers in Sweden (Swedish Nuclear Fuel Safety Project, 1979) to seal canister storage holes. In addition to blocking radioactive waste migration in ground water, compacted sandy clay mixtures are expected to provide ion exchange and sorption capabilities to help retard the migration of radionuclides through the plug system in two other ways.

In preliminary physical testing, emphasis was placed on materials readily available in the proximity of the Hanford Site. Compacted earth materials used in plugs should combine 
low permeability with low compressibility, have a high shear strength, and form a good bond with surrounding rocks. In a sand/clay mixture, impermeability is provided by the clay fraction while low compressibility and high shear strength are obtained by increasing the sand fraction. However, the addition of too much sand will affect the impermeability of the mixture. Preliminary screening tests were designed to evaluate the values and the sensitivity of selected mechanical properties (permeability and strength) to various sand/clay ratios, in order to select optimum mixtures for later testing of hydraulic properties.

\subsubsection{Candidate Earth Materials and Mixtures}

Compacted earth materials evaluated during the screening test phase and the sources for these materials are listed in Table XV. Samples for testing included mixtures of clays and glaciofluvial sand (in order to examine the properties of different clay/sand ratios) and skip-graded, coarse-crushed basalt in clay/sand mixtures (to ascertain the effect of a coarse aggregate on mixtures of fine-grained materials).

\subsubsection{Testing Program and Procedures}

Screening tests for compacted natural materials included:

- Grain size analysis, specific gravity, and relative density of non-cohesive granular materials;

- Grain size analysis, specific gravity, and Atterberg limits on clays; 
NATURAL MATERIALS USED IN SCREENING TESTS ON COMPACTED EARTH MATERIALS

\begin{tabular}{|c|c|}
\hline Seven candidate clayey soils & Source: Pasco Basin \\
\hline Oregon bentonite $(-200$ mesh $)$ & Teaque Mineral Industries \\
\hline Oregon bentonite $(-20$ to +160 mesh) & Teaque Mineral Industries \\
\hline Wyoming bentonite & Baroid National Brand \\
\hline Glaciofluvial sand & Hanford Site \\
\hline $\begin{array}{l}\text { Fine-crushed zeolite } \\
(-2.6 \mathrm{~mm})\end{array}$ & Teaque Mineral Industries \\
\hline $\begin{array}{l}\text { Fine-crushed basalt } \\
(-4.6 \mathrm{~mm})\end{array}$ & Hanford Site \\
\hline $\begin{array}{l}\text { Coarse crusheà basalt } \\
\quad(-1.9 \mathrm{~cm})\end{array}$ & Hanford Site \\
\hline
\end{tabular}


- Moisture/density relationships in mixtures after impact compaction;

- Swelling pressure under conditions of zero volume change on mixtures compacted at maximum dry density and at the optimum water content; and

- Determination of stress-strain relationships under unconfined compression for candidate mixtures compacted to the maximum dry density at the optimum water context.

The procedures used in testing compacted earth materials included both standard published procedures and special test methods developed and described in the quality Assurance program. A list of the procedures is given in Table XVI. The special test methods that were used in this study and that have no published reference, are described in more detail here.

5.3.3.1 Maximum/Minimum Density of Non-Cohesive Granular Material

Minimum density is first determined on an oven-dried sample by pouring the sample into a cylindrical mold $17 \mathrm{~cm}$ in diameter by $12.7 \mathrm{~cm}$ in height) through a $2.5-\mathrm{cm}$ diameter pouring spout of a funnel with a spiral motion from the outside toward the center until the mold is filled to overflowing capacity. The excess material is then struck off, and the weight of the material is recorded. This procedure is repeated a minimum of three times, and an average minimum density value is calculated.

The same volume mold is used to determine the maximum density. A porous stone is placed on the bottom of the mold, and the mold is filled with water to one-third of its 
TESTING PROCEDURES APPLIED TO COMPACTED EARTH MATERIALS

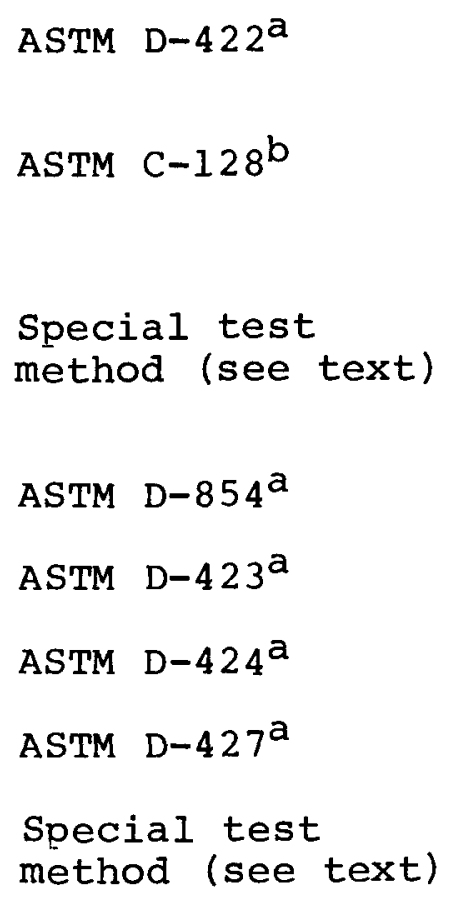

Particle size analysis of soils

Specific gravity and absorption of fine aggregate

Maximum/minimum density of non-cohesive granular material

Specific gravity of soils

Liquid limit of soils

Plastic limit of soils

Shrinkage factors of soils

Moisture/density relation of soil using a $4.5-\mathrm{kg}$ rammer and a 45-cm drop (tested in a $6.25-\mathrm{cm}$ diameter mold)

Determination of the swelling pressure under conditions of zero volume change

Unconfined compressive strength of cohesive soils 
capacity. The oven-dried soil is then added to fill the mold to within $3.8 \mathrm{~cm}$ of the top. A porous stone is placed on the upper end of the sample, and a spring is placed on the porous stone so that when the mold cap is bolted in place, there is a surcharge equivalent to $141 \mathrm{~g} / \mathrm{cm}^{2}$. A vacuum of about $0.1 \mathrm{MPa}$ is then applied to the lower end of the mold, and the upper end is open to the atmosphere. The mold is then vibrated at a Erequency of approximately 30 impact vibrations per minute, and the energy expended is approximately $2 \mathrm{kilonewton}-\mathrm{m} / \mathrm{m}^{3}$ per cycle. This energy and frequency are maintained until all excess water is removed from the mold and no further reduction in height can be observed. The height and weight of the sample are recorded, and the maximum dry density is calculated after the sample is oven-dried.

\subsubsection{Impact Compaction}

A method was designed to standardize the compaction process to be used on sand/clay and sand/clay/coarse-aggregate mixtures throughout the testing program. This method is sensitive to a maximum particle diameter in a sample when testing the strength and the swelling of soil samples with standard laboratory soil testing equipment. During compaction, densification is achieved by impacting the $5-\mathrm{cm}$ diameter tamper foot of a standard $4.5-\mathrm{kg}$ rammer concentrically into a $6.35-\mathrm{cm}$ diameter mold. Impact, height, and the number of lifts compacted in each sample are the same as for ASTM D-1557 standard procedure (ASTM, 1978b). Trie only difference between the two procedures is the size of the mold, which is $10.16 \mathrm{~cm}$ in diameter in ASTM D-1557. Comparative tests were carried out on a pure clay specimen and on a $-1.9-\mathrm{cm}$ coarse-crushed basalt/sand/clay mixture using both compaction methods. As shown in Figure 14, no significant difference was observed for the optimum water 


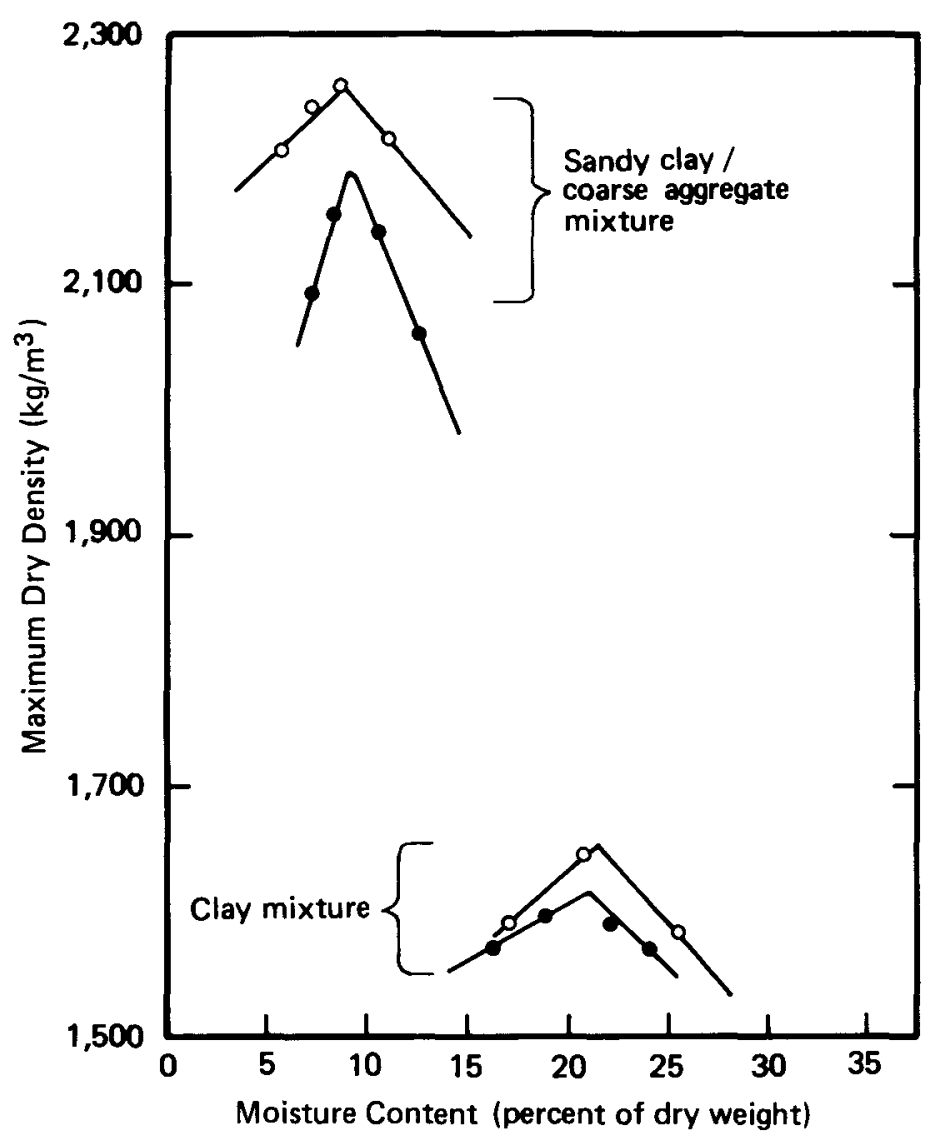

\section{EXPLANATION}

- Impact compaction ASTM D-1557

in a $10.16-\mathrm{cm}$ diameter mold

- Special compaction in a $6.35-\mathrm{cm}$ diameter mold 
content. A greater densification is obtained in the $6.35-\mathrm{cm}$ diameter mold for both mixtures, and the difference in maximum dry density between the two compactive methods is greater for larger, maximum aggregate size, indicating that good, standardized compaction can be obtained on coarse aggregate mixtures.

\subsubsection{Discussion of Screening Tests on Candidate Clayey Soils from near the Hanford site}

5.3.4.1 Index Tests and Field Reconnaissance

Atterberg limits were performed on representative composite samples of several fine-grained units in the Pasco Basin to provide a preliminary evaluation of the suitability of these clays as candidate cohesive materials. Criteria for this preliminary evaluation included high plasticity, good accessibility, homogeneity, and sufficient nominal thickness of the unit to assure availability in case of later use as an actual plug material (Figure 15). Atterberg limits, soil classifications, and first estimation of accessibility, homogeneity, and bulk availability of the units sampled are summarized in Figure 15c. Two clayey soils were selected as potential cohesive materials: (l) clayey soil from Unit $D$ (Ringold clay D) because of its high plasticity combined with a satisfactory bulk availability, homogeneity, and accessibility; and (2) clayey soil from Unit C (Ringold clay C), which is of an inorganic clay of medium plasticity and moderate compressibility. 
(a) Descriptive evaluation of bulk availability, homogeneity, and accessibility

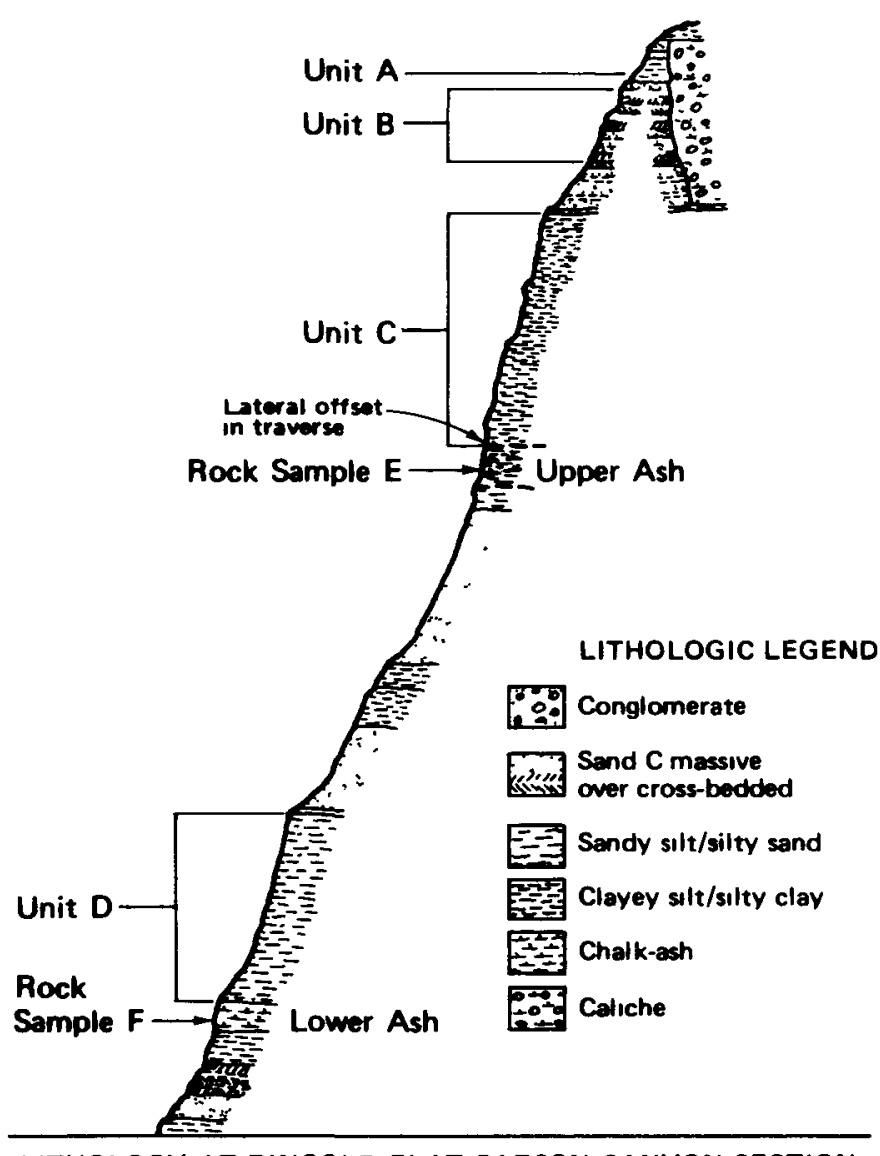

(b) Plasticity evaluation

Liquid Limit (LL)

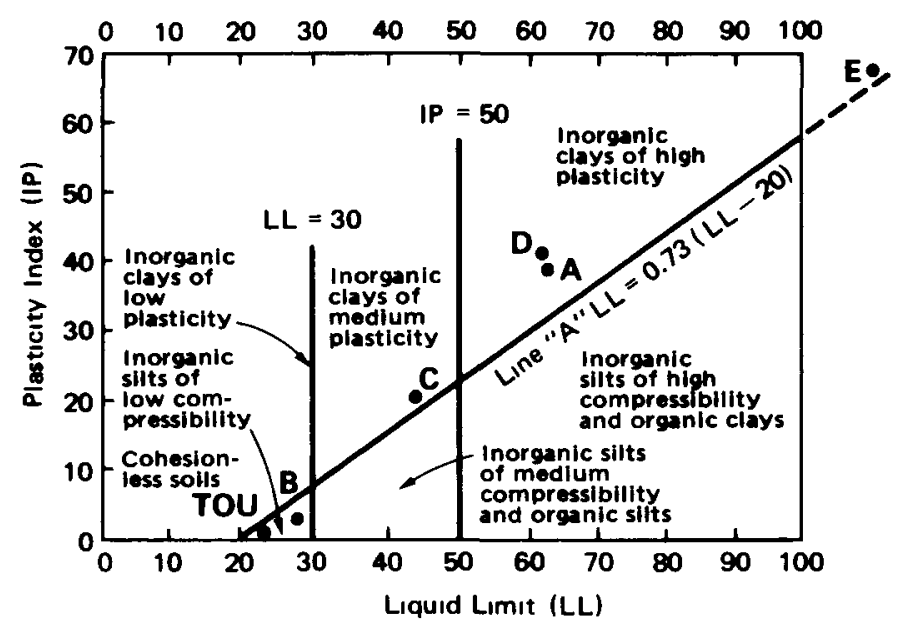

LITHOLOGY AT RINGOLD FLAT-PARSON CANYON SECTION

(c) Ringold clayey soil sample selection

\begin{tabular}{|c|c|c|c|c|c|c|}
\hline $\begin{array}{l}\text { Sample } \\
\text { Number }\end{array}$ & $\begin{array}{c}\text { Unit } \\
\text { (i.e., lithology) }\end{array}$ & $\begin{array}{l}\text { Liquid } \\
\text { Limit }\end{array}$ & $\begin{array}{l}\text { Plastic } \\
\text { Limit }\end{array}$ & $\begin{array}{l}\text { Plastic } \\
\text { Index }\end{array}$ & $\begin{array}{c}\text { Soil } \\
\text { Classification }\end{array}$ & $\begin{array}{l}\text { Availability } \\
\text { Accessibility } \\
\text { Homogeneity }\end{array}$ \\
\hline$A-62$ & A & 62.2 & 23.6 & 38.6 & $\mathrm{CH}$ & slight \\
\hline$A-63$ & B & 27.6 & 24.2 & 3.4 & $M L$ & fair \\
\hline$A-64$ & $\mathrm{C}$ & 44.6 & 25.8 & 18.8 & $\mathrm{CL}$ & good \\
\hline$A-66$ & $\bar{D}$ & 63.9 & 23.1 & 40.8 & $\mathrm{CH}$ & good \\
\hline$A-67$ & $E$ & 112.5 & 44.6 & 67.9 & $\mathrm{MH}-\mathrm{CH}$ & questionable \\
\hline$A-68$ & $F$ & & NON & ASTIC & & slight \\
\hline$A-69$ & $\begin{array}{l}\text { Touchet } \\
\text { Formation } \\
\text { (TOU) }\end{array}$ & 22.9 & 22.4 & 0.5 & ML & good \\
\hline
\end{tabular}

FIGURE 15

SELECTION CRITERIA AND DATA RESULTS

FOR THE CANDIDATE RINGOLD CLAYEY SOILS 


\subsubsection{Mechanical Properties}

Compaction tests and unconfined compression tests were carried out on Ringold clays $C$ and $D$ (Figure 16). The compaction curves (Figure 16a) indicated that slightly higher densification was obtained on Ringold clay $D$, although a low maximum dry density was observed $(1,650 \mathrm{~kg} / \mathrm{m} 3)$, indicating poor compactibility for this material. Unconfined compression curves (Figure 16b) for the two clay materials also showed that Ringold clay $D$ has higher strength and stiffness. The high optimum water content suggests further potential difficulty when using standard field compaction methods. An alternative candidate material is produced by mixing Ringold clay with sand, thus reducing the amount of water required and increasing the dry density. However, field mixing of Ringold clay with sand would probably be somewhat difficult and costly.

In conclusion, Ringold clay $D$ was selected for further testing based on index test data, geological reconnaissance, and its mechanical properties. The screening process compared the performances of selected samples from near the Hanford site in the Pasco Basin, and Ringold clay $D$ was considered to perform best of those cohesive soil materials screened. Although Ringold clay $D$ may have potential use as a plug material when compared with clayey soils from other regions, this material was not considered exceptional because of its high silt content, high shrinkage limit, and relatively low maximum dry density after compaction. 


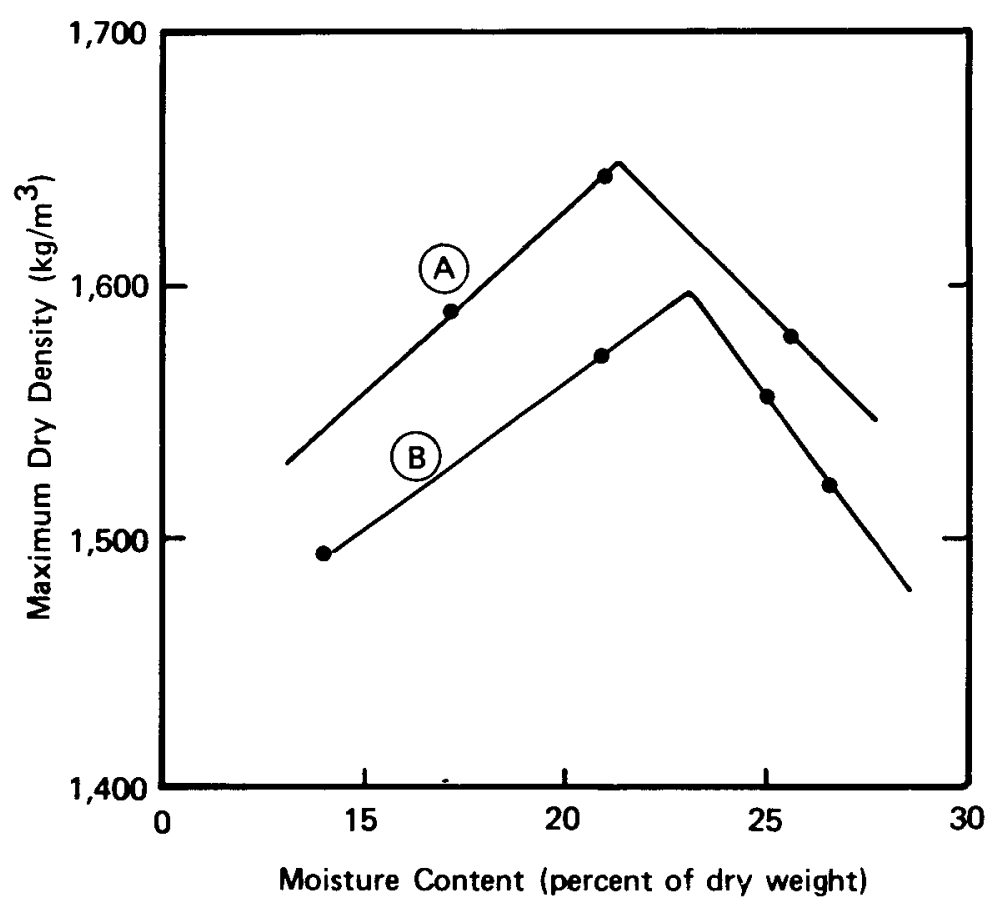

(a) Compaction curves for candidate Ringold clays

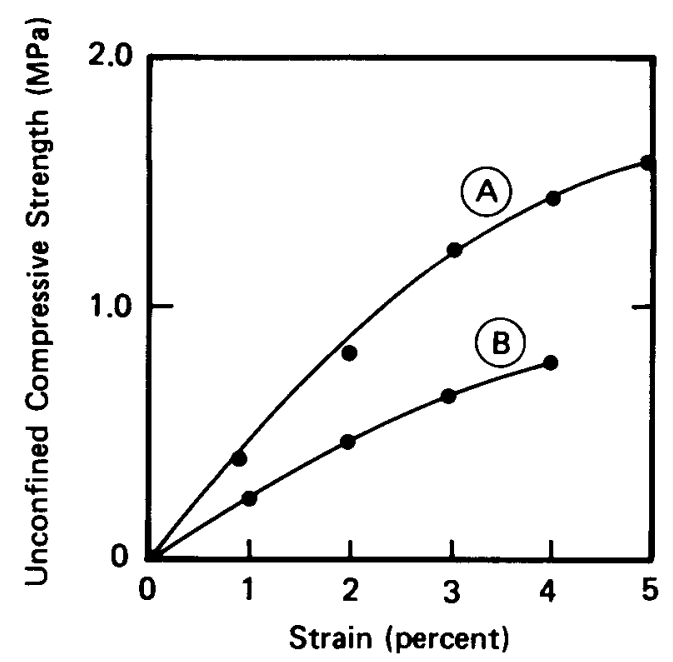

EXPLANATION

(A) Ringold clay D

(B) Ringold clay $\mathrm{C}$

(b) Unconfined compressive strength curves for candidate Ringold clays 


\subsubsection{Discussion of Screening Test on Candidate Non-Cohesive Granular Materials}

Grain size distributions of candidate non-cohesive granular inaterials are presented in Figures 12 and 17. Table XVII gives the index properties of these materials. As was discussed in Section 5.2.4.4, crushed basalt and glaciofluvial sand have the properties of strong and competent aggregates. If used in compacted backfill, they will provide structural strength and volumetric stability. By contrast, crushed zeolite has a low unit weight, low specific gravity, and high porosity. Breakdown was observed during the blending of composite zeolite samples. Because of the high ion exchange and sorption capacity of crushed zeolite, it will be retained for consideration as a candidate material to improve the performance of compacted backfill in inhibiting radionuclide migration. Crushed basalt and glaciofluvial sand remain the preferred candidates for use as aggregates in compacted cohesive mixtures in potential plugs.

5.3 .6 Discussion of Screening Tests on the Index Properties of Candidate Clays

Tests were performed to determine the index properties of four candidate clays: two Oregon bentonites; one Wyoming bentonite; and Ringold clay D. Results are presented in Figure 18a. Relationships between liquid limit and plasticity index (Figure 18b) and values of activity (Figure 18c) are given for various clay minerals. In the following discussion, clay activity, as defined by skempton (1953), is the ratio of the plasticity index to the amount of the clay fraction (defined as the percentage dry weight of the $-2-m m$ fraction of the sample). Wyoming bentonite has a high plasticity index and 


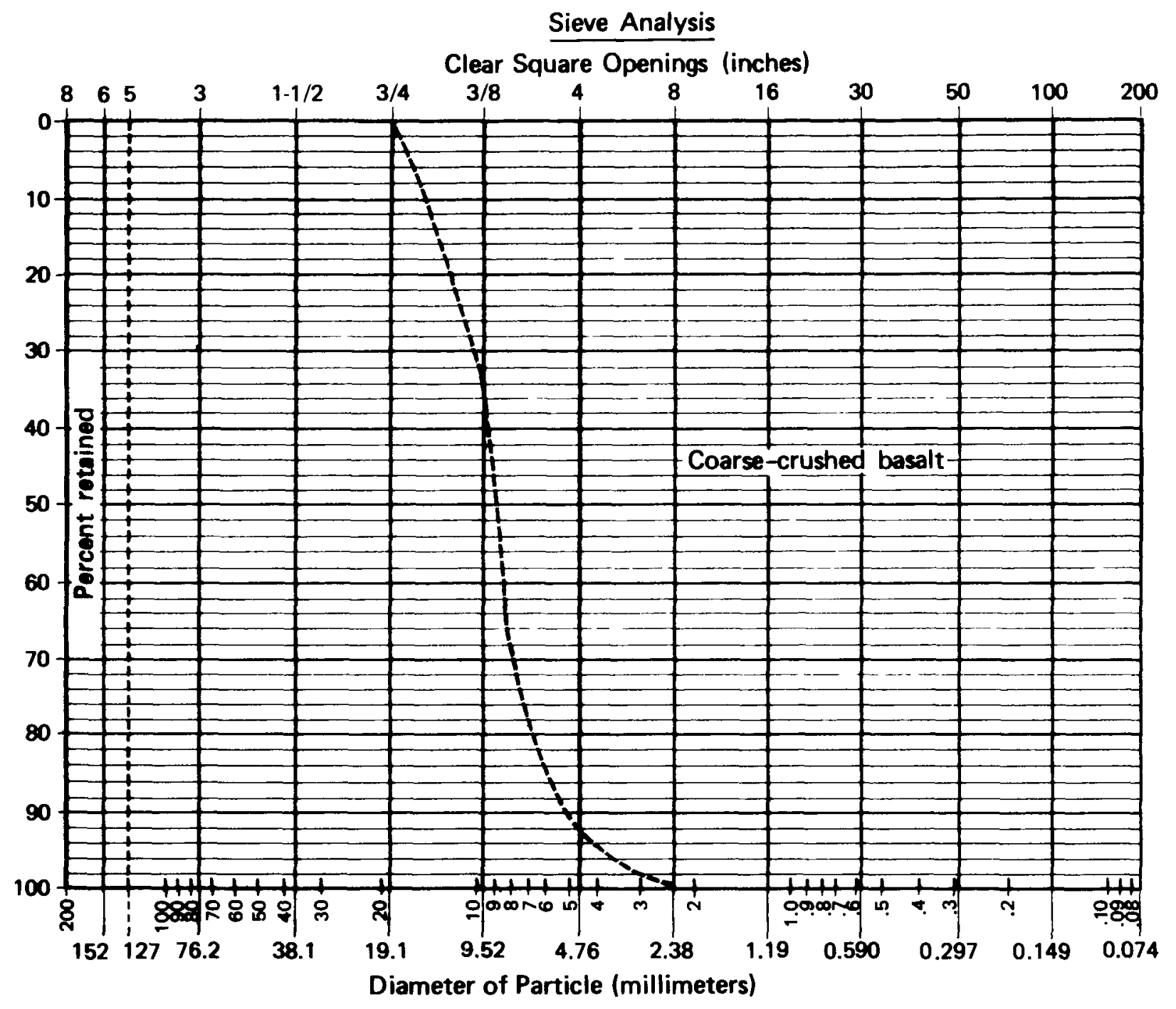

\begin{tabular}{|l|l|l|l|l|l|}
\hline \multirow{2}{*}{ Cobbles } & \multicolumn{2}{|c|}{ Gravel } & \multicolumn{3}{c|}{ Sand } \\
\cline { 2 - 5 } & Coarse & Fine & Coarse & Medium & Fine \\
\hline
\end{tabular}


TABLE XVII

INDEX PROPERTIES OF CANDIDATE NON-COHESIVE GRANULAR MATERIALS

\begin{tabular}{|c|c|c|c|c|}
\hline MATERIAL DESCRIPTION & $\begin{array}{c}\text { MAXIMUM } \\
\text { DENSITY } \\
\left(\mathrm{kg} / \mathrm{m}^{3}\right)\end{array}$ & $\begin{array}{c}\text { MINIMUM } \\
\text { DENSITY } \\
\left(\mathrm{kg} / \mathrm{m}^{3}\right)\end{array}$ & $\begin{array}{c}\text { GRAIN } \\
\text { POROSITY }\end{array}$ & $\begin{array}{c}\text { SPECIFIC } \\
\text { GRAVITY }\end{array}$ \\
\hline COARSE-CRUSHED BASALT & $1,619.5$ & $1,358.4$ & 2.3 & 2.84 \\
\hline FINE-CRUSHED BASALT & $1,911.0$ & $1,444.9$ & 2.3 & 2.84 \\
\hline GLACIOFLUVIAL SAND & $1,935.0$ & $1,704.4$ & 1.83 & 2.75 \\
\hline FINE-CRUSHED ZEOLITE & & & 34.3 & 1.73 \\
\hline
\end{tabular}


(a) Index properties of candidate clays

\begin{tabular}{|l|c|c|c|c|c|c|c|c|}
\hline Clay Description & $\begin{array}{c}\text { Liquid } \\
\text { Limit } \\
(\mathrm{LL})\end{array}$ & $\begin{array}{c}\text { Plastic } \\
\text { Limit } \\
(\text { LP) }\end{array}$ & $\begin{array}{c}\text { Plastic } \\
\text { Index } \\
(\mathrm{Ip})\end{array}$ & $\begin{array}{c}\text { Shrinkage } \\
\text { Limit } \\
(\%)\end{array}$ & $\begin{array}{c}\text { \% of soil } \\
\text { finer than } \\
-74 \mu \mathrm{m}\end{array}$ & $\begin{array}{c}\% \text { of soil } \\
\text { finer than } \\
2 \mu \mathrm{m}\end{array}$ & $\begin{array}{c}\text { Activity } \\
\text { Ip } \\
(\%<2 \mu)\end{array}$ & $\begin{array}{c}\text { Specific } \\
\text { Gravity } \\
\left(\mathrm{g} / \mathrm{cm}^{3}\right)\end{array}$ \\
\hline Wyoming bentonite & 553.1 & 33.6 & 519.5 & 07 & 98.03 & $\leq 98$ & $\geq 5.3$ & 2.77 \\
\hline $\begin{array}{c}\text { Oregon bentonite } \\
-200 \text { mesh }\end{array}$ & 212.69 & 38.1 & 174.6 & 8.96 & 99.21 & $\leq 99$ & $\geq 1.76$ & 2.85 \\
\hline $\begin{array}{l}\text { Oregon bentonite } \\
20 \text { to 160 mesh }\end{array}$ & 209.6 & 41.0 & 168.58 & 8.47 & 98.13 & $\leq 98$ & $\geq 1.72$ & 2.73 \\
\hline Ringold clay D & 63.9 & 23.1 & 40.8 & 19.75 & 94.58 & 26 & 1.57 & 2.71 \\
\hline Ringold clay C & 44.6 & 25.8 & 18.8 & - & - & - & - & - \\
\hline
\end{tabular}

(b) Liquid limit versus plasticity index from various clay minerals (from Grim, 1962)

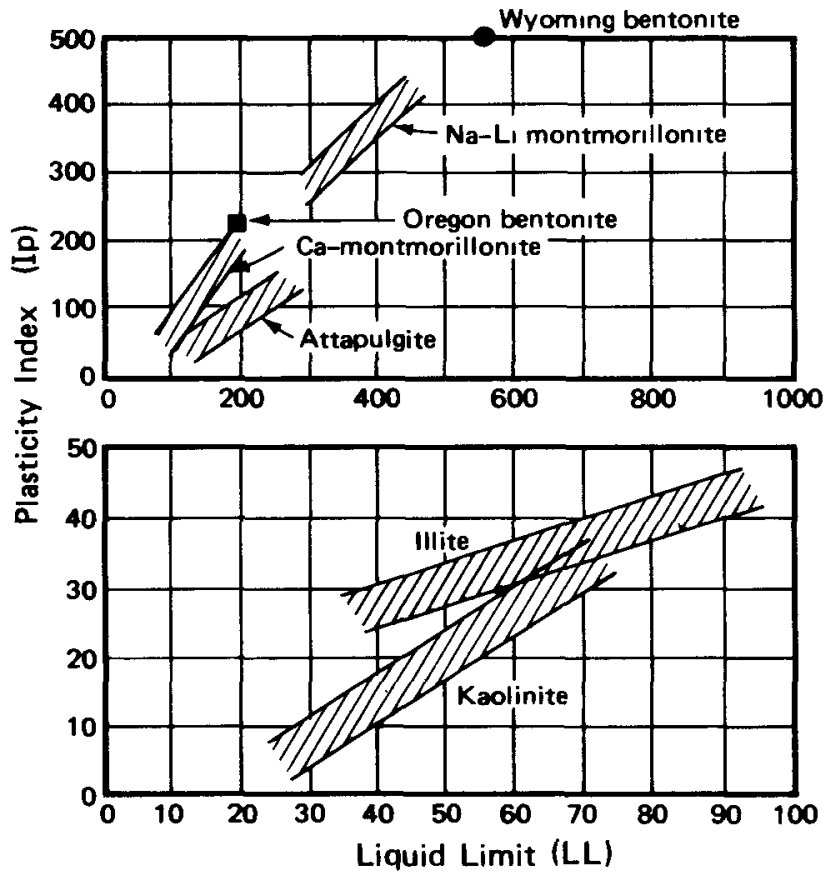

(c) Activity of clay minerals (from Kezdi, 1974)

\begin{tabular}{|l|c|}
\hline TYPE OF MINERAL & $\begin{array}{c}\text { ACTIVITY } \\
\text { Ip/Clay Content }\end{array}$ \\
\hline Quartz & $0 .-$ \\
Calcite & 0.18 \\
Muscovite & 0.23 \\
Kaolinite & 0.46 \\
Illite & 0.90 \\
Ca-montmorillonite & 1.5 \\
Na-montmorillonite & 7.5 \\
\hline
\end{tabular}


activity. The two Oregon bentonites exhibit significantly lower values for these properties. As shown on Figure 18b, Wyoming bentonite has the characteristics of a sodium montmorillonite, while the two Oregon bentonites are similar to a calcium montmorillonite. Results from geochemical testing (Section 4.5 .2 ) also indicate that oreyon bentonite is more calcic than wyoming bentonite. This distinction is important because the sodium form of montmorillonite exhibits considerably less permeability than the calcium form. Results given by Grim (1962) show that when 50 percent sodium bentonite is present in a quartz sand, the resulting clayey mixture is essentially impervious, while for the same proportions, mixtures made with calcium bentonite have a permeability coefficient of $5 \times 10^{-7} \mathrm{~cm} / \mathrm{sec}$.

Although analytical data are not available, Ringold clay D, which has an activity of 1.57 (Plasticity Index divided by clay content), is thought to be primarily composed of smectite clay, which generally exhibits an activity between 1 and 7 (Mitchell, 1976). However, the high percentage of silt present in this soil material and its high shrinkage factor could affect the bond strengths of candidate plug mixtures containing this material.

\subsubsection{Evaluation of the Mechanical Properties of Candidate Sand/Clay Mixtures}

Compaction, unconfined compression, and swelling tests were carried out on candidate cohesive mixtures for various clay/sand sample ratios using glaciofluvial sand as aggregate and Wyoming bentonite, Oregon bentonite, or Ringold clay $D$ as binding materials. These tests were designed to evaluate the variation in mechanical properties with the amount of clay (versus sand) present in the mixture. 


\subsubsection{Compaction of Candidate Sand/Clay Mixtures}

Figure 19 gives the compaction curves for 12 candidate clay mixtures composed of the various clays and glaciofluvial sand, with the proportion of sand ranging from 10 to 70 percent by weight when mixed with the bentonites and from 10 to 50 percent when mixed with Ringold clay. As explained in Section 5.3.3.2, compaction tests were carried out in a $6.35-\mathrm{cm}$ mold. Prior to compaction, clay and sand were thoroughly dry mixed. Water was then thoroughly admixed, and the mixtures were stored for three days in plastic bags to allow hydration of the clay fraction.

Figure 20 shows the relationship between the maximum dry density and clay content of Wyoming, oregon, and Ringold clay/sand mixtures. For clay contents ranging from 10 to 70 percent (alternatively 10 to 50 percent for Ringold clay D), the curves are linear and decreasing. For equivalent clay contents, mixtures containing Wyoming bentonite were found to be denser than mixtures made with Ringold clay; likewise, mixtures containing Oregon bentonite were denser than those containing wyoming bentonite. The density difference between each of the three types of mixtures increased with increasing clay content. It is useful to note that even with 50 percent Wyoming bentonite (alternatively 30 percent oregon bentonite), a soil density representative of competent engineered fills was obtained (greater than or equal to $2,000 \mathrm{~kg} / \mathrm{m}^{3}$ ). This result suggests that suitable compaction of nearly impervious clayey mixtures is feasible by standard compactive methods. Finally, the -200 mesh Oregon bentonite and the $-20 /+100$ mesh Oregon bentonite were compacted in two separate mixtures with 70 percent glaciofluvial sand in order to study the influence of clay-fraction grain size on compaction. No significant 


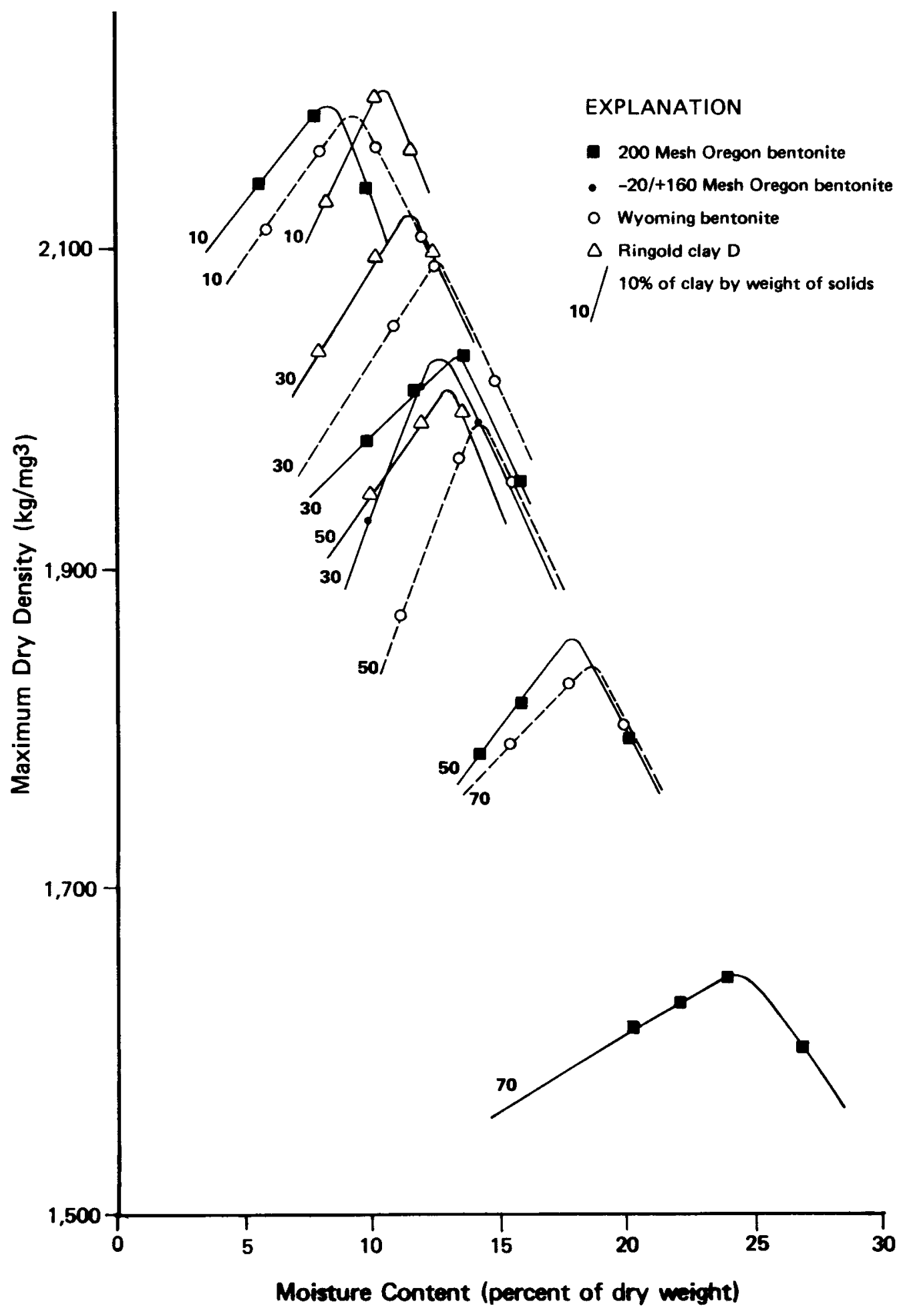

FIGURE 19

COMPACTION CURVES FOR CANDIDATE SAND/CLAY MIXTURES 


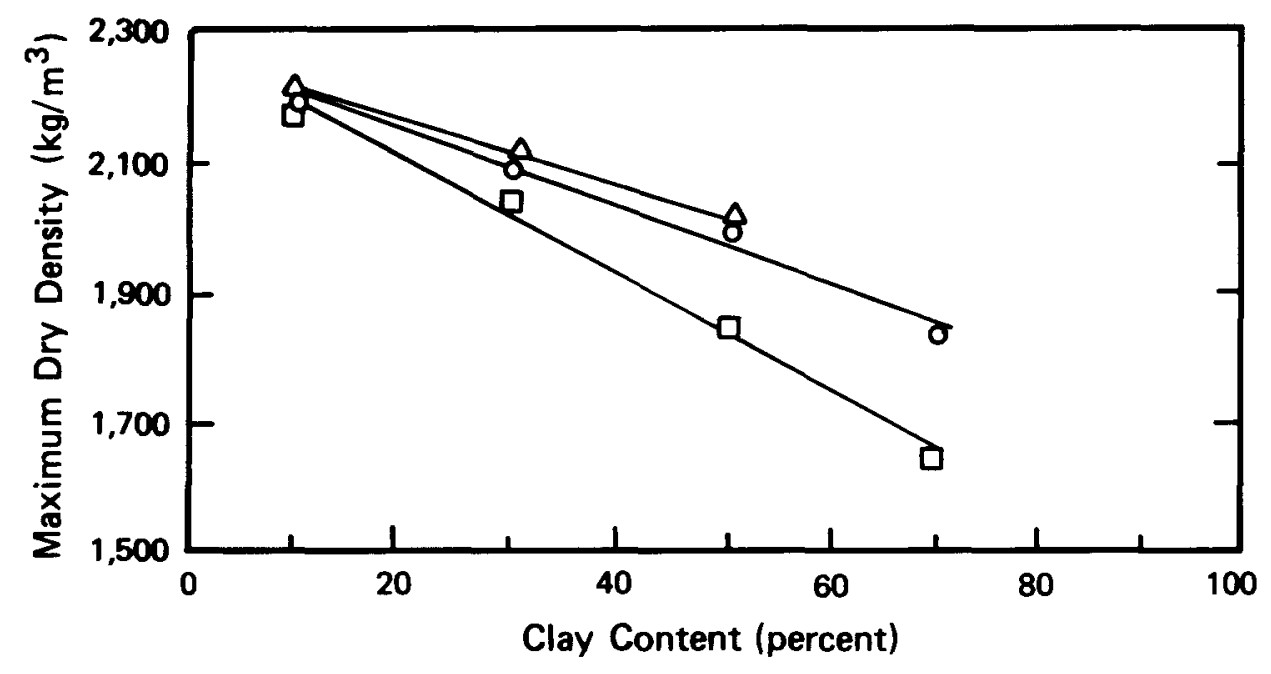
EXPLANATION
- Wyoming bentonite
$\square$ Oregon bentonite
$\Delta$ Ringold clay $D$ 
difference was observed either in dry density or in optimum water content between the $f$ ine and coarse bentonite mixtures.

\subsubsection{Swelling Pressure of Candidate Bentonite Mixtures}

Swelling tests were performed in a consolidometer apparatus on 10 cohesive mixtures in order to estimate the maximum swelling pressure at constant volume for each mixture compacted at the maximum dry density and at the optimum water content, as determined during compaction tests (Section 5.3.3.2). Additional water is made available to the sample during a swelling test through a saturated porous end plate. Curves illustrating the relationship between maximum swelling pressure and percentage of clay in clay/sand mixtures are shown on Figure 21 for the Oregon and Wyoming bentonites.

Figure 21 shows that the Oregon and Wyoming bentonite/sand mixtures have a similar swelling response. The swelling pressure at constant volume is negligible for clay contents less than or equal to 10 percent. For clay contents ranging from 10 to 70 percent, an almost exponential increase of swelling pressure is observed with increasing clay content. For a clay content of 70 percent, swelling pressures as high as 2 MPa were developed. For bentonite content more than or equal to 50 percent, the swelling pressure developed by a confined specimen was such that it was found difficult to constrain it perfectly; a small amount of expansion occurred during the night which had to be corrected the next morning by increasing the loading pressure. As noted by Martin (1975), a small expansion during the test can have a large influence on the measured value of the swelling pressure. Therefore, the measured swelling pressures should be considered as minimum and approximate. 


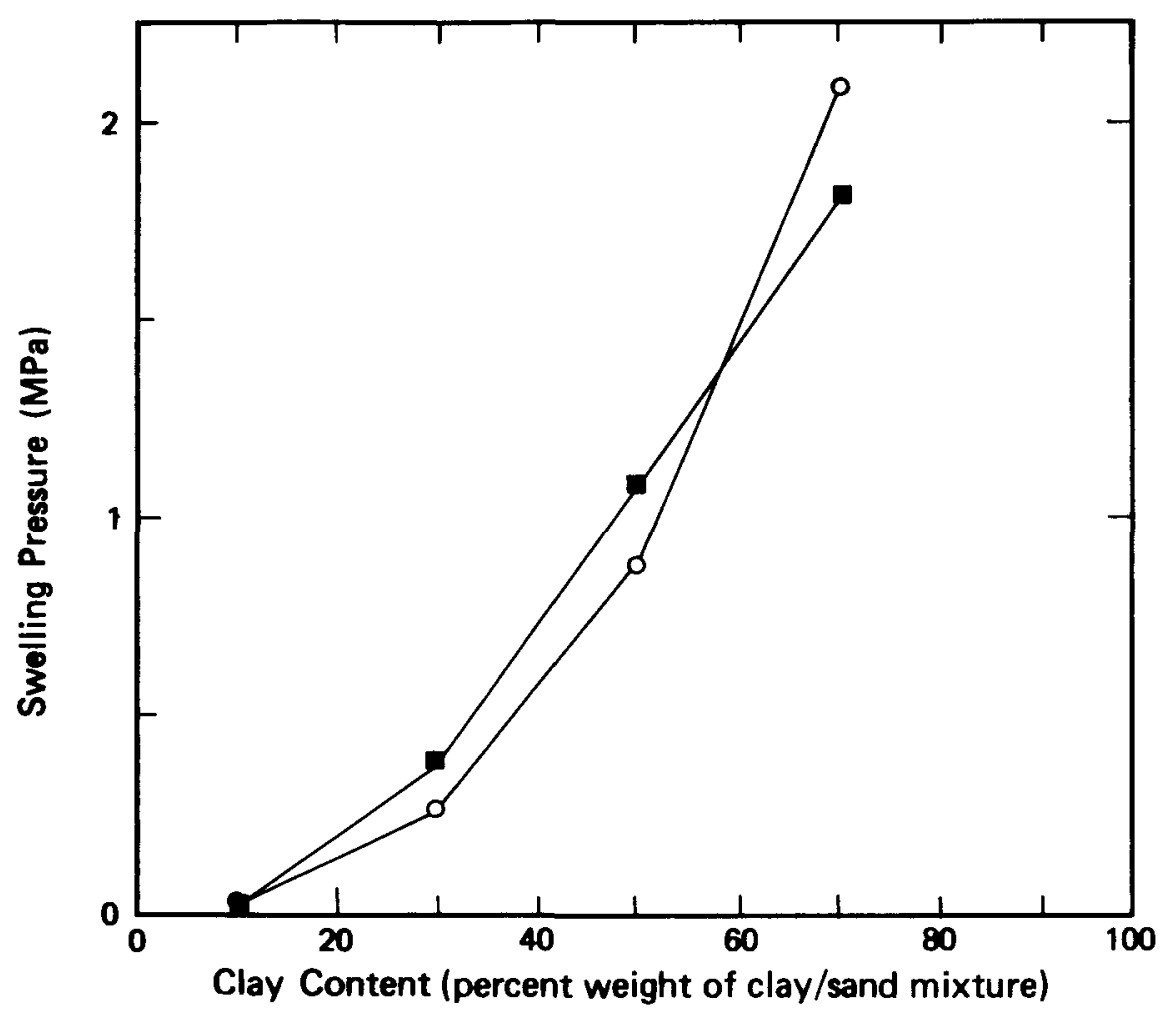

EXPLANATION

- Wyoming bentonite

- Oregon bentonite 
Swelling pressure of Ringold clay/sand mixtures was not studied except for a clay content equal to 10 percent where no swelling was observed. However, a lower swelling pressure is expected for Ringold clay (versus bentonites) considering the high silt content of Ringold clay.

\subsubsection{Rigidity and Cohesion of Candidate Sand/Clay Mixtures}

Unconfined compressive tests, including the determination of stress-strain relationships and maximum compressive strengths, were performed on the 10 candidate mixtures compacted at maximum dry density and optimum water content. These tests were designed to evaluate the strength behavior of clay/sand mixtures. In general, high strength and stiffness would be desirable in compacted soil mixtures used in plug designs because the plug material should provide restraint to the surrounding wall rock, which may be under lithostatic and thermomechanical loads. The behavior of this material should be as elastic as possible to maintain the best possible contact with the wall rock.

Figures 22 and 23 present curves showing the variation in unconfined compressive strength and the variation in Young's Modulus with varying clay content. Young's Modulus is taken as the tangent to the stress-strain curve at one percent strain. A notable result was the observed difference in behavior between bentonite/sand mixtures and Ringold clay/sand mixtures. For a clay content of 10 percent, the bentonite mixtures developed strengths 10 times higher and a Young's Modulus eight times greater than Ringold clay/sand mixtures. This result shows the exceptionally high strength of bentonite clays. As expected, mixtures containing oregon bentonite 


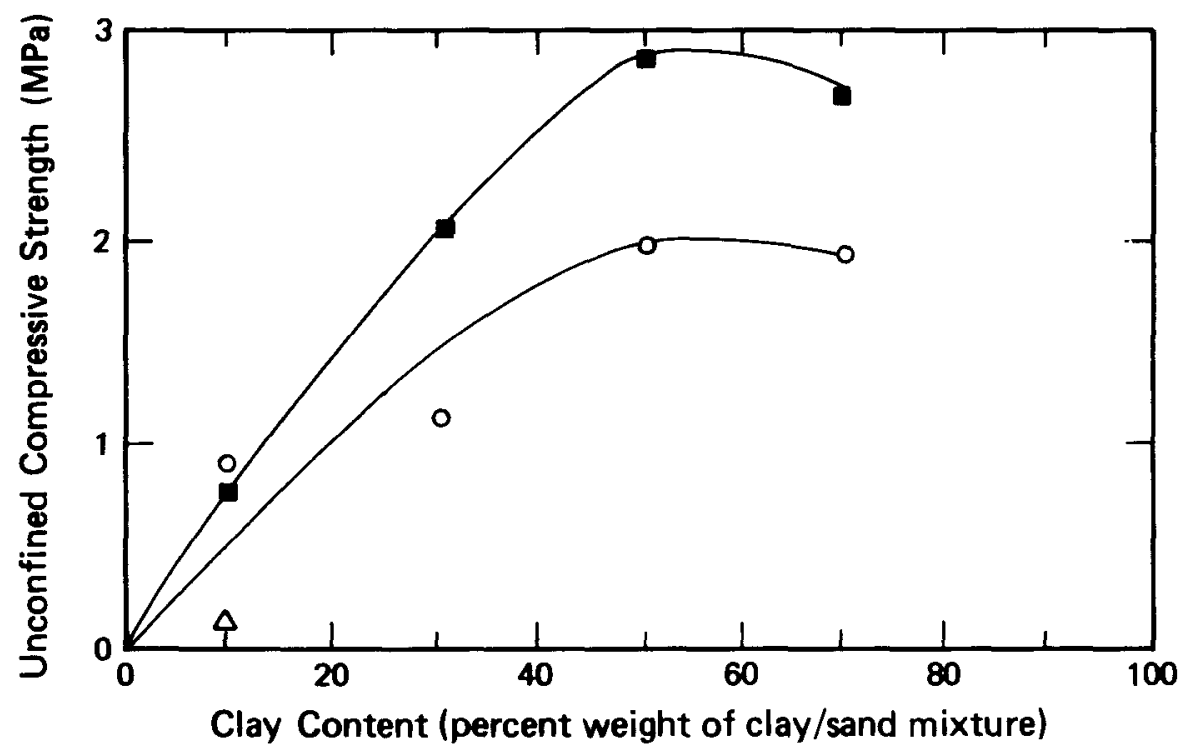
EXPLANATION
- Wyoming bentonite
- Oregon bentonite
$\Delta$ Ringold clay D 


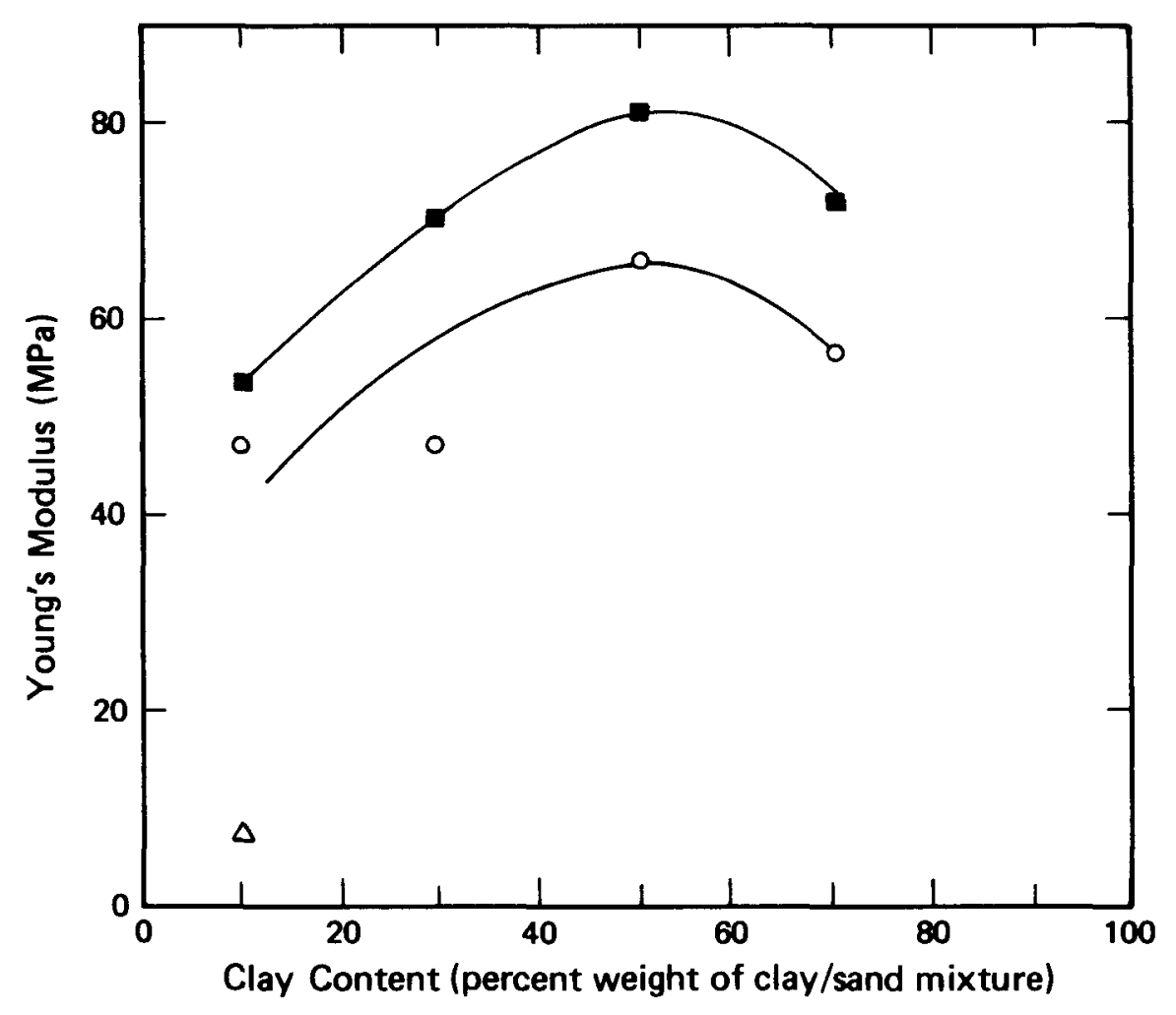

EXPLANATION

- Wroming bentonite

- Oregon bentonite

$\triangle$ Ringold clay D 
developed higher strength and had greater stiffness than those containing Wyoming bentonite. Data published by Grim (1962) indicate that the calcium form of montmorillonite gives the highest strength of all clays when mixed with sand. For clay contents varying from 10 to 50 percent, strength and stiffness increased with increasing clay content. For clay contents varying from 50 to 70 percent, a slight decrease was observed for both parameters with increasing clay content. Maximum values of strength and Young's Modulus were observed for a clay content of 50 percent. Compressive strength and Young's Modulus are exceptionally high, and an unconfined compressive strength of $2.9 \mathrm{MPa}$ with a Young's Modulus of $80 \mathrm{MPa}$ were observed for one Oregon bentonite/sand mixture.

\subsubsection{Design and Evaluation of Skip-Graded Aggregate/Clay Mixtures}

5.3.8.1 Design of Skip-Graded Aggregate/Clay Mixtures

Skip-graded, coarse-crushed basalt/sand/clay mixtures for potential use in backfill were designed and tested. Materials in these mixtures were composed of $-1.9 \mathrm{~cm}$ coarse-crushed basalt, glaciofluvial sand, and various clays. A clay/sand ratio of 50 percent was chosen to provide an essentially impervious and self-healing binder. The following three mixtures were tested, and the proportions of the various components are given as weight percents in parentheses:

- Coarse-crushed basalt (68 percent)/Oregon bentonite ( 16 percent)/glaciofluvial sand (16 percent). In this mixture, the coarse aggregate/sand/clay ratio was selected so that the bentonite/sand mixture filled the void spaces within the aggregate when compacted at its 
maximum density. This sample simulated a grain-support framework and was intended to combine relatively low permeability with low compressibility;

- Coarse-crushed basalt (66 percent)/crushed zeolite (17 percent)/Ringold clay (17 percent). In this mixture, crushed zeolite and Ringold clay were substituted for glaciofluvial sand and oregon bentonite, respectively. The purpose of this substitution was to examine the possibility of using a clay available near the Hanford Site in combination with a material having a high ion exchange potential. This mixture is intended for use in backfill designed to retard radionuclide migration and, at the same time, provide some structural strength; and

- Coarse-crushed basalt (50 percent)/glaciofluvial sand (25 percent)/Wyoming bentonite (25 percent). In this mixture, the coarse aggregate/sand/clay ratio was designed with a high percentage of clay in order to simulate a matrix support fabric (with clay as the matrix). This mixture is primarily designed to be an almost impervious backfill that has substantial selfhealing potential.

5.3.8.2 Evaluation of the Mechanical Properties of Skip-Graded Aggregate/Clay Mixtures

No swelling tests were attempted on these candidate mixtures; special test equipment would be necessary for the maximum aggregate sizes considered in these tests. Results on compaction and unconfined compression tests are given in Figure 24 . 


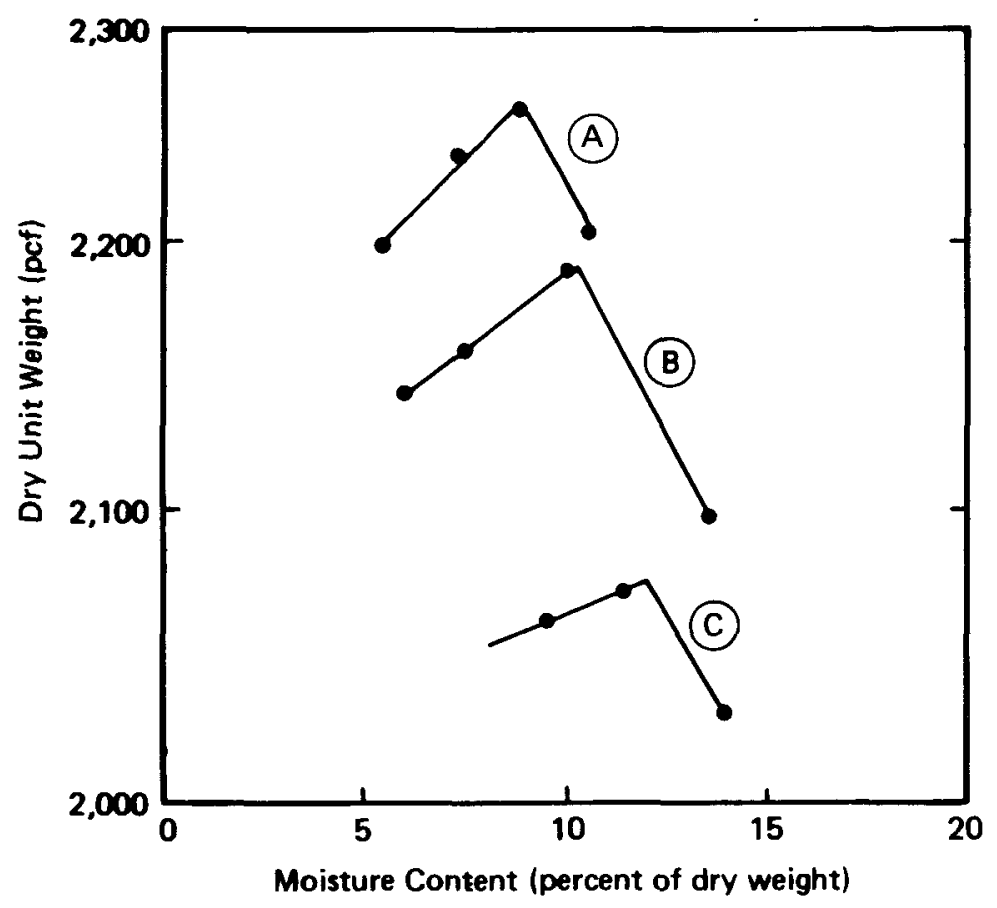

(a) Compaction curves for skip-graded aggregate/clay

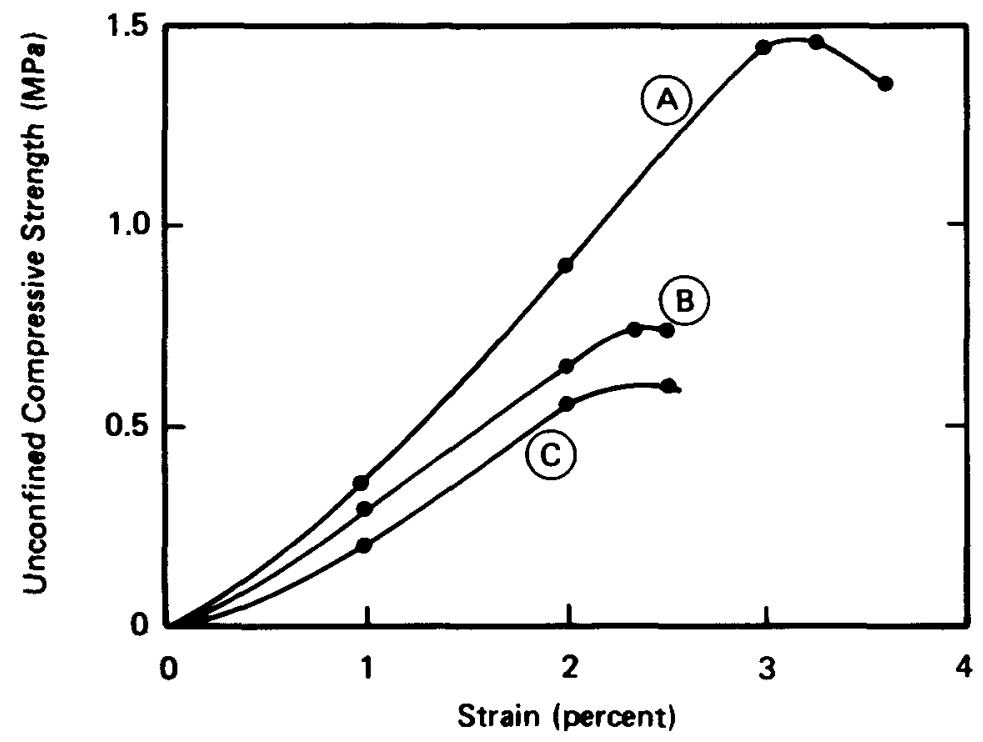

\section{EXPLANATION}

Mixture (A):

$50 \%$ Coarse-crushed basalt $25 \%$ Glaciofluvial sand $25 \%$ Wyoming bentonite

\section{Mixture (B):}

$68 \%$ Coarse-crushed basalt $16 \%$ Glaciofluvial sand 16\% Oregon bentonite

Mixture (C):

66\% Coarse-crushed basalt 17\% Crushed zeolite 17\% Ringold clay D

(b) Unconfined compressive strength curves for skip-graded aggregate/clay

\section{FIGURE 24}


The most effective compaction and maximum unconfined compressive strength results were obtained for the Wyoming bentonite/glaciofluvial sand/coarse-crushed basalt mixture. A maximum dry density of $2,266 \mathrm{~kg} / \mathrm{m}^{3}$ (at an optimum water content of 9.3 percent) and an unconfined compressive strength of $1.45 \mathrm{MPa}$ were measured for this sample. A somewhat lower maximum dry density $\left(2,195 \mathrm{~kg} / \mathrm{m}^{3}\right)$ and an unconfined compressive strength half that of the first mixture were measured for the mixture of Oregon bentonite, glaciofluvial sand, and coarsecrushed basalt. As expected, an even lower density was obtained for the Ringold clay/zeolite/coarse-crushed basalt mixture $\left(2,066 \mathrm{~kg} / \mathrm{m}^{3}\right)$ due principally to the high porosity and low specific gravity of the crushed zeolite. However, this density still has a range judged representative of multiplepurpose engineered fills. Moreover, the unconfined compressive strength developed by this last mixture was appreciable.

\subsubsection{Results of Screening Test on Compacted Earth Materials}

Geological reconnaissance and various index and mechanical tests resulted in the selection of Ringold clay $D$ as a preferred clay from among several fine-grained sedimentary units in the Pasco Basin. Although Ringold clay is considered the best performing clayey soil when compared to other clay units available near the Hanford site, this clay did not exhibit the optimum characteristics for use in plugs when compared to clays available from more distant sources. Ringold material has a high shrinkage limit, high silt content, and relatively low compaction.

A comparison of clay activity values showed that wyoming bentonite has characteristics close to a sodium montmorillonite, and oregon bentonite has characteristics close 
to a calcium montmorillonite. Consequently, Wyoming bentonite mixtures are expected to have higher compressibility, lower shear strength, and lower permeability.

Index tests performed on candidate non-cohesive granular materials indicated that glaciofluvial sand and crushed basalt are the most desirable aggregates for use in skip-graded aggregate/clay mixtures. Both offer acceptable grain-size distribution and structural strength. In contrast, crushed zeolite appears to be a very weak aggregate, but would be acceptable for use in backfill where an increase in ion exchange potential and sorption capacity are considered desirable.

Relatively good densities were achieved by impact compaction of bentonite/sand mixtures for clay contents lower than or equal to 50 percent in the case of Wyoming bentonite and 30 percent in the case of Oregon bentonite. Unconfined compressive strength on clay/sand samples indicated that bentonite/sand mixtures had considerably higher strength than Ringold clay/sand mixtures.

Swelling pressures at constant volume were measured for bentonite/sand mixtures compacted to maximum density at various optimum water contents and tested in a consolidometer under immersed water conditions. Swelling pressures were negligible for samples with clay contents of 10 percent, but increased exponentially to values reaching $2 \mathrm{MPa}$ when the clay content increased to 70 percent. If damaged by hydraulic fracturing or mechanical shearing, the swelling pressure behavior may provide compacted plug materials with cohesive self-healing properties. 
Results of compaction and compression tests on skip-graded agyreyate/clay mixtures show the best density and strength for mixtures containing 25 percent Wyoming bentonite, 25 percent glaciofluvial sand, and 50 percent $-1.9 \mathrm{~cm}$ coarse-crushed basalt. Density and strength in the range of multiple-purpose engineered fills and appreciable strength were obtained for mixtures composed of Ringold clay, crushed zeolite, and crushed basalt, although the values for these properties were comparatively lower them all other candidate, skip-graded aggregate/clay mixtures.

\subsection{CLAY SLURRIES - SCREENING TESTS}

\subsubsection{Candidate Materials}

Candidate materials that were mixed with water to form clay slurries and the source for each material are 1 isted in Table XVIII. A description of the test slurries and proportions of components in these slurries are given in Table XIX. The content of solid clay particles in slurries varied from 2 percent up to as much as 17 percent by weight.

\subsubsection{Testing Program and Procedures}

Preliminary screening tests of clay slurries included:

- Determination of the densities of fresh slurries using a container of known weight and volume;

- Determination of the flow properties of slurries by measuring the time of discharge of a specified volume of slurry from a standardized flow cone; and 
TABLE XVIII

\section{MATERIALS USED IN SCREENING TESTS ON CLAY SLURRIES}

Material

Shurgel (processed bentonite) Aquagel (processed bentonite) Wyoming bentonite Ringold clay from Unit $D$
Source

Baroid National Brand

Baroid National Brand

Baroid National Brand

Pasco Basin 
TABLE XIX

QUALITATIVE RESULTS OF THIXOTROPY TESTS ON CLAY SLURRIES

\begin{tabular}{|c|c|c|c|c|c|}
\hline \multicolumn{2}{|c|}{ SLURRY DESIGN } & \multirow{2}{*}{$\frac{\text { AS MIXED }}{\text { Low viscosity liquid }}$} & \multirow{2}{*}{$\frac{1 \text { DAY }}{\text { Low viscosity liquid }}$} & \multirow{2}{*}{$\frac{3 \text { DAYS }}{\text { Low viscosity liquid }}$} & \multirow{2}{*}{7 DAYS } \\
\hline \multirow{4}{*}{ 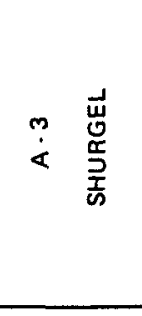 } & $2 \%$ Solıds & & & & \\
\hline & $4 \%$ Solıds & Low viscosity liquid & Low viscosity liquid & Moderate viscosity liquid & $\begin{array}{l}\text { Moderate to high } \\
\text { viscosity liquid }\end{array}$ \\
\hline & $6 \%$ Solids & Low viscosity liquid & $\begin{array}{l}\text { Moderate to high } \\
\text { viscosity liquid }\end{array}$ & $\begin{array}{l}\text { Some shear strength apparent } \\
\text { by indentation left in } \\
\text { surface of sample }\end{array}$ & $\begin{array}{l}\text { Increased shear strength } \\
\text { indicated by deeper indentation } \\
\text { left in surface of sample }\end{array}$ \\
\hline & $8 \%$ Solids & Very high viscosity liquid & $\begin{array}{l}\text { Some shear strength apparent } \\
\text { by indentation left in } \\
\text { surface of sample }\end{array}$ & $\begin{array}{l}\text { Increased shear strength } \\
\text { indicated by deeper indentation } \\
\text { left in surface of sample }\end{array}$ & $\begin{array}{l}\text { Greater shear strength } \\
\text { indicated by hole left } \\
\text { in surface of sample }\end{array}$ \\
\hline \multirow{4}{*}{ 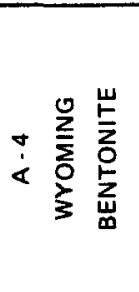 } & $2 \%$ Solids & Low viscosity liquid & Low viscosity liquid & & $\begin{array}{l}\text { Cloudy water, solids } \\
\text { at bottom of container }\end{array}$ \\
\hline & $4 \%$ Solıds & Low viscosity liquid & Low viscosity liquid & & $\begin{array}{l}\text { Low to moderate viscosity } \\
\text { liquid, some settling of solids }\end{array}$ \\
\hline & $6 \%$ Solids & Low viscosity liquid & $?$ & & $\begin{array}{l}\text { Moderate to high } \\
\text { viscosity liquid }\end{array}$ \\
\hline & $8 \%$ Solıds & Low viscosity liquid & Moderate viscosity lıquid & & High viscosity liquid \\
\hline \multirow{4}{*}{ 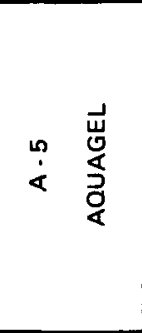 } & $2 \%$ Solıds & Low viscosity liquid & Low viscosity liquid & & $\begin{array}{l}\text { Cloudy water, solıds at } \\
\text { bottom of container }\end{array}$ \\
\hline & $4 \%$ Solıds & Low viscosity liquid & Low viscosity liquid & & $?$ \\
\hline & $6 \%$ Solıds & Low viscosity liquid & $?$ & & $\begin{array}{l}\text { Moderate to high } \\
\text { viscosity liquid }\end{array}$ \\
\hline & $8 \%$ Solids & Low viscosity liquid & $\begin{array}{l}\text { Moderate to high } \\
\text { viscosity liquid }\end{array}$ & & $\begin{array}{l}\text { Some shear strength apparent } \\
\text { by indentation left in } \\
\text { surface of sample }\end{array}$ \\
\hline \multirow{4}{*}{ 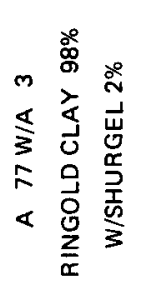 } & $2 \%$ Solıds & Essentrally cloudy water & $\begin{array}{l}\text { Clear water, solids at } \\
\text { bottom of container }\end{array}$ & & $\begin{array}{l}\text { Clear water, solids at } \\
\text { bottom of container }\end{array}$ \\
\hline & $4 \%$ Solıds & Essentially cloudy water & Cloudy water & & $\begin{array}{l}\text { Clear water, solids at } \\
\text { bottom of container }\end{array}$ \\
\hline & $6 \%$ Solıds & Essentrally cloudy water & Cloudy water & & $\begin{array}{l}\text { Clear water, solids at } \\
\text { bottom of container }\end{array}$ \\
\hline & $8 \%$ Solıds & Essentıally cloudy water & Cloudy water & & $\begin{array}{l}\text { Clear water, solids at } \\
\text { bottom of container }\end{array}$ \\
\hline
\end{tabular}


- Evaluation of the thixotropic properties of slurries by measuring the shear strength of the slurry at increasing time using a laboratory vane shear test.

Parameters of gel strength, thixotropy (increase of gel strength with time), and stability (ability of the solids to remain in suspension) define the principal properties needed by slurry mixtures to perform the anticipated design functions for a borehole plug. Screening tests were designed to identify the best mixtures of candidate materials in a slurry to obtain the best values of the parameters.

\subsubsection{Preliminary Test Results and Discussion}

Tests were conducted to evaluate the density, flow properties, and thixotropic properties of candidate slurries having solids content varying from 2 to 17 percent by weight. The results of these tests are presented in Figures 25 and 26 and Table XIX.

\subsubsection{Slurry Densities}

For complete dispersion of solids, a linear relationship can be demonstrated between slurry density and solids content, as shown in Figure 25. The slope of this straight line, as drawn through a plot of experimental data points, is a function of the specific gravity of the solids. Note that the point corresponding to a slurry containing 15 percent Aquagel was plotted at a density lower than was expected because of the presence of several air voids in the sample used for the density determination. For the slurry in which solids consisted of 98 percent Ringold clay and 2 percent wyoming bentonite, there was a great deal of scatter in the test results due to the difficulty in obtaining a representative 


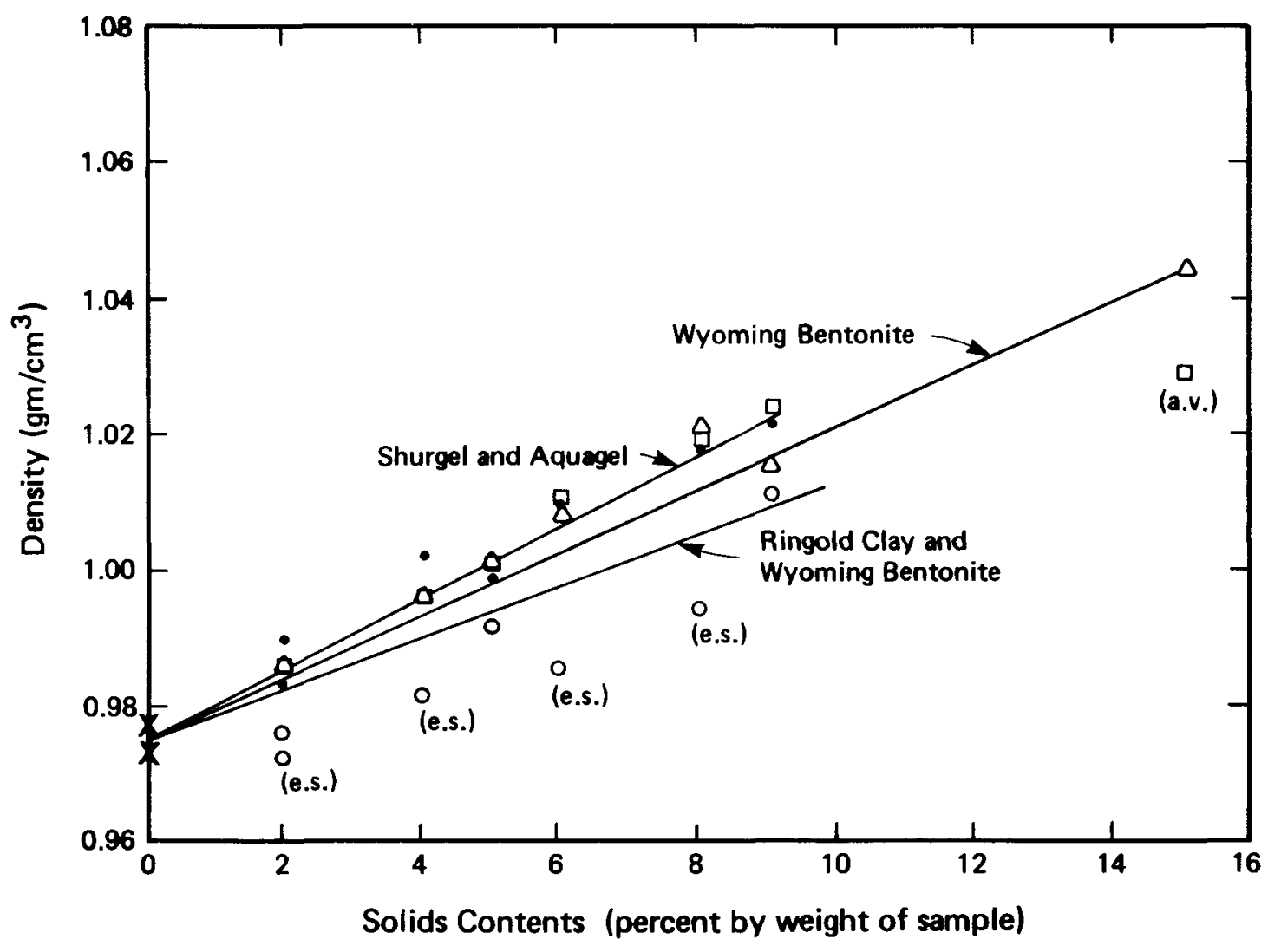

\author{
EXPLANATION \\ $X$ Water alone \\ - Shurgel (A-3) \\ - Aquagel (A-5) \\ $\triangle$ Wyoming bentonite $(A-4)$ \\ - 98\% Ringold clay (A-77) \\ 2\% Wyoming bentonite (A-4) \\ (e.s.) Excess silt \\ (a.v.) Air void
}

FIGURE 25 


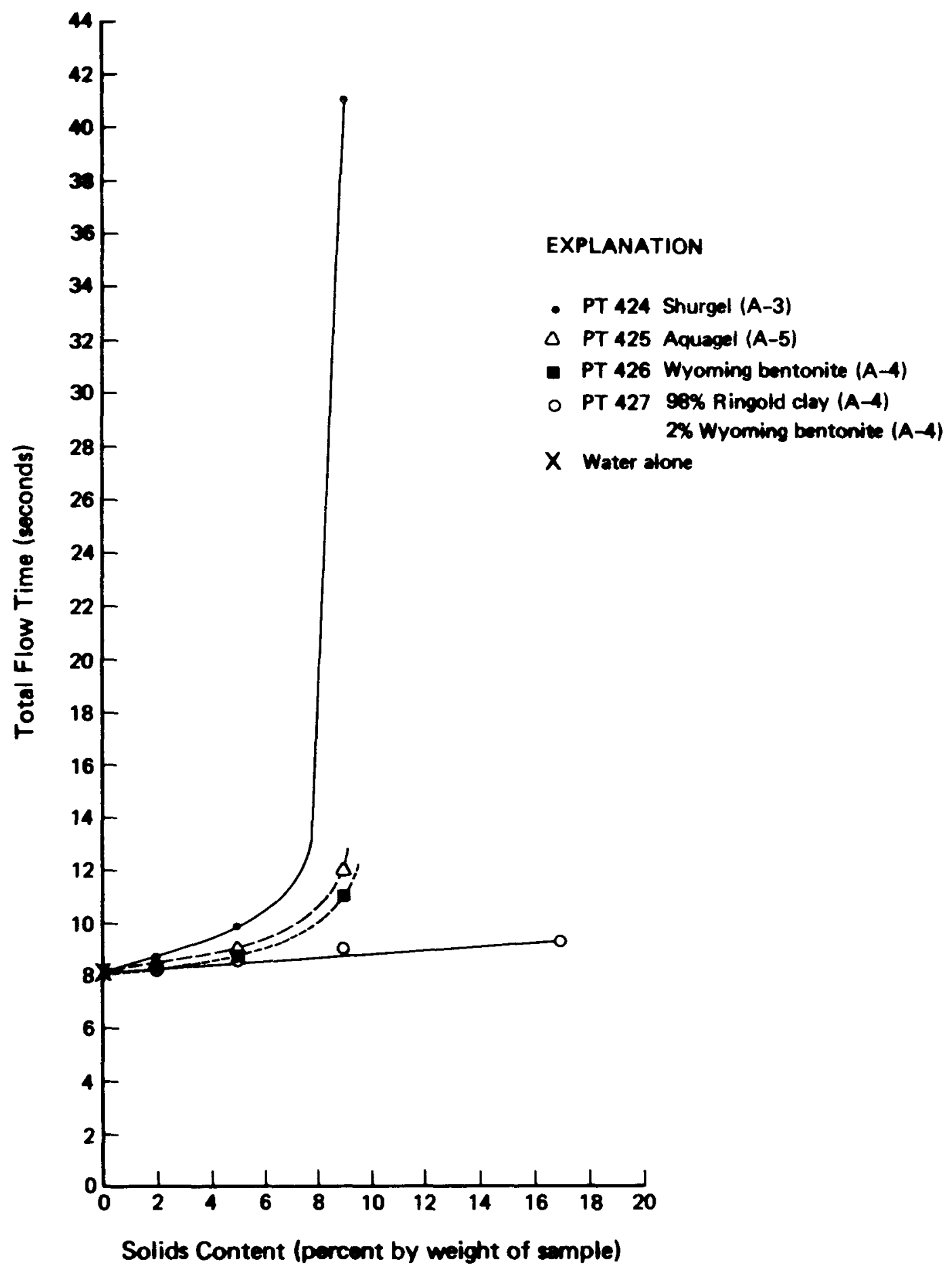

FIGURE 26

FLOW TIME OF CLAY SLURRIES 
sample for density determination. This difficulty was primarily caused by the high silt content of Ringold clay D; the solids rapidly settled whenever agitation of the slurry ceased, thereby effectively reducing the solids content of the slurry. Thus, it was difficult to produce a consistent slurry when using Ringold clay. With the exception of these discrepancies, the test results do show the linear relationship between slurry density and solids content. The slurries consisting of Shurgel and Aquagel produced the greatest densities.

\subsubsection{Flow Properties of Slurries}

In conjunction with tests to determine slurry densities, the same slurry mixtures were used to determine the flow properties (viscosity) of slurries at various solids content by measuring the time required for a given volume of slurry to flow out of a test funnel. It should be noted that the flow time of water at $25^{\circ} \mathrm{C}$ was approximately 8.3 seconds. Tests performed to monitor consistency indicated that test repeatability was reasonable (about \pm 0.20 second).

As shown in Figure 26, for slurries with solids consisting of Shurgel, Aquage1, or Wyoming bentonite, the viscosity is close to that of water for solids content less than 6 percent. The viscosity increased rapidly for solids content above 6 percent. For solids content greater than 9 percent (the consistency of a heavy drilling mud), the slurries became too viscous to flow through the cone used for this test. The slurry containing Shurgel increased in viscosity (with increase in solids content) much more rapidly than slurries containing either Aquagel or Wyoming bentonite, both of which increased equally in viscosity with increasing solids content. However, 
the slurry that contained 98 percent Ringold clay and 2 percent Wyoming bentonite maintained a viscosity close to that of water for all solids content tested, including solids content as high as 17 percent. This result confirms the instability of this mixture as a permanent suspension in a slurry because of the rapid settling of solids upon cessation of mixing.

\subsubsection{Thixotropic Properties of Slurries}

After evaluating the results of tests for slurry densities and flow properties, it was possible to select slurry mixtures that received further testing with respect to thixotropic (shear strength) properties. In an attempt to quantify test results, laboratory vane shear tests were performed. However, the test apparatus was not sensitive enough to measure the low shear strength associated with the slurries, and qualitative descriptions given in Table XIX must be used to present the results of these tests. Each time a vane shear test was performed on a slurry sample, the sample condition was monitored by taking a solids content specimen from the sample (Figures 27 and 28). These specimens were taken by scraping some slurry from the top of the sample with a spoon. It was this procedure that produced indentations and holes in the surface of samples, as noted in Table XIX. These indentations and holes are considered a valid basis for an initial qualitative comparison of shear strength because the slope stability of the cut of any material is a function of its shear strength.

The descriptions given in Table XIX are presented to illustrate the following test results: (1) for solid contents less than 6 percent, no apparent shear strength was developed by any of the slurries tested; (2) 7 days after being mixed, apparent 

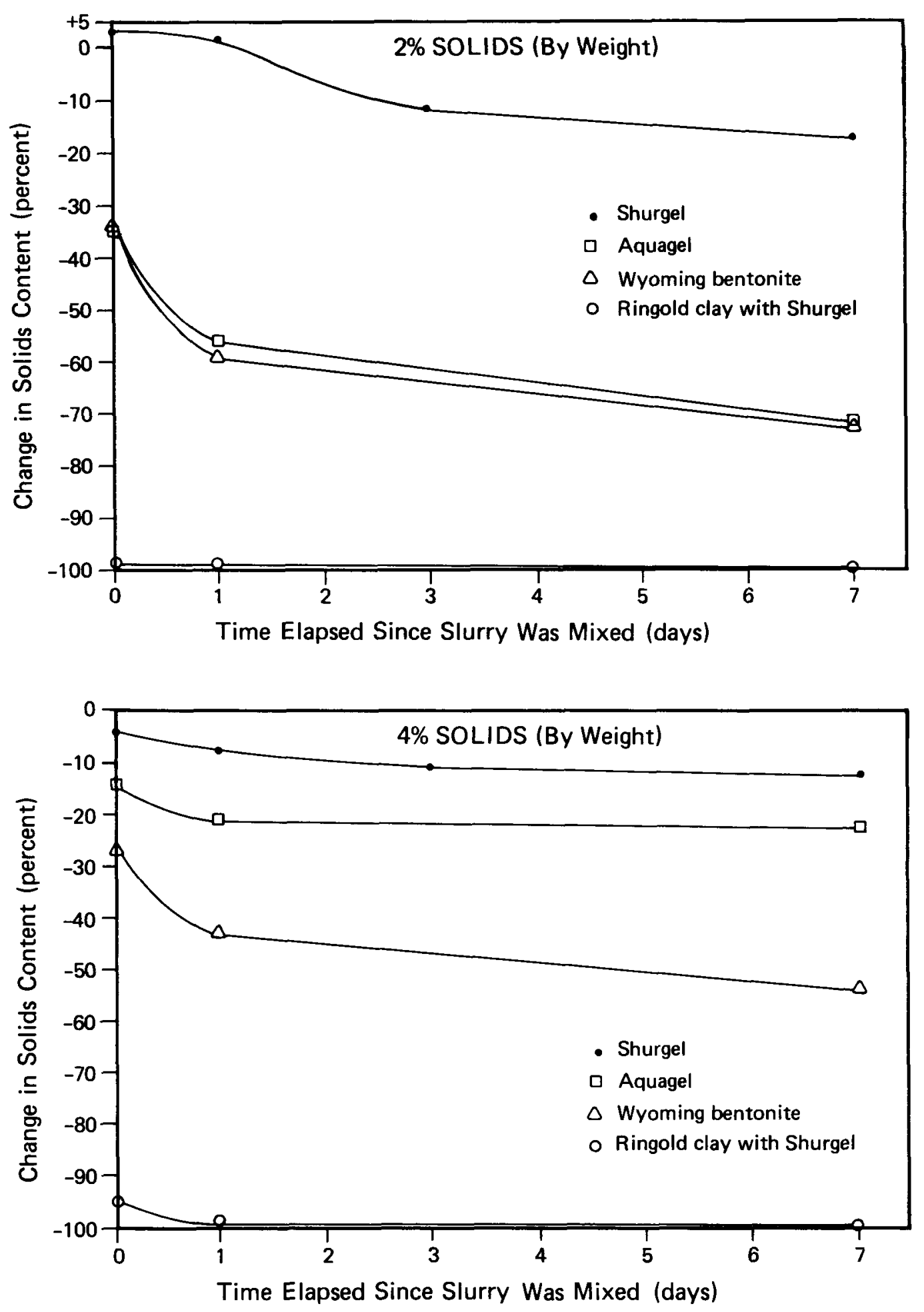

FIGURE 27

VARIATION OF SOLIDS CONTENTS ( $2 \%$ and $4 \%)$ OF CLAY SLURRIES 

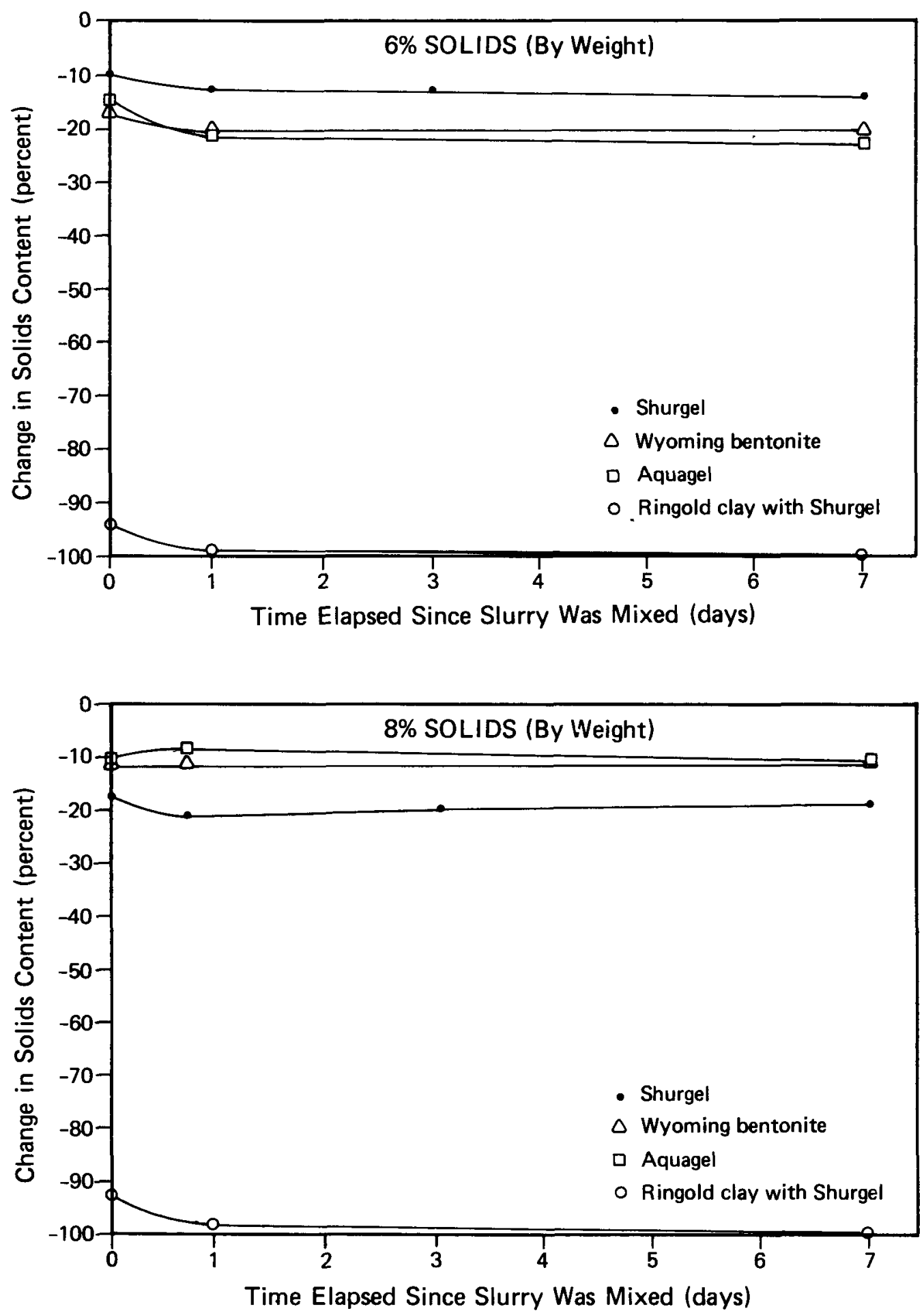

FIGURE 28 
shear strength was only developed by slurries containing 6 percent and 8 percent Shurgel and 8 percent Aquagel; (3) the slurry containing 6 percent Shurgel developed apparent shear strength after a period of 3 days, while the slurry containing 8 percent Shurgel developed apparent shear strength after a period of only 24 hours; and (4) the slurry containing 8 percent Shurgel developed sufficient shear strength after a period of 7 days to maintain vertical sides of a groove in the sample. However, this shear strength was still too small to be measured with the laboratory vane shear apparatus (the minimum measurable shear strength is $\left.1.4 \mathrm{~g} / \mathrm{cm}^{2}\right)$. These results indicate that, in terms of shear strength, slurries should contain at least 6 percent by weight of solids and that the greatest strength will be developed by slurries containing Shurgel.

These results were further substantiated by data obtained by continuous monitoring of thixotropy tests (Figures 27 and 28). The change in solids content for a sample, as shown in these figures, is given as the percent change from the original solids content of that sample; that is, -10 percent indicates that at the surface of the sample, there were 10 percent fewer solids than when the sample was originally prepared. These figures illustrate the extent to which the solids in a slurry remained "suspended" throughout the slurry or "settled" towards the bottom of the sample. The results indicate that shurgel solids essentially remained suspended throughout the sample for all solids content tested, whereas in the mixture of 98 percent Ringold Clay with 2 percent Shurgel, solids settled to the bottom of the sample for all solids content tested (Table XIX). The slurries containing Aquagel and wyoming bentonite exhibited significant settling of solids for mixtures containing 2 percent solids; however, for solids 
content of 6 percent and 8 percent, the solids essentially remained suspended throughout the sample.

If this phenomenon of "suspended" and "settling" solids can be explained in terms of the repulsion and attraction of individual clay particles, these results appear to be consistent with those shown in Table XIX. That is, development of viscosity and shear strength in a stable slurry is consistent with the ability of the clay particles to remain suspended throughout the slurry volume. Similarly, these results are considered consistent with results shown in Figures 25 and 26 in which increases in slurry density and viscosity were related to the ability of clay particles to remain suspended throughout the slurry volume.

\subsubsection{Results of Screening Tests on Clay Slurries}

Screening tests on four candidate clays used in slurries demonstrated:

- The development of gel strength for slurries composed of more than 6 percent Shurgel, Aquagel, or Wyoming bentonite;

- A high increase in viscosity of Shurgel, Aquagel, or Wyoming bentonite slurries for solids content more than 8 percent;

- A segregation of particle sizes and absence of gel formation in slurries composed of Ringold clay plus wyoming bentonite; and

- The best gel strength, thixotropy (increase of gel 
strength with time), and stability (ability of the solids to remain in suspension) were observed for slurries mixed with Shurgel (processed bentonite). A mixture of 7 percent by weight of dry Shurgel in water is recommended to obtain the best shear strength with good stability.

\subsection{CEMENTITIOUS GROUTS AND CONCRETES - PERFORMANCE TESTS}

\section{5 .1 Materials}

The screening test results for cementitious mixtures (presented in Section 5.2) led to the selection of materials for more detailed performance test evaluations: (1) on the basis of workability, volume change, and structural strength for mixtures to be placed at locations where temperatures are expected to be low (less than $100^{\circ} \mathrm{C}$ ); and (2) on the basis of workability, volume change, structural strength, and thermal stability for mixtures to be placed at locations where high temperatures are expected (greater than $100^{\circ} \mathrm{C}$ ). A list of materials employed in performance tests is given in Table $x$.

\subsubsection{Mixture Designs}

\subsubsection{Grout Mixtures}

The proportions of components used in grout samples were chosen to produce relatively dense, impervious but easily pumpable mixtures. Mixture guidelines were as follows:

- Water/cement ratios were selected to produce a flow of $16 \pm 1$ seconds as determined with the c-79-77 "Test Method for Flow of Grout Mixtures (Flow Cone Method)" (U.S. Army Corps of Engineers, 1978); 
TABLE XX

MATERIALS USED IN PERFORMANCE TESTS

FOR CEMENTITIOUS MIXTURES

\section{Cementitious Materials}

Portland Type $\mathrm{V}$ cement and silica flour (high temperature locations: $\mathrm{T} \geq 100^{\circ} \mathrm{C}$ )

Portland Type $\mathrm{V}$ cement and Lassenite (moderate temperature locations: $\mathrm{T}\left(100^{\circ} \mathrm{C}\right)$

TXI Chem Com cement and Lassenite (low temperature locations: $\mathrm{T} \leq 50^{\circ} \mathrm{C}$ )

\section{Fine Aggregates}

Glaciofluvial sand or crushed basalt sand (from the Hanford Site)

\section{Coarse Aggregates}

Minus $2.5 \mathrm{~cm}$ crushed river gravel or crushed basalt gravel (from the Hanford site)

\section{Additives}

Water-reducing retarder agent (Plastiment)

-325 mesh polished, leafing-type aluminium powder 
- Cement/pozzolan/sand proportions expressed by weight were 5 parts cement to 2 parts pozzolan and 6 parts sand;

- The aluminum powder to cement ratio equaled 0.03 percent by weight (only in portland cement mixtures); and

- The addition of $90 \mathrm{ml}$ of Plastiment were used per bag of cement $(42.6 \mathrm{~kg})$.

\subsubsection{Concrete Mixtures}

Mixtures were designed following U.S. Bureau of Reclamation recommended procedures for concretes containing a WRA, fine aggregate, 2.5-cm maximum size coarse aggregate, and a slump of 7.5 to $10 \mathrm{~cm}$ at the mixer. Corresponding proportions were then adjusted to ascertain actual values of the fineness modulus of sand. Data giving the relative proportion of pozzolan and silica flour used in cements are the same as those presented in Section 5.2.2 for cement mortars:

- A pozzolan to cement ratio of 20 percent; and

- A silica to silica plus cement ratio equal to 35 percent.

\subsubsection{Testing Program and Procedures}

Performance tests of candidate grout and concrete mixtures included: (1) standard index tests of freshly prepared cementitious mixtures; (2) density, porosity, volume change, and strength determinations of hardened mixtures; and (3) model 
testing, including the determination of the permeability and bond strength of cementitious mixtures and basalt host rock. A list of testing methods is presented in Table XXI. Special test methods (including model testing of concrete materials and basalt host rock) are described in the following sections.

5.5.3.1 Sampling and Curing of a Plug/Basalt (Host Rock) Model

Two types of plug/basalt models were prepared: one using a clean basalt surface, and the other using a mud-contaminated basalt surface:

The preparation of a clean basalt rock sample was intended to simulate placement of a grout plug (concrete plug) against the clean wall of a borehole (borehole, shaft, or tunnel). Freshly mixed grout (concrete) was placed in a $2.60-\mathrm{cm}(6.45-\mathrm{cm}$ for concrete tests) diameter hole drilled down the center of a piece of basalt core which was $5.08 \mathrm{~cm}$ in diameter $(10.16 \mathrm{~cm}$ for concrete tests) and $4.45 \mathrm{~cm}$ long $(7.62 \mathrm{~cm}$ for concrete). After 24 hours of curing in a moist room and 6 days of curing in a lime-water bath at standard temperature, the plug/basalt models were autoclaved under the steam pressure of water at $100^{\circ} \mathrm{C}$ for 72 hours. Plug/basalt models were then removed from the autoclave and again placed in the lime-water bath until testing.

- Mud is the common drilling fluid used in boreholes. It is circulated down to the drill bit, then back out of the hole in order to remove cuttings, cool the bit, and lubricate the drill stem. The drilling mud 
TABLE XXI

\section{PERFORMANCE TEST PROCEDURES USED FOR CEMENTITIOUS MIXTURES}

Grout Test Methods

CRD-C 79-77a

ASTM $C-191^{b}$

CRD-C $81-74^{a}$

API RP-40 C

API $R P=40^{\circ}$

CRD-C 588-78A

Modified ASTM $c-39$ d

Special Test Method

Special Test Method

Special Test Method

Special Test Method

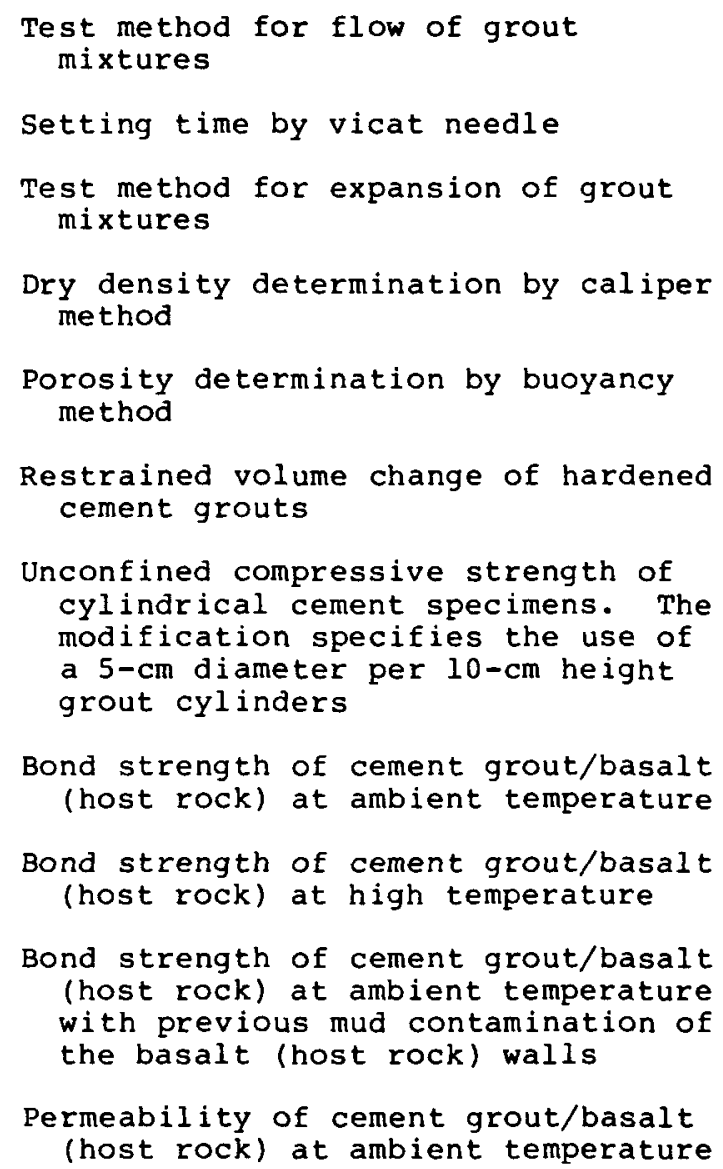


TABLE XXI (continued)

Concrete Test Method

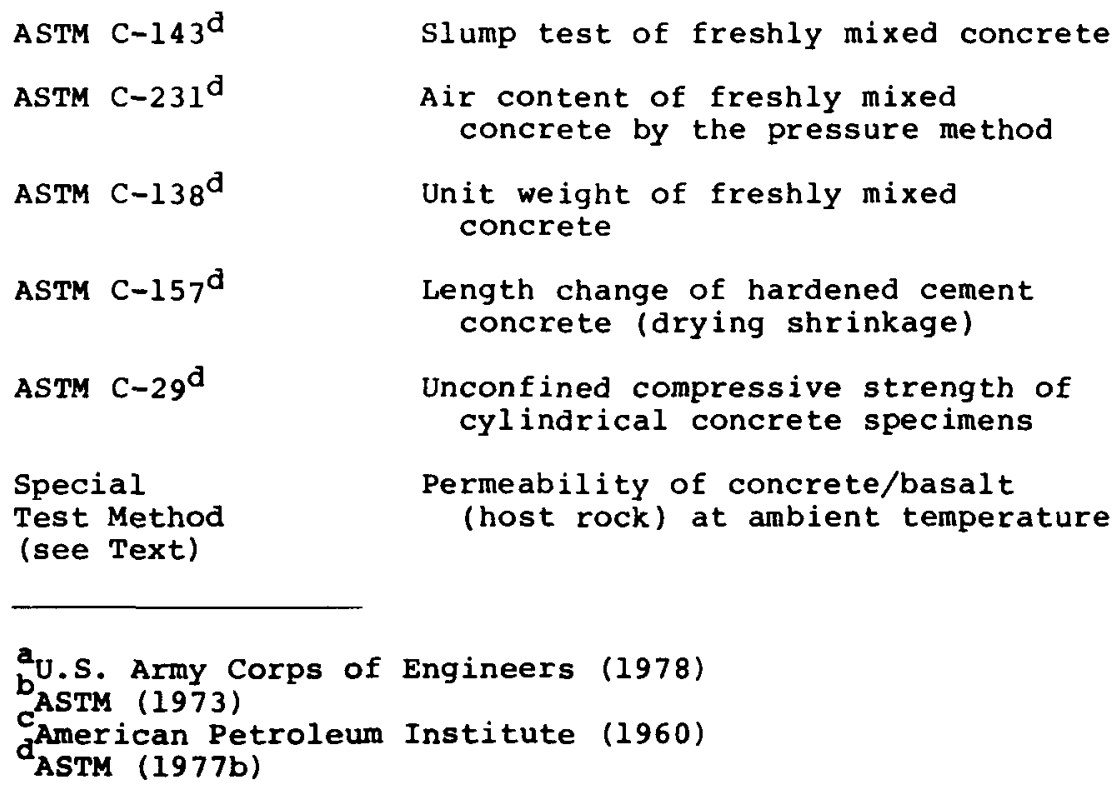


produces a cake which builds up on the borehole wall. Consequently, a mud cake can be present prior to plugging the borehole. Mud contamination of a borehole was simulated by filling a hole drilled lengthwise into a basalt (host rock) core with bentonite slurry ( 8 percent by weight of Shurgel) prior to plugging. The bentonite slurry was then left set for at least two hours inside the basalt core. The mud slurry was drained from the bottom of the piece of core before simulated plugging with concrete, as described above.

5.5.3.2 Bond Strength of a Cement Plug/Basalt (Host Rock) Model at Ambient Temperature

Bond strength in the cement plug/basalt model was obtained by axially loading the miniature plug until failure of the plug/wall rock bond occurred. Plug loading was accomplished using a mechanical loading frame to push a piston $(2.54 \mathrm{~cm}$ in diameter) which was concentrically aligned with the $2.60-\mathrm{cm}$ diameter plug. To allow plug extrusion, a flat metal loading base, which had a 3.18-cm diameter hole drilled through it, was placed at the bottom of the basalt when testing grout plugs. Bond strength values were mathematically obtained by dividing the maximum loading force obtained during plug extrusion by the contact area between the plug and the wall rock.

\subsubsection{Bond Strength of a Cement Plug/Basalt (Host Rock) Model At High Temperature}

Bond strengths of the miniature plug models were also determined using the maximum assumed temperature of $100^{\circ} \mathrm{C}$ at plug seats (see Table A-I, Appendix A) resulting from thermal 
loading of radioactive wastes stored in the repository. Prior to testing, the plug/basalt model was dried for 48 hours at $100^{\circ} \mathrm{C}$ in a conventional laboratory oven. The model was then removed from this oven and immediately placed in the preheated chamber of a special split test oven maintained at a constant temperature of $100^{\circ} \mathrm{C}$. Thermocouples directly connected to an electronic temperature readout monitored the oven chamber temperature throughout the duration of the test runs. Temperatures in the plug were checked prior to testing by the readout of a thermocouple inserted inside the plug. The test oven was set up between the loading plates of a 45,000-kg hydraulic press. This configuration, which was designed to minimize the temperature gradient inside the oven chamber, included: (1) a permanent, insulated $15-\mathrm{cm}$ diameter pedestal (protruding from the lower loading plate of the hydraulic press and extending up into the oven); and (2) a 10-cm diameter insulated loading ram (protruding through the top of the oven to the pressure cell directly connected to the upper loading plate of the hydraulic press). Plug extrusion and bond strength calculations followed the same procedures as for low temperature bond strength determination.

5.5.3.4 Permeability of a Cement Plug/Basalt (Host Rock) Model at Ambient Temperature

Permeability tests of cement plug/basalt (host rock) models were carried out inside a conventional triaxial cell using the falling head method. A pressure differential of $0.05 \mathrm{MPa}$ for concrete plugs and $0.03 \mathrm{MPa}$ for grout plugs was applied between the top and the bottom of the full surface of the composite samples, corresponding to an approximate value of 70 for the hydraulic gradient. Thus, the permeability measurement represents an average permeability for the entire plug/basalt model. 


\subsubsection{Test Results and Discussion}

Test results are given for each cemetitious mixture on Figures 29 to 34 .

\subsubsection{Grout Performance}

- The initial setting time for the three grout mixtures was greater than 6 hours. The time of set could be reduced by decreasing the amount of the WRA (Plastiment) in the mixtures. However, a final evaluation of the setting time should be done under in-situ downhole temperature conditions because an increase in temperature may decrease the setting time;

- Oven dry densities of grout composed of Chem Com TXI cement plus Lassenite (G-TXI-L) and grout composed of portland cement Type $V$ plus Lassenite $(G-V-L)$ were found to be the same $\left(1.64 \mathrm{~g} / \mathrm{cm}^{3}\right)$, while a significant difference in porosity was observed $(42.3$ percent for G-TXI-L and 33 percent for G-V-L). Data on water cement ratios indicated that porosity data were consistent. Thus, oven-dry densities may be misleading. An explanation may be the difference in specific gravity between Chem Com TXI and portland cement Type V. The high value of oven-dry density for the grout composed of portland cement Type $V$ plus silica flour $(G-V-S)$ is due to the high specific gravity of the silica flour $\left(2.65 \mathrm{~g} / \mathrm{cm}^{3}\right)$ when compared with the specific gravity of Lassenite $\left(2.43 \mathrm{~g} / \mathrm{cm}^{3}\right)$. 

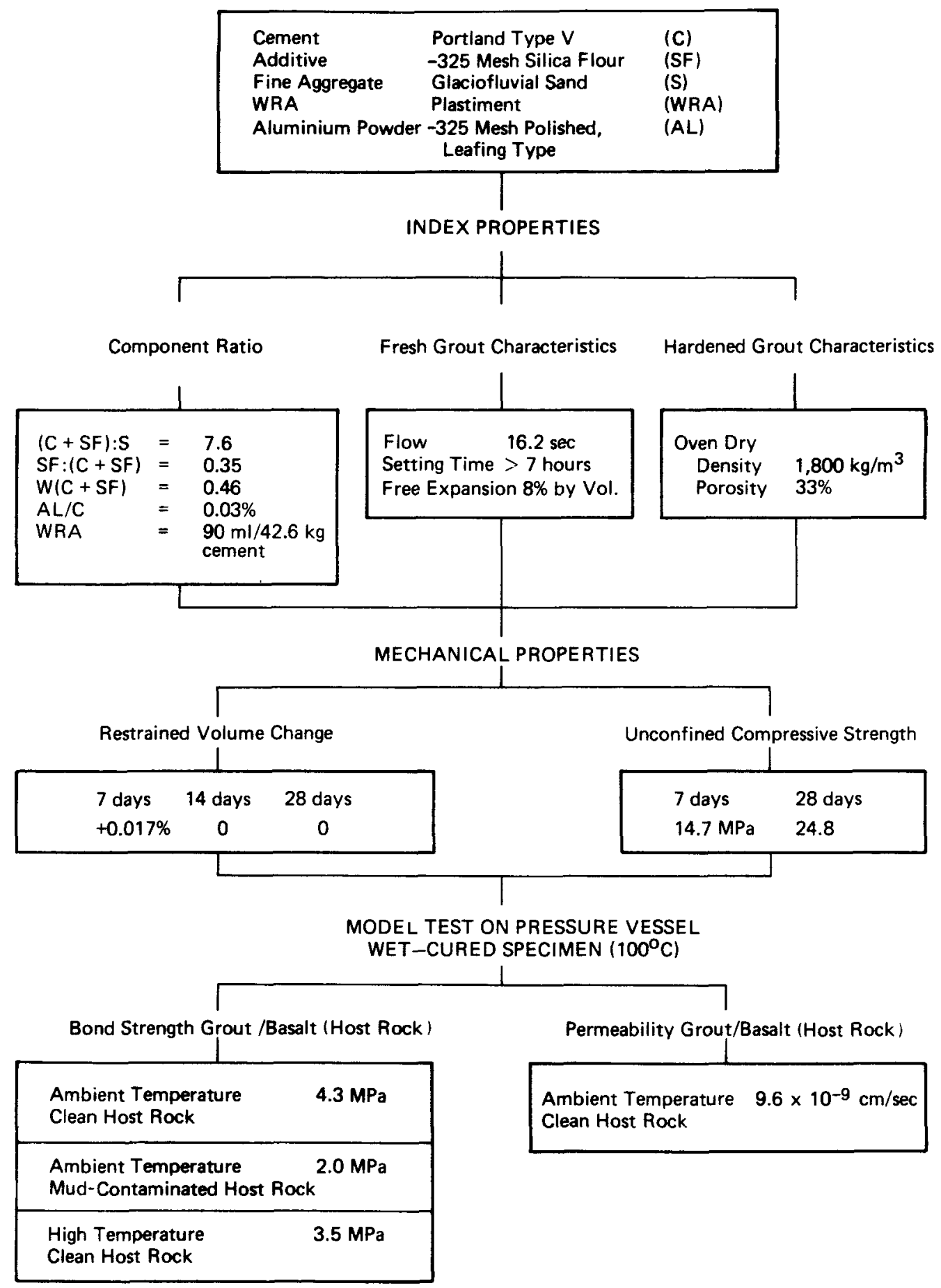

FIGURE 29

SUMMARY OF GROUT PERFORMANCE: FOR HIGH TEMPERATURE LOCATION $\left(T \geq 100^{\circ} \mathrm{C}\right)$ 


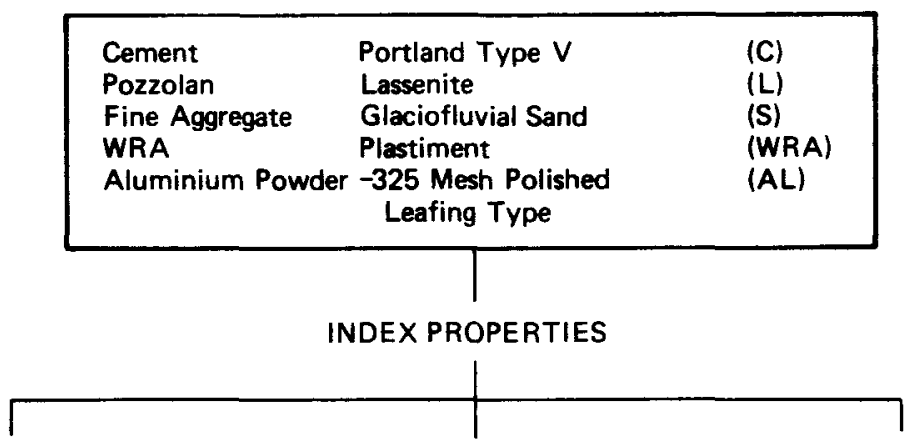

Component Ratio

Fresh Grout Characteristics

Hardened Grout Characteristıcs

1

$\begin{array}{|lll|} & & \\ C: L: S & = & 5: 2: 6 \\ W /(C+L) & = & 0.53 \\ A L / C & = & 0.03 \% \\ W R A & = & 90 \mathrm{ml} / 42.6 \mathrm{~kg} \\ & & c e m e n t\end{array}$

\section{Flow $\quad 16 \mathrm{sec}$}

Setting Time $>61 / 2$ hours

Free Expansion $8 \%$ by Vol.

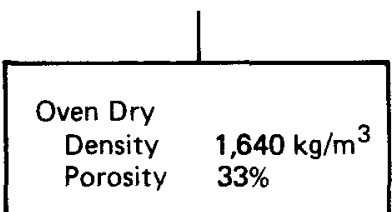

Porosity $33 \%$
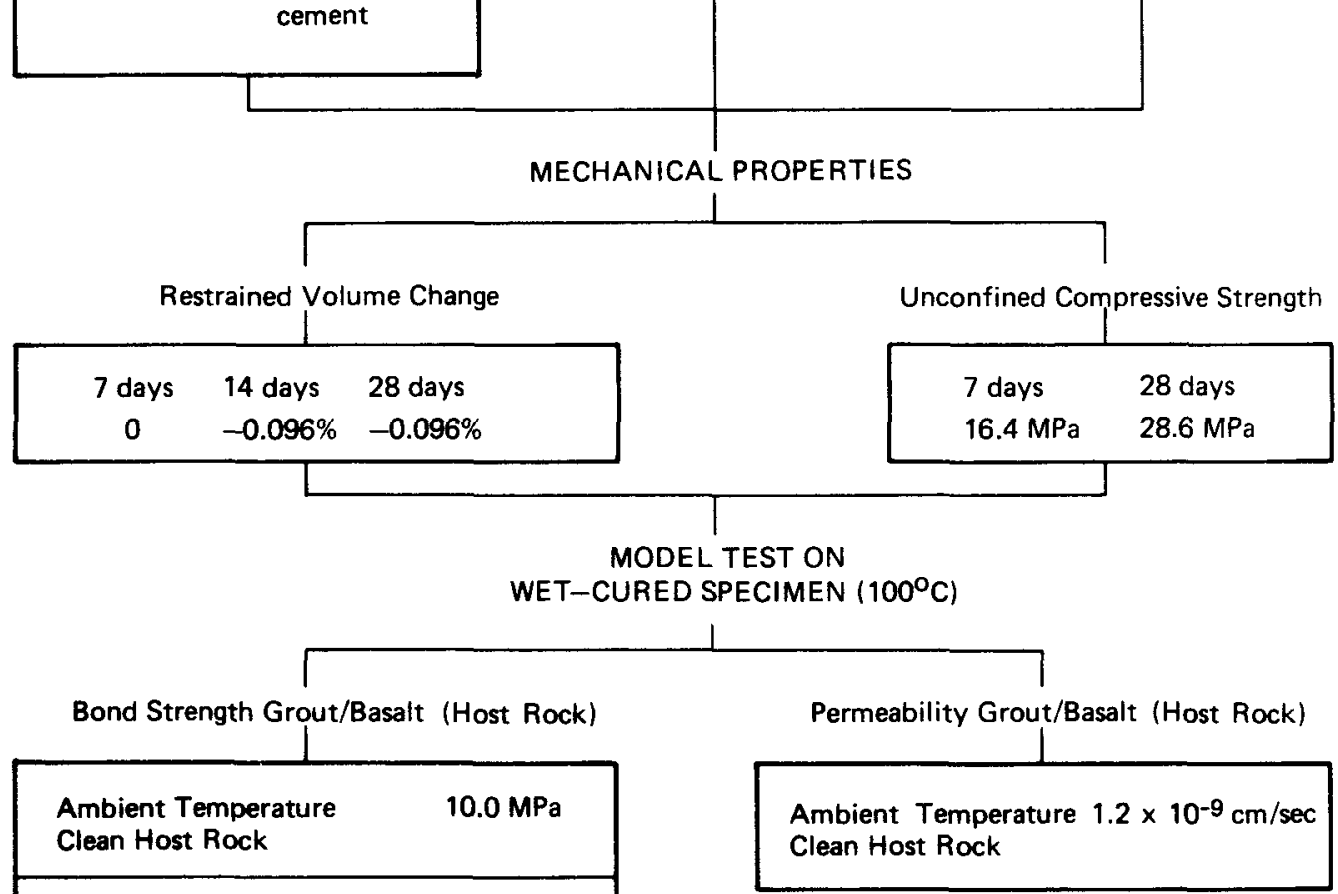

Ambient Temperature $\quad 2.5 \mathrm{MPa}$

Mud-Contaminated Host Rock

High Temperature $\left(100^{\circ} \mathrm{C}\right) \quad 3.9 \mathrm{MPa}$

Clean Host Rock 


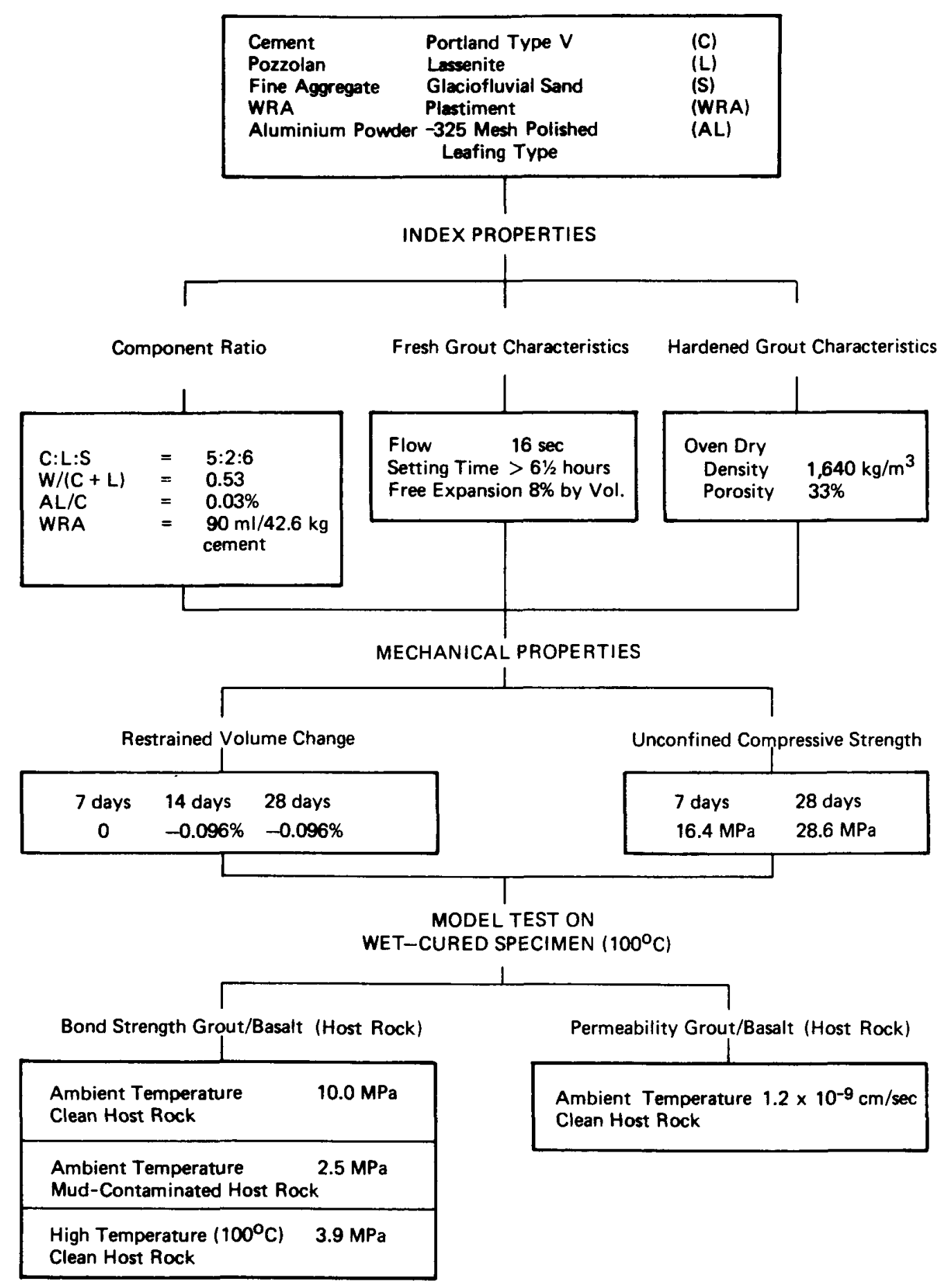

FIGURE 31

SUMMARY OF GROUT PERFORMANCE:

EXPANSIVE GROUT FOR RELATIVELY LOW TEMPERATURE LOCATIONS $\left(T \leq 50^{\circ} \mathrm{C}\right)$ 


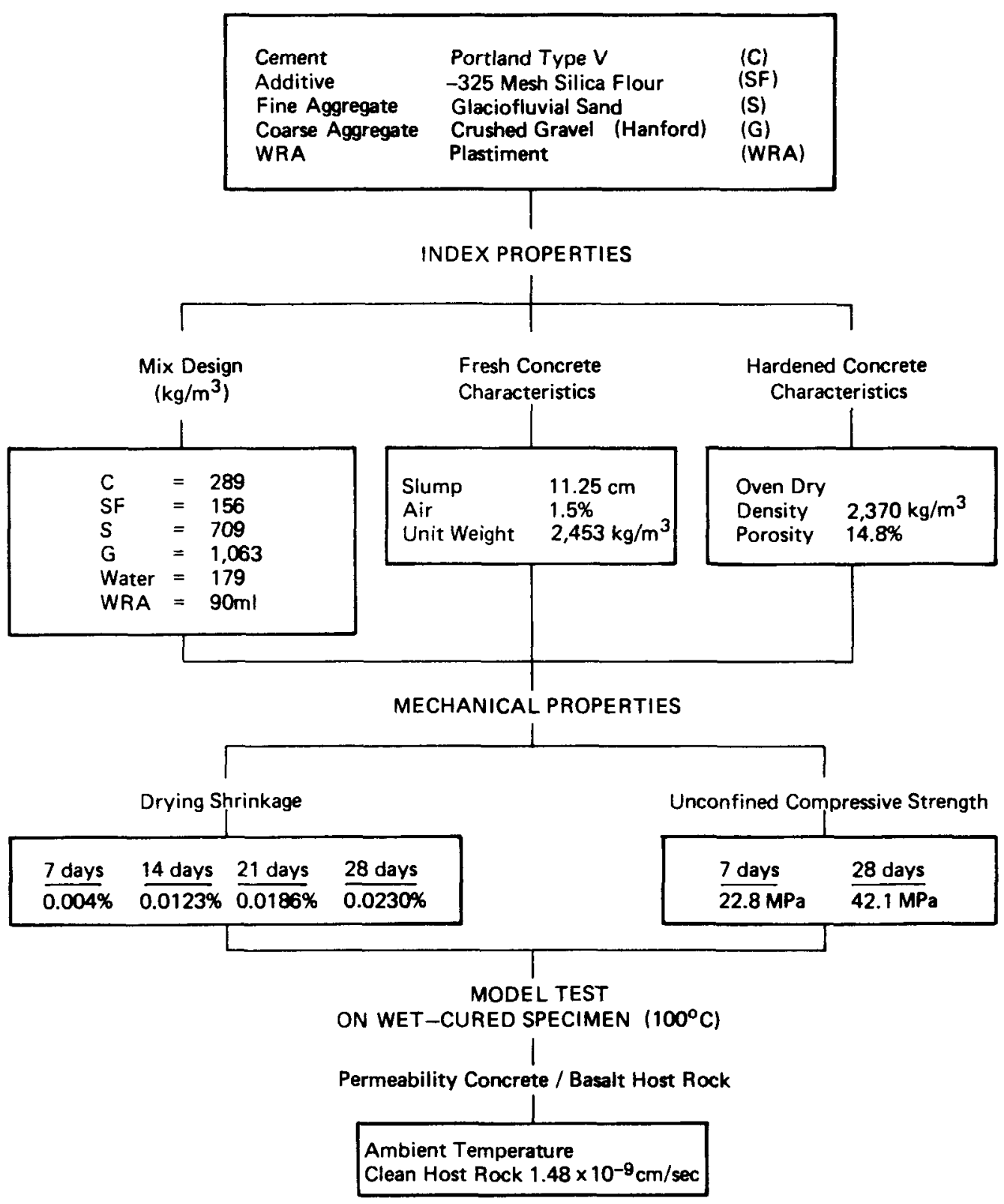

\section{FIGURE 32}




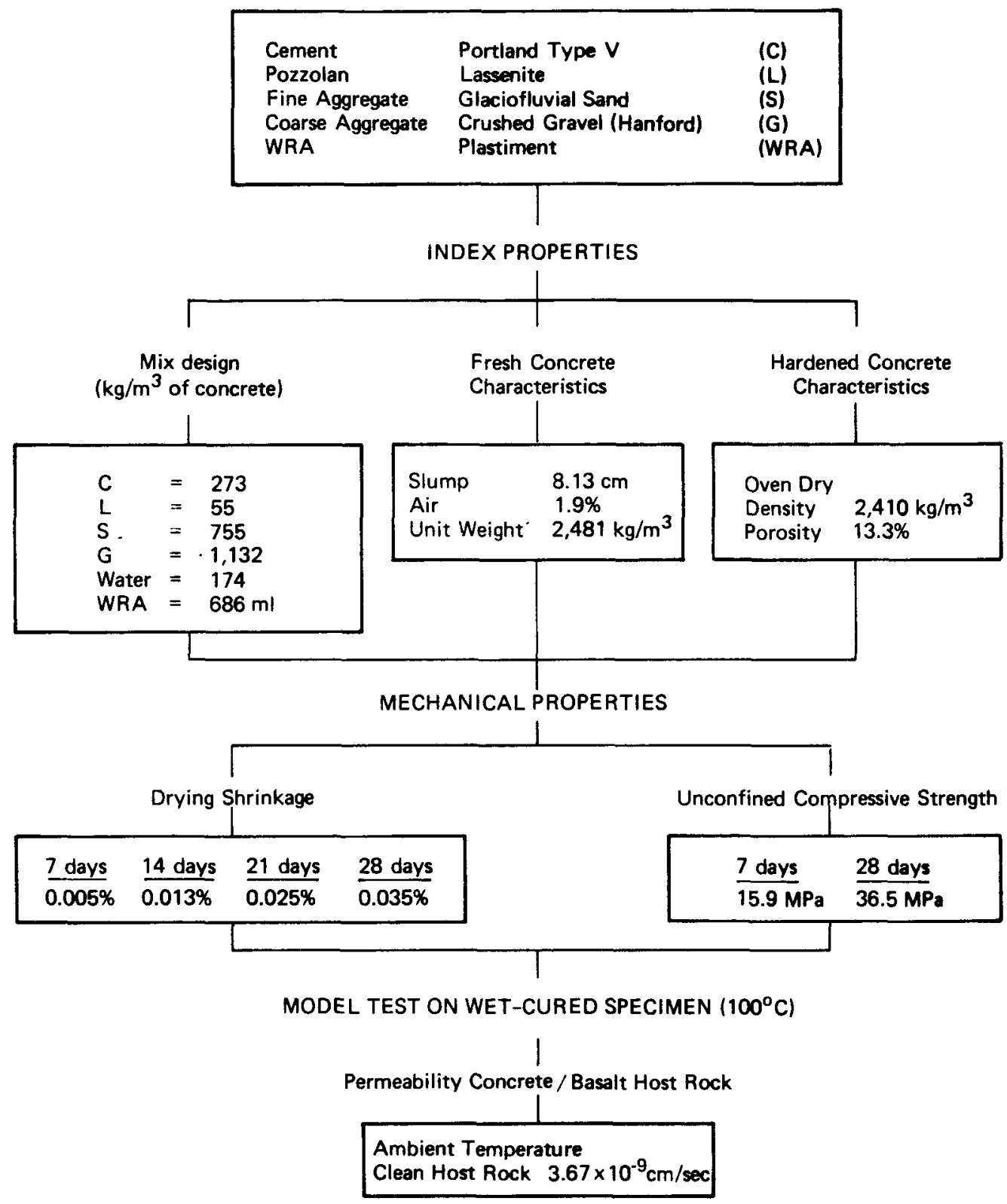

FIGURE 33

SUMMARY OF CONCRETE PERFORMANCE:

FOR MODERATE TEMPERATURE LOCATION $\left(T<100^{\circ} \mathrm{C}\right)$ 


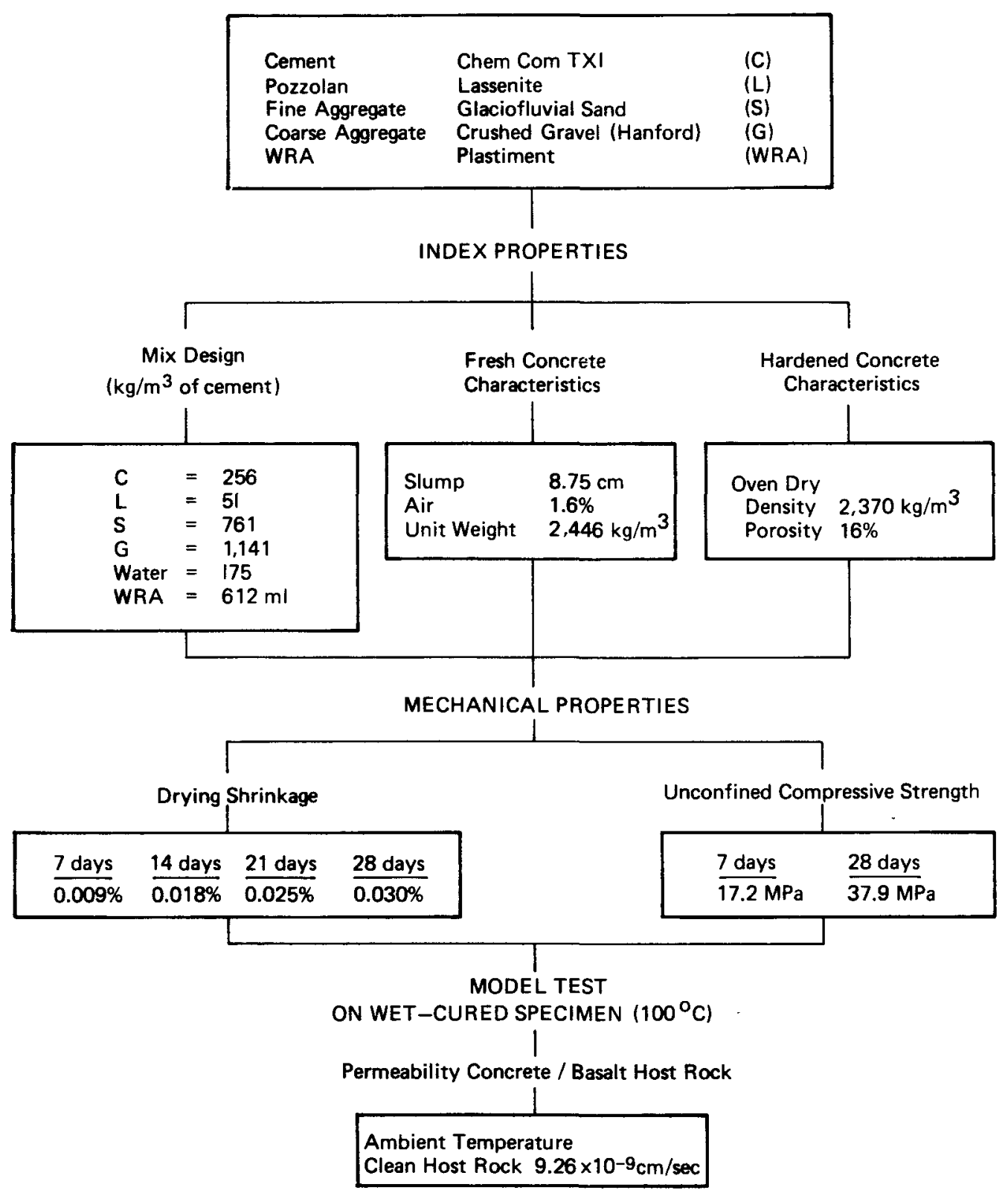

\section{FIGURE 34}


- The restrained volume change of G-TXI-L grout did not meet the non-shrink grout requirements specified in the Corps of Engineers "Handbook for Concrete and Cement" C-588 (U.S. Army Corps of Engineers, 1978) because a slight shrinkage $(0.05$ percent) was observed after 28 days of wet curing. This shrinkage cannot be explained by the addition of Lassenite because the presence of a pozzolan in a cement mixture generally decreases shrinkage. Further testing is needed to refute or confirm this result. The 28-day restrained shrinkage result for $G-V-L$ was found to be twice that for the G-TXI-L. Nonetheless, it is considerably lower than that reported earlier for portland cement Type $V$ mortar without an additive, even though a higher water/cement ratio was used. A non-shrink grout could be obtained by adding a slightly greater amount of aluminum powder and/or Plastiment and/or Lassenite in the G-V-L mix. No shrinkage was observed for G-V-S grout, indicating that the addition of finely ground aluminum powder tends to reduce the shrinkage behavior of cement mixtures.

- The "28-day" compressive strength measurements of grout cylinders under standard curing and testing temperatures were found to be $39.2 \mathrm{MPa}$ for G-TXI-L, $28.6 \mathrm{MPa}$ for $G-V-L$, and $24.8 \mathrm{MPa}$ for $G-V-S$. These values are within the design range needed for plugs to restrain the expected lithostatic and thermomechanical loading forces at plug-seat depths (see Table A-I, Appendix A).

- Grout plug/basalt (host rock) bond strengths measured at standard temperature are significantly higher for G-TXI-L $(10.8 \mathrm{MPa})$ and G-V-L $(10.0 \mathrm{MPa})$ than for G-V-S (4.3 $\mathrm{MPa})$. The high values and the similarity in bond 
strengths for $\mathrm{G}-\mathrm{V}-\mathrm{L}$ and $\mathrm{G}-\mathrm{TXI}-\mathrm{L}$ are attractive for better meeting $\mathrm{plug} /$ wall rock interface performance requirements and tend to confirm the mixture design studies conducted during screening tests.

Significantly lower bond strengths were obtained for models with mud-contaminated drill hole walls, which suggests that in actual practice, boreholes should be flushed before plugging.

- Comparisons of bond strengths obtained at standard temperature with bond strengths obtained at high temperature $\left(100^{\circ} \mathrm{C}\right)$ indicate a decrease in bond strength with increasing temperature. Percentage deterioration of bond strength is 19 percent for G-V-S, 61 percent for G-V-L, and 88 percent for G-TXI-L. Once again, the addition of silica flour greatly improved the high temperature performance of the cement mixtures. Note that these bond strengths take into account shrinkage of grout plugs caused by 48-hour oven curing prior to testing.

The test data show model plugs composed of portland cement Type $V$ have a permeability of less than $10^{-8} \mathrm{~cm} / \mathrm{sec}$, which is surprisingly low considering the relatively high porosity of these mixtures. The model plug composed of Chem Com TXI cement is somewhat more permeable $(3.5 \times 10-8 \mathrm{~cm} / \mathrm{sec})$. It should be remembered that each model plug was subjected to a 72-hour curing period in an autoclave at $100^{\circ} \mathrm{C}$ prior to testing. This procedure was chosen to accelerate the curing of the grout mixtures in order to meet project time constraints. As mentioned earlier, cement mixtures containing Chem Com TXI cement exhibited a deterioration in structural strength when 
cured at elevated temperature. Consequently, lower permeability may be expected for mixtures cured at ambient temperature.

\subsubsection{Concrete Performance}

- The mixture containing $\mathrm{C}-\mathrm{V}-\mathrm{S}$ had a slightly higher slump $(11.43 \mathrm{~cm})$ than the other concrete mixtures. This should be considered when comparing performance results of the various concrete mixtures. Thus, for a lower slump, C-V-S may have a higher density and strength and lower permeability.

- Once again, concrete mixtures containing C-TXI-L had a higher porosity. Porosity and density data for the three concrete mixtures seemed consistent and were characteristic of relatively dense concretes.

- As in the case of the grout, the concrete mixture containing chem com TXI cement does not exhibit the expected expansive behavior but shows a slight shrinkage ( 0.03 percent) after the standard 28 -day dry curing. In fact, no significant difference in volume change was observed between the three concrete mixtures. As in the case of the grout, $C-V-S$ exhibited the lowest shrinkage, while the concrete mixture containing $C-V-L$ had the highest.

- The "28-day" compressive strength measurements for concrete cylinders were $42.1 \mathrm{MPa}$ for $\mathrm{C}-\mathrm{V}-\mathrm{S}, 37.9 \mathrm{MPa}$ for $\mathrm{C}-\mathrm{TXI}-\mathrm{L}$, and $36.5 \mathrm{MPa}$ for $\mathrm{C}-\mathrm{V}-\mathrm{L}$. Concretes containing silica flour appear to have the greatest structural strength, even when cured under standard temperatures. 
- The results of permeability tests on concrete plug/basalt (host rock) models confirm the results obtained on model grout plugs. C-TXI-L is slightly more permeable $(9.26 \quad x \quad 10-9 \mathrm{~cm} / \mathrm{sec})$ than $\mathrm{C}-\mathrm{V}-\mathrm{L}$ $\left(3.7 \times 10^{-9} \mathrm{~cm} / \mathrm{sec}\right)$ and $\mathrm{C}-\mathrm{V}-\mathrm{S}\left(1.5 \times 0^{-9} \mathrm{~cm} / \mathrm{sec}\right)$. The permeability obtained for $\mathrm{C}-\mathrm{V}-\mathrm{S}$ is on the order of the permeability of the basalt core container (assumed to be 10-9 cm/sec from Table A-I, Appendix A). This result suggests that the design of a concrete plug having similar hydraulic characteristics as those reported for basalt flows at the Hanford site is possible (see Table A-I, Appendix A).

5.6 COMPACTED EARTH MATERIAL - PERFORMANCE TESTS

\subsubsection{Materials and Mixtures}

Except for the elimination of six fine-grained sediments from the Pasco Basin, no further screening was attempted in the first phase of physical testing described in Section 5.3. Some of the materials and mixtures that survived the screening tests may be more or less suitable than others as potential plug components. However, no definitive arguments were found to justify not testing those mixtures remaining after the screening tests on compacted earth materials. Therefore, mixtures considered in this section are the same as those described in Section 5.3.2, except for the deletion of the six materials from the Pasco Basin. 


\subsubsection{Testing Program and Procedures}

Performance tests included: (1) model tests of the bond strength and permeability of miniature compacted soil plugs; and (2) consolidation tests on compacted sandy clay mixtures. Consolidation tests were made using ASTM D-2435 method "One Dimensional Consolidation of Soil Materials" (ASTM, 1978b). Bond strength tests were carried out using the same procedures as for bond strength determinations on concrete plug/basalt (host rock) models described in section 5.5.3. Plug placement simulation and permeability tests are described below.

\subsubsection{Compacted Soil Plug Model Preparation}

Prior to compaction, soil components of the model plug were dry-mixed. Subsequently, sufficient water was added to dampen the mixture to optimum water content. This mixture was then stored in sealed plastic bags and allowed to hydrate for two days. The geometric characteristics of the basalt (host rock) core used to model bond strengths during test runs (and alternatively, to model permeability tests) were chosen as follows: the outer core diameter was $10.16 \mathrm{~cm}$, the internal hole diameter (drilled lengthwise into the core) was $6.35 \mathrm{~cm}$, and the core length was $13.97 \mathrm{~cm}$ (and alternatively for permeability tests, $7.62 \mathrm{~cm}$ ) . Borehole walls were thoroughly washed and allowed to air-dry before placement and compaction of the simulated plug materials. Samples simulating mud contamination of boreholes were prepared using the same procedure described in section 5.5.3.1. Soil placement was performed by compacting the soil materials in the $6.35-\mathrm{cm}$ diameter hole drilled into the basalt core in five equal layers (three layers for permeability tests); this placement would give a total length of compacted soil not exceeding $12.5 \mathrm{~cm}$ 
$(7.62 \mathrm{~cm}$ for permeability tests), such that 95 percent of maximum dry density was achieved using the compacting method described earlier in section 5.3.3.2.

\subsubsection{Permeability Measurements of Compacted Soil} Plug/Basalt (Host Rock) Models

Special permeameters and cap plates were designed for the permeability testing of the miniature soil plugs which have 15.24-cm diameter bases. The cap plate has a recessed $7.62-\mathrm{cm}$ diameter $O$ ring and a $6.35-\mathrm{cm}$ diameter porous stone through which channels ( $3 \mathrm{~mm}$ in diameter) are drilled and machined such that a flow path exists between the porous stones and hydraulic fittings screwed into the plate. Base plate and cap plate were placed directly on the dressed surface of the basalt (host rock) core containing the compacted soil materials. As in the case of cement plugs, permeability was determined using the falling head method. However, to avoid any potential for particle migration, only a $0.003 \mathrm{MPa}$ pressure differential was applied between the top and the bottom of the compacted plug, corresponding to an approximate hydraulic gradient of 4 .

\subsubsection{Test Results and Discussion}

5.6.3.1 Bond Strength of Compacted Soil Plug

Results of bond strength tests carried out at ambient temperature on soil plugs compacted in clean basalt (host rock) cores are given on Figure 35 for Wyoming bentonite, Oregon bentonite, and Ringold clay D, each mixed with glaciofluvial sand. Clay content ranged from 10 to 70 percent. Highest bond strengths were observed for Oregon bentonite/sand mixtures for all clay contents, closely followed by bond strengths obtained 


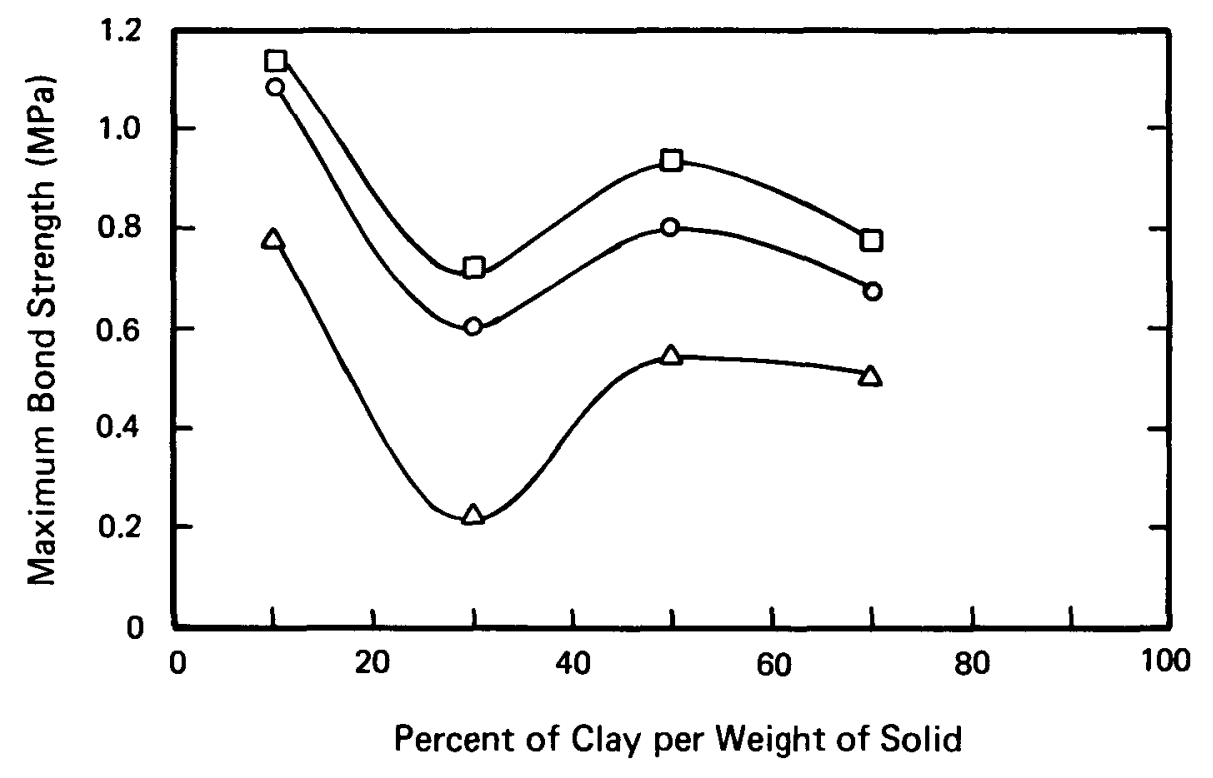
EXPLANATION
- Wyoming bentonite
$\square$ Oregon bentonite
$\Delta$ Ringold clay 
for Wyoming bentonite/sand mixtures. Ringold clay D/sand mixtures had significantly lower bond strengths, particularly for clay content less than 50 percent. The shapes of curves plotted on the basis of experimental values for bond strength are similar for all three types of clay.

Maximum bond strength was observed for a clay content equal to 10 percent. For clay contents varying between 10 and 30 percent, bond strengths decreased sharply. Subsequently, bond strengths alternately increased and decreased for clay content ranging from 30 to 50 percent and from 50 to 70 percent.

The variation in curve shapes for clay content varying from 10 to 50 percent indicate a change in the physical nature of the bond between the compacted soil plug and the basalt (host rock). This change is interpreted as a transition from an essentially frictional to an essentially cohesive bond. This hypothesis is supported by comparing (for increasing clay percentage) the variation of the unconfined compressive strength of clay/sand mixtures, which is considered to be an approximation of twice the cohesion of the clay mixtures (Figure 36), and the variation in the friction angle. In the absence of specific data for the friction angle, Figure 36 gives the variation of the residual friction angle (expressed by its tangent) with variations in the clay content, as obtained by Kenney (1967) for sodium montmorillonite/quartz sand mixtures under an effective confining pressure of $0.1 \mathrm{MPa}$.

Figure 36 indicates a low and approximately constant value of the friction angle for clay content greater than 20 percent. Accordingly, variations in bond strength should follow these values of cohesion (unconfined compressive strength). Thus, the bond between the compacted soil plug and basalt host rock 


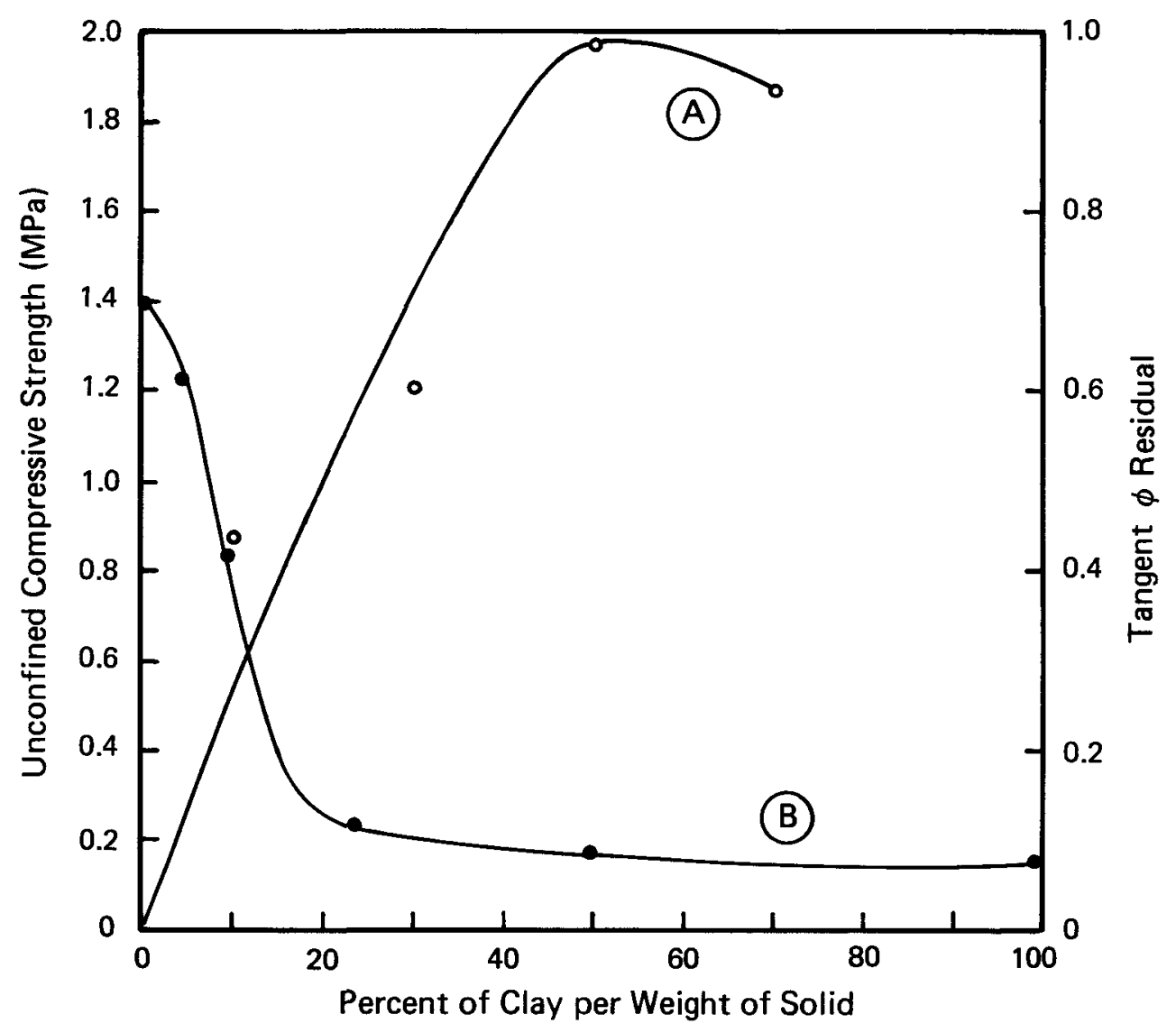

EXPLANATION (A) - Wyoming bentonite compressive strength values
obtained in WCC physical testing

(B) - Tangent $\phi$ residual of sodium montmorillonite/quartz sand mixtures under $\sigma_{n}^{\prime}=0.1 \mathrm{MPa}$ (Kenney, 1967) 
is essentially cohesive in nature. For clay content ranging from 10 to 20 percent, the linear increase in cohesion is accompanied by a sharp decrease in friction angle, and the nature of the bond varies from frictional to cohesive. Accordingly, the minimum value for bond strength is expected to occur for clay content between 10 and 20 percent. Further testing is needed to precisely locate this minimum.

This hypothesis of a transition in bond nature from frictional to cohesive seems to be in agreement with the shapes of curves giving the change in bond strength with the percent of sliding deformation. Typical curves given in Figure 37 for 10 percent clay content ratios of Wyoming bentonite and sand show a relatively slow differential increase in bond strength until the peak value is reached, which is followed by a slow decrease in strength (residual bond strength). These curves also show a greater differential increase in bond strength followed by a sharp loss of cohesion for clay content greater than 10 percent. Note that for all clay percentages, significant residual bond strength was observed after the peak bond strength was achieved, indicating only a partial destruction of the bond under large sliding deformations. Other data (not included in this report) indicate that the bond strength is strongly dependent on percent compaction. Bond strengths of Oregon bentonite/sand mixtures (for a clay content of 10 percent) exhibited a 70 percent decrease when soil plugs compacted at 95 percent and at 87 percent were compared.

Table XXII summarizes the results of bond strength measurements for: (1) soil plugs compacted at ambient temperature in a mudcontaminated basalt (host rock) core; and (2) soil plugs compacted at high temperature $\left(100^{\circ} \mathrm{C}\right)$ in a clean basalt (host rock) core for two different clay contents of 10 and 50 percent: 


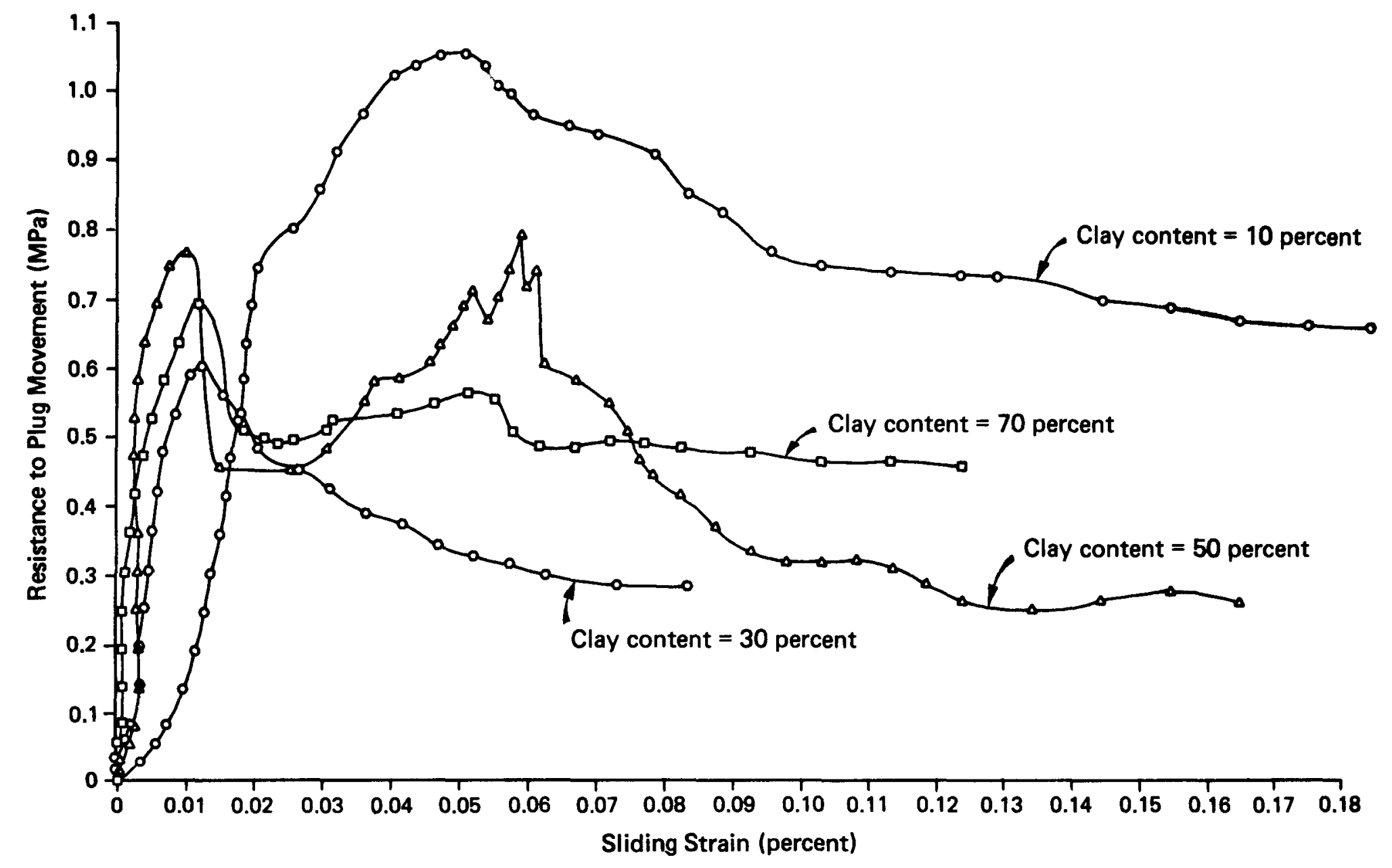

FIGURE 37

BOND STRENGTH -SLIDING STRAIN CURVES FOR SAND/CLAY MIXTURES,

CONTAINING WYOMING BENTONITE AND GLACIOFLUVIAL SAND 
TABLE XXII

SUMMARY OF BOND STRENGTH DATA

FOR SELECTED CLAY/SAND MIXTURES

\begin{tabular}{|c|c|c|c|}
\hline $\begin{array}{l}\text { MIXTURE } \\
\text { COMPONENTS }\end{array}$ & $\begin{array}{l}\text { BOND STRENGTH } \\
\text { Q AMBIENT } \\
\text { TEMPERATURE (MPa) }\end{array}$ & $\begin{array}{l}\text { BOND STRENGTH } \\
\text { @ AMBIENT } \\
\text { TEMPERATURE ON } \\
\text { MUD CONTAMINATED } \\
\text { HOST ROCK (MPa) }\end{array}$ & $\begin{array}{c}\text { BOND STRENGTH } \\
0100^{\circ} \mathrm{C}(\mathrm{MPa})\end{array}$ \\
\hline $\begin{array}{l}10 \% \text { Wyoming bentonite } \\
\text { 90\% Glaciofluvial send }\end{array}$ & 0.11 & 0.67 & $\approx 7^{*}$ \\
\hline $\begin{array}{l}50 \% \text { Wyoming bentonite } \\
50 \% \text { Glecieftuvid sand }\end{array}$ & 0.80 & 0.30 & 0.51 \\
\hline $\begin{array}{l}10 \% \text { Oregon bentonite } \\
90 \% \text { Glaciofluviel sand }\end{array}$ & 0.11 & 0.10 & $\approx 7^{*}$ \\
\hline $\begin{array}{l}50 \% \text { Oregon bentonite } \\
50 \% \text { Glaciofluviel sand }\end{array}$ & 0.94 & 0.45 & 0.27 \\
\hline $\begin{array}{l}\text { 10\% Ringold clay } \\
\text { co\% Glaciofluvial sand }\end{array}$ & 0.78 & 0.46 & 0.63 \\
\hline $\begin{array}{l}\text { 50\% Ringold clay } \\
50 \% \text { Glaciofluvial sand }\end{array}$ & 0.54 & 0.37 & $?$ \\
\hline
\end{tabular}

"Model plug left for 12 hours in basalt block in oven at $100^{\circ} \mathrm{C}$ prior to testing. Bond strength values are approximate and are obtained from pressure gange indication of a hydraulic jack. 
- In general, the contamination of the simulated borehole walls in the basalt core produced a decrease in bond strength. Percent deterioration was found to be greater for higher clay content; and

- Experimental values for bond strength obtained at high temperature $\left(100^{\circ} \mathrm{C}\right)$ indicated a net deterioration of the bond for a clay content of 50 percent. This may be due to shrinkage of the clay fraction in the compacted soil plug; testing at high temperature was made without attempting to maintain moisture content in the plug.

An exceptionally high bond strength $(7 \mathrm{MPa})$ was observed for bentonite/sand mixtures containing 90 percent glaciofluvial sand. In this test, the miniature plug/basalt host rock models were left for 12 hours in a conventional oven at $100^{\circ} \mathrm{C}$ prior to testing. Accordingly, no comparison of bond strengths was attempted between mixtures containing various percentages of clay because different curing methods were applied. Note that bond strengths obtained for bentonite mixtures containing 90 percent sand were approximately twice those observed for grout plug/basalt (host rock) models at high temperature (see section 5.5.3.3). These high bond strengths are significant and may be the result of cementation between the basalt core walls and the compacted soil plug. Further testing is strongly recommended to confirm this result.

5.6.3.2 Permeability of Compacted Soil Plug/Basalt (Host Rock) Models

Saturation time and permeability results are given in Table XXIII for the compacted soil plug/basalt (host rock) models. Only one permeability test was completed within the 
TABLE XXIII

$$
\begin{aligned}
& \text { SUMMARY OF PERMEABILITY TESTS ON } \\
& \text { COHESIVE PLUG/BASALT (HOST ROCK) MODELS }
\end{aligned}
$$

\begin{tabular}{|l|c|c|}
\hline $\begin{array}{c}\text { MIXTURE } \\
\text { COMPONENTS }\end{array}$ & $\begin{array}{c}\text { SATURATION } \\
\text { TIME (DAYS) }\end{array}$ & $\begin{array}{c}\text { PERMEABILITY } \\
\text { (cm/sec) }\end{array}$ \\
\hline $\begin{array}{l}10 \% \text { Wyoming bentonite } \\
90 \% \text { Glaciofluvial sand }\end{array}$ & 42 & Still saturating \\
\hline $\begin{array}{l}50 \% \text { Wyoming bentonite } \\
50 \% \text { Glaciofluvial sand }\end{array}$ & 53 & Still saturating \\
\hline $\begin{array}{l}10 \% \text { Oregon bentonite } \\
50 \% \text { Glaciofluvial sand }\end{array}$ & 37 & $9.5 \times$ 10-8 \\
\hline $\begin{array}{l}50 \% \text { Oregon bentonite } \\
50 \% \text { Glaciofluvial sand }\end{array}$ & 62 & Still saturating \\
\hline $\begin{array}{l}50 \% \text { Ringold clay } \\
50 \% \text { Glaciofluvial sand }\end{array}$ & 38 & Still saturating \\
\hline
\end{tabular}

NOTES: Plug volume $=2.32 \times 10^{-4} \mathrm{~m}^{3}$

Hydraulic gredient $=4$ 
time limit of the physical testing program. A model plug composed of 10 percent Oregon bentonite and 90 percent glaciofluvial sand was observed to have a permeability of $9.5 \times 10-8 \mathrm{~cm} / \mathrm{sec}$. This value is somewhat higher than that desired in laboratory testing of permeability, which should be near the permeability reported for intact basalt (Table A-I, Appendix A). Actual field placement of a similar plug in a borehole, shaft, or tunnel should result in a still higher insitu permeability.

The four other permeability model tests were still not completely saturated by the end of this testing program. In the case of mortar or concrete plugs, saturation times varied between one and two weeks for permeabilities less than 10-8 cm/sec. Saturation times for soil plugs composed of 10 percent Oregon bentonite and 90 percent glaciofluvial sand were more than twice as long (four weeks) for a sample having a permeability almost 10 times greater. This clearly shows the slowness of the hydration process in bentonite mixtures. For the mixture having 10 percent Wyoming bentonite and 90 percent glaciofluvial sand, 42 days were insufficient to obtain complete saturation of the model plug.

In some respects, soil consolidation theory governing the displacement of excess pressured water out of clay samples may be representative of the mechanisms governing the movement of excess pressured water into an unsaturated sample. Rough calculations with such a theory suggest 50 days of saturation time is not excessive. Furthermore, similar calculations show that a 7-m diameter prototype plug of compacted Wyoming bentonite and sand (with a clay content of 50 percent) may require more than 1,000 years to achieve saturation. Furthermore, clay/sand mixtures with 50 percent Wyoming 
bentonite are expected to be essentially impervious, as stated by Grim (1962), although no experimental data are available to confirm this. These observations confirm the relatively good performance of compacted clay/sand plugs as seepage barriers.

\subsubsection{Consolidation Tests on Compacted Sand/Clay Mixtures}

Curves showing variations in void ratio with variations in consolidation pressure are given in Figures 38 and 39 for Oregon bentonite/glaciofluvial-sand mixtures having clay contents of 10 and 50 percent. Oregon bentonite mixtures with a clay content of 10 percent had a low compressibility. Under consolidation pressures ranging fron 3 to $6.4 \mathrm{MPa}$, the compression index was only 0.02. However, the unloading part of the consolidation curve exhibits a hysteresis that suggests the potential for separation at the interface between the soil plug and borehole wall after cyclic loading. Such cyclic loading could be produced by thermal cycles in the repository environment due to radioactive waste decay.

By contrast, the Oregon bentonite mixture with a clay content of 50 percent exhibited a higher compressibility; a compression index of 0.105 was computed for consolidation pressures ranging from 3 to $6.4 \mathrm{MPa}$. However, in this case the unloading part of the consolidation curve indicates a strong swelling potential for this mixture. Void ratio values more than or equal to the initial void ratio of the compacted mixture were observed for consolidation pressures less than or equal to $3 \mathrm{MPa}$ during loading and less than or equal to $2.2 \mathrm{MPa}$ during unloading. This result suggests that, even after cyclic loading, a tight contact between the soil plug and borehole wall should be expected. For unloading pressures less than $2.2 \mathrm{MPa}$, the confined plug should even exert a self-stressing pressure against the walls due to swelling of the plug material. This 


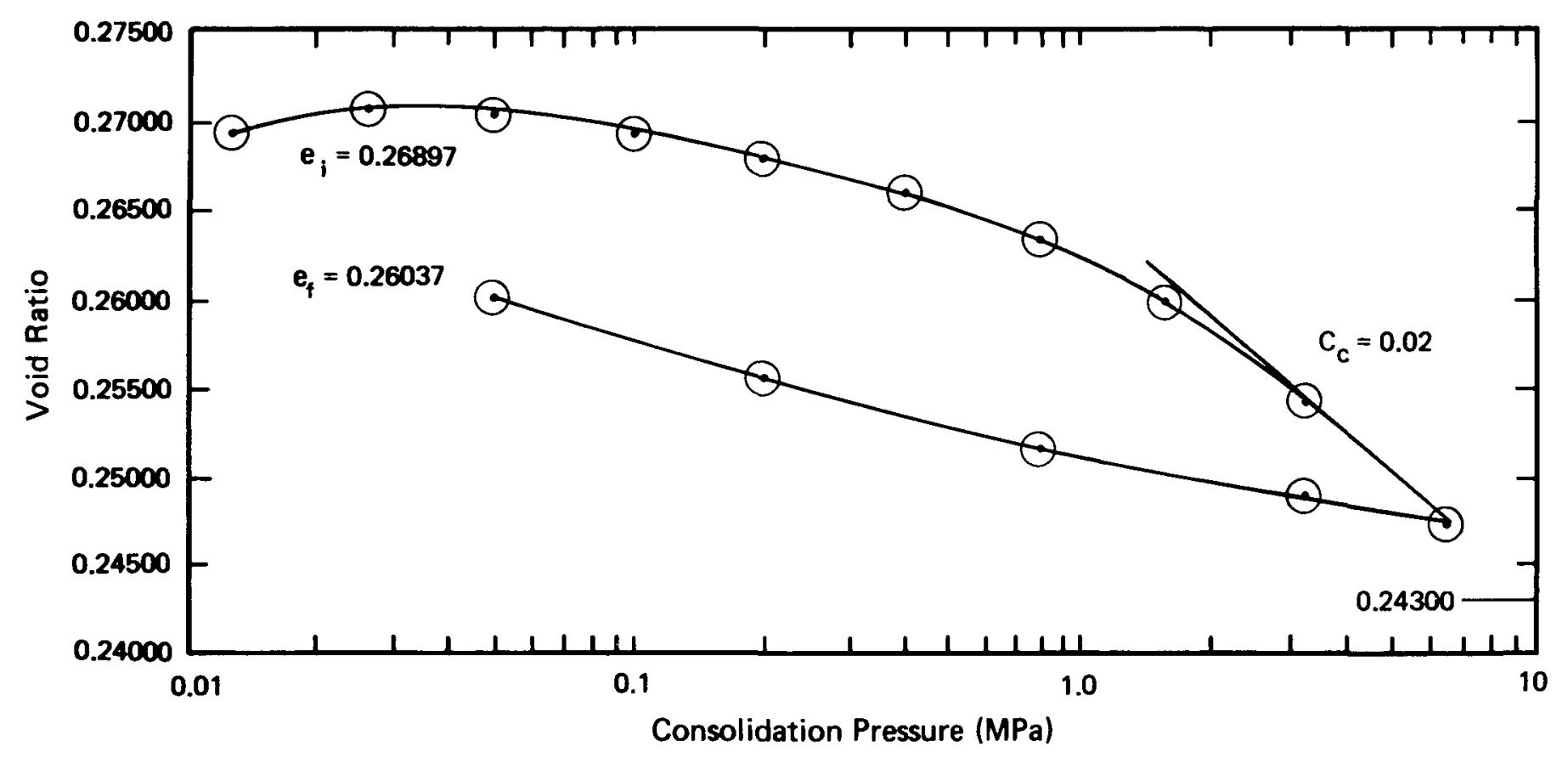

\footnotetext{
EXPLANATION

$e_{i}=$ Mutual void ratio

$e_{f}=$ Final void ratio

$\mathrm{C}_{\mathrm{c}}=$ Compression index (for loading pressure ranging from 3.2 to $6.4 \mathrm{MPa}$ )
} 


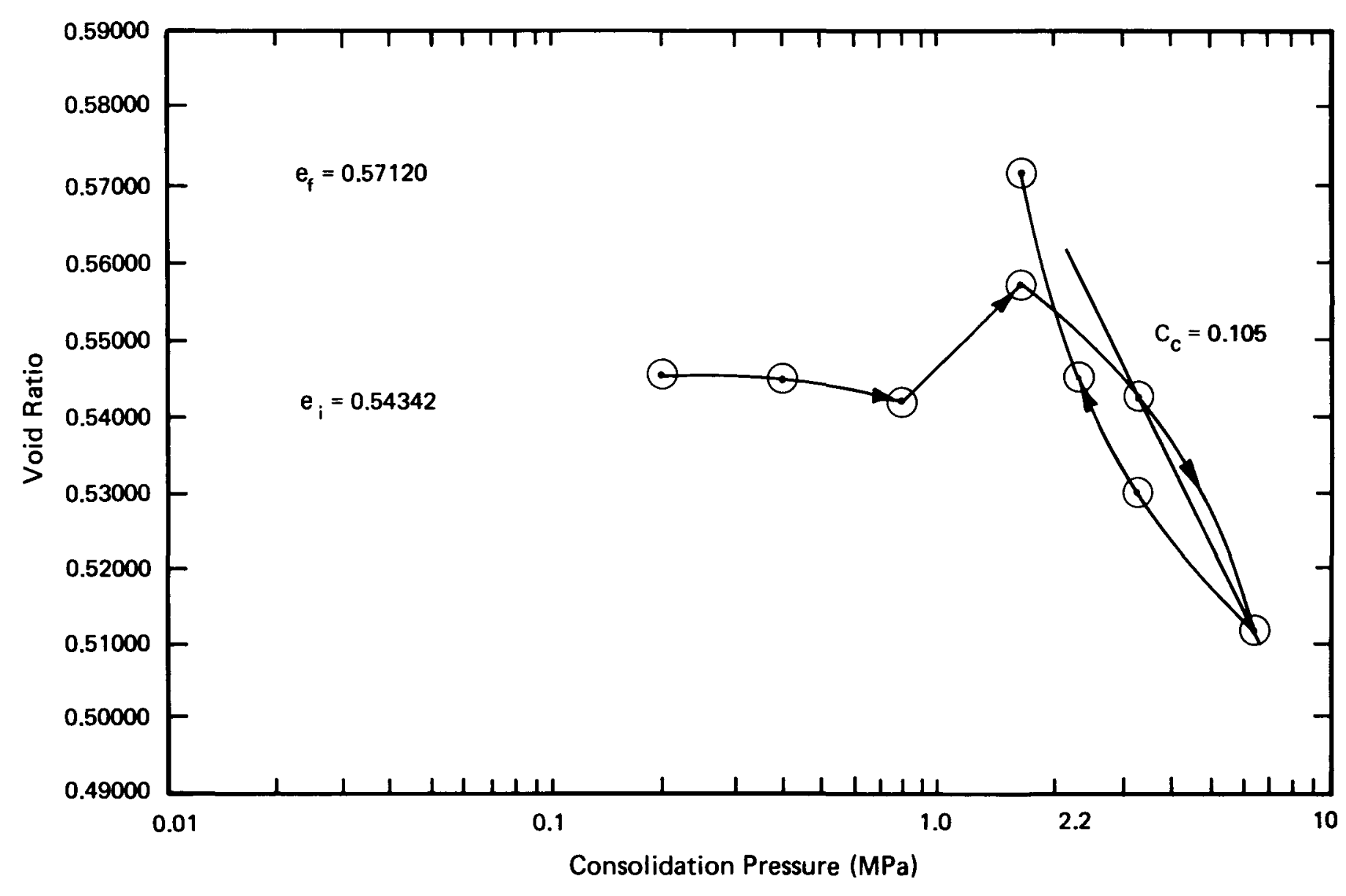

\footnotetext{
EXPLANATION

$e_{i}=$ Initial void ratio

$e_{f}=$ Final void ratio

$\mathrm{C}_{\mathrm{c}}=$ Compression index (for loading pressure ranging from 3.2 to $6.4 \mathrm{MPa}$ )
} 
result is considered promising but should be confirmed and extended by testing the long-term swelling potential of sand/clay mixtures under elevated temperature conditions.

\subsection{SOIL/CLAY SLURRIES - PERFORMANCE TESTS}

As discussed in section 5.4, the primary objective of evaluating clay slurries was to determine the most suitable slurry for use in conjunction with crushed basalt gravel. Such material would derive its strength from a framework of crushed basalt in grain-to-grain contact; the slurry would be intruded into framework voids to act as an impermeable filler which would inhibit fluid migration as well as adding to the ion exchange potential and sorption capacity of this type of plug material. On the basis of workability, stability and thixotropy evaluated for various candidate clays during screening tests (Section 5.4), only those slurries containing 6 to 8 percent by weight of premium grade bentonite (Shurgel) were found to be suitable.

Premixed combinations of clay slurries and gravel or coarsecrushed basalt should have the same low permeability, enhanced ion exchange potential, and sorption capacity as slurry/aggregate mixtures produced by injection of a slurry into a coarse granular framework. Premixed materials make it possible to use slurries containing sand and natural clay that were found to be unsuitable for slurry injection during screening tests and, thereby, allow for a wider variety of plug materials. The sand and clay can occupy a significant portion of the void space between coarse gravel or basalt aggregate as well as be incorporated into the grain-to-grain contacts of the structural framework itself. Consequently, the relative proportions of components in premixed slurry/aggregate samples can be more varied than for slurry injection samples 


\subsubsection{Design of Materials and Mixtures}

As was discussed in section 5.4.3, a slurry containing 6 to 8 percent by weight shurgel (processed bentonite) was found to exhibit the best properties of workability, stability, and thixotropy. Therefore, this slurry was adopted for further study in this phase of physical testing and was combined with fine-crushed zeolite $(-4.6 \mathrm{~mm})$ from Oregon, Ringold clay $D$, and precompressed bentonite pellets to form a variety of samples. Crushed basalt gravel $(-1.9 \mathrm{~cm})$ used in these tests was from the Hanford Site.

Test mixtures are listed in Tables XXIV and XXV. Percentages listed on these tables indicate percentage of solids by weight. All materials, except Shurgel, were inixed in an airdried condition. Shurgel was prepared as a slurry that contained the percent solids by weight given in parenthesis on Tables XXIV and XXV.

The following rationale was used in developing each of these mixtures:

- For samples PT 428 I, II, and III, air-dried gravel was packed as densely as possible; slurry was then injected into the sample;

- For sample PT 429 A, air-dried gravel was premixed with slurry containing bentonite pellets to determine if the hydration and swelling of the pellets would offset, or even exceed, consolidation of the mixture; 
Summary of Data and Test Results for Preplacement and Slurry Injection of Aggregate

\begin{tabular}{|c|c|c|c|}
\hline Mixture & Density & Porosity & Bond Strength \\
\hline 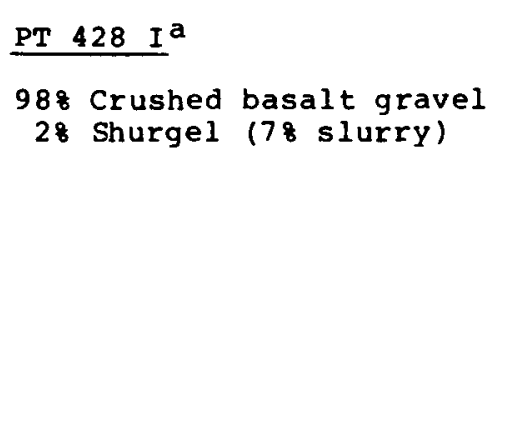 & $\begin{aligned} \text { Sample volume }=409.75 \mathrm{~cm}^{3} \\
\text { Dry density of aggregate }=1.46 \mathrm{gm} / \mathrm{cm}^{3} \\
=398 \mathrm{relative} \\
\text { density } \\
\text { Density of slurry }=1.009 \mathrm{gm} / \mathrm{dm}^{3} \\
\text { Initial sample density }=1.95 \mathrm{gm} / \mathrm{cm}^{3} \\
\text { (questionable data) }\end{aligned}$ & 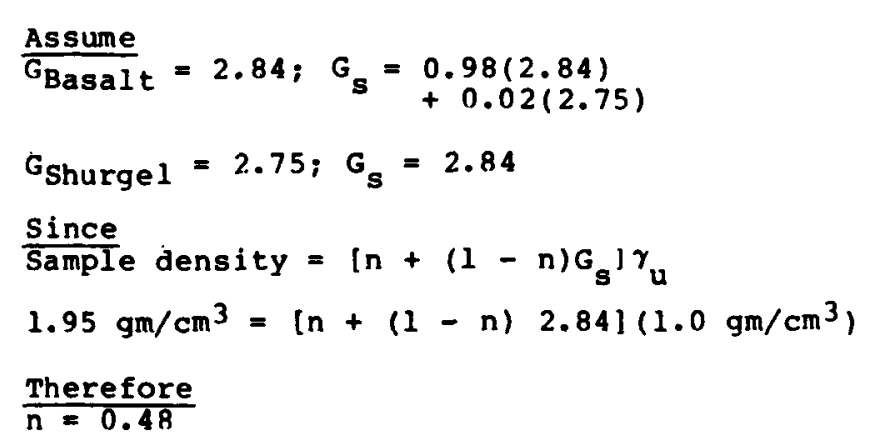 & $\begin{array}{l}\text { - Sample slumped out of steel mold. } \\
\text { - Rubber membranes were not used inside } \\
\text { steel mold. }\end{array}$ \\
\hline $\begin{array}{l}\text { PT } 428 \text { II }^{\mathrm{a}} \\
988 \text { Crushed basalt gravel } \\
28 \text { Shurgel ( } 78 \text { slurry) }\end{array}$ & 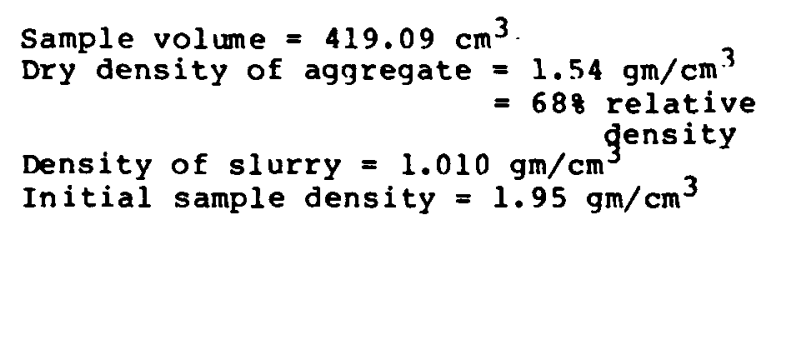 & $\begin{aligned} & \frac{\text { Assume }}{\text { as above, }}, G_{s}= 0.98(2.84) \\
&+0.02(2.75) \\
& G_{s}=2.84 \\
& \frac{\text { Since }}{1.95 \mathrm{gm} / \mathrm{cm}^{3}=}=[\mathrm{n}+(1-n) 2.84]\left(1.0 \mathrm{gm} / \mathrm{cm}^{3}\right) \\
& \frac{\text { Therefore }}{n=0.48}\end{aligned}$ & $\begin{array}{l}\text { - Sample slumped out of steel mold after } \\
\text { plug resistance reached } 0.002 \mathrm{~kg} / \mathrm{cm}^{2} \text {. } \\
\text { - Rubber membrane was not used inside } \\
\text { steel mold. }\end{array}$ \\
\hline $\begin{array}{l}\text { PT } 428 \text { III } \\
988 \text { Crushed basalt gravel } \\
\text { 28 Shurgel }(78 \text { slurry) }\end{array}$ & 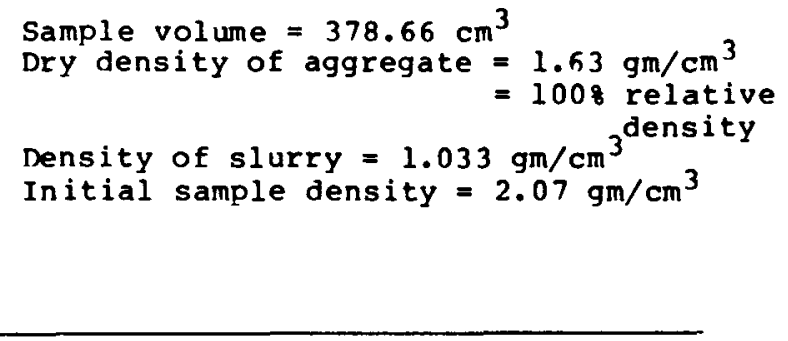 & 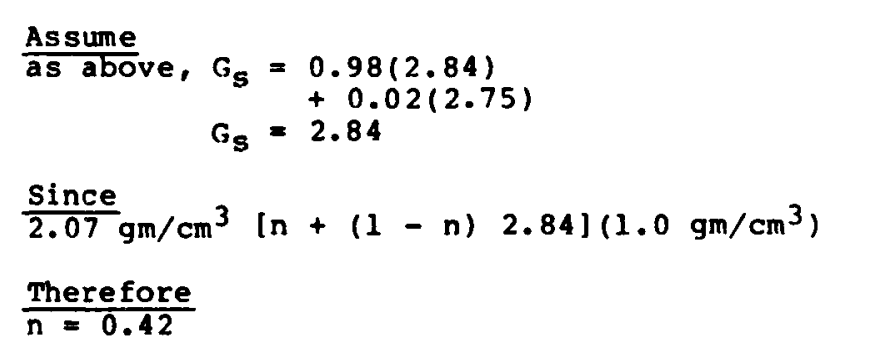 & $\begin{array}{l}\text { No test possible } \\
\text { - Rubber membrane was used inside steel } \\
\text { mold. } \\
\text { - Triaxial compressive strength test } \\
\text { pending. }\end{array}$ \\
\hline 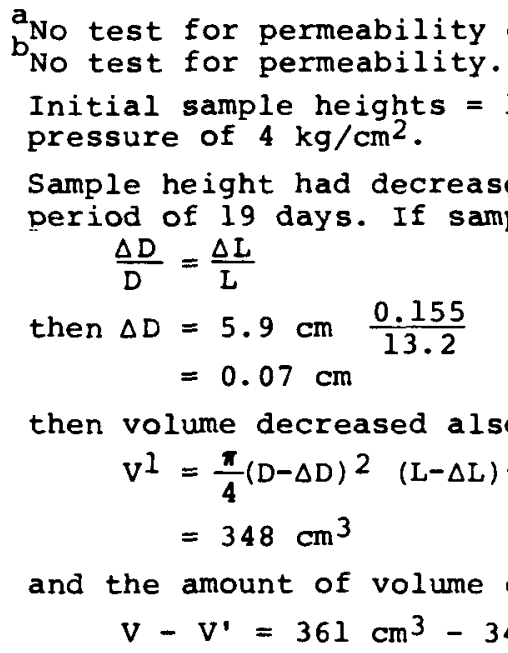 & $\begin{array}{l}\text { compressibility. } \\
\text { mpressibility: } \\
2 \mathrm{~cm} \text { under an effective consolidation } \\
\text { by } 2.55 \mathrm{~mm} \text { when measured after a } \\
\text { diameter also decreased }\end{array}$ & & \\
\hline
\end{tabular}


TABLE XXV

SUMMARY OF DATA AND TEST RESULTS FOR PREMIXED SLURRY AND AGGREGATE

\begin{tabular}{|c|c|c|c|}
\hline 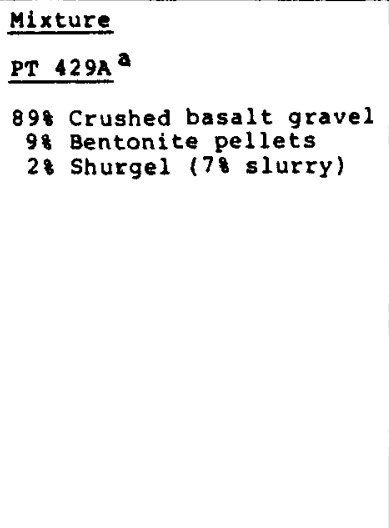 & 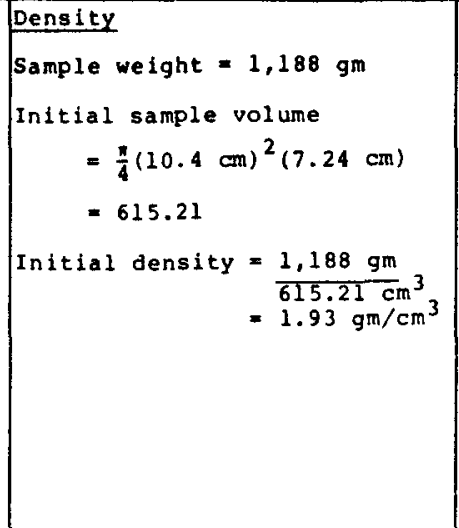 & 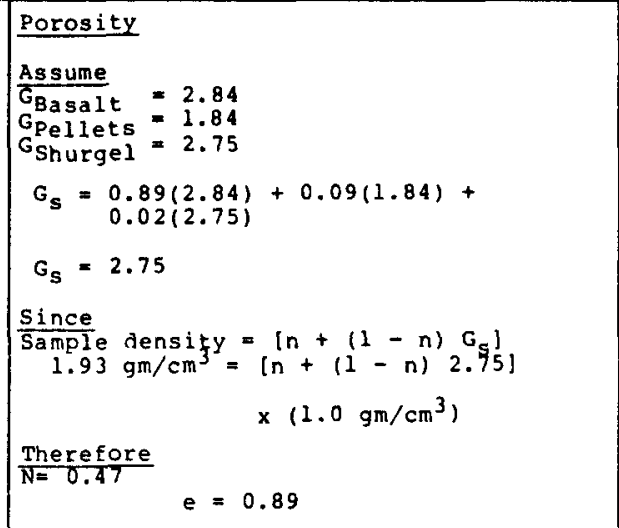 & $\begin{array}{l}\text { Compressibility } \\
\text { Initial sample volume }=615.21 \mathrm{~cm}^{3} \\
\text { Cumulative change in sample volume } \\
=8.68 \mathrm{~cm} \text { over a period of } 22 \text { days } \\
\text { (effective pressure }=5 \mathrm{~kg} / \mathrm{cm}^{2} \text { ) } \\
\text { When sample removed from mold, a } \\
\text { significant amount of bentonite had } \\
\text { still not hydrated. } \\
\text { During the } 22 \text {-day period the change in } \\
\text { sample volume involved: } \\
26.06 \mathrm{~cm}^{3} \text { of swelling, and } \\
-34.74 \mathrm{~cm}^{3} \text { of compression }\end{array}$ \\
\hline $\begin{array}{l}\text { PT } 429 \text { B } \\
208 \text { Crushed basalt gravel } \\
458 \text { Crushed zeolite. } \\
278 \text { Ringold Clay } \\
88 \text { Shurgel (88 slurry) }\end{array}$ & 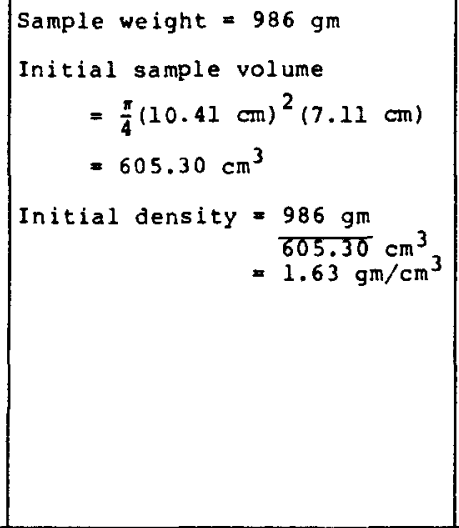 & 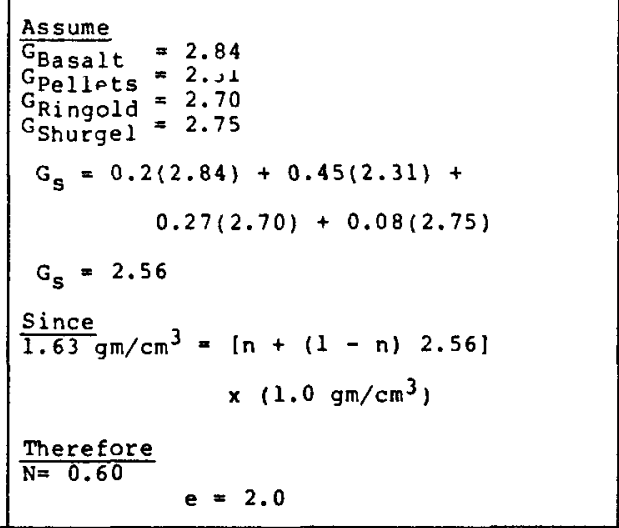 & $\begin{array}{l}\text { Initial sample volume }=605.30 \mathrm{~cm}^{3} \\
\text { Under an effective pressure of } 5 \mathrm{~kg} / \mathrm{cm}^{2} \\
\text { Sample volume decreased by } 40.15 \mathrm{~cm} \\
\text { over a period of } 825 \text { minutes; } \\
\text { thereafter, no significant change in } \\
\text { sample volume occurred since the loading } \\
\text { platen was now sitting on the steel } \\
\text { mold. }\end{array}$ \\
\hline $\begin{array}{l}\frac{\text { PT } 429 C^{b}}{508 \text { Crushed basalt gravel }} \\
258 \text { Crushed zeolite } \\
198 \text { Ringold clay } \\
68 \text { Shurgel (88 slurry) }\end{array}$ & 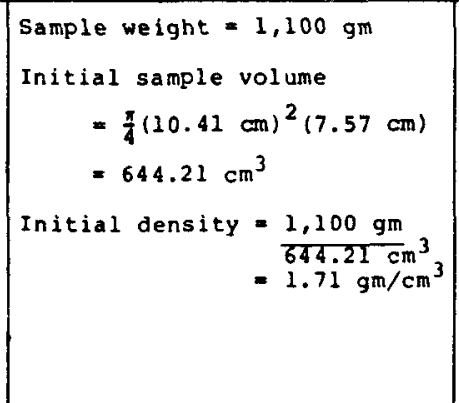 & 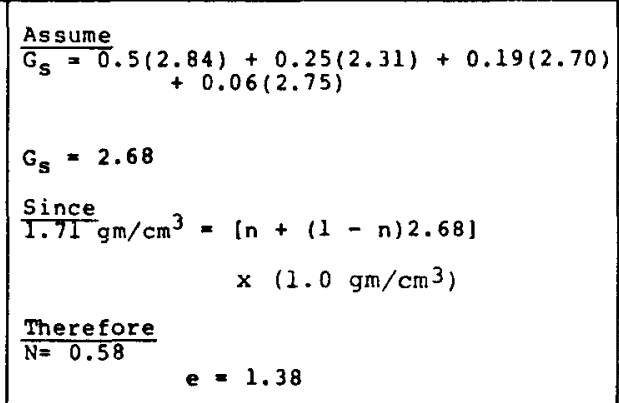 & $\begin{array}{l}\text { Initial sample volume }=644.21 \mathrm{~cm}^{3} \\
\text { under the influence of an ef fective } \\
\text { pressure of } 4.5 \mathrm{~kg} / \mathrm{cm}^{2} \text {. } \\
\text { Sample volume decreased by } 37.85 \mathrm{~cm}^{3} \\
\text { after a period of } 101 \text { minutes, then } \\
\text { decreased by } 10.65 \mathrm{~cm}^{3} \text { over the next } \\
3,844 \text { minutes, the sample was then } \\
\text { unloaded, readjusted and reloaded which } \\
\text { produced do derease in sample volume of } \\
33.27 \mathrm{~cm} \text {. over a period of } 2,850 \\
\text { minutes. No further change occurred } \\
\text { thereafter. }\end{array}$ \\
\hline
\end{tabular}


- For sample PT 429 B, a fine aggregate of crushed zeolite and Ringold clay was added to gravel and slurry to determine if the addition of these would decrease the mixture's permeability; and

- For sample PT 429 C, a different ratio of coarse aggregate to fine aggregate was used to determine what effect this ratio had on the permeability and consolidation of mixtures.

\subsubsection{Tests and Procedures}

The original intention of these studies was to test slurry/aggregate mixtures where the samples were prepared by injecting slurry into a coarse matrix. A special mold for sample preparation was developed which produced samples that could be placed in a conventional triaxial pressure cell for permeability and compressive strength tests. This sample preparation procedure allowed a sample to be subjected to isotropic consolidation while simultaneously performing a falling head permeability test on the same sample and then failing the sample in triaxial compression. This procedure was followed for sample PT 428 III (see Table XXIV); samples PT 428 I and II represent attempts to measure the bond strength developed between slurry/aggregate mixtures and the steel, sample preparation mold.

When testing was later expanded to include samples of premixed slurry and aggregate, there was no time to develop laboratory equipment which could test these mixtures in a manner identical to the conventional triaxial tests used on mixtures prepared by slurry injection. However, equipment in the WCC laboratory in Oakland, California, was available to modify a triaxial 
pressure cell with a steel consolidometer so that samples could be premixed, placed in the consolidometer, and then subjected to one-dimensional consolidation while simultaneously performing a falling head permeability test.

It is important to note that the procedures used to test the two types (injection versus premixed) of slurry/aggregate mixtures were significantly different. Slurry injection samples were isotropically consolidated within a rubber membrane. However, the premixed slurry/aggregate samples were one-dimensionally consolidated within a steel consolidometer. In the case of slurry injection samples, the rubber membrane syueezing the sample intruded void spaces around the sample perimeter and altered the cross-sectional area of the sample itself. On the other hand, the steel consolidometer maintains a constant cross-sectional area, and contact conditions with the sample are different. Consequently, the two types of slurry/aggregate mixtures were not only consolidated differently, conditions around the sample perimeter during permeability tests were also significantly different for the two types of samples.

\subsubsection{Test Results and Discussion}

A summary of data and test results for slurry injection samples is given in Table XXIV, and a summary for premixed slurry/aggregate samples is given in Table XxV. Both tables use the same format, but procedures used to obtain data and test results were significantly different, as discussed above. Thus, caution must be exercised when comparing data from one table with data from the other. However, if used with care, the data and results are still considered a legitimate basis for reasonable comparisons and valid conclusions. 


\subsubsection{Bond Strength for Slurries}

The two attempts at determing the bond strength of slurry/aygregate mixtures that involved injection proved futile. In both instances, the sample essentially slumped out of the steel mold under the influence of its own weight, indicating that little cohesive or frictional force was available to resist sample movement. The lack of cohesion was attributed to the inability of the shurgel clay particles to interact with the walls of the mold, while the lack of significant granular frictional resistance on the wall was attributed to the low relative density of the aggregate as well as the lubrication of aggregate particles when coated with slurry. However, this lack of cohesion and friction was not exhibited by the samples themselves because they were capable of supporting their own weight when the split steel mold was disassembled froln around them.

Some important observations on strength characteristics were made when a sample of premixed slurry and aggregate (sample PT 429I, Table XXV) was removed from the steel consolidometer. This sample was essentially the same composition as slurry injection samples, except that it contained bentonite pellets and had undergone a period of consolidation. Due to swelling of the bentonite and simultaneous consolidation, the sample was tightly squeezed within the steel consolidometer; it did not slump out of the container under the influence of its own weight as other similar samples had. This sample was, in fact, difficult to aig out of the container. In addition, bonding between gravel grains was significantly greater than that exhibited by samples prepared by slurry injection. It appears that hydration and swelling of the bentonite pellets, in 
conjunction with sample consolidation, had an important influence on the cohesive strength of the mixture.

\subsubsection{Compressibility of Clay Slurries}

From test results shown in Tables XXIV and XXV, inconsistencies resulted due to problems with maintaining pressures and measuring changes in sample height. However, general data trends indicate that compressibility of the various mixtures increased with increasing porosity. With respect to sample PT 429A (Table XXV), the relationship between porosity and compressibility is difficult to evaluate because test results were strongly influenced by swelling of the bentonite pellets. The volume changes experienced by this sample alternated between swelling and compression, in part due to the bentonite and in part due to the cell pressure regulator which allowed the effective consolidation pressure to fluctuate between 0.1 and $0.48 \mathrm{MPa}$. However, the capacity of bentonite to swell did appear to offset the effect of consolidation.

Test results for premixed slurry/aggregate samples PT 429 B and PT $429 \mathrm{C}$ indicate that an increase in the percentage of fine aggregate will produce an increase in porosity and an attendant increase in compressibility. In addition to the high porosity of these mixtures (which, in turn, affects compressibility), D'Appolonia and Ryan (1979) present data showing that compressibility of a slurry/aggregate mixture will also increase as the percentage of coarse aggregate (structural framework) is decreased. One other consideration, mentioned earlier, is the low strength and breakdown of crushed zeolite, which will also increase the compressibility of mixtures. 


\subsubsection{Permeability of Clay Slurries}

As shown on Tables XXIV and XXV, only one permeability test was fully completed. The sample (PT $429 \mathrm{C}$ ) incorporated premixed slurry, coarse aggregate, and fine aggregate that was consolidated under an effective pressure of $0.45 \mathrm{MPa}$ and then subjected to a falling head permeability test with the effective pressure reduced to $0.1 \mathrm{MPa}$. The coefficient of permeability was determined to be $10-8 \mathrm{~cm} / \mathrm{sec}$, which is consistent with results presented by D'Appolonia and Ryan (1979) for such a mixture.

Special note should be made of a problem which arose when sample PT 429 A (Table XXV) was being consolidated prior to a permeability test. The sample was connected to hydraulic pressure lines that allowed water at a back pressure of $0.4 \mathrm{MPa}$ to flow through the sample under the influence of a differential pressure of approximately $0.025 \mathrm{MPa}$. Filter paper had been placed on top of the sample to prevent particle migration out of the sample under the influence of seepage forces. Unfortunately, a fold developed in the filter paper, particle inigration occurred, and a small channel developed through the sample. Once this small channel formed, water began flowing through it essentially unimpeded, and erosion of fine particles from the sample occurred. Thus, it would appear that particle inigration and channeling of slurry/aggregate mixtures is a very real possibility and must be given serious consideration when dealing with these mixtures in plug design schemes. 
5.7.3.4 Suminary of Results for Clay Slurries

Based on preliminary test results for clay slurries, the following conclusions were made:

- The bond strength of a slurry/aggregate mixture was greatly enhanced when bentonite pellets were added and the mixture was subjected to consolidation;

- Compressibility of a slurry/aggregate mixture increased as its porosity increased and percent coarse aggregate decreased;

- For slurry mixtures containing 6 percent bentonite by weight, the permeability should be on the order of $10^{-8} \mathrm{~cm} / \mathrm{sec}$; and

- It appears that channeling (piping) of slurry/aggregate mixtures can develop rapidly once particle migration has been initiated and should be taken into consideration in preconceptual plug design schemes.

5.8 SUMMARY OF THE PHYS ICAL TESTING PROGRAM

\subsubsection{Preferred Materials}

A preliminary evaluation of the suitability of materials and mixtures for further testing and evaluation in preconceptual plug design can be made based on the results of the physical testing program. However, final design criteria defining the performance limits of a suitable plug system and long-term tests (which include the simulation of critical thermomechanical and hydrological in-situ conditions) are 
needed prior to the final selection of materials for plug design. Nonetheless, quantitative experimental data collected during the physical testing program provide guidelines for recommending the suitability of various candidate materials at this time. A description of candidate materials included in this discussion of suitability is given for: (1) cements plus their additives (Table XXVI); (2) cohesive materials (Table XXVII); and (3) non-cohesive granular materials (Table XXVIII).

\subsubsection{Cements Plus Cement Additives}

On the basis of these studies, portland cement Type $V$ is the preferred cement for use in plugs; it combines high sulfate resistance with an acceptable mechanical performance. The addition of a finely ground, high-silica pozzolan to portland cement is recommended and was found to reduce shrinkage, increase workability, improve impermeability, and increase stability of cement mixtures exposed to moderate temperature (less than $\left.100^{\circ} \mathrm{C}\right)$. The addition of a finely ground silica flour to portland cements was found to reduce the shrinkage and substantially improve thermal stability and structural strengths of cement mixtures exposed to temperatures greater than $100^{\circ} \mathrm{C}$.

TXI Chem Com cement and portland pozzolan cement combine low shrinkage with good structural strength when cured at standard temperatures. However, they show a substantial deterioration when cured at elevated temperatures, and their chemical resistance to sulfate attack still needs to be demonstrated.

Secar (calcium aluminate cement) and portland cement Type II may be acceptable, although performance tests did not equal that of portland cement Type $V$. In addition, their high demand 
TABLE XXVI

SUITABILITY OF CEMENTS AND ADDITIVES BASED ON PHYSICAL TESTING

Materials

Portland cement Type II

Portland cement Type $V$

Portland pozzolan cement

Fondu cement

Secar cement

TXI Chem com

Lassenite (pozzolan)

Silica flour

Plastiment

Alumini um powder

Alumini um powder
Description

Moderate sulfate resistant

High sulfate resistant

Portland Type I-I I cement + Gypsum +158 of finely ground expanded shale

Calcium aluminate cement with high early strength

Calcium aluminate cement with high early strength

Expansive cement

Calcined volcanic ash

-325 Mesh silica powder

Water-reducing retarder agent (hydroxylated carboxylic acid)

$-200 /+325$ Mesh and -325 Mesh (unpolished)

-325 Mesh (polished, leafing type)
Suitability

liess stable and lower structural strength than Portland Type $\mathrm{V}$ cement.

Recommended

Low shrinkage, high strength at low temperature. Significant loss in structural

strength at high tempera-

ture. Sulfate resistance has to be tested.

High heat of hydration, difficult to handle. Significant loss in structural strength at

Suite stable at high temperature. Low shrinkage. High water/cement ratio for a given consistency. Relatively low structural strength.

Low shrinkage, high strength at low temperature. Significant loss in structural strength at high temperature. Sulfate resistant has to be tested.

Recommended as additive in portland cement mixtures for moderate temperature locations $\mathrm{T} \leq 100^{\circ} \mathrm{C}$.

Recommended as additive in portland cement mixtures for high temperature 100 $\mathrm{T} \geq 100^{\circ} \mathrm{C}$

Recommended

Poor reactivity as a gas-

forming agent

Recommended 
TABLE XXVII

\section{SUITABILITY OF COHESIVE MATERIALS BASED ON PHYSICAL TESTING}

\section{Materials}

Ringold clay Unit A

Ringold clay Unit B

Ringold clay Unit C

Ringold clay Unit D

Ringold clay Unit E

Ringold clay unit $F$

Touchet Formation

Oregon bentonite

Wyoming bentonite

Shurgel

Aquage 1

Bentonite pellets

\section{Description}

Inorganic clay with high plasticity

Inorganic silt with low compressibility

Inorganic clay with

medium plasticity

Inorganic clay with high plasticity

Inorganic clay with high plasticity

Silt

Inorganic silt with low compressibility

Montmorillonite clay

Montmorillonite clay

Processed bentonite

Processed bentonite

$1.25 \mathrm{~cm}$ diameter, highly

compacted spherical

pellets.
Suitability

Poor availability

Low plasticity

Low compactibility

Recommended as second choice for compacted

backfill

slight homogeneity

Non-plastic

Low plasticity

Recommended as first choice for compacted backfill

Recommended as first choice for compacted backfill

Recommended for bentonite slurries

Develops slightly lower viscosity than shurgel when mixed with water.

Recommended 
TABLE XXVIII

SUITABILITY OF NON-COHESIVE MATERIALS, BASED ON PHYSICAL TESTING

\begin{tabular}{|c|c|c|}
\hline Materials & Description & Suitability \\
\hline Glaciofluvial sand & $\begin{array}{l}\text { Washed sand from the } \\
\text { Hanford Site }\end{array}$ & $\begin{array}{l}\text { Recommended in } \\
\text { cementitious and } \\
\text { compacted earth } \\
\text { mixtures. }\end{array}$ \\
\hline Crushed basalt sand & $\begin{array}{l}\text { Crushed, dense, and sound } \\
\text { basalt from the Hanford } \\
\text { Site }\end{array}$ & $\begin{array}{l}\text { Recommended in } \\
\text { cementitious and } \\
\text { compacted earth } \\
\text { mixtures. }\end{array}$ \\
\hline Crushed zeolite sand & $\begin{array}{l}\text { Clinoptilolite from } \\
\text { eastern Oregon }\end{array}$ & $\begin{array}{l}\text { Weak and porous aggregate } \\
\text { with a high ion exchange } \\
\text { potential; recommended } \\
\text { for non-optimum plug } \\
\text { backfill. }\end{array}$ \\
\hline Crushed gravel & $\begin{array}{l}-2.5 \mathrm{~cm} \text { crushed gravel } \\
\text { from the Hanford Site }\end{array}$ & $\frac{\text { Recommended in }}{\text { cementitious mixtures. }}$ \\
\hline Crushed basalt gravel & $\begin{array}{l}-1.9 \mathrm{~cm} \text { coarse-crushed } \\
\text { basalt sand from the } \\
\text { Hanford Site }\end{array}$ & $\begin{array}{l}\text { Recommended in } \\
\text { cementitious, compacted } \\
\text { earth and premixed clay } \\
\text { slurry mixtures. }\end{array}$ \\
\hline
\end{tabular}


for water to achieve a given consistency may produce relatively high permeabilities in the final products. Fondu (calcium aluminate cement) is not recommended; it was initially chosen as a candidate cement for high temperature locations but was found to have a high heat of hydration for a short time of set. This could lead to in-situ placement difficulty. It also undergoes a significant decrease in structural strength when exposed to an elevated curing temperature.

From among the three types of aluminum powder that were tested, the polished, leafing-type showed far more reactivity as a gasforming agent than did the two unpolished types. The addition of a WRA, Plastiment, in cement mixtures was found to effectively reduce water demand, improve workability of freshly mixed cement, and slightly increase structural strength and density of hardened mixtures.

\subsubsection{Cohesive Materials}

Bentonite clay is recommended for use in compacted clay/sand or skip-graded clay/sand/aggregrate mixtures. Its extreme plasticity (indicative of a very low permeability) and high ion exchange potential and sorption capacity should substantially help to decrease both fluid and radionuclide migration through plugs. The high swell potential of bentonite should result in a tight closure between the plug and wall rock. Bentonite is also expected to provide some self-healing capacity to plug mixtures and to fill wall rock fractures. On the basis of this study, a slight preference is given to Wyoming bentonite because of its somewhat higher plasticity and greater compactability when compared to Oregon bentonite. Of the seven fine-grained clay samples from the Pasco Basin that were tested, Ringold clay $D$ may be the only satisfactory material 
for use in plugs. The performance of other clay materials was found to be superior to Ringold clay $D$; the recommendation at this time is to limit its use to general applications and to not use it in high-performance plugs.

From among candidate bentonite samples, Shurgel was found to have the best gel strength in slurry mixtures. Gel strength evaluations at ambient temperature indicate that a clay/water ratio of 7 percent produces the most efficient pumpability and most acceptable thixotropy in slurries. The use of precompacted bentonite pellets in premixed slurry/aggregate samples appeared to increase cohesion and bond strength with the wall rock after consolidation of the mixture. Further tests are needed to verify this result.

5.8.1.3 Non-Cohesive Granular Materials

Fine and coarse-crushed basalt samples collected from the Umtanum and other lower basalt flows, and glaciofluvial sand and gravel collected from the Hanford site, are strong, competent granular materials; they are recommended for use as aggregate in cementitious mixtures, in compacted earth materials, and in premixed clay slurries containing aggregate. Crushed zeolite samples had low unit weights, low specific gravity, and very high porosity. Because of the high ion exchange potential and sorption capacity of zeolite, crushed zeolite is recommended for use only in compacted backfill.

\subsection{CONCLUSIONS AND RECOMMENDATIONS}

At this time, concrete, grout, compacted earth materials, and clay slurries are all considered feasible materials for sealing man-made accesses to a repository in basalt. Tests conducted 
during this study evaluated the permeability and bond strength of miniature plug/basalt (host rock) models at low and high temperatures. These tests indicate that the design mixtures of candidate plug materials that have permeabilities of less than 10-8 $\mathrm{cm} / \mathrm{sec}$ and that will form acceptable bond strengths with the host rock are possible. Other major conclusions are:

- The addition of finely ground silica flour greatly improves the structural and bond strength of portland cement cured at elevated temperature; it also reduces shrinkage of portland cement mixtures cured at standard temperature;

- Compaction test results for bentonite/sand inixtures indicate that compaction to produce a relatively impervious clayey mixture is feasible by standard compactive methods;

- Significant time is required for a miniature, simulated compacted bentonite/sand plug to hydrate. On the basis of test data and theoretical considerations, the time required to saturate a 7-m diameter compacted bentonite/sand plug with a clay content ratio of 50 percent may be more than 1,000 years;

- Consolidation test results for bentonite/sand mixtures with a clay content of 50 percent indicate an expansive behavior in these mixtures for unloading pressures less than $2.2 \mathrm{MPa}$. These results suggests a high swelling potential and self-healing properties for plugs composed of these materials. The results also suggest that tight contact between the plug and basalt (host rock) will be maintained even after cyclic thermal loading; and 
- Mud contamination of simulated borehole walls during model testing was found to substantially decrease the bond strength of miniature cement and soil plugs with the basalt (host rock), which strongly suggests that drilling mud should be flushed from boreholes before plugging.

Results of the physical testing program point to promising areas of future study that would require extensive experimental investigations to obtain additional conclusive and useful quantitative information. The promising areas most recommended for future study are:

- The potential for cementation between the basalt (host rock) and compacted bentonite/sand mixtures at high temperature. This study is suggested by the exceptionally high bond strengths observed for soil plug/basalt (host rock) models cured at high temperature; and

- The retardation of the hydration and swelling processes of bentonite pellets in slurries. This retardation resulted in a significant increase in cohesion and bond strength between premixed bentonite slurries containing aggregate and the host rock upon consolidation of the slurries. 


\section{SUITABILITY OF MATERIALS FOR USE IN PRECONCEPTUAL PLUG SYSTEMS}

\subsection{INTRODUCTION}

The main objective of the geochemical and physical testing programs discussed in the previous two chapters was to help assess the suitability of preferred candidate plug materials selected by the process described in Taylor and others (1979), and in Chapter 3 of this report. These programs were designed to screen materials from the preferred list (Table I) and select those which continued to show the greatest promise for meeting the initial requirements of preconceptual plug designs and compatibility with the natural environment at the Hanford site (and with alterations to that environment produced by excavation of the repository).

Both testing programs used essentially the same set of samples prepared from the list of preferred candidate materials. The geochemical program examined reaction rates of individual materials in simulated ground water (similar to that expected to exist at the depths of plug seats on the Hanford site) and the reaction rates of mixtures of candidate materials in simulated ground water. The tests were performed under a variety of temperatures and pressures designed to maximize (and in most cases accelerate) potential reactivity between the various components.

The physical testing program combined the candidate pluy materials (using various grain sizes and proportions) in mixtures that are precursors to actual plug designs. These tests were, again, designed as a screening step to select those individual materials and mixtures that exhibited the most 
desirable performance when submitted to a wide variety of mechanical and physical test sequences. The results of these two testing programs (Sections 4.5, 4.6, and 5.8) are combined in the following discussion of suitability and preference for materials to be used in preconceptual plug designs and plug sys tems .

\subsection{SUITABILITY OF MATERIALS BASED ON TESTING PROGRAMS}

As indicated in Chapter 4, on the basis of geochemical testing, all preferred candidate plug materials are considered suitable for further testing and use in preconceptual plug design. Small differences in relative reactivity were noted for the various samples, but the reactivities of all test samples were so low that all are considered acceptable. The self-cementing characteristics of basalt under hydrothermal test conditions give this material an added degree of desirability at this stage of evaluating plug materials.

A list of preferred material mixtures, designed and tested during the physical testing program for preconceptual plugging systems, is given in Table XXIX. In this table, the components and proportioning data used in constructing these preferred samples during the physical testing program are also tabulated. The mixtures listed in Table XXIX are the same as those tested in the geochemical testing program. At this stage, data on mixture proportions are flexible and approximate; they need to be confirmed and refined by further advanced testing. Seven preferred mixtures are proposed as most suitable for sealing man-made accesses to a nuclear waste repository in basalt. 
TABLE XXIX

PREFERRED MATERIAL MIXTURES FROM THE RESULTS OF PHYSICAL TESTING

\begin{tabular}{|c|c|c|c|c|}
\hline Type of M1xtures & Compound Description & \multicolumn{2}{|c|}{ Proportioning Data } & Comments \\
\hline $\begin{array}{l}\text { Cement grout } \\
\text { Moderate temperature } \\
\text { Location }\left(\mathrm{T}<100^{\circ} \mathrm{C}\right)\end{array}$ & $\begin{array}{l}\text { Portland Type } V \\
\text { Lassenite } \\
\text { Glaciofluvial sand } \\
\text { Aluminum powder } \\
\text { Plastiment } \\
\text { Water }\end{array}$ & $\begin{array}{l}602 \mathrm{~kg} \\
241 \mathrm{~kg} \\
723 \mathrm{~kg} \\
180 \mathrm{~g} \\
125 \mathrm{ml} \\
447 \mathrm{l} \text { ters }\end{array}$ & \multirow{4}{*}{ 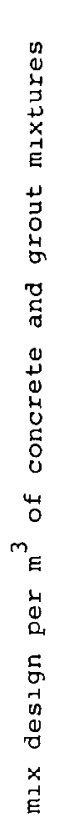 } & $\begin{array}{l}\text { Refinement in } \\
\text { proportioning } \\
\text { data needed to } \\
\text { obtain a non- } \\
\text { shrink grout }\end{array}$ \\
\hline $\begin{array}{l}\text { Cement grout } \\
\text { High temperature } \\
\text { Location }\left(\mathrm{T} \geq 100^{\circ} \mathrm{C}\right)\end{array}$ & $\begin{array}{l}\text { Portland Type } v \\
\text { Sllica flour } \\
\text { Glaciofluvial sand } \\
\text { Aluminum powder } \\
\text { Plastiment } \\
\text { Water }\end{array}$ & $\begin{array}{ll}586 & \mathrm{~kg} \\
315 & \mathrm{~kg} \\
772 & \mathrm{~kg} \\
176 & \mathrm{~g} \\
122 & \mathrm{ml} \\
414 & 11 \text { ters }\end{array}$ & & \\
\hline $\begin{array}{l}\text { Concrete } \\
\text { Moderate temperature } \\
\text { Location }\left(\mathrm{T}<100^{\circ} \mathrm{C}\right)\end{array}$ & $\begin{array}{l}\text { Portland Type } V \\
\text { Lassenite } \\
\text { Glaciofluvial sand } \\
\text { Crushed gravel } \\
\text { Plastiment } \\
\text { Water }\end{array}$ & $\begin{aligned} 273 \mathrm{~kg} \\
55 \mathrm{~kg} \\
755 \mathrm{~kg} \\
1,132 \mathrm{~kg} \\
686 \mathrm{mi} \\
174 \text { liters }\end{aligned}$ & & $\begin{array}{l}\text { Water cenient } \\
\text { ratio can be } \\
\text { reduced to } \\
\text { obtain a } \\
7.5 \mathrm{~cm} \text { slump }\end{array}$ \\
\hline $\begin{array}{l}\text { Concrete } \\
\text { High temperature } \\
\text { Location }\left(\mathrm{T} \geq 100^{\circ} \mathrm{C}\right)\end{array}$ & $\begin{array}{l}\text { Portland Type } V \\
\text { Silica flour } \\
\text { Glaciofluvial sand } \\
\text { Crushed gravel } \\
\text { Plastiment } \\
\text { Water }\end{array}$ & $\begin{aligned} 289 \mathrm{~kg} \\
156 \mathrm{~kg} \\
709 \mathrm{~kg} \\
1,063 \mathrm{~g} \\
931 \mathrm{ml} \\
17911 \text { ters }\end{aligned}$ & & \\
\hline $\begin{array}{l}\text { Compacted clay/ } \\
\text { sand mixture } \\
\text { in confined plug }\end{array}$ & $\begin{array}{l}\text { Wyoming bentonite } \\
\text { Glaciofluvial sand }\end{array}$ & \multicolumn{2}{|c|}{$\begin{array}{l}\text { Clay/sand ratio } \\
\text { rang } 1 \text { ng from } 0.3 \\
\text { to } 0.5\end{array}$} & $\begin{array}{l}\text { Permeability } \\
\text { test data } \\
\text { needed }\end{array}$ \\
\hline $\begin{array}{l}\text { Compacted clay/ } \\
\text { sand mixture } \\
\text { in confined plug }\end{array}$ & $\begin{array}{l}\text { Oregon bentonite } \\
\text { Glaciofluvial sand }\end{array}$ & \multicolumn{2}{|c|}{$\begin{array}{l}\mathrm{Clay} / \mathrm{sand} \text { ratio } \\
\text { around } 0.3\end{array}$} & $\begin{array}{l}\text { Permeability } \\
\text { test data } \\
\text { needed }\end{array}$ \\
\hline $\begin{array}{l}\text { Slurry/aggregate } \\
\text { mixture in } \\
\text { confined plug }\end{array}$ & $\begin{array}{l}\text { Shurgel ( } 78 \text { in slurry) } \\
\text { bentonite pellets } \\
\text { coarse-crushed basalt }\end{array}$ & \multicolumn{2}{|c|}{$\begin{array}{l}\text { Clay/pellets/ } \\
\text { aggregate ratio } \\
0.02 / 0.09 / 0.89\end{array}$} & $\begin{array}{l}\text { Permeability } \\
\text { bond strength } \\
\text { test data } \\
\text { needed }\end{array}$ \\
\hline \multicolumn{5}{|c|}{$\begin{array}{l}\text { a Lassenite (brand name) is a natural pozzolan. } \\
\text { b plastiment (brand name) is an organic water reducing agent in cements. }\end{array}$} \\
\hline
\end{tabular}


Note that these mixtures may not be acceptable as single materials in a monolithic plug system. For example, the use of a high silica pozzolan in portland cement Type $V$ mixtures is only recommended for temperatures less than $100^{\circ} \mathrm{C}$, while the use of silica flour was found to be beneficial in portland cement mixtures exposed to temperatures of $100^{\circ} \mathrm{C}$ or more. In addition, permeability tests are still needed to develop precise proportioning data on compacted bentonite/sand mixtures. However, testing to date has shown that a minimum of 30 percent bentonite by weight is needed to obtain low permeabilities in these mixtures. This percentage is also an upper limit at which good compactibility of the oregon bentonite/sand mixture can be obtained. By contrast, in compacted Wyoming bentonite/sand mixtures, acceptable compaction was observed with clay contents as high as 50 percent. Considering the high percentage of bentonite required for the desired hydraulic performance, the use of compacted clay/sand mixtures is recommended primarily for multizone plug systems where confinement is provided by a rigid material capable of having good structural strength. This limitation is also valid for premixed aggregate clay slurries that will require confinement in order to prevent channeling or piping of plug materials.

\subsection{MATERIALS PREFERRED FOR PRECONCEPTUAL DES IGN} AND FURTHER TESTING

The results of the geochemical and physical testing indicate that the materials considered suitable for further testing and use in preconceptual design schemes are various combinations of compacted natural materials, grouts, and concretes. Geochemical testing in the hydrothermal test conditions employed during laboratory testing at SRI shows that the 
materials are generally non-reactive or have low reactivities, which suggests stability in the proposed plug environment. Table XXIX summarizes the physical test results and shows the preferred combinations and proportions of potential plug components that exhibited desirable behavior during test runs. The major plug components considered most suitable on the basis of the laboratory testing are listed on Table Xxx. Also included on Table XXX are those additives that were incorporated into the testing programs and that produced improved behavior and mechanical response in mixtures during physical testing. 
MATERIALS DETERMINED TO BE MOST SUITABLE FOR FURTHER STUDY

Major Component

Plug Material

Basalt

Glaciofluvial sand (in cement)

Oregon bentonite

Wyoming bentonite

Crushed gravel (in cement)

Portland Type $\mathrm{V}$ cement

Zeolite c $^{2}$
Tested

Additive

Lassenite ${ }^{a}$

Plastiment $t^{b}$

Aluminum powder

Silica flour

${ }^{a}$ Lassenite (brand name) is a natural pozzolan.

$\mathrm{b}_{\text {Plastiment (brand name) is an organic water-reducing }}$ agent in cements.

Ceolite is considered usable for backfill purposes on the basis of physical testing; however, it has marginal strength when placed in mixtures. Its known properties (ability to inhibit radionuclide migration and chemical compatibility with the natural environment) make it desirable for use in some applications in plug design. Further testing is needed. 


\section{LIMITATIONS OF THE RESULTS}

Each of the previous five chapters represents a significant step in establishing design limits and selecting materials for preconceptual plugs and systems. However, limitations exist on the uses of the data and results presented in this report.

\subsection{DATA CHARACTERIZ ING THE ENVIRONMENT OF MAN-MADE ACCESSES}

Chapter 2 and Appendix A present the first attempt at tabulating environmental conditions and factors that influence preconceptual plug design and materials selection. The tabulation, as it now stands, reflects the current knowledge on a large number of conditions and parameters. Many of the values for physical and chemical parameters presented in Table A-I (Appendix A) are based on only a limited number of measurements and/or tests. Design conditions (such as borehole diameters, hydraulic gradients, lithostatic stress, etc.) included on the table are preliminary in nature and are subject to significant future revision.

Thus, the total characterization of man-made accesses and the plug-seat environment will undergo constant review, and any value on Table A-I should be used with these limitations in mind. In addition, Table A-I (though reasonably comprehensive in nature) will need to be enlarged as plugging requirements are improved. Not all possible design conditions, chemical and physical parameters, and other environmental considerations have been listed; more will be identified and will require clarification and data. 


\subsection{THE MATERIALS SELECTION PROCESS}

Chapter 3 and Appendix B present a modified scheme for selecting candidate plug materials. This revised scheme is an outgrowth of earlier materials selection work presented by Taylor and others (1979). The lists of preferred candidate plug materials developed by the present and earlier selection processes are similar; they are by no means considered a final selection of materials for all future plug testing and design. This list is not intended to limit the number of materials that can be considered in plug design and testing programs. The addition of materials that have not yet been considered in selection processes and may have potential application in various plug functions could result in a recasting of the initial, comprehensive list of potential materials. Also, the number of material properties used to rank materials may be expanded, thus requiring modification of the details of the decision analysis discussed in this report.

Another limitation of the materials selection process is that only materials to be used as major plug components were considered; additives (materials added to plugs in small amounts to produce certain desirable conditions) were not included in the screening. However, the testing programs have already begun to rectify this last limitation; various additives (particularly to cements) were investigated as the testing programs proceeded.

\subsection{THE MATERIALS TESTING PROGRAMS}

The results of the geochemical and physical testing programs described in Chapters 4 and 5 represent the first major steps in further examining and screening candidate plug materials 
selected by the process described in Chapter 3. Materials determined suitable for future testing and preconceptual design work as a result of these testing programs will require far more detailed examination before final preconceptual design schemes can be adopted. The results of the materials testing programs are used in preliminary, preconceptual design and for the selection of plug placement equipment. Detailed design work will require advanced geochemical and physical laboratory testing, in-situ borehole testing of plug designs, computer modeling of various plug designs and schemes, and the incorporation of many additional physical and chemical parameters in order to refine the selection of materials, machines, and plug designs. Recommendations presented in the next chapter address future studies that will help overcome limitations discussed in this chapter.

\subsubsection{Limitations of the Geochemical Testing Program}

Specific limitations on the results of the geochemical testing program relate, in part, to the short time frame under which the program was conducted; 3-month test runs are limited in their ability to completely characterize long-term behavior and reactivities of materials. Also, the shortened time frame did not allow for modifications of experimental procedures as the program progressed. For example, a substitution of gold capsules, after some of the PTFE sample capsules cracked, would have been desirable.

Other limitations on the ability to make more than tentative predictions from these test results relate to how accurately the experiments model the actual physical situation. Bagged powder mixtures in relatively small volumes of static solutions may not be a realistic simulation of the conditions experienced 
by a borehole plug material. As discussed in the next chapter, these questions should be considered in the next phase of work.

\subsubsection{Limitations of the Physical Testing Program}

The most significant limitation of the physical testing was the difficulty of collecting, within a 5-month period, sufficient quantitative experimental data on the short-term and long-term behavior of candidate materials. The scope of the problem is illustrated by the large number of candidate materials and mixtures (28 materials and more than 55 mixtures) and the numerous in-situ hydrological and thermomechanical conditions needed for labcratory simulation. In particular:

- Proportioning data of preferred cement mixtures still need to be refined by taking into consideration the initial in-situ temperature and moisture conditions;

- A relatively moderate expansive behavior was observed for the expansive cement used in the physical testing program, contradicting other project-related test results cited in the literature. Thus, it seems wise to extend the testing to a brand of expansive cement other than Chem Com cement;

- 'The two months scheduled for permeability tests proved insufficient to allow complete saturation of the miniature, compacted bentonite/sand plugs. Nevertheless, quantitative data on permeability and bond strength of saturated plug samples (cured and tested at low and high temperatures) are still useful in helping to determine the optimum clay content in mixtures and in confirming the suitability of such mixtures for plugging; and 
- Model results for premixed clay slurry/aggregate samples are promising but are still preliminary and qualitative. In order to complete a suitability evaluation of plug systems, numerous physical parameters (needed for design) must still be determined. Foremost among these are: (1) the thermal expansion coefficient of preferred plug materials; and (2) the short-term elastoplastic behavior and the long-term viscoelastoplastic behavior of preferred plug materials under simulated in-situ conditions. 


\section{CONCLUSIONS AND RECOMMENDA'TIONS}

This report describes work recently completed for the BWIP. The following primary objectives of the study (described in Chapter 1 of this report) have been met during this phase of work:

- Man-made accesses to a repository in basalt and details of the plug environment have been characterized. This characterization is in the form of a lengthy tabulation, and known and postulated conditions for these accesses and the environment are referenced (Chapter 2 and Appendix A);

- The materials selection process developed earlier (Taylor and others, 1979) was reviewed and modified. The modified selection process was by decision analysis. The list of preferred candidate materials developed by the modified selection process confirmed the general validity of the list of preferred materials developed earlier;

- Geochemical and physical testing programs for evaluating the chemical stability and physical properties of candidate plug materials were completed (Chapters 4 and 5, and Appendix $C$ ); and

- The results of the testing programs were used to evaluate the suitability of materials from the preferred candidate list for use in preliminary preconceptual plug designs (to be described in a separate report). 


\subsection{CONCLUSIONS}

The major conclusions from the work described in this report are:

- The available data on environmental conditions (both natural and man-made) at the Hanford site are sufficient for preconceptual plug system design. These data are preliminary in nature and will require verification, expansion, and clarification as work on plug system design continues;

- The process for materials selection has been documented by the present work;

- The results of the geochemical testing program indicate that preferred candidate plug materials are chemically non-reactive during laboratory tests that simulated some of the expected environmental conditions;

- On the basis of geochemical test results, all tested materials are considered suitable for consideration in future test programs and in preconceptual plug design. Agitated, crushed-basalt samples and mixtures containing basalt were found to be self-cementing under the hydrothermal conditions of the laboratory tests. This ability is considered a positive finding for this material.

- On the basis of physical test results, those materials considered most suitable for consideration in future test programs and preconceptual plug design are mixtures of natural materials (basalt, clay, glaciofluvial sand, 
gravel, and zeolite) and processed natural materials (portland cement Type $V$ and grouts plus additives). Specific proportions and components are discussed in this report; and

- On the basis of results from both geochemical and physical testing programs, those materials considered most suitable for future test programs and preconceptual plug design are combinations of natural and processed natural materials, most of which are readily available at or near the Hanford Site. Most importantly, all of these materials exhibit chemical stability under conditions that partially simulate the expected plug environment, and all can be combined and engineered under laboratory conditions to produce mixtures that have low permeabilities and/or requisite structural strength and other behavioral characteristics desirable in preconceptual plug designs.

\subsection{RECOMMENDATIONS}

The following recommendations appear appropriate in view of the above results:

- A comprehensive program should be developed for the advanced testing of chemical stability factors critical to the performance of borehole plug materials used in plug systems. This program should include: (1) the elements of an exploratory testing phase that will help determine the experimental procedures for future testing; (2) an approach to the long-term testing and computer modeling of reaction rates (kinetics of reactions) using preferred candidate materials; (3) an approach to 
measuring ion exchange potentials and sorption capacities of various borehole plugs designed from preferred materials; (4) an approach to examining the effect of $\mathrm{pH}$ on leach rates of plug materials; (5) an approach to examining the deterioration of mechanical properties of plug materials due to chemical reactions; (6) an approach to examining the self-cementing properties of plug materials (particularly basalt) in order to identify the chemical processes involved and ways of promoting these reactions; and (7) a long-term plan for geochemical testing.

- An advanced physical testing program should be developed to support repository backfill and borehole plugging needs during field testing, demonstration, licensing, and construction. This program should include: (1) the development of concepts and a detailed program plan for advanced physical testing; (2) modification and procurement of selected testing equipment and the acquisition of materials for testing; (3) advanced testing that screens some materials at elevated temperature for repository backfill and for canister plug placement $\left(100^{\circ} \mathrm{C}\right.$ to $\left.400^{\circ} \mathrm{C}\right)$, including autoclave curing of candidate materials followed by compression and permeability tests at ambient temperatures projected for the plug environment; (4) the assessment of the coefficient of thermal expansion and, possibly, thermal conductivity of selected plug materials; (5) the assessment of the potential of some soft plug materials to act in a fluid manner; (6) the assessment of creep characteristics of some low temperature plug materials; (7) the determination of bond strengths of monolithic plug-wall rock interfaces after thermal cyclic loading; 
(8) the use of a multizone-plug/wall-rock model to quantify the nature of changes in permeability and bond strength due to multizone conditions; and (9) an advanced testing program that identifies rates and selects high-temperature, high-pressure laboratory tests that will model the performance of plug materials and plug systems under simulated in-situ conditions (including temperatures up to $400^{\circ} \mathrm{C}$ ).

- Analytical modeling of borehole plug design and systems should be undertaken to serve several purposes in the design/construction process: (1) preliminary studies would permit the identification of critical parameters/conditions requiring more careful examination in planned field studies; (2) such analyses would provide the basis to predict (forecast) relevant performance patterns and would assist in designing experiments (e.g., instrumentation selection and configuration); (3) experimental evaluations would provide the basis for refining models and analytical techniques and for determining the reliability of existing methods in predicting performance; and (4) optimization of analysis capabilities should be accomplished concurrently with preliminary field test programs in order to effectively meet the design, construction, and monitoring objectives of the program. The approach should be to model some of the key aspects of plug behavior and to coordinate this work with the development of a field test of shallow borehole plugging systems. 
- A program should be undertaken to evaluate the impact on the design and performance of borehole plugs of natural fractures in basalt flows and the effects of disturbed rock and rock fracturing that may accompany tunnel and shaft excavations and related repository borings. Specification control and monitoring of the boring or excavation process can help to minimize the man-made disturbance and fractures. The proposed study should include: (1) an evaluation of mechanisms and past field experience in underground excavations; (2) an evaluation of the degree of fracturing that may occur around a borehole, the size of fractures that can be filled, and the effect of structural reinforcement and grout type on long-term plug performance; (3) an evaluation of rock reinforcement techniques (such as spiling or bolting of large diameter excavations) in order to minimize the zone of disturbed rock around the excavation; (4) a review and evaluation of grouting theory, practice, and field results for the sealing of both existing and man-made fractures in hard-rock formations; and (5) laboratory testing designed to support this phase of the work.

- A field test of shallow borehole plugging should be performed at the Hanford Site. This field testing should examine leading candidate plug materials and plug placement schemes and should incorporate data and results from work to date and programs described in the other recommendations above. Initial field testing work should include: (1) a consideration of various options for in-situ mechanical, hydraulic, and geophysical testing; (2) a selection of tests for the separate environments of boreholes (small boreholes, shafts, and tunnels); and 
(3) a selection of the various plug options (plugs designed from natural materials, cement plugs, and solid machined plugs) considered appropriate for field testing.

These are the primary recommendations to be made from the results of the present studies. A separate report will present in greater detail a discussion of preconceptual plug systems and placement equipment; that discussion will provide additional data and results that led to some of the above recommendations. 


\section{REFERENCES}

Akaiwa, S., and Sudoh, G., 1966, Strength and microstructure of hardened cement pastes cured by autoclaving, in Symposium on Structure of Portland Cement Paste and Concrete: Highway Research Board Special Report 90, pp. 36-47.

American Petroleum Institute, 1960, API Recommended Practice for Core Analysis Procedure: lst Edition, API Division of Production, RP 40, API, Dallas, Texas, 55 p.

American Society for Testing and Materials, 1973, Annual Book of ASTM Standards: Part 9 - Cement, Lime, Gypsum. Manual of Cement Testing: ASTM, Philadelphia, Pennsylvania.

American Society for Testing and Materials, 1977(a), Standard method of test for compressive strengths of hydraulic cement mortars (using 2-inch specimens): ASTM, v. 13, p. $62-67$.

American Society for Testing and Materials, 1977(b), Annual Book of ASTM Standards: Part 14 - Concrete and Mineral Aggregates: ASTM, Philadelphia, Pennsylvania.

American Society for Testing and Materials, 1978(a), Standard test method for metals in water and waste water by atomic absorption spectrophotometry (ASTM Method D-2576-76): ASTM, v. 31, p. 410-414.

American Society for Testing and Materials, 1978(b), Annual Book of ASTM Standards: Part 19 - Natural Building Stones, Soil and Rock, Peats, Mosses, and Humus: ASTM, Philadelphia, Pennsylvania. 
Ames, L.L., Basalt Waste Isolation Program staff, 1978, Radionuclide batch $k_{d}$ values on basalt, huelandite, and nontronite, in Basalt Waste Isolation Program Annual Report - Fiscal Year 1978: RHO-BWI-78-100, Rockwell Hanford Operations, Richland, Washington, p. 136-144.

Boa, J.A., Jr., 1978, Borehole plugging program (waste disposal) report l: initial investigations and preliminary data: U.S. Army Engineer Waterways Experiment Station, Miscellaneous Paper C-78-1, Vicksburg, Mississippi, 16 p.

Brunauer, S., Emmett, P.H., and Teller, E., 1938, Adsorption of gases in multimolecular layers: Journal of American Chemical Society, v. 60, p. 309-319.

Clark, D.E., Dilmore, M.S., Ethridge, E.C., and Hench, L.L., 1976, Aqueous corrosion of soda-silica and soda-lime silica glass: Journal of the American Ceramic Society, v. 59, no. 1 , p. 62-65.

-D'Appolonia, D.S., and Ryan, C.R., 1979, Soil-bentonite slurry trench cut-off walls: Geotechnical Exhibition and Technical Conference, Chicago, Illinois, $112 \mathrm{p}$.

Eilers, L.H., and Spangle, L.B., 1973, Borehole Sealing: ORNL/Sub/15966-73/1, Union Carbide Corporation, Nuclear Division, Oak Ridge, Tennessee, $110 \mathrm{p}$.

Ford, C.K., Keeney, R.L., and Kirkwood, C.W., 1979, Evaluating methodologies -- A procedure and application to nuclear power plant siting methodologies: Management Science, v. 25, p. $1-10$. 
Fournier, R.O., and Truesdale, A.H., 1973, An empirical Na-K-Ca geothermometer for natural waters: Geochimica et Cosmochimica Acta, v. 37, p. 1255-1275.

Grim, R.E., 1962, Applied Clay Mineralogy: McGraw-Hill, New York, $422 \mathrm{p}$.

Holloway, C.A., 1979, Decision Making under Uncertainty: Prentice-Hall, Englewood Cliffs, New Jersey, 522 p.

International Society for Rock Mechanics, Commission on Standardization of Laboratory and Field Tests, 1978, Suggested methods for determination of the swelling pressure index under conditions of zero volume change: International Journal of Rock Mechanics and Mining Sciences and Geomechanical Abstracts, v. 10, p. 151-153.

Keeney, R.L., 1973, A decision analysis with multiple objectives: The Mexico City Airport: Bell Journal of Economics and Management Science, v. 4, p. 101-117.

Keeney, R.L., and Raiffa, H., 1976, Decisions with Multiple Objectives: John Wiley and Sons, New York, 569 p.

Kenney, T.C., 1967, The influence of mineralogical composition on the residual strength of natural soils: Oslo Geotechnical Conference on the Shear Strength Properties of Natural Soils and Rocks, v. l, p. 123-129.

Kezdi, A., 1974, Handbook of soil mechanics: Elsevier Scientific Publishing Company, New York, 287 p. 
Lankard, D.R., Birkimer, D.L., Fondriest, F.F., and Snyder, M.S., 1970, Effects of moisture content on the structural properties of portland cement concrete exposed to temperatures up to $500^{\circ} \mathrm{F}$ : American Concrete Institute Special Publication 25, p. 59-10l.

Martin, R.T., 1975, Feasibility of sealing boreholes with compacted natural earthen material: Research Report 75-28, Massachusetts Institute of Technology, Cambridge, Massachusetts, v. 1, $121 \mathrm{p}$.

Mather, K., 1977, Minimize alkali-silica reaction: U.S. Army Engineer Waterways Experiment Station, Vicksburg, Mississippi, $4 \mathrm{p}$.

Mitchell, J.K., 1976, Fundamentals of Soil Behavior: John Wiley and Sons, New York, $422 \mathrm{p}$.

Pareto, V., 1897, Cours d'Economie Politique: Rouge, Lausanne, France, 2 volumes.

Roy, D.M., White, W.B., Grutzeck, M.W., Sweet, J.R., and Oyefesobi, D., 1976, Borehole plugging by hydrothermal transport - Final Report: ORNL/SUB-4091/3, Materials Research Laboratory, The Pennsylvania State University, University Park, Pennsylvania, $78 \mathrm{p}$.

Skempton, A.W., 1953, The colloidal "activity" of clay, in The Third International Conference of Soil Mechanics, Part 1 , p. 57-6I. 
Swedish Nuclear Fuel Safety Project, 1979, Safe handing and storage of high level radioactive waste; $A$ condensed version of the proposals of the Swedish KBS-Project regarding reprocessing waste and spent fuel: Karnbranslesakerhet, Stockholm, Sweden, 58 p.

Taylor, C.L., Anttonen, G.J., O'Rourke, J.E., and Niccum, M.R., 1979, Borehole plugging of man-made accesses to a basalt repository: A preliminary study: RHO-BWI-C-49, Rockwell Hanford Operations, Richland, Washington, 157 p.

U.S. Army Corps of Engineers, 1978, Handbook for Concrete and Cement (2 volumes): Waterways Experiment Station, Vicksburg, Mississippi.

U.S. Bureau of Reclamation, 1975, Concrete Manual, 8 th edition: United States Government Printing office, Washington, D.C., $627 \mathrm{p}$.

Wirth, G.S., and Gieskes, J.M., 1979, The initial kinetics of the dissolution of vitreous silica in aqueous media: Journal of Colloid and Interface Science, v. 68, no. 3 , p. $492-500$.

Zeleny, M. 1973, Compromise programming, in Multiple Criteria Decision Making, Cochrane, J.L., and Zeleny, M. (eds.): University of South Carolina Press, Columbia, South Carolina, p. 262-301. 

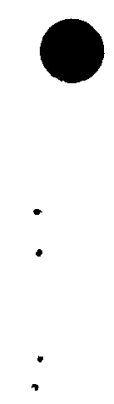
RHO-BWI-C -66

APPENDIX A

SELECTED PRECONCEPTUAL DESIGN CONDITIONS

OF THE PLUG ENVIRONMENT 


$$
A-i
$$

RHO-BW I $-\mathrm{C}-66$

APPENDIX A

SELECTED PRECONCEPTUAL DESIGN CONDITIONS

OF THE PLUG ENVIRONMENT

TABLE OF CONTENTS

$\underline{\text { Page }}$

LIST OF TABLES

$A-i$

INTRODUCTION

$A-1$

REFERENCES

$A-29$ 


$$
A-i j
$$

RHO-BW I-C -66

\section{LIST OF TABLES}

Table No.

$\mathrm{A}-\mathrm{I}$

A-I I
Title

PRECONCEPTUAL DESIGN CONDITIONS

PHYSICAL DATA COMPILATION
Page

$A-3$

$A-20$ 


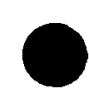

$\because$

$\checkmark$

- 


\author{
APPENDIX A \\ SELECTED PRECONCEPTUAL DESIGN CONDITIONS \\ OF THE PLUG ENVIRONMENT
}

\title{
INTRODUCTION
}

This appendix presents a preliminary listing of some assumed preconceptual design conditions (both natural and man-made) of the plug environment at the Hanford Site. Table A-I, which presents this list of conditions, is divided into data on assumed physical conditions and data on assumed chemical conditions. These conditions are tabulated with respect to four possible subsurface micro-environments: boreholes starting at the surface; boreholes starting in the subsurface, tunnels, and shafts. The physical and chemical conditions included in this document are based primarily on published data, on data transmitted from personal communication from Rockwell to WCC, and, to a lesser extent, on subjective judgment. The data base from which many of these conditions and values were obtained is tabulated in Table A-II, and the publications containing the complete data sets are included in the reference 1 ist for this appendix.

The design conditions contained in Table A-I are preliminary and tentative. However, they appear reasonable in light of current knowledge and concepts and will be used until alternative or confirmed data become available. In general, the "assumed values" listed in Table A-I under the headings "Boreholes that Start in the Surface" and "Shafts" represent the arithmetic mean obtained from one or more data sets representing a range of depths and variations in material. Where several data sets are available, a weighted mean based on the number of pieces of data is used. The "assumed values" 
listed for "Boreholes that start in the Subsurface" and "Tunnels" are based on data from the Umtanum flow, where such data are available. Data from the Pomona flow, or from the depth range within which the repository is to be located, are given the next order of priority in the absence of data specifically designated as being obtained from the Umtanum flow. Finally, data from Columbia Plateau basalts are given precedence over data obtained from basalt sequences in other regions. Values and discussions in Table A-I for conditions having no supporting laboratory or field data are subjective and judgmental in nature; they should be viewed as preliminary working hypotheses.

This appendix is a working document that may be revised, and the conditions and values presented herein should not be considered final. Some values are based on a relatively limited number of laboratory tests on small samples, which may not be entirely representative of average in-situ conditions encountered during actual excavation of the repository. Chemical data obtained for ground water extracted from depths at which the repository is likely to be located are probably relatively reliable. The least reliable laboratory data are considered to be those obtained for sonic velocities and for permeabilities. Field data on hydraulic gradients (to the extent that they are available) are equivocal. Thus, for a variety of reasons, it is anticipated that some of the assumed values presented herein will be modified or superseded as additional data become available. The emphasis of future data gathering efforts should be on those parameters that have the greatest effect on preconceptual plug designs. 
TABLE A-1

PRECONCEPTUAL DESIGN CONDITIONS

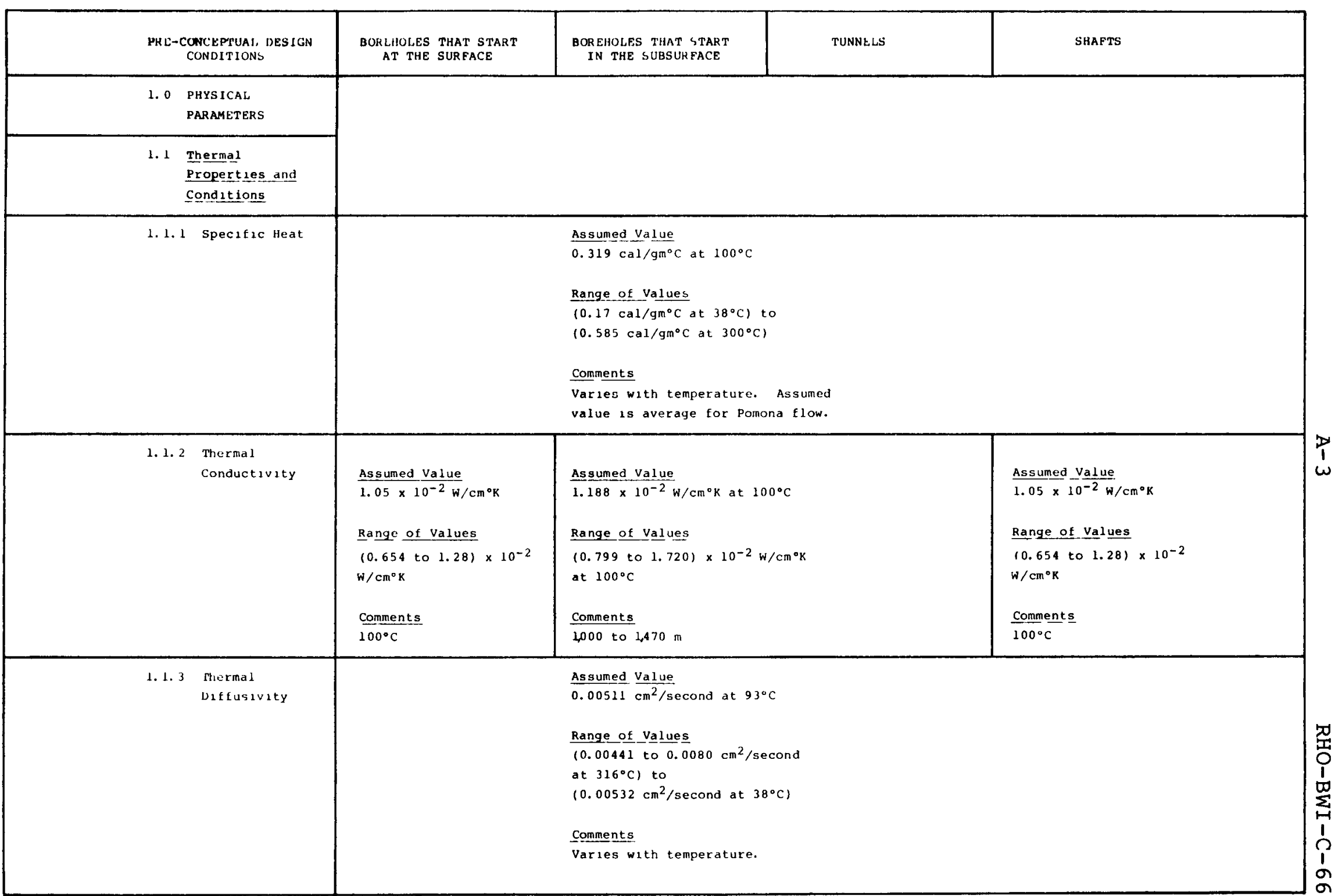


TABLE A-I (continued)

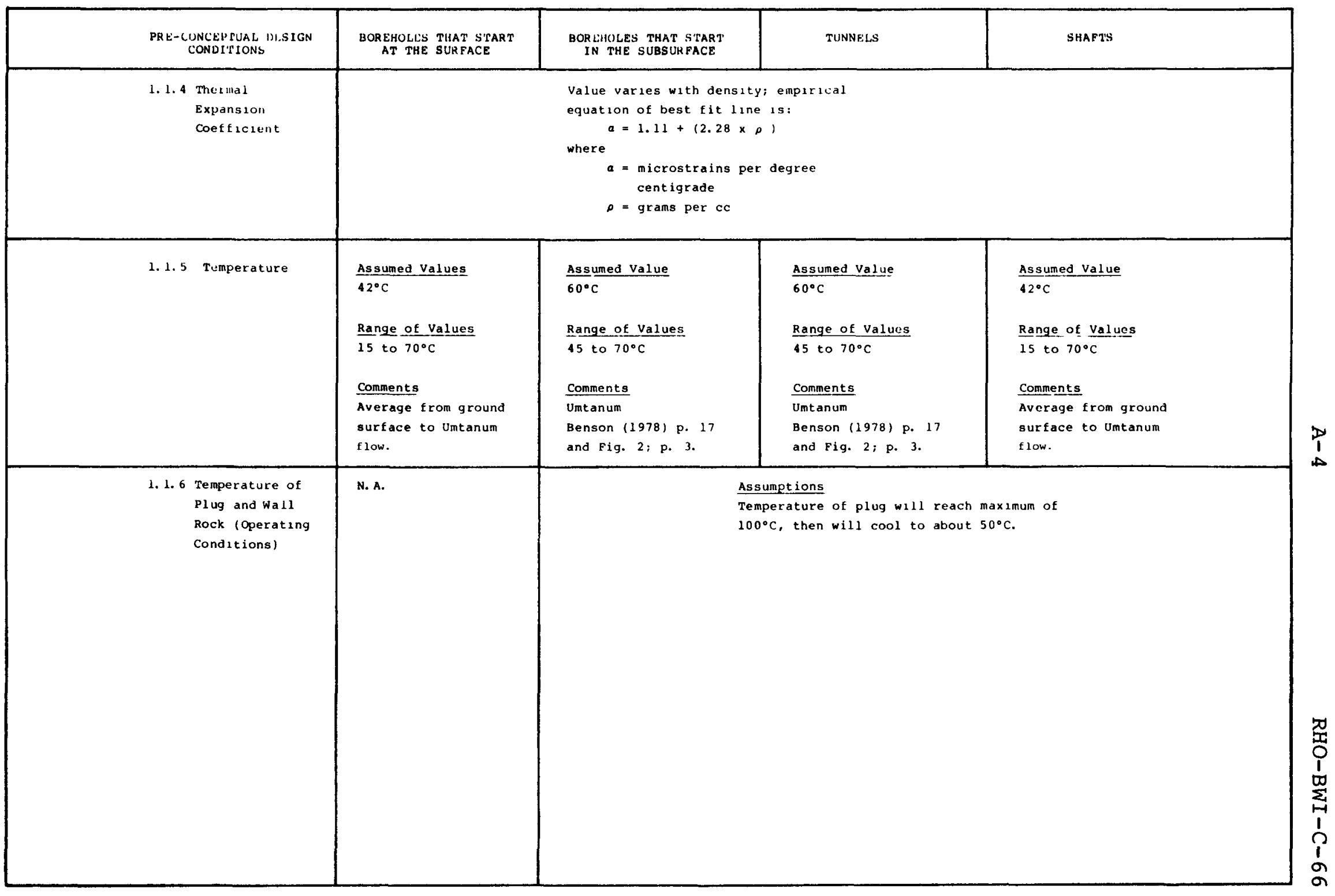


TABLE A-I (continued)

\begin{tabular}{|c|c|c|c|c|c|}
\hline \multicolumn{2}{|c|}{$\begin{array}{l}\text { PRE-CONCEPT UAL DESIGN } \\
\text { CONDITIONS }\end{array}$} & $\begin{array}{c}\text { BORCHOLES THAT START } \\
\text { AT THE SURFACE }\end{array}$ & $\begin{array}{l}\text { BOREHOLES THAT START } \\
\text { IN THE SUBSURFACE }\end{array}$ & TUNNELS & SHAFTS \\
\hline \multicolumn{6}{|c|}{$\begin{array}{ll}1.2 & \text { Hydraulic } \\
\text { Properties and } \\
\text { Conditions }\end{array}$} \\
\hline 12. & $\begin{array}{l}\text { Distance to } \\
\text { Nearest } \\
\text { Potentially } \\
\text { Permeable Zone }\end{array}$ & $\begin{array}{l}\frac{\text { Ass sumed Value }}{0 \mathrm{~m}} \\
\frac{\text { Range of Values }}{0 \text { to? }} \\
\text { Comments } \\
\text { Hole may penetrate } \\
\text { zone where irrigation } \\
\text { water may be collected } \\
\text { and returned to the } \\
\text { blosphere. }\end{array}$ & $\begin{array}{l}\frac{\text { Assumed Valuc }}{30 \mathrm{~m}} \\
\frac{\text { Range of Values }}{30 \text { to } 50 \mathrm{~m}} \\
\text { Comments } \\
\text { Assumes repository flow } \\
\text { is } 60 \text { to } 100 \mathrm{~m} \text { thick. }\end{array}$ & $\begin{array}{l}\frac{\text { Assumed value }}{25 \mathrm{~m}} \\
\frac{\text { Range of Values }}{25 \text { to } 45 \mathrm{~m}} \\
\frac{\text { Comments }}{\text { Assumes repository flow }} \\
1 \mathrm{~s} 60 \text { to } 100 \mathrm{~m} \text { thick. }\end{array}$ & $\begin{array}{l}\frac{\text { Assumed Value }}{0 \cdot m} \\
\text { Range of Values } \\
0 \text { to ? } \\
\text { Comments } \\
\text { Shaft may penetrate zone } \\
\text { where irrigation water } \\
\text { may be collected and } \\
\text { returned to the } \\
\text { biosphere. }\end{array}$ \\
\hline \multicolumn{2}{|c|}{$\begin{array}{ll}1.2 .2 & \text { Distance to } \\
& \text { nearest pumped } \\
\text { aquifer }\end{array}$} & $\begin{array}{l}\frac{\text { Assumed Value }}{0 \mathrm{~m}} \\
\frac{\text { Range of Values }}{0 \text { to ? }} \\
\frac{\text { Comments }}{\text { Hole may penetrate }} \\
\text { Vantage Member. }\end{array}$ & $\begin{array}{l}\frac{\text { Assumed Value }}{250 \mathrm{~m}} \\
\frac{\text { Range of Values }}{250 \text { to } 600 \mathrm{~m}} \\
\text { Comments } \\
\text { Assumes Vantage Member } \\
\text { is nearest pumped } \\
\text { aquifer and repository } \\
\text { flow is } 250 \text { to } 600 \mathrm{~m} \\
\text { below this horizon. }\end{array}$ & $\begin{array}{l}\frac{\text { Assumed Value }}{250 \mathrm{~m}} \\
\frac{\text { Range of Values }}{250 \text { to } 600 \mathrm{~m}} \\
\text { Comments } \\
\text { Assumes Vantage Member } \\
\text { is nearest pumped } \\
\text { aquifer and repository } \\
\text { flow is } 250 \text { to } 600 \mathrm{~m} \\
\text { below this hor } 120 \mathrm{n} \text {. }\end{array}$ & $\begin{array}{l}\frac{\text { Assumed Value }}{0 \mathrm{~m}} \\
\frac{\text { Range of Values }}{0 \text { to? }} \\
\frac{\text { Comments }}{\text { Shaft will penetrate }} \\
\text { Vantage Member. }\end{array}$ \\
\hline
\end{tabular}


TABLE A-I (continued)

\begin{tabular}{|c|c|c|c|c|c|}
\hline \multicolumn{2}{|c|}{$\begin{array}{l}\text { PKE-CUNCLPTUAL DESIGN } \\
\text { CONDITIONS }\end{array}$} & $\begin{array}{l}\text { BORCHOLES THAT START } \\
\text { AT THE SURFACE }\end{array}$ & $\begin{array}{l}\text { BOREHOLES THAT START } \\
\text { IN THE SUBSURFACE }\end{array}$ & TUNNELS & SHAFTS \\
\hline 1. 2.3 & $\begin{array}{l}\text { D1stance } \\
\text { to Nearest } \\
\text { Pumpable } \\
\text { Aquifer }\end{array}$ & $\begin{array}{l}\text { Assumed Value } \\
\frac{\mathrm{m}}{\text { Range of Values }} \\
0 \text { to } 600 \mathrm{~m} \\
\text { Conments } \\
\text { Assumes hole stops } \\
\text { at Vantage Member } \\
\text { and that pumpable } \\
\text { aquifer may exist } \\
\text { at repository flow } \\
\text { boundary. }\end{array}$ & $\begin{array}{l}\frac{\text { Assumed value }}{400 \mathrm{~m}} \\
\text { Range of Values } \\
30 \text { to } 600 \mathrm{~m} \\
\text { Comments } \\
\text { Assumes holes are } \\
\text { some distance bel } \\
\text { the vantage Membe } \\
\text { and another lower } \\
\text { aquifer. }\end{array}$ & $\begin{array}{l}\frac{\text { Assumed Value }}{375 \mathrm{~m}} \\
\frac{\text { Range of }}{25 \text { to } 600 \mathrm{~m}} \\
\text { Comments } \\
\text { Assumes holes are at } \\
\text { some distance below } \\
\text { the Vantage Member and } \\
\text { another lower aquifer. }\end{array}$ & $\begin{array}{l}\frac{\text { Assumed Value }}{0 \mathrm{~m}} \\
\text { Range of Values } \\
0 \text { to } ? \mathrm{~m} \\
\text { Comnents } \\
\text { Assumes access shafts } \\
\text { will penetrate All } \\
\text { potential aquifers. }\end{array}$ \\
\hline 1.2 .4 & $\begin{array}{l}\text { Hydraulic } \\
\text { Conduct 1vity } \\
\text { (Permeability } \\
\text { Coefficient) }\end{array}$ & & $\frac{c}{H}$ & $\begin{array}{l}\text { e } \\
\frac{\text { ues }}{3 \mathrm{~cm} / \mathrm{sec}} \\
\text { 2n flow tops. }\end{array}$ & \\
\hline 1. 2.5 & Transmissivity & & $\frac{\text { As }}{0 .}$ & $\begin{array}{l}\text { e } \\
\text { ues } \\
\text { to } 7.2 \mathrm{~m}^{2} / \mathrm{day}\end{array}$ & \\
\hline 1. 2.6 & $\begin{array}{l}\text { Apparent } \\
\text { Porosity }\end{array}$ & & $\frac{A s}{1 .}$ & & \\
\hline
\end{tabular}


TABLE A-I (continued)

\begin{tabular}{|c|c|c|c|c|}
\hline \multicolumn{2}{|c|}{$\begin{array}{l}\text { PRE-CONCEP IUAL DESIGN } \\
\text { CONDITIONS }\end{array}$} & $\begin{array}{l}\text { BOREHOLES THAT START } \\
\text { AT THE SURFACE }\end{array}$ & $\begin{array}{l}\text { BOREHOLES THAT START } \\
\text { IN THE SUBSURFACE }\end{array}$ & SHAFTS \\
\hline 1. 2.7 & $\begin{array}{l}\text { Hydraulic } \\
\text { Gradient } \\
\text { (Horizontal) } \\
\text { (Pre-mining) }\end{array}$ & & $\begin{array}{l}\frac{\text { Assumed Value }}{1 \times 10^{-4}} \\
\frac{\text { Range of values }}{\left(5 \times 10^{-5}\right) \text { to }\left(5 \times 10^{-4}\right)} \\
\text { Comments } \\
\text { De ju and others }(1978) \text {, } \\
\text { Table } I, \text { p. } 9 .\end{array}$ & \\
\hline 1. 2.8 & $\begin{array}{l}\text { Hydraulic } \\
\text { Gradient } \\
\text { (Vertical) } \\
\text { (Pre-mining) }\end{array}$ & & $\begin{array}{l}\frac{\text { Assumed Value }}{1 \times 10^{-3}} \\
\frac{\text { Range of values }}{\left(5 \times 10^{-4}\right) \text { to }\left(4 \times 10^{-1}\right)} \\
\text { Comments } \\
\text { Deju and others }(1978) \text {, } \\
\text { Table I, p. } 9 .\end{array}$ & \\
\hline 1. 2.9 & $\begin{array}{l}\text { Long-Terfil } \\
\text { Hydraulic } \\
\text { Gradients } \\
\text { (with thermal } \\
\text { influence) }\end{array}$ & & $\begin{array}{l}\text { Assumed Value } \\
1 \mathrm{~m} / \mathrm{km} \text { horizontal and } \\
1 \mathrm{~m} / 100 \mathrm{~m} \text { upward } \\
\text { Unknown } \\
\text { Steady state flow conditions } \\
\text { (expanding thermal effects) }\end{array}$ & \\
\hline
\end{tabular}


TABLE A-1 (continued)

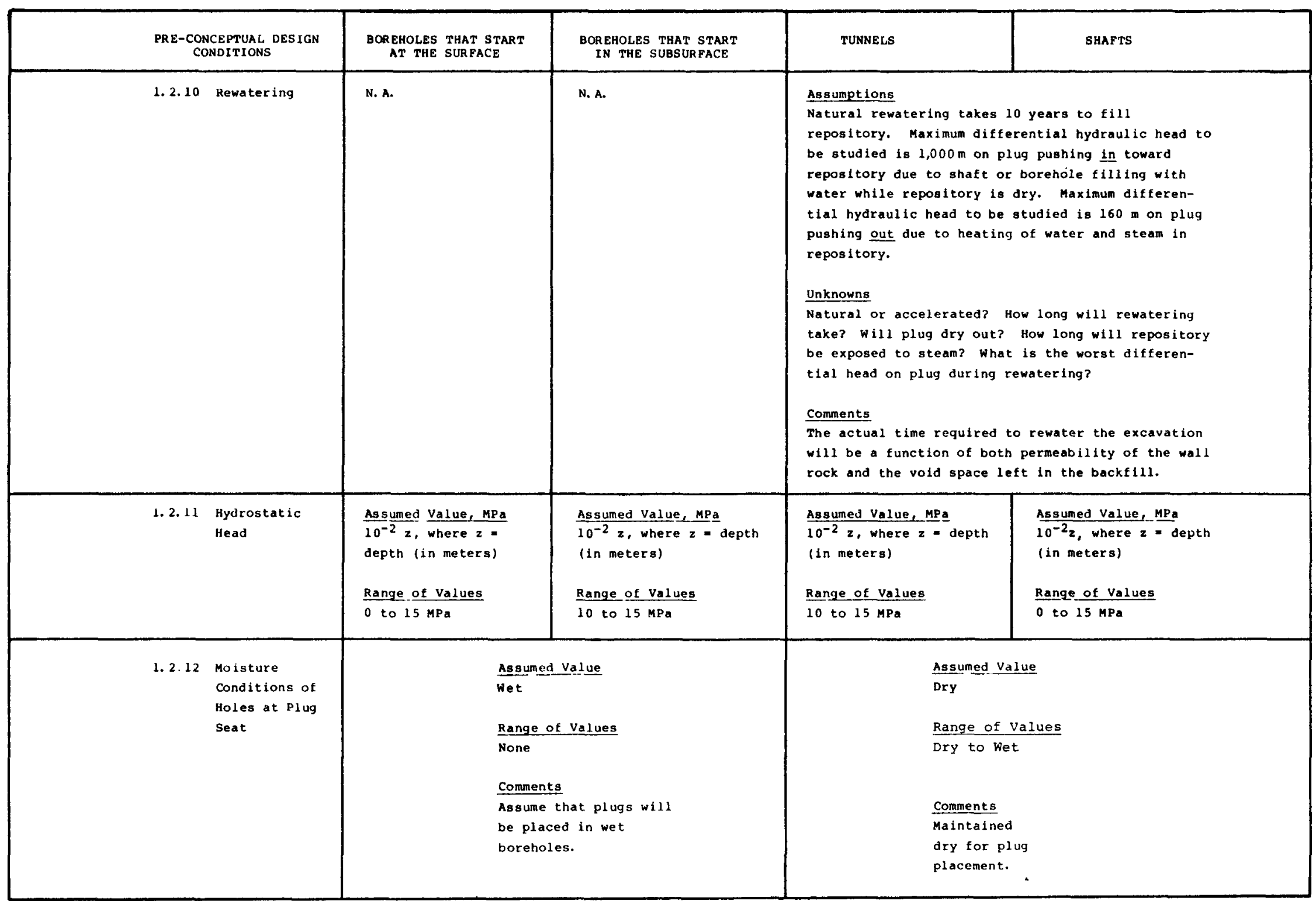


TABLE A-I (continued)

\begin{tabular}{|c|c|c|c|c|c|}
\hline \multicolumn{2}{|c|}{$\begin{array}{l}\text { PRE-CONCEPTUAL DESIGN } \\
\text { CONDITIONS }\end{array}$} & $\begin{array}{l}\text { BOREHOLES THAT START } \\
\text { AT THE SURFACE }\end{array}$ & $\begin{array}{l}\text { BOREHOLES THAT START } \\
\text { IN THE SUBSUR FACE }\end{array}$ & TUNNELS & SHAFTS \\
\hline \multicolumn{6}{|c|}{$\begin{array}{l}\text { 1. } 3 \frac{\text { Mechanical }}{\text { Properties and }} \\
\text { Sonditions }\end{array}$} \\
\hline 1.3 .1 & $\begin{array}{l}\text { Th1ckness of } \\
\text { Repository Flow }\end{array}$ & N. A. & \multicolumn{2}{|c|}{$\begin{array}{l}\frac{\text { Assumed Value }}{60 \mathrm{~m}} \\
\frac{\text { Range of Values }}{60 \text { to } 100 \mathrm{~m}}\end{array}$} & N. A. \\
\hline 1.3 .2 & $\begin{array}{l}\text { Fracture } \\
\text { Spacing }\end{array}$ & \multicolumn{3}{|c|}{$\begin{array}{l}\frac{\text { Assumed Value }}{10 \text { per meter }} \\
\frac{\text { Range of values }}{1 \text { to } 28 \text { per meter }} \\
\frac{\text { Comments }}{\text { Well DH-5 }} \\
\text { Long (1978) }\end{array}$} & \\
\hline 1. 3.3 & $\begin{array}{l}\text { Casings/Linings } \\
\text { of Plug Seats }\end{array}$ & $\begin{array}{l}\text { Assumed Value } \\
\text { Uncased } \\
\text { Range of values } \\
\text { Casing } \\
\text { Comments } \\
\text { Assumes casing will } \\
\text { be removed prior to } \\
\text { plugging. }\end{array}$ & $\begin{array}{l}\frac{\text { Assumed Value }}{\text { Uncased }} \\
\text { Range of Values } \\
\text { Uncased or filled with } \\
\text { grout or steel } \\
\text { Comments } \\
\text { Assumes open holes } \\
\text { will be uncased. }\end{array}$ & $\begin{array}{l}\text { Assumed Value } \\
\text { Unlined } \\
\text { Range of Values } \\
\text { Unlined to lined with } \\
\text { shotcrete, gunite, } \\
\text { concrete, etc. }\end{array}$ & $\begin{array}{l}\text { Assumed Value } \\
\text { Lined } \\
\text { Range of Values } \\
\text { Unlined to lined } \\
\text { Comments } \\
\text { Assumes } 1 \text { ining may } \\
\text { be removed prior } \\
\text { to plugging. }\end{array}$ \\
\hline 1.3 .4 & $\begin{array}{l}\text { Radius of } \\
\text { Induced } \\
\text { Fracturing } \\
\text { Around Hole }\end{array}$ & $\frac{\text { Assumed value }}{\text { No fracturing }}$ & $\frac{\text { Assumed Value }}{\text { No fracturing }}$ & Data Needed & Data Needed \\
\hline
\end{tabular}


TABLE A-I (continued)

\begin{tabular}{|c|c|c|c|c|c|}
\hline PRE-CO & $\begin{array}{l}\text { NCEPTUAL DESIGN } \\
\text { ONDITIONS }\end{array}$ & $\begin{array}{c}\text { BOREHOLES THAT START } \\
\text { AT THE SURFACE }\end{array}$ & $\begin{array}{l}\text { BOREHOLES THAT START } \\
\text { IN THE SUBSURFACE }\end{array}$ & TUNNELS & SHAFTS \\
\hline 1.35 & $\begin{array}{l}\text { Wall Rock Type } \\
\text { at Plug Seat }\end{array}$ & $\begin{array}{l}\text { Assumed Value } \\
\text { Basalt and basalt } \\
\text { interflow material } \\
\text { Range of Values } \\
\text { Basalt, flow tops, and } \\
\text { sedimentary units } \\
\text { Comments } \\
\text { Hole intersects } \\
\text { various rock types. }\end{array}$ & $\begin{array}{l}\frac{\text { Assumed Value }}{\text { Basalt }} \\
\text { Range of Values } \\
\text { None } \\
\text { Comments } \\
\text { Hole } 18 \text { within } \\
\text { repository flow. }\end{array}$ & $\begin{array}{l}\text { Assumed Value } \\
\text { Basalt } \\
\text { Range of Values } \\
\text { None } \\
\text { Comments } \\
\text { Hole is within } \\
\text { repository flow. }\end{array}$ & $\begin{array}{l}\text { Assumed Value } \\
\text { Basalt and basalt } \\
\text { interflow material } \\
\text { Range of values } \\
\text { Basalt, flow tops, and } \\
\text { sedimentary units } \\
\text { Comments } \\
\text { Hole intersects } \\
\text { various rock types. }\end{array}$ \\
\hline 1. 3.6 & $\begin{array}{l}\text { Hole Diameter } \\
\text { at Repository } \\
\text { Depth }\end{array}$ & $\begin{array}{l}\frac{\text { Assumed Value }}{17 \mathrm{~cm}(6-3 / 4 \text { inches })} \\
\frac{\text { Range of Values }}{5 \text { to } 25 \mathrm{~cm}} \\
\text { Comments } \\
\text { Holes smaller than } \\
10 \mathrm{~cm} \text { will probably } \\
\text { be re-drilled to a } \\
\text { larger diameter. }\end{array}$ & $\begin{array}{l}\frac{\text { Assumed Value }}{10 \mathrm{~cm}} \\
\frac{\text { Range of values }}{7 \text { to } 14 \mathrm{~cm}}\end{array}$ & $\begin{array}{l}\frac{\text { Assumed Value }}{7 \mathrm{~m}} \\
\frac{\text { Range of Values }}{6 \text { to } 10 \mathrm{~cm}}\end{array}$ & $\begin{array}{l}\frac{\text { Assumed Value }}{6 \mathrm{~m}} \\
\frac{\text { Range of Values }}{2 \text { to } 9 \mathrm{~m}}\end{array}$ \\
\hline 1.3 .7 & $\begin{array}{l}\text { Hole Depth- } \\
\text { Length }\end{array}$ & $\begin{array}{l}\text { Assumed Value } \\
1,000 \mathrm{~m} \\
\frac{\text { Range of Values }}{900 \text { to } 1,500 \mathrm{~m}} \\
\text { Comments } \\
\text { Assumes repository } \\
\text { depth in excess of } \\
900 \mathrm{~m} \text {. }\end{array}$ & $\begin{array}{l}\text { Assumed Value } \\
15 \mathrm{~m} \\
\frac{\text { Range of values }}{5 \text { to } 50 \mathrm{~m}} \\
\text { Comments } \\
\text { Assumes holes will be } \\
\text { exploratory or for } \\
\text { advancing tunnels. }\end{array}$ & $\begin{array}{l}\frac{\text { Assumed Value }}{3 \mathrm{~km}} \\
\frac{\text { Range of values }}{3 \text { to } 8 \mathrm{~km}} \\
\frac{\text { Comments }}{\text { Assumes tunnels will }} \\
\text { be approx 2mately } 3 \mathrm{~km} \\
\text { long. }\end{array}$ & $\begin{array}{l}\text { Assumed Value } \\
1,000 \mathrm{~m} \\
\text { Range of Values } \\
900 \text { to } 1,500 \mathrm{~m} \\
\text { Comments } \\
\text { Assumes repository } \\
\text { depth to exceed } \\
900 \mathrm{~m} \text {. }\end{array}$ \\
\hline
\end{tabular}


TABLE A-I (continued)

\begin{tabular}{|c|c|c|c|c|c|}
\hline \multicolumn{2}{|c|}{$\begin{array}{l}\text { PRL-CONCEPTUAL DESIGN } \\
\text { CONDITIONS }\end{array}$} & $\begin{array}{l}\text { BOKEHOLES THAT START } \\
\text { AT THE SURFACE }\end{array}$ & $\begin{array}{l}\text { BOREHOLES THAT START } \\
\text { IN THE SUBSURFACE }\end{array}$ & TUNNEISS & SHAFTS \\
\hline 1.3 .8 & $\begin{array}{l}\text { Lithostatic } \\
\text { Pressure } \\
\text { (Horizontal) } \\
\text { (Cook, 1977) }\end{array}$ & \multicolumn{2}{|c|}{ 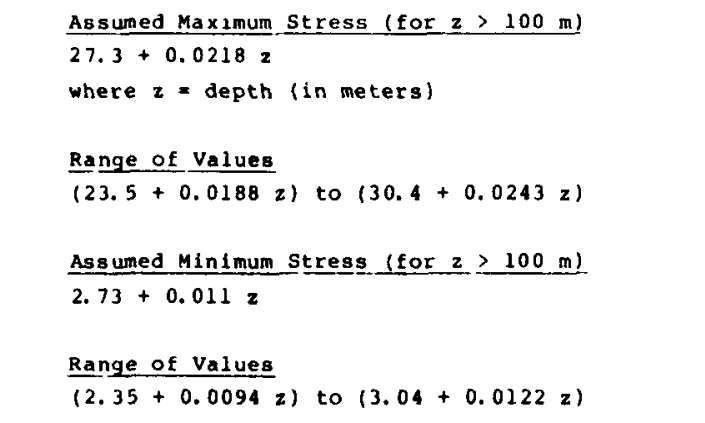 } & $\begin{array}{l}\frac{\text { Assumed Maximum Stress }}{49 \mathrm{MPa}} \\
\frac{\text { Range of Values }}{42 \text { to } 55 \mathrm{MPa} 1000 \mathrm{~m}} \\
\frac{\text { Assumed Minimum Stress }}{14 \mathrm{MPa}} \\
\frac{\text { Range of Values }}{12 \text { to } 15 \mathrm{MPa}} 1000 \mathrm{~m}\end{array}$ & $\begin{array}{l}\text { Comments } \\
\text { See data at left } \\
\text { for "boreholes." }\end{array}$ \\
\hline 1.3 .9 & $\begin{array}{l}\text { Lithostatic } \\
\text { Pressure } \\
\text { (Vertical) }\end{array}$ & $\begin{array}{l}\frac{\text { Assumed Value }}{21 \mathrm{MPa}} \\
\frac{\text { Range of Values }}{0 \text { to } 42 \mathrm{MPa}} \\
\text { Comments } \\
\text { Average vertical } \\
\text { stress from surface to } \\
\text { repository depth. }\end{array}$ & $\begin{array}{l}\frac{\text { Assumed Value }}{35 \mathrm{MPa}} \\
\frac{\text { Range of }}{28 \text { to } 42} \mathrm{MPa} \\
\frac{\text { Comments }}{\text { Vertical stress between }} \\
1,000 \text { and } 1,500 \mathrm{~m}\end{array}$ & $\begin{array}{l}\frac{\text { Assumed Value }}{35 \mathrm{MPa}} \\
\frac{\text { Range of Values }}{28 \text { to } 42 \mathrm{MPa}} \\
\frac{\text { Comments }}{\text { Vertical stress between }} \\
1,000 \text { and } 1,500 \mathrm{~m} \text { Benson } \\
(1978) \text { calculated a } \\
\text { pressure of } 270 \text { bars. }\end{array}$ & $\begin{array}{l}\frac{\text { Assumed value }}{21 \mathrm{MPa}} \\
\frac{\text { Range of values }}{0 \text { to } \$ 2 \mathrm{MPa}} \\
\frac{\text { Comments }}{\text { Average vertical stress }} \\
\text { from surface to } \\
\text { repository depth. }\end{array}$ \\
\hline 1.3 .10 & $\begin{array}{l}\text { Angle of } \\
\text { Internal } \\
\text { Friction }\end{array}$ & & $\begin{array}{l}\frac{\text { Assumed }}{46 \text { degre }} \\
\frac{\text { Range of }}{28 \text { to } 58} \\
\text { Comments } \\
\text { Colorado } \\
\text { Mines (1 }\end{array}$ & $\begin{array}{l}\text { ues } \\
\text { nees } \\
\text { rees } \\
\text { ool of }\end{array}$ & \\
\hline
\end{tabular}


TABLE A-I (continued)

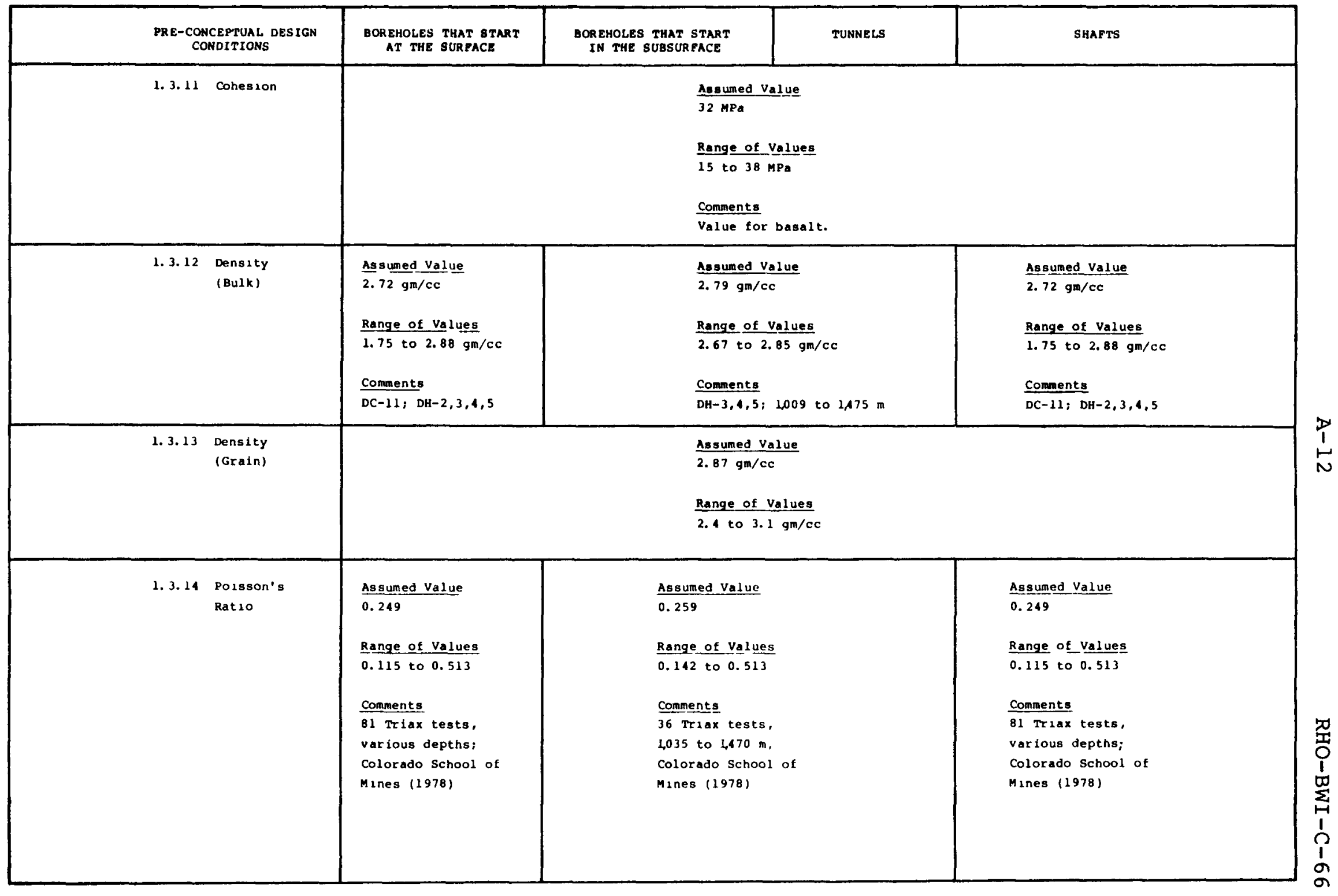


TABLE A-I (continued)

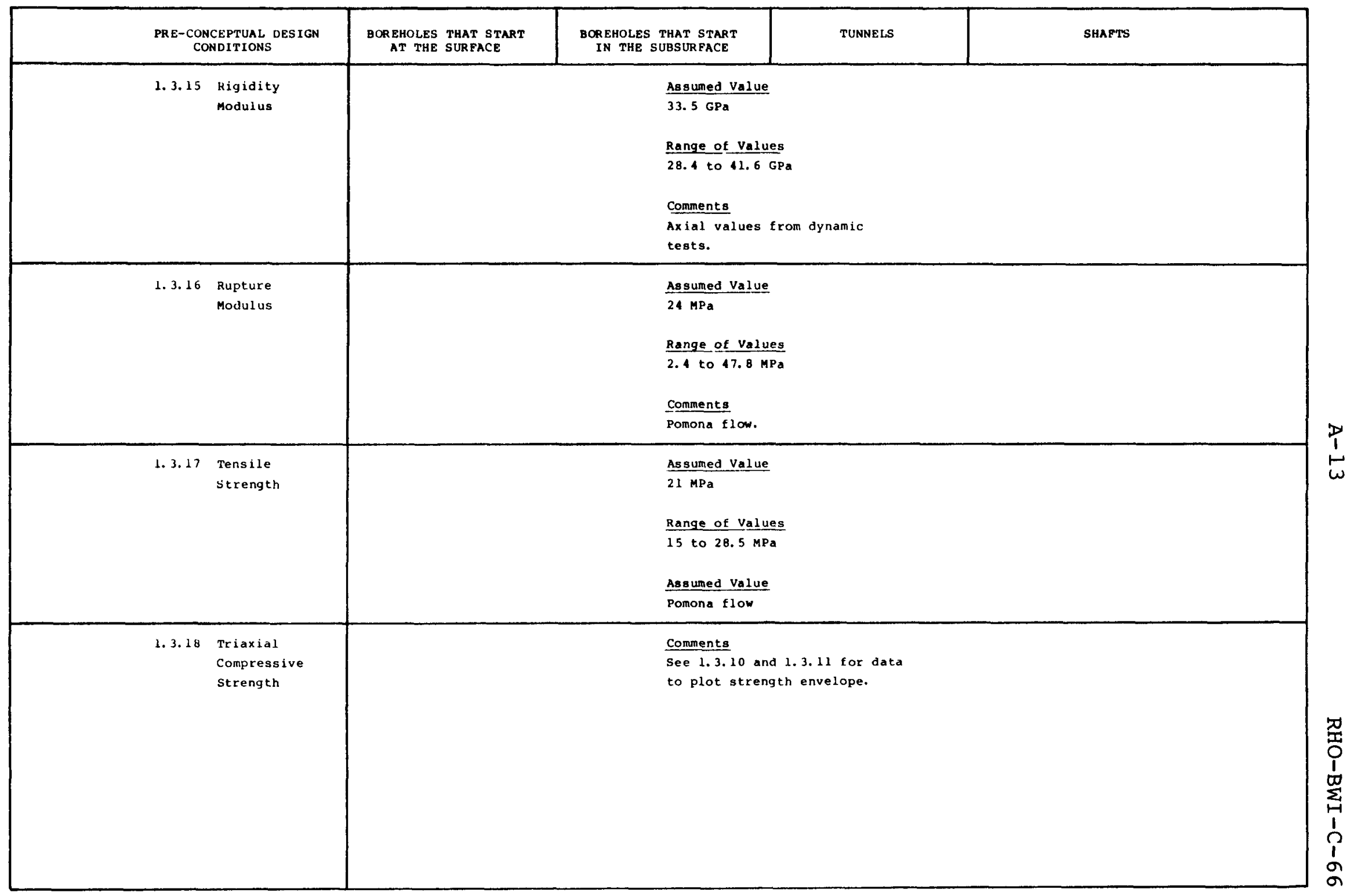


TABLE A-I (continued)

\begin{tabular}{|c|c|c|c|c|}
\hline \multicolumn{2}{|c|}{$\begin{array}{l}\text { PRE-CONCEPTUAL DESIGN } \\
\text { CONDITIONS }\end{array}$} & $\begin{array}{l}\text { BOREHOLES THAT STRART } \\
\text { AT THE SURFACE }\end{array}$ & $\begin{array}{l}\text { BOREHOLES THAT START } \\
\text { IN THE SUBSURFACE }\end{array}$ & SHAFTS \\
\hline 1.3 .19 & $\begin{array}{l}\text { Uniaxial } \\
\text { Compressive } \\
\text { Strength }\end{array}$ & $\begin{array}{l}\frac{\text { Assumed Value }}{218 \mathrm{MPa}} \\
\text { Range of values } \\
4 \text { to } 378 \mathrm{MPa} \\
\text { Comments } \\
\text { DC-11; DH-2,3,4,5; } \\
\text { Colorado School of } \\
\text { Mines (1978) }\end{array}$ & $\begin{array}{l}\text { Assumed Value } \\
219 \mathrm{MPa} \\
\frac{\text { Range of values }}{86 \text { to } 378 \mathrm{MPa}} \\
\text { Comments } \\
\text { DH-3,4,5; } 1035 \text { to } 1470 \mathrm{~m} \text {; } \\
\text { Colorado School of } \\
\text { Mines (1978) }\end{array}$ & $\begin{array}{l}\frac{\text { Assumed value }}{218 \mathrm{MPa}} \\
\frac{\text { Range of }}{4 \text { to } 378} \frac{\mathrm{MPa}}{\mathrm{MPa}} \\
\text { Comments } \\
\text { DC-11; DH-2,3,4,5, } \\
\text { Colorado School of . } \\
\text { Mines (1978) }\end{array}$ \\
\hline 1. 3.20 & $\begin{array}{l}\text { Young's } \\
\text { Modulus } \\
\text { (Dynam1c) }\end{array}$ & $\begin{array}{l}\text { Assumed Value } \\
54.2 \mathrm{GPa} \\
\frac{\text { Range of Values }}{0.38 \text { to } 165 \mathrm{GPa}} \\
\text { Comments } \\
\text { Various depths }\end{array}$ & $\begin{array}{l}\text { Assumed Value } \\
51 \mathrm{GPa} \\
\frac{\text { Range of Values }}{2.65 \text { to } 142 \mathrm{GPa}} \\
\frac{\text { Comments }}{1,000 \text { to } 1,470 \mathrm{~m}}\end{array}$ & $\begin{array}{l}\frac{\text { Assumed Value }}{54.2 \mathrm{GPa}} \\
\frac{\text { Range of Values }}{0.38 \text { to } 165 \mathrm{GPa}} \\
\frac{\text { Comments }}{\text { Various depths }}\end{array}$ \\
\hline 1.3 .21 & $\begin{array}{l}\text { Young's } \\
\text { Modulus } \\
\text { (Stat1c) }\end{array}$ & & $\begin{array}{l}\frac{\text { Assumed Value }}{65.4 \mathrm{GPa}} \\
\frac{\text { Range of Values }}{27.4 \text { to } 121.6 \mathrm{GPa}} \\
\frac{\text { Comments }}{\text { Tr } 1 \text { ax tests, } 1,035 \text { to } 1,470 \mathrm{~m} \text {. }}\end{array}$ & \\
\hline
\end{tabular}


TABLE A-I (continued)

\begin{tabular}{|c|c|c|c|c|}
\hline $\begin{array}{l}\text { PRE-CONCEPTUAL DESIGN } \\
\text { CONDITIONS }\end{array}$ & $\begin{array}{l}\text { BOREHOLES THAT START } \\
\text { AT THE SURFACE }\end{array}$ & $\begin{array}{l}\text { BOREHOLES THAT START } \\
\text { IN THE SUBSUR FACE }\end{array}$ & TUNNELS & SHAFTS \\
\hline \multicolumn{5}{|l|}{$\begin{array}{l}\text { 2. } 0 \text { GEOCHEMICAL } \\
\text { CONDITIONS }\end{array}$} \\
\hline \multicolumn{5}{|l|}{$\begin{array}{l}2.1 \text { Ground-water } \\
\text { Chemistry }\end{array}$} \\
\hline 2.1.1 Bicarbonate & $\begin{array}{l}\frac{\text { Assumed Value }}{90 \mathrm{mg} / 1} \\
\frac{\text { Range of Values }}{2 \text { to } 315 \mathrm{mg} / 1} \\
\frac{\text { Comments }}{\text { Average }}\end{array}$ & $\begin{array}{l}\frac{\text { Assumed Value }}{23 \mathrm{mg} / 1} \\
\frac{\text { Range of Values }}{\text { single sample }} \\
\frac{\text { Comments }}{\text { Umtanum }}\end{array}$ & $\begin{array}{l}\frac{\text { Assumed value }}{23 \mathrm{mg} / 1} \\
\frac{\text { Range of Values }}{\text { single sample }} \\
\text { Comments } \\
\text { Umtanum }\end{array}$ & $\begin{array}{l}\frac{\text { Assumed Value }}{9 \mathrm{c} \mathrm{mg} / 1} \\
\frac{\text { Range of Values }}{2 \text { to } 315 \mathrm{mg} / 1} \\
\frac{\text { Comments }}{\text { Average }}\end{array}$ \\
\hline 2. 1.2 Boron & $\begin{array}{l}\frac{\text { Assumed Value }}{0.38 \mathrm{mg} / 1} \\
\text { Range of Values } \\
0 \text { to } 0.94 \mathrm{mg} / 1 \\
\text { Comments } \\
\text { Average; Lasals and } \\
\text { Doty (1971). }\end{array}$ & $\begin{array}{l}\frac{\text { Assumed Value }}{0.17 \mathrm{mg} / 1} \\
\frac{\text { Range of Values }}{\text { single sample }} \\
\frac{\text { Comments }}{\text { ARH-DC-1, } 978 \text { to } 990 \mathrm{~ms}} \\
\text { LaSala and Doty }(1971) .\end{array}$ & $\begin{array}{l}\frac{\text { Assumed Value }}{0.17 \mathrm{mg} / 1 \text { iter }} \\
\frac{\text { Range of Values }}{\text { single sample }} \\
\frac{\text { Comments }}{\text { ARH-DC-1, } 978 \text { to } 990 \mathrm{~m} \text {; }} \\
\text { Lasal a and Doty }(1971) .\end{array}$ & $\begin{array}{l}\frac{\text { Assumed Value }}{0.38 \mathrm{mg} / \mathrm{l}} \\
\frac{\text { Range of Values }}{0 \text { to } 0.94 \mathrm{mg} / 1} \\
\frac{\text { Comments }}{\text { Average; LaSala and }} \\
\text { Doty (1971). }\end{array}$ \\
\hline 2.1.3 Calcium & $\begin{array}{l}\frac{\text { Assumed Value }}{10.8 \mathrm{mg} / 1} \\
\frac{\text { Range of Values }}{0.5 \text { to } 72 \mathrm{mg} / 1} \\
\frac{\text { Comments }}{\text { Average }}\end{array}$ & $\begin{array}{l}\frac{\text { Assumed value }}{1.3 \mathrm{mg} / 1} \text { 列 } \\
\frac{\text { Range of Values }}{\text { single sample }} \\
\frac{\text { Comments }}{\text { Umtanum }}\end{array}$ & $\begin{array}{l}\frac{\text { Assumed Value }}{1.3 \mathrm{mg} / 1} \\
\frac{\text { Range of Values }}{\text { single sample }} \\
\frac{\text { Comments }}{\text { Umtanum }}\end{array}$ & $\begin{array}{l}\text { Assumed value } \\
10.8 \mathrm{mg} / 1 \\
\text { Range of Values } \\
0.5 \text { to } 72 \mathrm{mg} / 1 \\
\text { Comments } \\
\text { Average }\end{array}$ \\
\hline
\end{tabular}


TABLE A-I (continued)




TABLE A-I (continued)

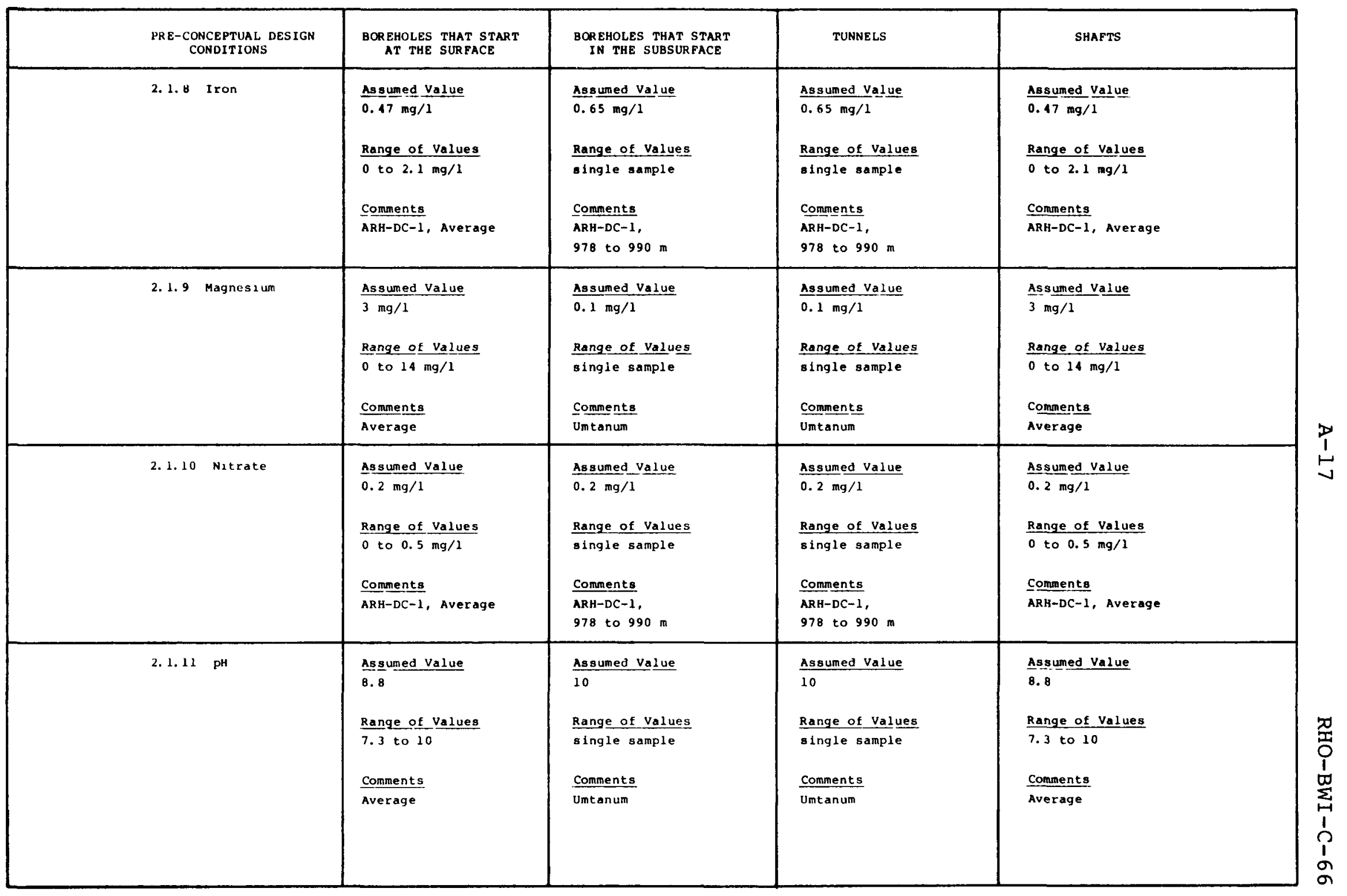


TABLE A-I (continued)

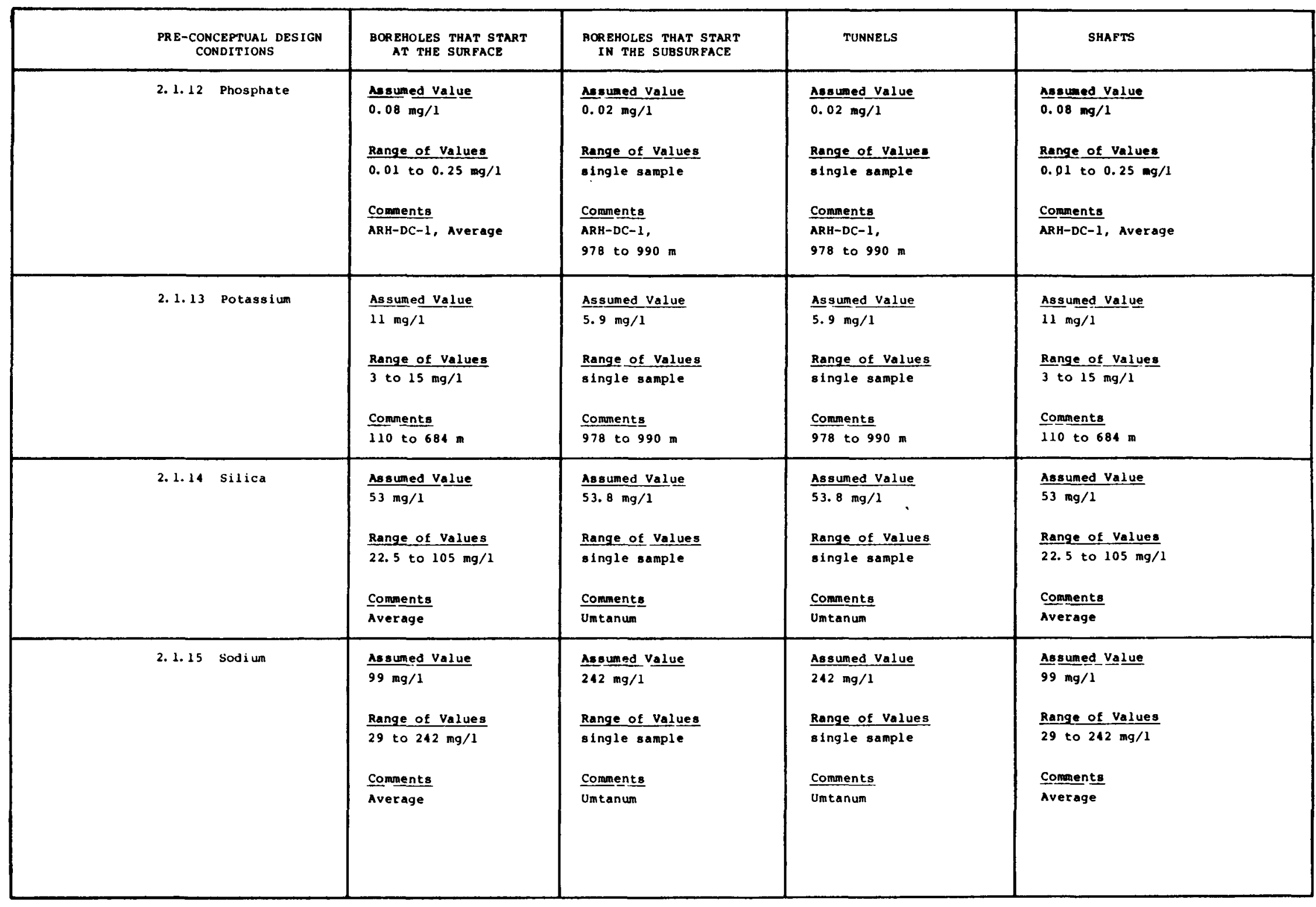


TABLE A-I (continued)

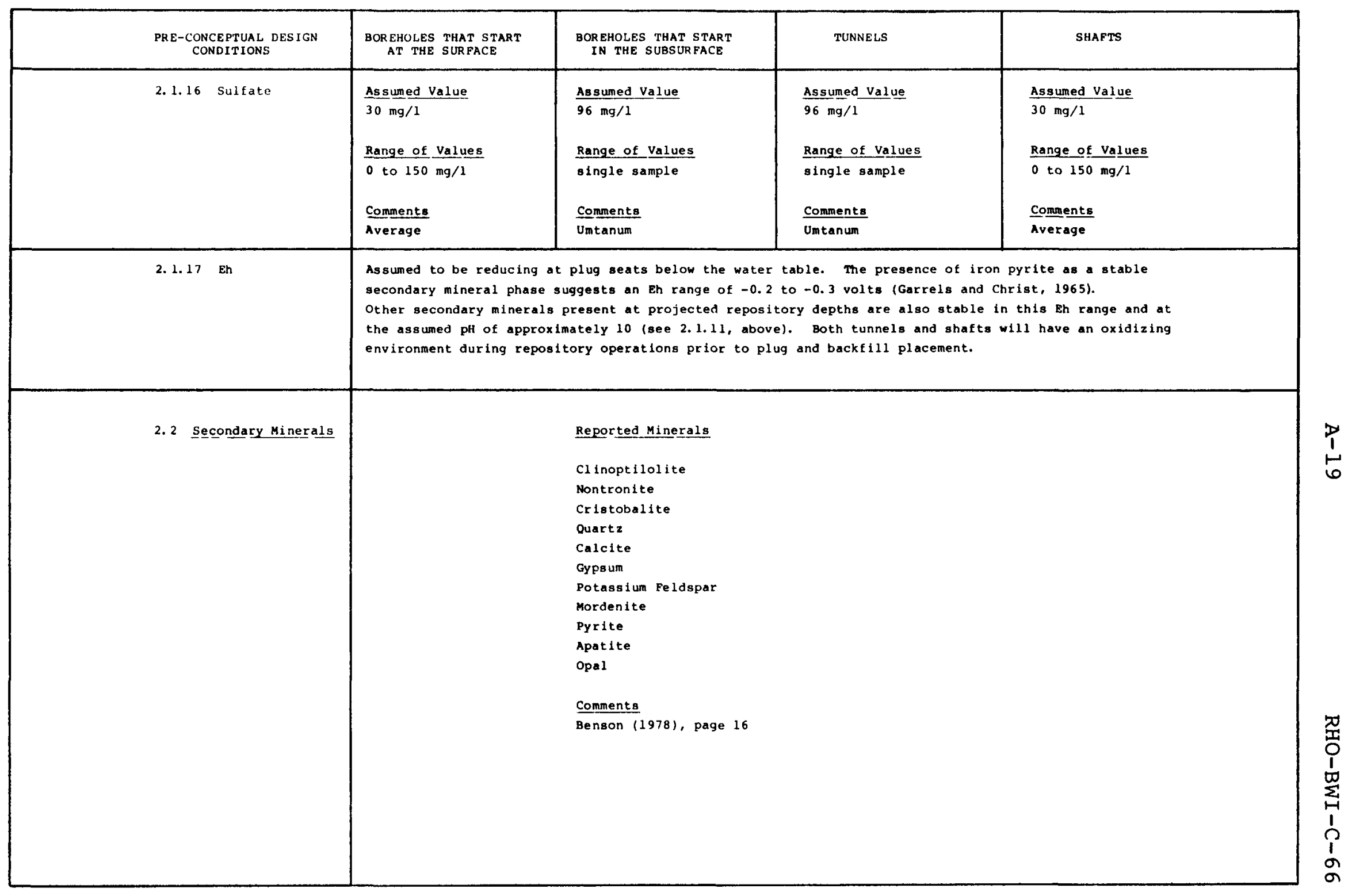


TABLE A-II

PHYSICAL DATA COMPILATION

\begin{tabular}{|c|c|c|c|c|c|c|c|c|}
\hline PAKAMETER & $\begin{array}{l}\text { AVERAGE } \\
\text { VALUE }\end{array}$ & $\begin{array}{l}\text { KANGE } \\
\text { OF VALUES }\end{array}$ & UNITS & $\begin{array}{l}\text { NO. OF } \\
\text { TESTS }\end{array}$ & REMARKS & $\begin{array}{l}\text { DATA SOURC } \\
\text { AUTHOR (YEAR) }\end{array}$ & TABLL & PAGE \\
\hline $\begin{array}{l}\text { THERMAL PROPERTIES } \\
\text { Specific Heat }\end{array}$ & $\begin{array}{l}0.319 \\
0.425 \\
0.538 \\
0.35 \\
0.175 \\
0.175 \\
0.186 \\
0.197 \\
0.208 \\
0.219 \\
0.230 \\
1.0\end{array}$ & $\begin{array}{l}0.288 \text { to } 0.355 \\
0.394 \text { to } 0.460 \\
0.474 \text { to } 0.585 \\
0.23 \text { to } 0.25 \\
\\
0.174 \text { to } 0.176 \\
0.186 \text { to } 0.187 \\
0.197 \text { to } 0.198 \\
0.207 \text { to } 0.210 \\
0.217 \text { to } 0.222 \\
0.227 \text { to } 0.234 \\
0.95 \text { to } 1.05\end{array}$ & 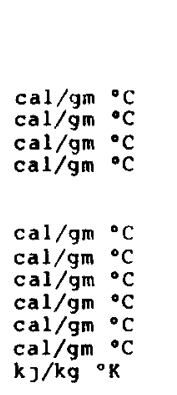 & $\begin{array}{l}3 \\
3 \\
3 \\
3 \\
\\
2 \\
2 \\
2 \\
2 \\
2 \\
2\end{array}$ & 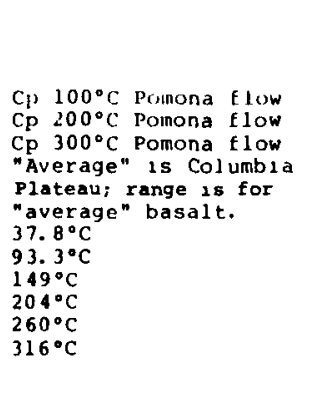 & 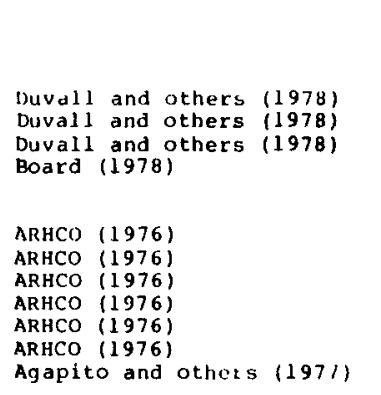 & 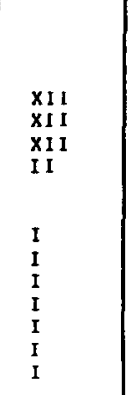 & $\begin{array}{l}120 \\
120 \\
120 \\
120 \\
120 \\
120\end{array}$ \\
\hline $\begin{array}{l}\text { Thermal } \\
\text { Conduct tuvity }\end{array}$ & $\begin{array}{l}0.349 \\
0.347 \\
0.348 \\
0.36 \\
0.258 \\
0.267 \\
0.275 \\
0.283 \\
0.290 \\
0.300 \\
1.5 \\
1.53 \\
1.05 \times 10^{-2} \\
1.48 \times 10^{-2} \\
1.9 \times 10^{-2} \\
1.188 \times 10^{-2} \\
1.574 \times 10^{-2} \\
2.01 \times 10^{-2}\end{array}$ & 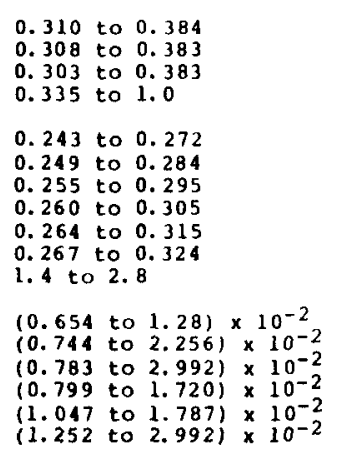 & 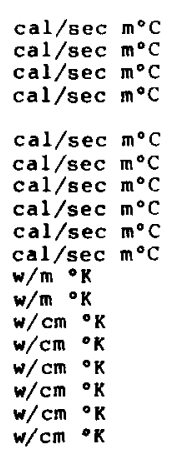 & $\begin{array}{l}3 \\
3 \\
3 \\
8 \\
2 \\
2 \\
2 \\
2 \\
2 \\
2 \\
3 \\
3 \\
29 \\
29 \\
29 \\
13 \\
13 \\
13\end{array}$ & 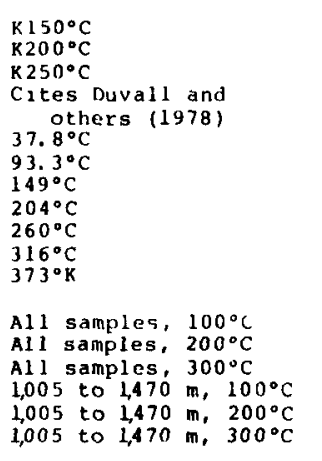 & $\begin{array}{l}\text { Duval1 and others (1978) } \\
\text { Duval1 and others (1978) } \\
\text { Duval1 and others (1978) } \\
\text { Board (1978) } \\
\text { ARHCO (1976) } \\
\text { ARHCO (1976) } \\
\text { ARHCO (1976) } \\
\text { ARCO (1976) } \\
\text { ARHCO (1976) } \\
\text { ARCCO (1976) } \\
\text { Agapito and oth rs (1977) } \\
\text { Agapito and others (1977) } \\
\text { Colorado Sch. M1nes (1978) } \\
\text { Colorado Sch. Mines (1978) } \\
\text { Colorado Sch M1nes (1978) } \\
\text { Colorado Sch. M1nes (1978) } \\
\text { Colorado Sch. M1nes (1978) } \\
\text { Colorado Sch. Mines (1978) }\end{array}$ & $\begin{array}{l}\text { XI } \\
\text { XI } \\
\text { XI } \\
\text { II } \\
I \\
I \\
I \\
I \\
I \\
I \\
I \\
I V \\
\text { FI } \\
\text { F19.15 } \\
\text { F19.15 } \\
\text { F19.15 }\end{array}$ & $\begin{array}{l}120 \\
120 \\
120 \\
120 \\
120 \\
120 \\
\\
70 \\
70 \\
70 \\
71-74 \\
7174 \\
71-74\end{array}$ \\
\hline $\begin{array}{l}\text { Thermal } \\
\text { biffusivity }\end{array}$ & $\begin{array}{l}0.00524 \\
0.00511 \\
0.00497 \\
0.00482 \\
0.00459 \\
0.00454 \\
0.00650\end{array}$ & $\begin{array}{l}0.00516 \text { to } 0.00532 \\
0.00503 \text { to } 0.00519 \\
00.00488 \text { to } 0.00506 \\
0.00472 \text { to } 0.00493 \\
0.00157 \text { to } 0.00480 \\
0.0044 \text { to } 0.00467 \\
0.0052 \text { to } 0.0080\end{array}$ & $\begin{array}{l}\mathrm{cm}^{2} / \mathrm{sec} \\
\mathrm{cm}^{2} / \mathrm{sec} \\
\mathrm{cm}^{2} / \mathrm{sec} \\
\mathrm{cm}^{2} / \mathrm{sec} \\
\mathrm{cm}^{2} / \text { sec } \\
\mathrm{cm}^{2} / \mathrm{sec} \\
\mathrm{cm}^{2} / \text { sec }\end{array}$ & $\begin{array}{l}2 \\
2 \\
2 \\
2 \\
2 \\
2 \\
2\end{array}$ & $\begin{array}{l}37.8^{\circ} \mathrm{C} \\
93.3^{\circ} \mathrm{C} \\
149^{\circ} \mathrm{C} \\
204^{\circ} \mathrm{C} \\
260^{\circ} \mathrm{C} \\
316^{\circ} \mathrm{C}\end{array}$ & $\begin{array}{l}\text { ARHCO }(1976) \\
\text { ARHCO }(1976) \\
\text { ARHCO }(1976) \\
\text { ARHCO }(1976) \\
\text { ARHCO }(1976) \\
\text { ARHCO (1976) } \\
\text { Ag apto and others (1977) }\end{array}$ & $\begin{array}{l}I \\
I \\
I \\
I \\
I \\
I \\
I \\
I\end{array}$ & $\begin{array}{l}120 \\
120 \\
120 \\
120 \\
120 \\
120\end{array}$ \\
\hline $\begin{array}{l}\text { Thermal Expansion } \\
\text { Coefficient }\end{array}$ & $\begin{array}{l}6.5 \times 10^{-6} \\
6.6 \times 10^{-6} \\
5.4 \times 10^{-6} \\
5.4 \times 10^{-6}\end{array}$ & $\begin{array}{l}(6.5 \text { to } 6.7) \times 10^{-6} \\
(2.9 \text { to } 11.6) \times 10^{-6} \\
(2.9 \text { to } 11.6) \times 10^{-6} \\
(4.3 \text { to } 6.5) \times 10^{-6}\end{array}$ & 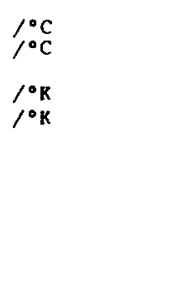 & $\begin{array}{l}3 \\
? \\
? \\
?\end{array}$ & 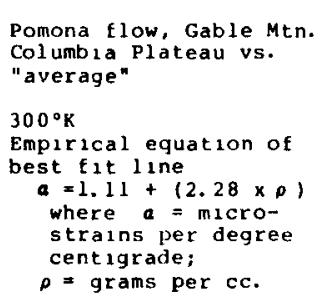 & $\begin{array}{l}\text { Duval1 and others (1978) } \\
\text { Board (1978) } \\
\text { Agapito and others (1977) } \\
\text { Agap1to and others (1977) } \\
\text { Colorado Sch. M1nes (1978) }\end{array}$ & $\begin{array}{l}x \\
I+1 \\
I \\
\text { V }\end{array}$ & 66 \\
\hline
\end{tabular}


TABLE A-II (continued)

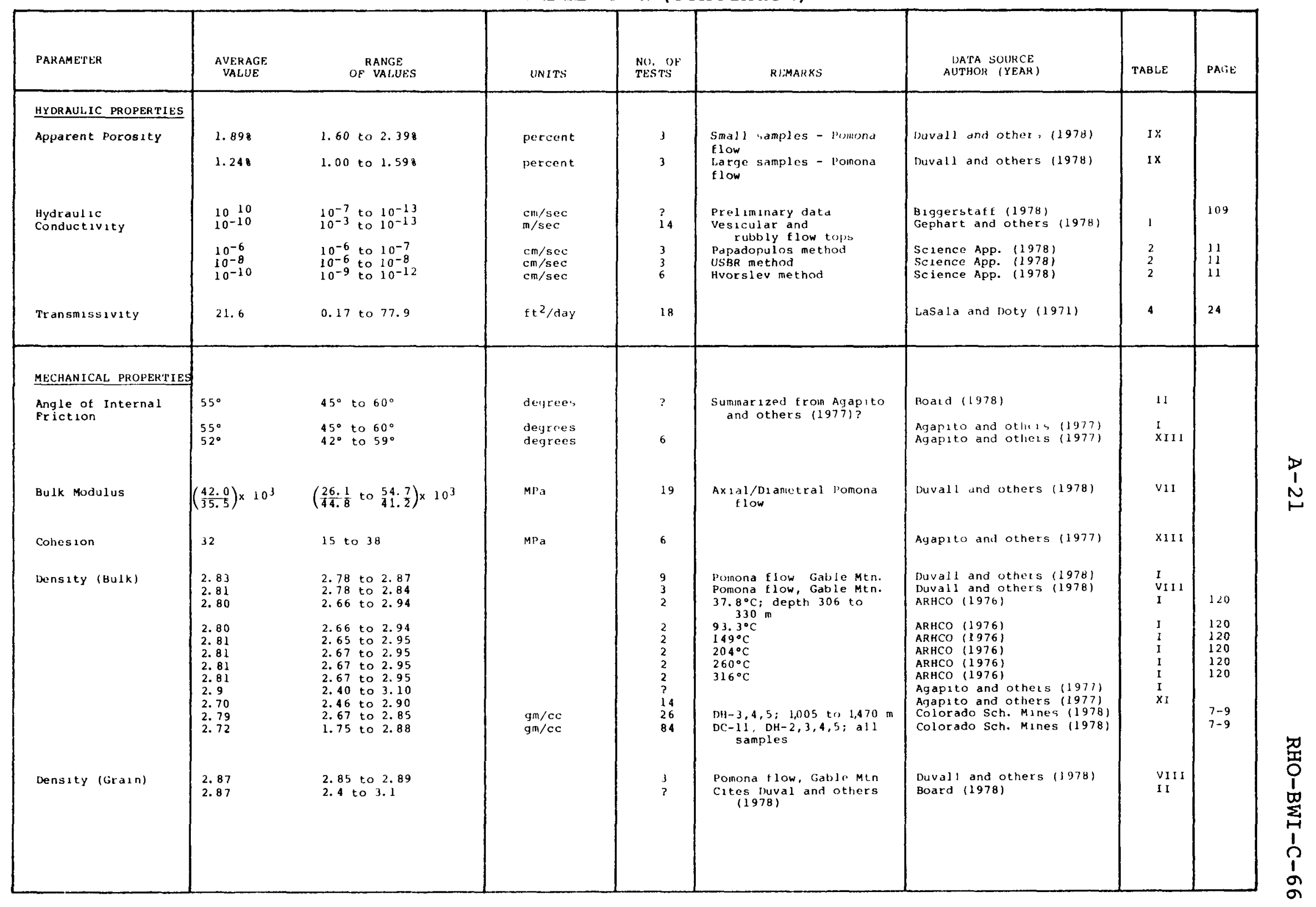


TABLE A-II (continued)

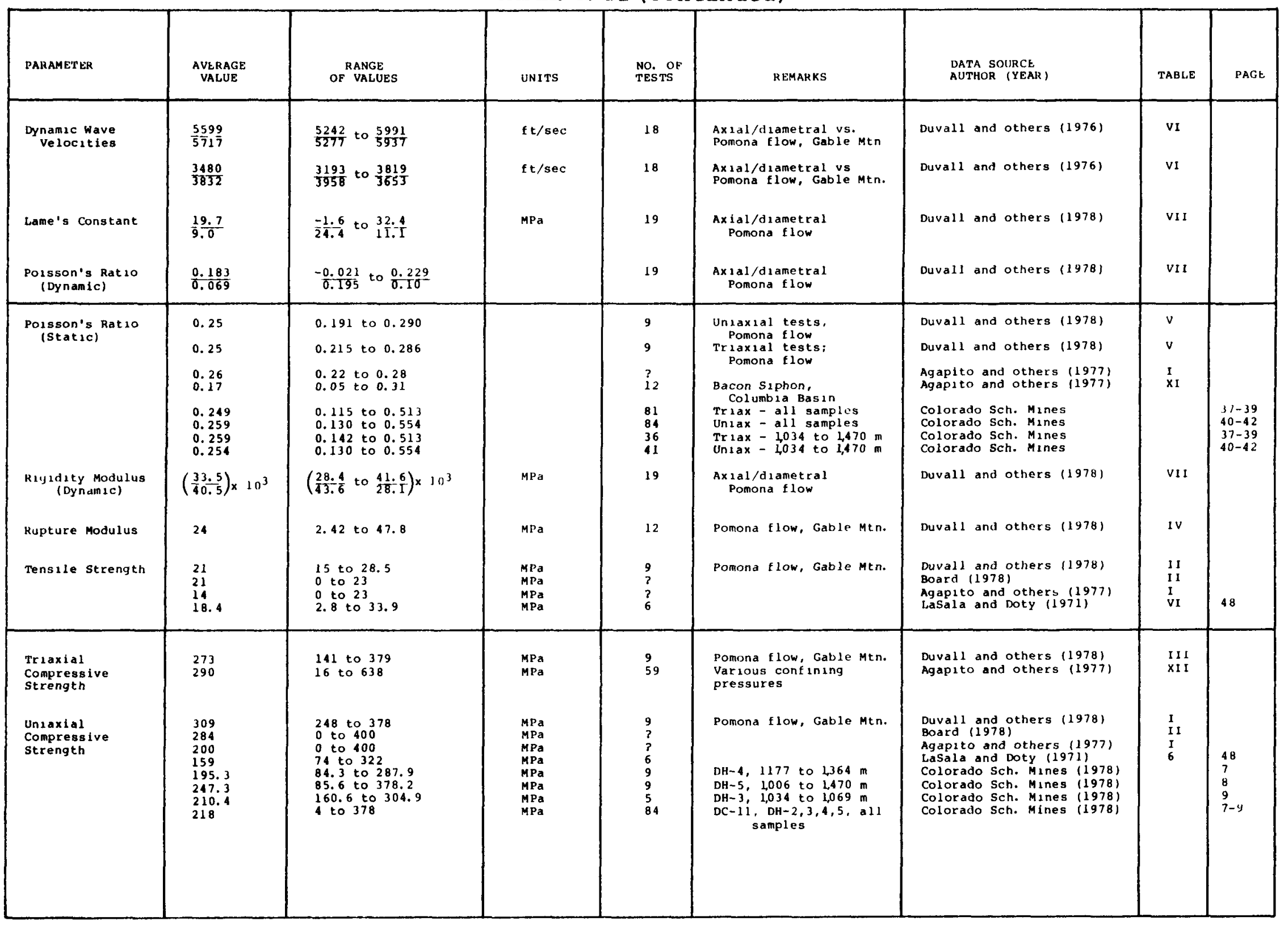


TABLE A-II (continued)

\begin{tabular}{|c|c|c|c|c|c|c|c|c|}
\hline PARAMETEK & $\begin{array}{c}\text { AVEHAGE } \\
\text { VALUE }\end{array}$ & $\begin{array}{c}\text { RANGE } \\
\text { OP VALULS }\end{array}$ & unitss & $\begin{array}{l}\text { No.) OF } \\
\text { TLSTS }\end{array}$ & RFMARKS & $\begin{array}{l}\text { DATA SOURCE } \\
\text { ALTTHOR (YEAR) }\end{array}$ & TABHLE & PACE \\
\hline $\begin{array}{l}\text { Young's Modulus } \\
\text { (Dynam1c) }\end{array}$ & $\begin{array}{l}76 \\
77 \\
77 \\
111.5 \\
61 \\
85 \\
88.5 \\
60 \\
6.54 \times 10^{4} \\
55.78 \times 10^{4} \\
6.52 \times 10^{4} \\
6.01 \times 10^{4} \\
\\
\left.\left(\frac{72.7}{75}\right) \times 10^{3}\right) \times 10^{3} \\
5.42 \times 10^{4} \\
5.10 \times 10^{4}\end{array}$ & 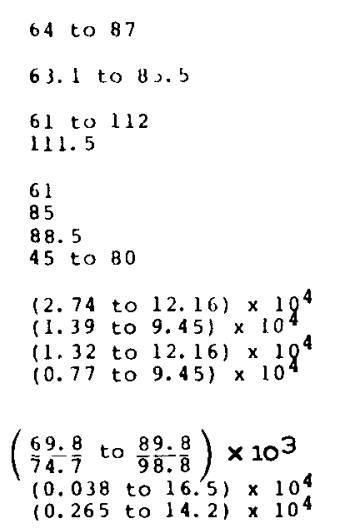 & $\begin{array}{l}\mathrm{GPa} \\
\mathrm{GiPa} \\
\mathrm{GPa} \\
\mathrm{GPa} \\
\mathrm{GPa} \\
\mathrm{GPa} \\
\mathrm{GPa} \\
\mathrm{GPa} \\
\mathrm{MPa} \\
\mathrm{MPa} \\
\mathrm{MPa} \\
\mathrm{MPa} \\
\mathrm{GPa} \\
\mathrm{MPa} \\
\mathrm{MPa}\end{array}$ & $\begin{array}{l}9 \\
9 \\
3 \\
1 \\
1 \\
1 \\
12 \\
12 \\
36 \\
42 \\
81 \\
84 \\
19 \\
19 \\
214 \\
110\end{array}$ & 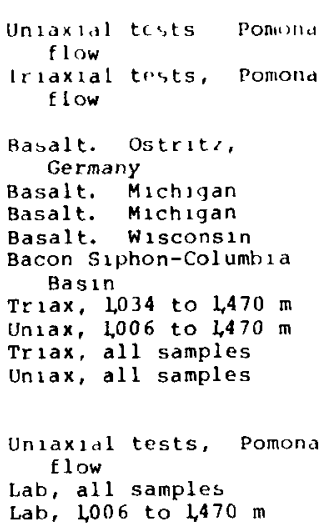 & 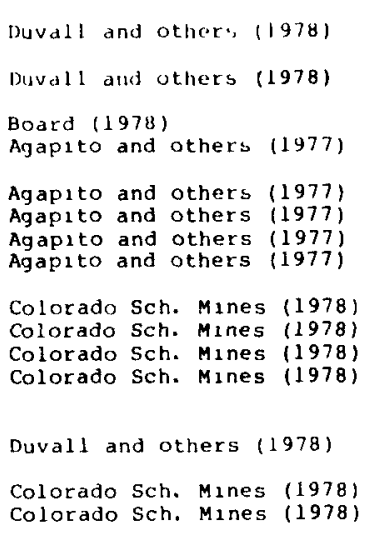 & $\begin{array}{l}v \\
v \\
v \\
I 1 \\
v 1 \\
v_{1} \\
v_{1} \\
v_{1} \\
x 1\end{array}$ & $\begin{array}{l}37-39 \\
40-42 \\
37-39 \\
40-42 \\
\\
\\
55-60 \\
55-60\end{array}$ \\
\hline
\end{tabular}


TABLE A-II (continued)

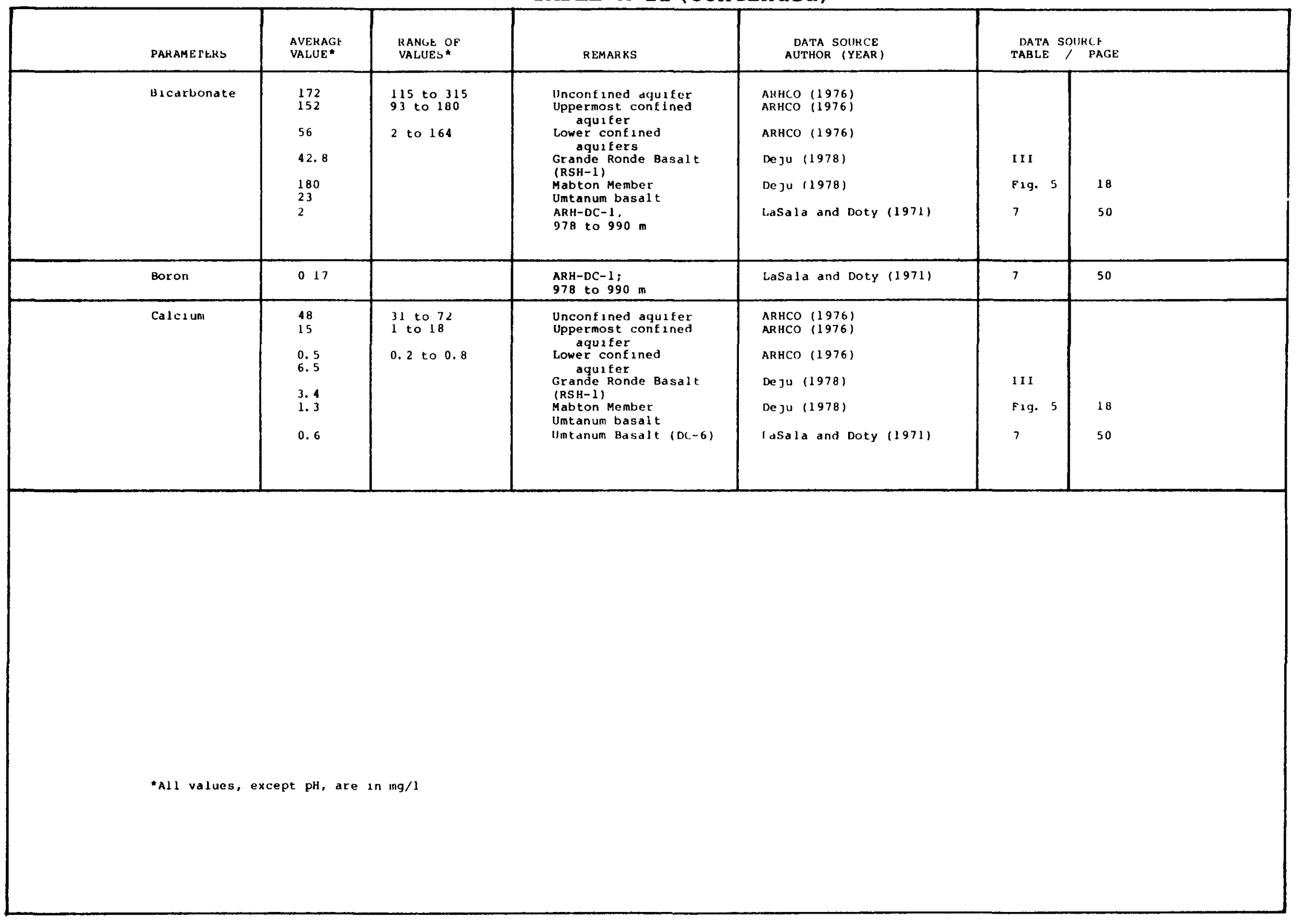


TABIE A-II (continued)

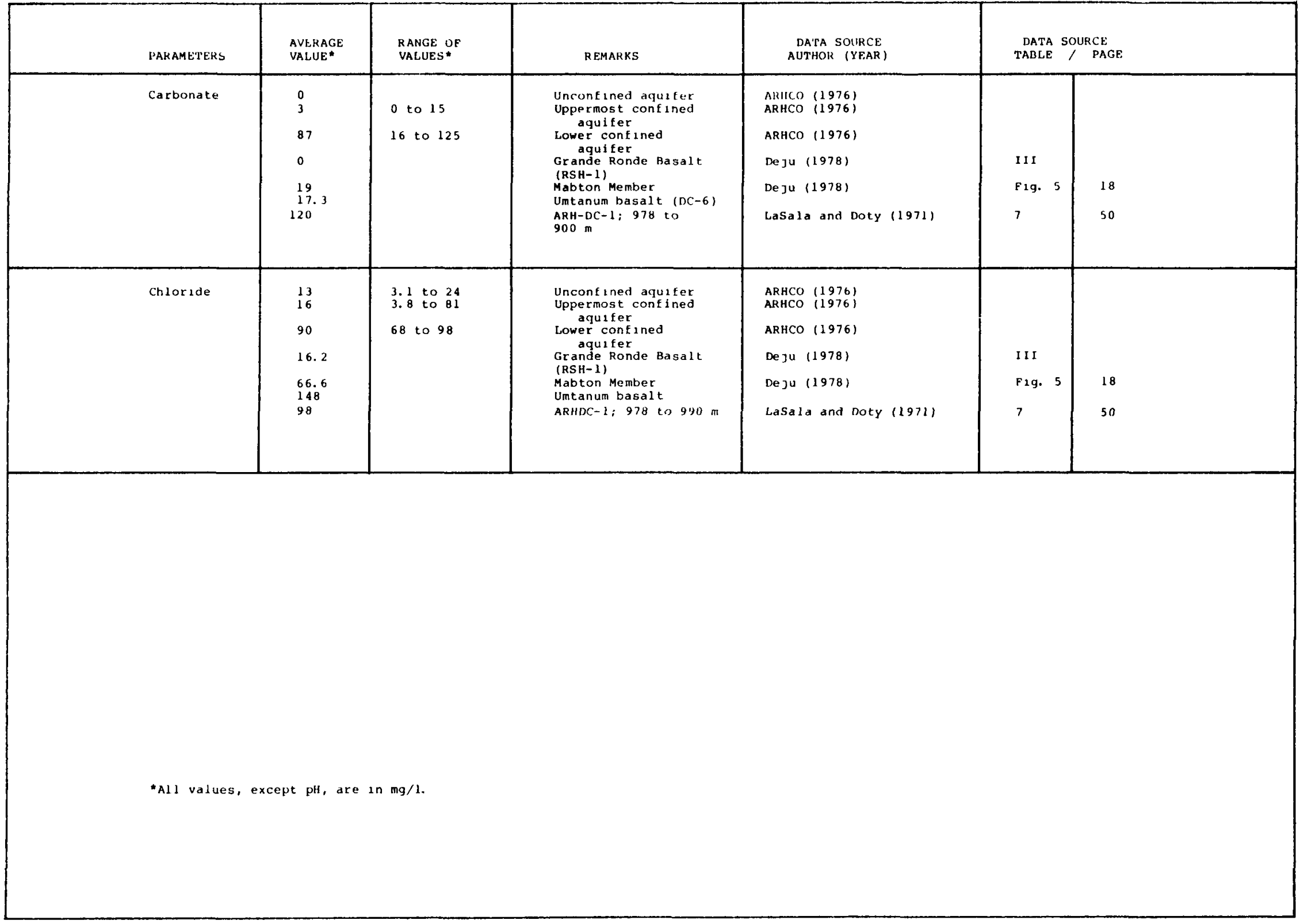


TABLE A-II (continued)

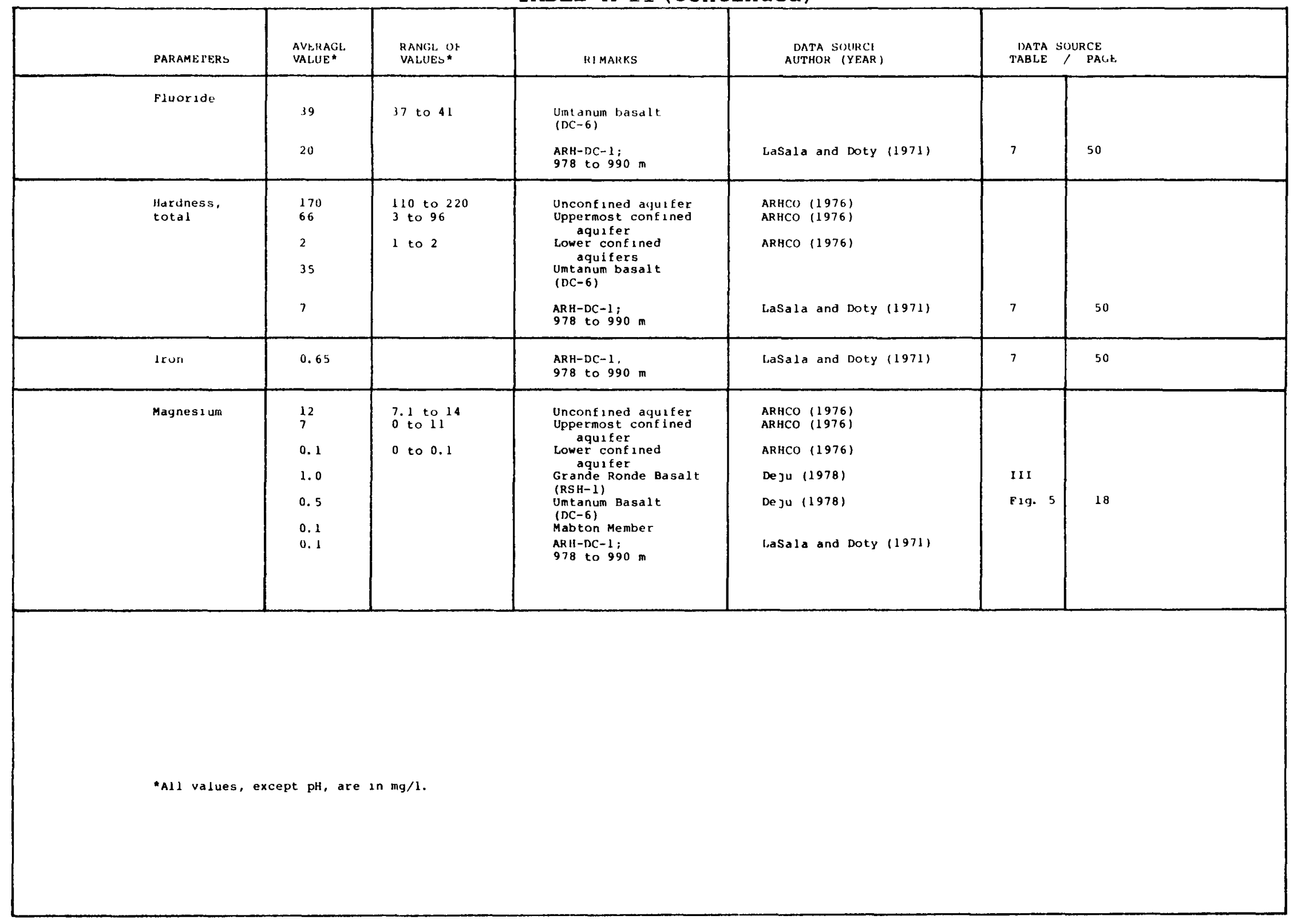


TABLE A-II (continued)

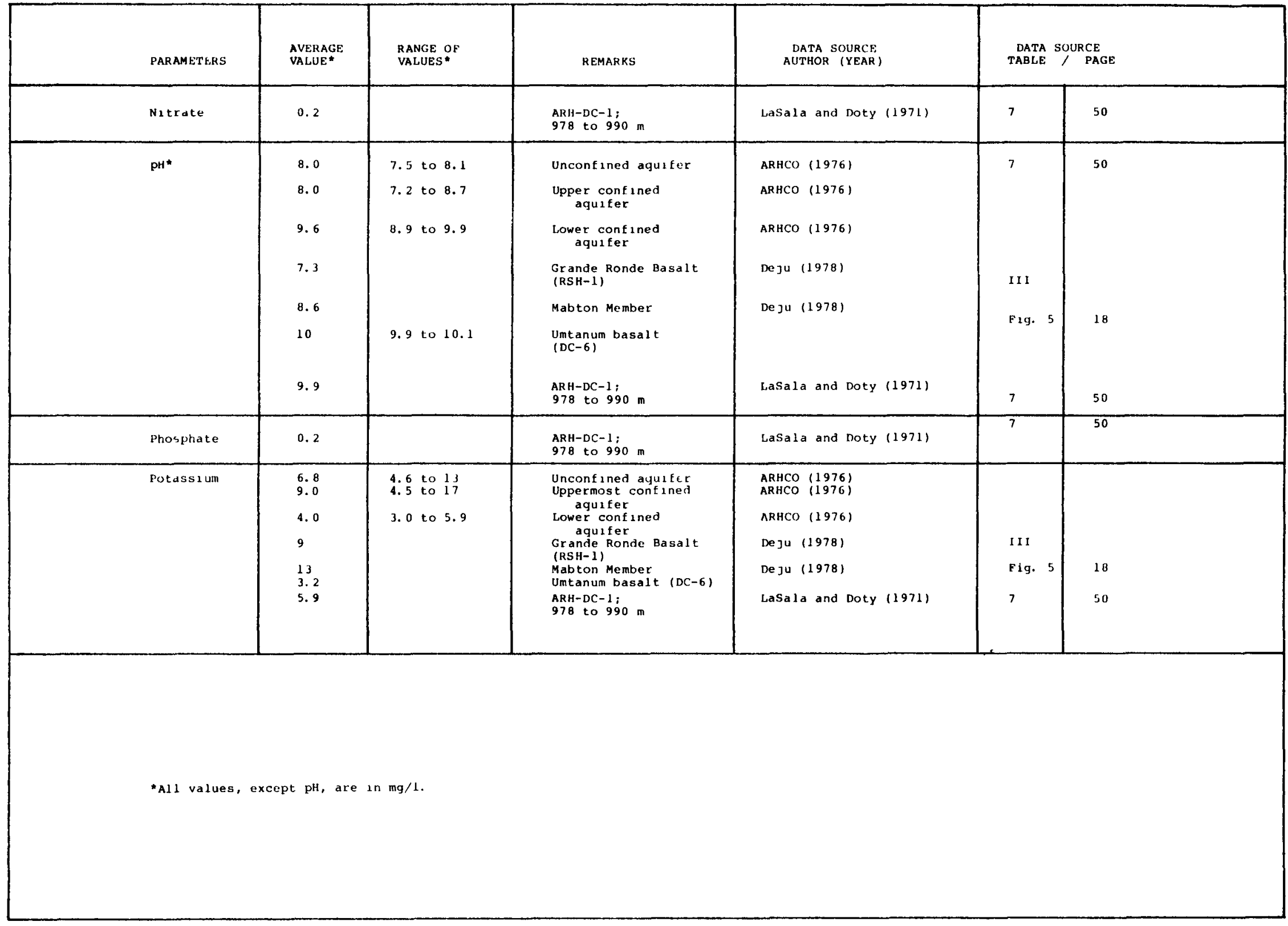


TABLE A-II (continued)

\begin{tabular}{|c|c|c|c|c|c|c|}
\hline PAIRAMEI'LRS & $\begin{array}{l}\text { AVISHAGL: } \\
\text { VALUE* }\end{array}$ & $\begin{array}{l}\text { KANC, ot } \\
\text { VALUES* }\end{array}$ & REMARKS & $\begin{array}{l}\text { IDA'IA SOURCE } \\
\text { AITHOK (YEAR) }\end{array}$ & \multicolumn{2}{|c|}{$\begin{array}{l}\text { IDATA SOUHRCE } \\
\text { TABLE } / / \text { PAGF }\end{array}$} \\
\hline $\begin{array}{l}S_{11} 1 \mathrm{Ca} \\
\left(\text { As } S_{1}\right)\end{array}$ & $\begin{array}{l}22.5 \\
31.9 \\
53.8 \\
105\end{array}$ & & $\begin{array}{l}\text { Grande Ronde Basdlt } \\
\text { (RSH-1) } \\
\text { Mabton Mermber } \\
\text { Umtanum basalt (DC-6) } \\
\text { ARH-DC- } 1 \\
978 \text { to } 990 \mathrm{~m}\end{array}$ & $\begin{array}{l}\text { De ju (1978) } \\
\text { De ju (1978) } \\
\text { LaSala and Doty (1971) }\end{array}$ & $\begin{array}{l}\text { III } \\
\text { F1g. } 5 \\
7\end{array}$ & $\begin{array}{l}18 \\
50\end{array}$ \\
\hline Sod I uin & $\begin{array}{l}29 \\
40 \\
168 \\
30 \\
110 \\
242 \\
176\end{array}$ & $\begin{array}{l}16 \text { to } 64 \\
4.1 \text { to } 122 \\
134 \text { to } 182\end{array}$ & $\begin{array}{l}\text { Unconf ined aquifer } \\
\text { Uppermost conf ined } \\
\text { aquifer } \\
\text { Lower conf } \\
\text { aquifers } \\
\text { Grande Ronde Basalt } \\
\text { (RSH-1) } \\
\text { Mabton Member } \\
\text { Umtanum basalt (DC-6) } \\
\text { ARH-DC-1; } \\
978 \text { to } 990 \mathrm{~m}\end{array}$ & $\begin{array}{l}\text { ARHCO (1976 } \\
\text { ARHCO (1976) } \\
\text { ARHCO (1976) } \\
\text { De Ju (1978) } \\
\text { De Ju (1978) } \\
\text { Rockwe11 Hanford } \\
\text { Operations (1979), } \\
\text { Personal Conmunicatiun } \\
\text { LaSala and Doty (1971) }\end{array}$ & $\begin{array}{l}\text { III } \\
\text { Fig. } 5\end{array}$ & $\begin{array}{l}18 \\
50\end{array}$ \\
\hline Sultate & $\begin{array}{l}58 \\
9 \\
14 \\
23 \\
0.6 \\
96 \\
10\end{array}$ & $\begin{array}{l}20 \text { to } 150 \\
0 \text { to } 29 \\
10 \text { to } 21\end{array}$ & $\begin{array}{l}\text { Unconfined aguifer } \\
\text { Uppermost conf ined } \\
\text { aquifer } \\
\text { Lower conf } \\
\text { aquifers } \\
\text { arande Ronde Basalt } \\
\text { (RSH-1) } \\
\text { Mabton Member } \\
\text { Umtanum basalt } \\
\text { ARII-DC-1; } \\
978 \text { to } 990 \mathrm{~m}\end{array}$ & $\begin{array}{l}\text { ARHCO }(1976) \\
\text { ARHCO }(1976) \\
\text { ARHCO }(1976) \\
\text { Deju (1978) } \\
\text { Deju (1978) } \\
\text { LaSala and Doty }(1971)\end{array}$ & $\begin{array}{l}\text { II I } \\
\text { Fig. } 5 \\
7\end{array}$ & $\begin{array}{l}18 \\
50\end{array}$ \\
\hline \multicolumn{7}{|c|}{ 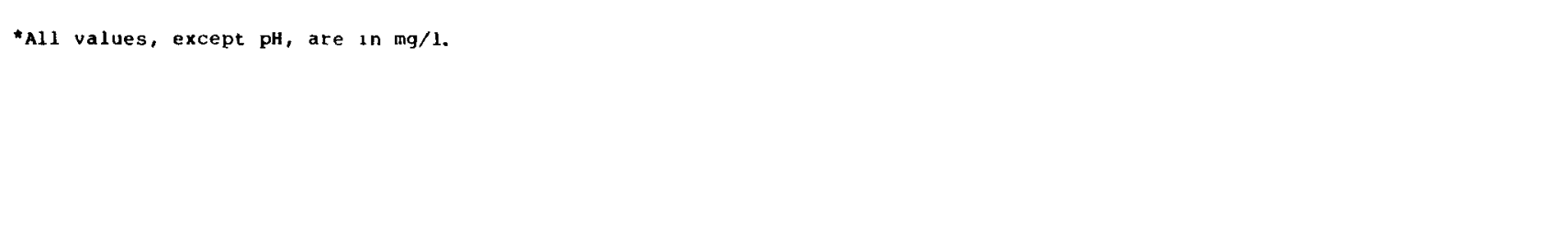 } \\
\hline
\end{tabular}




\section{REF ERENCES}

Agapito, J.F.T., Hardy, M.P., and St. Laurent, D.R., 1977, Geoengineering review and proposed program outline for the structural design of a radioactive waste repository in Columbia Plateau basalts: RHO-ST-6, Rockwell Hanford Operations, Richland, Washington, $95 \mathrm{p}$.

ARHCO, 1976, Preliminary feasibility study on storage of radioactive wastes in Columbia River basalts: ARH-ST-137, Atlantic Richfield Hanford Company, Richland, washington.

Benson, L.V., 1978, Secondary minerals, oxidation potentials, pressure and temperature gradients in the Pasco Basin of Washington State - Topical Report No. I: RHO-BWI-C-34, Rockwell Hanford Operations, Richland, Washington, 21 p.

Biggerstaff, R.L., Basalt Waste Isolation Program staff, 1978, Drilling program, in Basalt Waste Isolation Program Annual Report - Fiscal Year 1978: RHO-BWI-78-100, Rockwell Hanford Operations, Richland, Washington, p. 97-111.

Board, M.P., 1978, The thermal and mechanical properties of Columbia Plateau Basalt, in Basalt Waste Isolation Program Annual Report - Fiscal Year 1978: RHO-BWI-78-100, Rockwell Hanford Operations, Richland, Washington, p. 152-156.

Colorado School of Mines, 1978, Final report for fiscal year 1978 on the physical and thermal properties of basalt cores: RHO-BWI-C-38, Rockwell Hanford Operations, Richland, Washington, $76 \mathrm{p}$. 
Cook, N.W., 1977, An appraisal of hard rock for potential underground repositories of radioactive wastes: LBL-7004, Lawrence Berkeley Laboratory, University of California, Berkeley, California, $15 \mathrm{p}$.

Deju, R.A., 1978, Preliminary analysis of some waters from the confined aquifers underlying the Hanford Site: RHO-BWI-LD-12, Rockwell Hanford Operations, Richland, Washington, $22 \mathrm{p}$.

Deju, R.A., Board, M.P., Gephart, R.E., and Meyers, C.W., 1978, Structural considerations in the design of a repository to store radioactive waste in basalt formations: RHO-SA-10, Rockwell Hanford Operations, Richland, Washington, $17 \mathrm{p}$.

Duvall, W.I., Miller, R.J., and Wang, F.D., 1978, Preliminary report on physical and thermal properties of basalt, drill hole DC-10, Pomona Flow - Gable Mountain: RHO-BWI-C-11, Rockwell Hanford Operations, Richland, Washington, 46 p.

Garrels, R.M., and Christ, C.L., 1965, Solutions, Minerals, and Equilibria: Harper \& Row, New York, New York, 450 p.

Gephart, R.E., Arnett, R.C., and Leonhart, L.C., 1978, Status of the Pasco Basin hydrology studies, in Basalt Waste Isolation Program Annual Report - Fiscal Year 1978: RHO-BWI-78-100, Rockwell Hanford Operations, Richland, Washington, p. 114-121. 
LaSala, A.M., Jr., and Doty, G.C., 1971, Preliminary evaluation of hydrologic factors related to radioactive waste storage in basaltic rocks at the Hanford Reservation, Washington: U.S. Geological Survey, Water Resources Division, Open File Report $68 \mathrm{p}$.

Long, P.E., 1978, Characterization and recognition of intraflow structures Grande Ronde Basalt: RHO-BWI-LD-l0, Rockwell Hanford Operations, Richland, Washington, 74 p.

Science Applications, Inc., 1978, Hydrologic testing in borehole DC-2: RHO-BWI-C-36, Rockwell Hanford Operations, Richland, Washington, $41 \mathrm{p}$. 


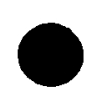


RHO-BWI-C -66

APPENDIX B

THE MODIFIED MATERIALS

SELECTION PROCESS 
APPENDIX B

THE MODIFIED MATERIALS

SELECTION PROCESS

TABLE OF CONTENTS

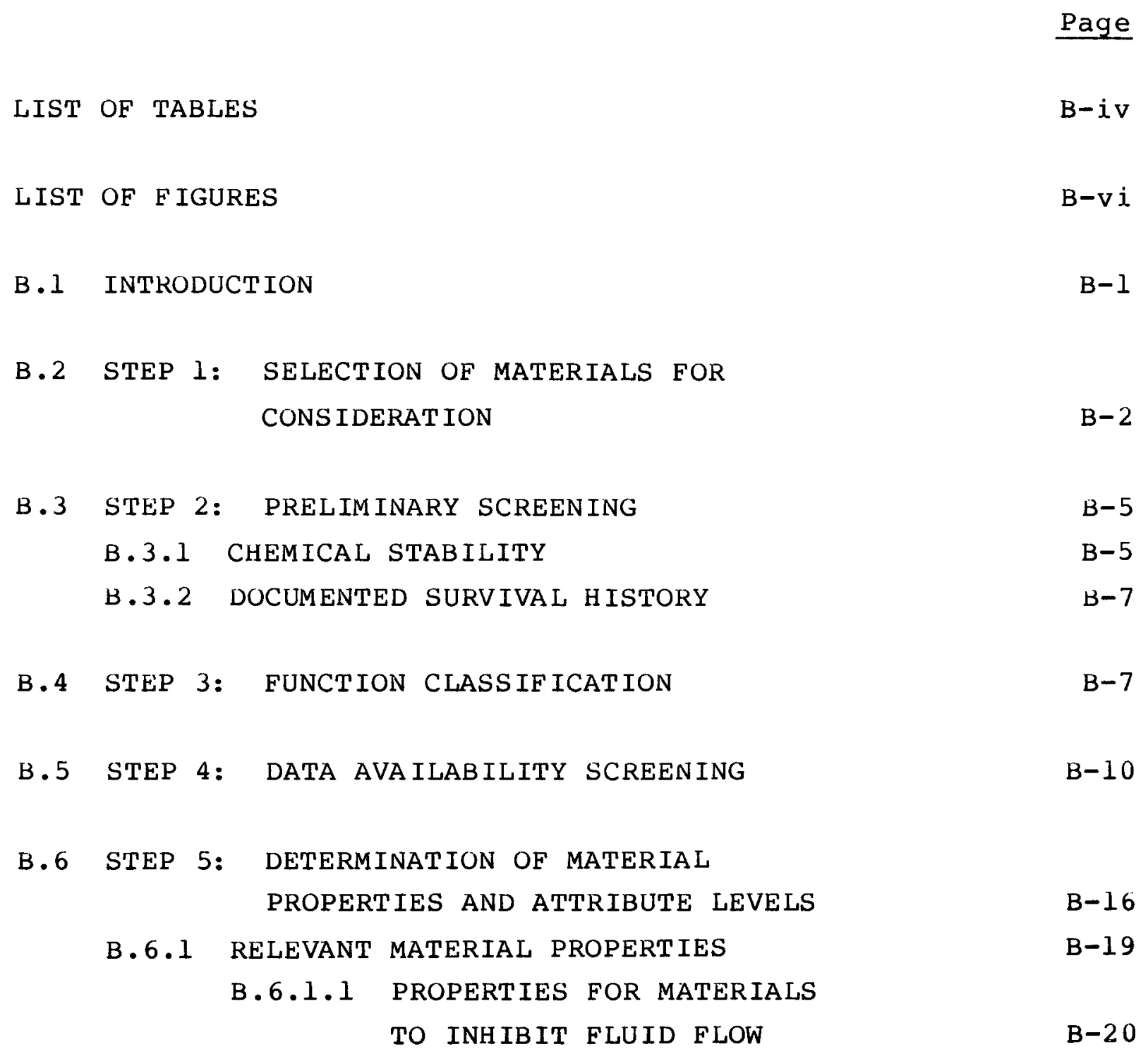




\begin{tabular}{|c|c|c|c|}
\hline & B. 6.1 .2 & PROPERTIES AND ATTRIBUTES & \\
\hline & & OF MATERIALS FOR INHIBITING & \\
\hline & & RADIONUCLIDE MIGRATION & $B-22$ \\
\hline & B.6.1.3 & PROPERTIES OF MATERIALS FOR & \\
\hline & & PROVIDING STRUCTURAL INTEGRITY & $B-25$ \\
\hline .6 .2 & ATTRIBUT & E LEVELS FOR MATERIALS & $B-27$ \\
\hline
\end{tabular}

B.7 STEP 6: EVALUATION OF PHYSICAL AND CHEMICAL PROPERTIES OF MATERIALS

$\mathrm{B}-31$

B.7.1 DOMINANCE ANALYSIS PROCEDURE

$\mathrm{B}-34$

B.7.1.1 DEFINITION A-1 (DOMINANCE)

B-35

B.7.1.2 DEFINITION A-2 (SET DOMINANCE)

B-35

B.7.1.3 SET DOMINANCE ANALYSIS

PROCEDURE

B-36

B.7.1.4 PROOF THAT PROCEDURE IDENTIFIES

$M_{1}, M_{2}, \ldots, M_{n}$

$B-39$

B.7.2 RESULTS OF EVALUATION OF PHYSICAL AND

CHEMICAL PROPERTIES OF MATERIALS

$B-42$

B.8 STEP 7: CONSIDERATION OF OTHER FACTORS

$B-42$

B.8.1 CONSIDERATION OF OTHER FACTORS FOR THE

GENERIC GROUP -- ROCKS

$B-49$

B.8.1.1 BASALT

B-49

B.8.1.2 GRANITE AND SLATE

$B-50$

B.8.1.3 SERPENTINITE, SHALE, AND

NATURAL GLASS

B-50

B.8.2 CONSIDERATION OF OTHER FACTORS FOR THE GENERIC GROUP -- MINERALS

B- 50

B.8.2.1 QUARTZ

$\mathrm{B}-50$

B.8.2.2 SMECTITE CLAYS, VERMICULITE,

AND KAOLINITE

$\mathrm{B}-5 \mathrm{I}$

B.8.2.3 CLINOPTILOLITE AND PHILLIPSITE

$\mathrm{B}-52$

B.8.2.4 ILLITE AND TALC

B-52 
B.8.3 CONSIDERATION OF OTHER FACTORS FOR THE GENERIC GROUP -- NATIVE ELEMENTS AND METALS B-52

B.8.3.1 GOLD, SILVER, PLATINUM, COPPER, LEAD, AND METAL ALLOYS B-52

B.8.3.2 CARBON B-53

B.8.4 CONSIDERATION OF OTHER FACTORS FOR THE GENERIC GROUP -- NATURAL ORGANIC MATERIALS B-53

B.8.4.1 TAR AND AMBER B-53

B.8.5 CONSIDERATION OF OTHER FACTORS FOR THE GENERIC GROUP -- CERAMICS B-53

B.8.5.1 MULLITE AND STEATITE B-53

B.8.6 CONSIDERATION OF OTHER FACTORS FOR THE GENERIC GROUP -- GROUTS B-54

B.8.6.1 PORTLAND CEMENTS AND HYDROTHERMAL CEMENTS B-54

B.8.7 CONSIDERATION OF OTHER FACTORS FOR THE GENERIC GROUP -- CONCRETES B-54

B.8.7.1 PORTLAND CEMENTS PLUS AGGREGATE

AND HYDROTHERMAL CEMENTS PLUS AGGREGATE $\quad B-54$

B.8.8 DISCUSSION B-55

B.9 CONCLUDING REMARKS B-55

$\begin{array}{lr}\text { REFERENCES } & B-60\end{array}$ 


\section{LIST OF TABLES}

Table No. Title

Page

B-I

MATERIALS FOR CONSIDERATION

B-4

B-I I

PRELIMINARY SCREENING ATTRIBUTES

$B-6$

B-I I I

RESULTS OF PRELIMINARY SCREENING

$\mathrm{B}-8$

$B-I V$

MATERIALS REMAINING AFTER

PRELIMINARY SCREENING

B-9

$B-V$

RELEVANT MATERIAL PROPERTIES FOR

EVALUATING MATERIALS

B-1 1

$\mathrm{B}-\mathrm{V}$ I

FUNCTION CLASSIFICATION OF MATERIALS

$\mathrm{B}-12$

B-VI I

MATERIALS THAT DO NOT FIT ONE OF THE

THREE FUNCTION CLASSIFICATIONS

B-13

B-VIII

DATA AVAILABILITY ATTRIBUTE

B -15

$B-I X$

RESULTS OF THE DATA AVA ILABILITY

SCREENING

B-17

$B-X$

MATERIALS REMAINING AFTER DATA

AVAILABILITY SCREENING

$\mathrm{B}-18$

$B-X I$

ATTRIBUTE SCALES FOR MATERIALS TO

INHIBIT FLUID FLOW

$B-21$ 
ATTRIBUTE SCALES FOR MATERIALS TO INHIBIT RADIONUCLIDE MIGRATION

ATTRIBUTE SCALES FOR MATERIALS TO PROVIDE STRUCTURAL INTEGRITY

PAIRWISE DOMINANCE ANALYSIS OF MATERIALS TO INHIBIT FLUID FLOW

PAIRWISE DOMINANCE ANALYSIS OF MATERIALS TO INHIBIT RADIONUCLIDE MIGRATION MATERIALS TO PROVIDE STRUCTURAL INTEGRITY

RESULTS OF SET DOMINANCE ANALYSIS OF MATERIALS TO INHIBIT RADIONUCLIDE MIGRATION

$$
B-X X I
$$

RESULTS OF SET DOMINANCE ANALYSIS OF MATERIALS TO PROVIDE STRUCTURAL INTEGRITY 


$$
B-v i
$$

\section{LIST OF FIGURES}

Figure No.

Title

$B-1$

$B-2$
MATERIAL SELECTION PROCESS

EXAMPLE OF DOMINANCE RELATIONS
$\mathrm{RHO}-\mathrm{BWI}-\mathrm{C}-66$
Page

B-3

B-33 
- 


\section{APPENDIX B \\ THE MODIFIED MATERIALS \\ SELECTION PROCESS}

\section{B.1 INTRODUCTION}

This appendix documents the modified process for selecting candidate plug materials developed during the present studies. The original selection process was developed during earlier work and was described in Taylor and others (1979). The background and philosophy of the materials selection process is discussed in detail in Chapter 3 of this report. The objective of the materials selection process was to identify candidate materials for use in the testing programs; these materials have a high probability for successful use in plugs and a high probability of meeting projected NRC criteria and are considered suitable for use in advanced geochemical and physical testing programs.

The selection process presented here is an outgrowth of a reevaluation of the materials selection process used in earlier work. This revised approach formally and systematically examines the material selection problem using decision analysis. The selection process evaluates candidate materials in sufficient detail so that the most appropriate materials, based on current information, are selected for testing. The procedure is documented in sufficient detail so that a revised analysis can be carried out if additional information becomes available on the materials being analyzed or if potentially useful new materials are identified. 
This appendix is organized as follows: details of each step of the selection process and implementation of each step are described in Sections B.2 through B.8 and conclusions are discussed in section B.9. A flowchart summarizing the materials selection process is shown in Figure $B-1$.

\section{B.2 STEP 1: SELECTION OF MATERIALS FOR CONSIDERATION}

As discussed in Chapter 3 of this report, the initial list of materials to be considered in step 1 of the materials selection process was assembled by WCC personnel during Task I work and is shown in Table B-I. This list is modified during step 3 (Section B.4) to remove any materials that are considered to be exclusively additives; only potential major plug components are being evaluated in this selection process. The list presented in Table B-I is not exhaustive; it is a sampling of material types rather than a complete list of every conceivable candidate material under a given classification. For instance, some natural materials on the list (such as the zeolite, clinoptilolite, or the crystalline rock, granite) are representatives of groups of minerals or rocks possessing particular properties. Likewise, manufactured items, such as concretes, are representative of a class of man-made materials that include many alternative choices. Various factors (such as availability) may make the alternate possibilities in each of the various classifications more desirable than the specific one currently listed. However, the process of listing representatives from these groups and comparing their characteristics suffices to discriminate between their relative desirability at the present level of study and plug design. 


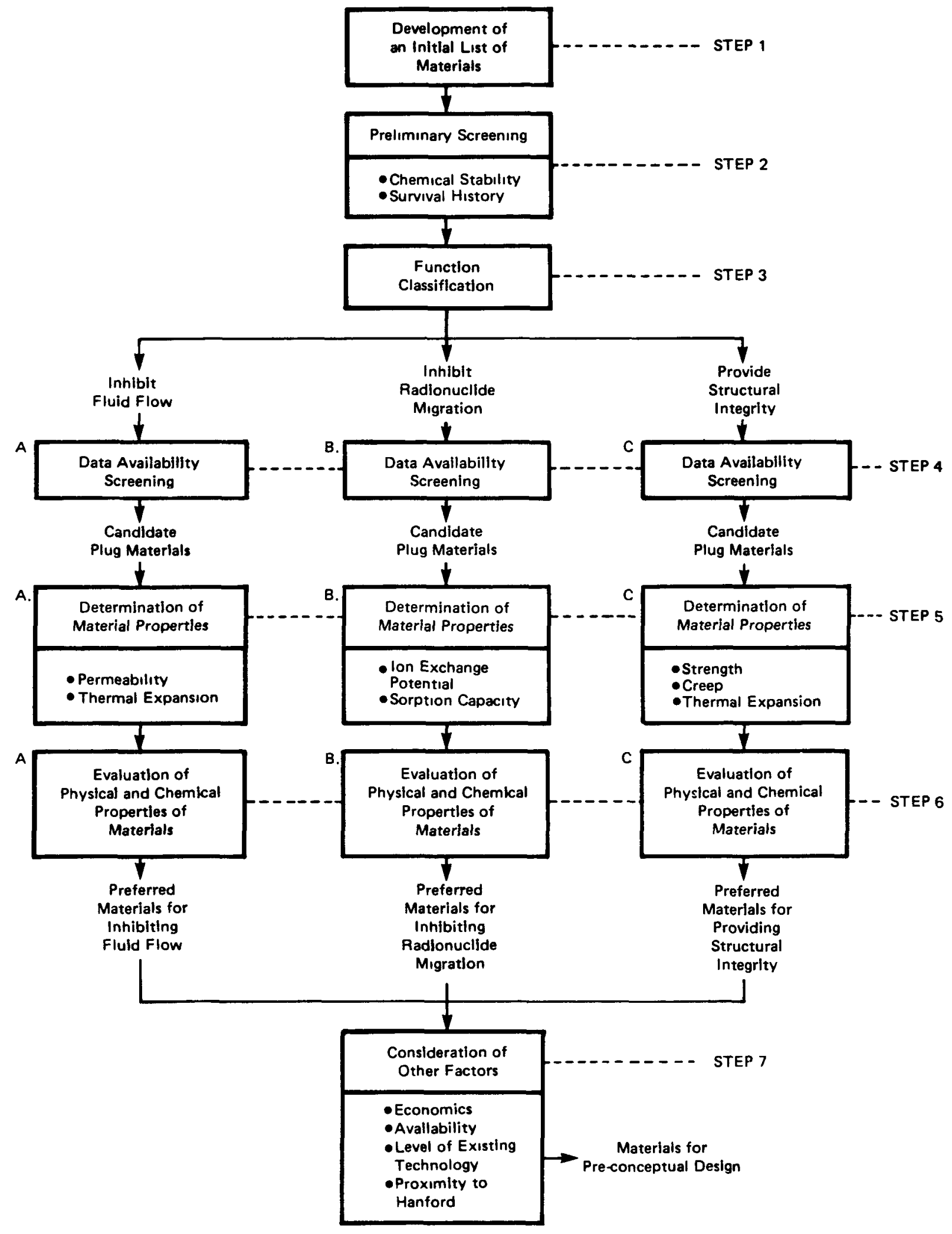

FIGURE B-1

MATERIAL SELECTION PROCESS 


$$
B-4
$$$$
\text { RHO-BWI-C- } 66
$$

TABLE B-I

MATERIALS FOR CONSIDERATION*

Igneous and Metamorphic Rocks

Basalt

Granite

Natural glass

Slate

Serpentinite

Sedimentary Materials

Shale

Diatomaceous earth

Minerals

Quartz

Smectite clays

Vermiculite

Kaolinite

Illite

Talc

Clinoptilolite

Phillipsite

Magnetite

Hematite

Barite

Gypsum

Native Elements

Gold

Silver

Platinum

Carbon

Copper

Natural Organic Materials

Tar

Amber

Processed Metals

Lead

Metal alloys
Ceramics

Mullite

Steatite

Manufactured Glasses

Quasi-Natural Materials

Fly ash

Synthetic Resins

Epoxy

Polyacrylamide

Phenoplast

Aminoplast

Polyester

Polyvinyl

Furnan compounds

Silicones

Polymers

Grouts

Portland cements

Type I

Type II

Type V

pozzolan

Hydrothermal cements

(calcium aluminate types)

Concretes

Portland cements plus

aggregate

Hydrothermal cements

plus aggregate

Asphalts

* Modified after Table B-II in Taylor and others (1979). 
This initial list of materials is based on a literature review and on the judgment of knowledgeable individuals. If new materials that might be applicable to the the borehole plugging study become known during the program, they can be evaluated using the procedure presented in this appendix. The reader is referred to Chapter 3, Section 3.3.1, of this report for a more complete discussion of the development of the initial list of materials.

\section{B.3 STEP 2: PRELIM INARY SCREENING}

The preliminary screening (Step 2 in Figure B-1) eliminates from further consideration those materials that are unacceptable on the basis of chemical stability or documented survival history. Each of these properties alone is critical enough to the design and performance of a plug that a low rating for either one makes a material unacceptable, regardless of its other characteristics. The attributes used in this screening are discussed below, and specific scales used in the screening are presented in Table B-II.

\section{B.3.1 Chemical Stability}

Any material that is chemically unstable in environments characterized by $\mathrm{pH}$ levels of 7 to 10 and $\mathrm{Eh}$ levels of -0.2 volt or less is unacceptable because the natural geologic environment at the Hanford site is basic and reducing in character. Thus, a rating of zero on the chemical stability attribute in Table B-II eliminates a material from further consideration. 
TABLE B-I I

\begin{tabular}{|c|c|c|}
\hline Attribute & Scale & Description \\
\hline \multirow[t]{2}{*}{ Chemical Stability } & 0 & $\begin{array}{l}\text { Affected by } \mathrm{pH} 7 \text { to } 10 \\
\text { at Eh } \leq-0.2 \text { volt }\end{array}$ \\
\hline & 1 & $\begin{array}{l}\text { Stable in } \mathrm{pH} 7 \text { to } 10 \\
\text { at } E \text { h } \leq-0.2 \text { volt }\end{array}$ \\
\hline \multirow[t]{3}{*}{$\begin{array}{l}\text { Documented History } \\
\text { of Survival }\end{array}$} & 0 & $\begin{array}{l}\text { Less than a few thousand } \\
\text { years of relevant documen- } \\
\text { ted history of survival } \\
\text { and no analogs of similar } \\
\text { material in nature }\end{array}$ \\
\hline & 1 & $\begin{array}{l}\text { Man-made material; an } \\
\text { analog or the actual } \\
\text { material can be documented } \\
\text { for thousands of years (on } \\
\text { the order of the } \\
\text { containment lifetime of } \\
\text { the repository) }\end{array}$ \\
\hline & 2 & $\begin{array}{l}\text { Natural material; survival } \\
\text { history of millions of } \\
\text { years in nature }\end{array}$ \\
\hline
\end{tabular}

a A rating of zero on either criterion is sufficient to eliminate a material from further consideration.

${ }^{b} \mathrm{pH}$ and Eh ranges determined from data in Table $A-I$, Appendix A, of this report.

C Attribute ranges reflect the expected long-term containment lifetime of the repository as well as logical limits based on data for most categories of materials. 


\section{B.3.2 Documented Survival History}

Materials used as plugs will be required to survive for thousands of years. Thus, conservative engineering practice dictates that only materials with a substantial documented history of survival be used in plug construction. It is unlikely that a material with an inadequately documented history of survival through time will be acceptable for use in plugs. The documented survival history screen eliminated any material with less than several thousand years of documented history for that material specifically or for a natural analog of the material (i.e., a rating of zero on the attribute for documented history of survival in Table B-II).

The ratings of individual materials were based on data that are currrently available to WCC project staff and are included in publications listed as references to this appendix. The ratings are presented in Table B-III. Materials that survived the preliminary screening are listed in Table B-IV.

B.4 STEP 3: FUNCTION CLASSIF ICATION

Candidate materials remaining after the preliminary screening were classified by three major functions: (1) to inhibit fluid flow; (2) to inhibit radionuclide migration; or (3) to provide structural integrity. Materials that could serve more than one function were classified under all relevant categories. These function classifications are described in more detail in Section 3.3 .3 of this report.

This classification (Step 3 in the materials selection process) was necessary because the evaluation process was somewhat different for each category. In particular, the relevant material 
TABLE B-III

\section{RESULTS OF PRELIMINARY SCREENING}

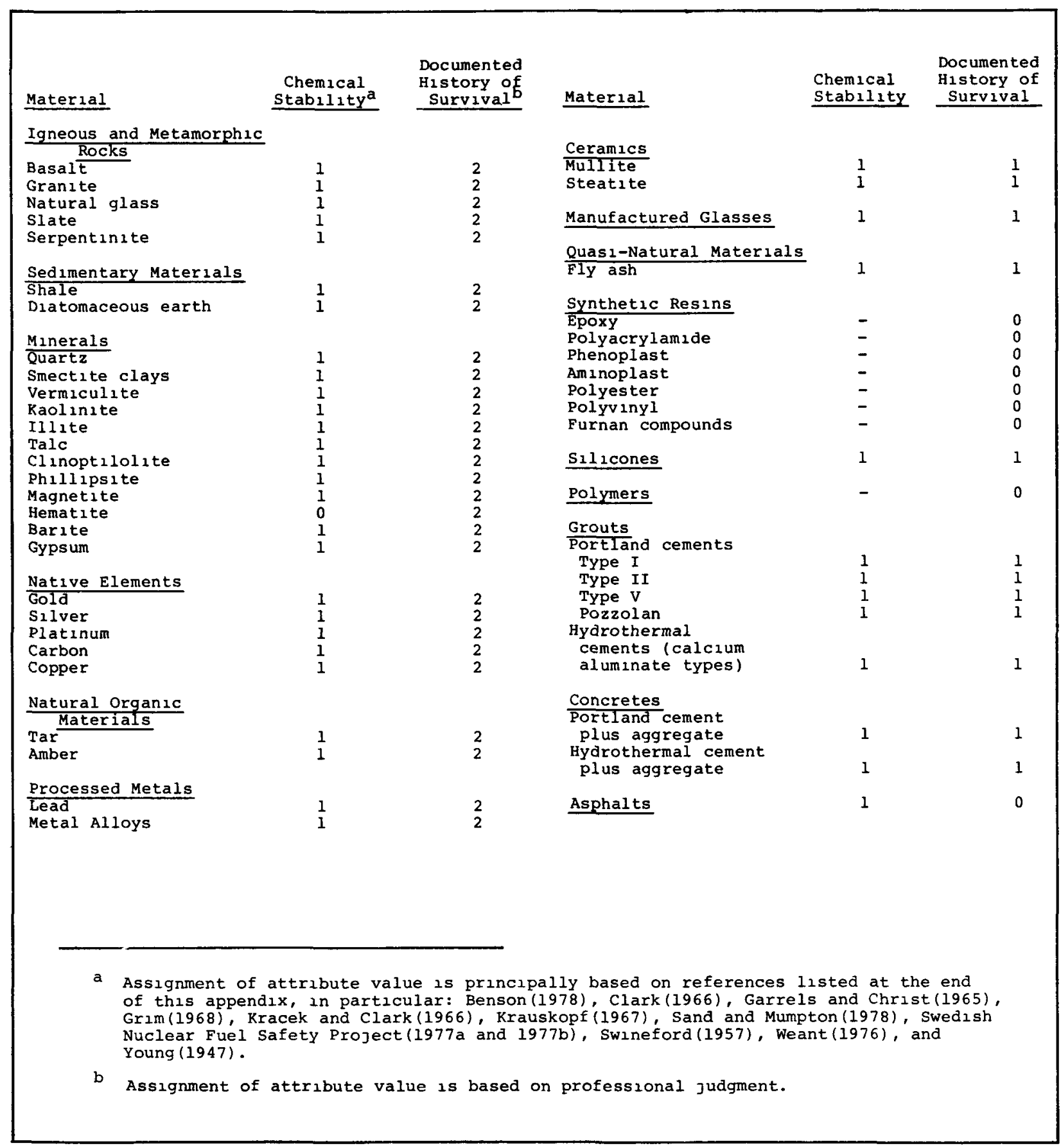


TABLE B-IV

MATERIALS REMAINING AFTER PRELIMINARY SCREENING

Igneous and Metamorphic Rocks

Basalt

Granite

Natural glass

Slate

Serpentinite

Sedimentary Materials

Shale

Diatomaceous earth

Minerals

Quartz

Smectite clays

Vermiculite

Kaolinite

Illite

Talc

Clinoptilolite

Phillipsite

Magnetite

Barite

Gypsum

Native Elements

Gold

Silver

Platinum

Carbon

Copper
Natural Organic Materials Tar

Amber

Processed Metals

Lead

Metal alloys

Ceramics

Mullite

Steatite

Manufactured Glasses

Ouasi-Natural Materials

Fly ash

$\underline{\text { Silicones }}$

Grout

Portland cements

Type I

Type II

Type V

Pozzolan

Hydrothermal cements

(calcium aluminate types)

Concretes

Portland cements plus aggregate

Hydrothermal cements plus aggregate 
properties that need to be considered while evaluating a material depend on the function for which the material will be used. Table $\mathrm{B}-\mathrm{V}$ shows the relevant properties for each function. (The rationale for selecting these properties is discussed in sections 3.3 .5 and B.6 of this report). Table B-VI presents the list of materials according to function.

During function classification, it was determined that some of the materials that had initially been selected for consideration as possible plugging materials from the original list (modified from Taylor and others, 1979) in step 1 of this selection process did not fit any of the three possible classifications for potential use in plugs. These materials were dropped from further consideration at this time. In general, these materials were initially considered because they provide shielding against radiation or could be mixed with other materials (such as cement) as additives to provide certain desirable properties. While radiation shielding may be desirable for repository backfill near storage canisters, it is not a necessary function for a borehole, shaft, or tunnel plug. In addition, the use of materials as additives will be examined on a case by case basis during pre-conceptual design and testing. The materials dropped from further consideration at this time are shown in Table B-VII.

\section{B.5 STEP 4: DATA AVA ILABILITY SCREENING}

During pre-conceptual design and in the testing programs, materials will be evaluated on their suitability for plugs, based on how material properties affect their expected behavior over time in the natural geologic environment of the repository site. Materials for which a large data base has been accumulated are more predictable than are materials for which 
TABLE B-V

RELEVANT MATERIAL PROPERTIES FOR EVALUATING MATERIALS *

Function

Inhibit fluid flow

Inhibit radionuclide migration

Provide structural integrity
Relevant Material Properties

Permeability

Thermal Expansion

Ion exchange potential

Sorption capacity

Strength

Creep characteristics

Thermal expansion

* Selection of material properties for each function classification is discussed in detail in section 3.3.5 (Chapter 3) and Section B.6 (Appendix B) of this report. 
TABLE B-VI

FUNCTION CLASSIFICATION OF MATERIALS

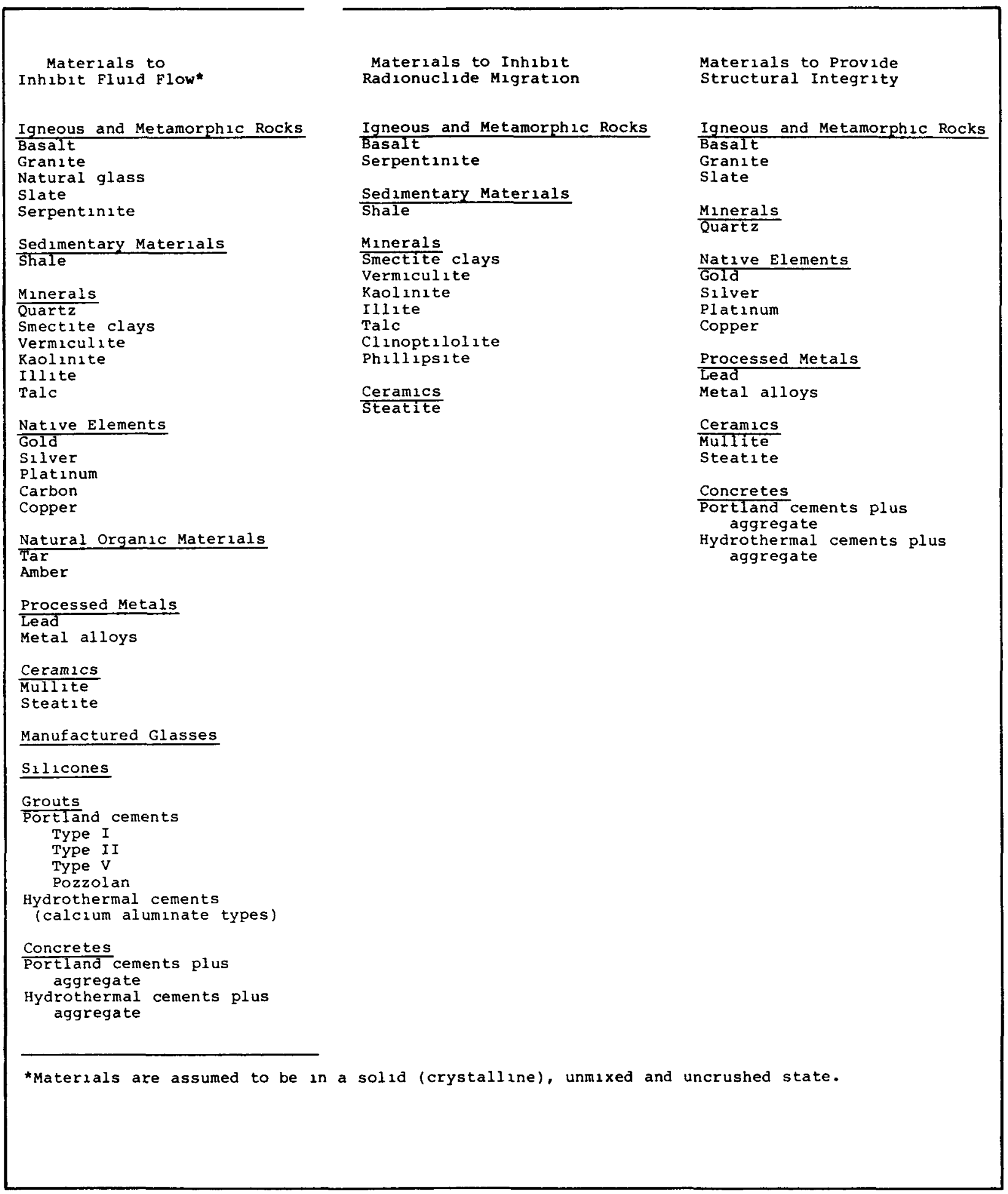




$$
\text { B }-13
$$

RHO-BWI-C- 66

TABLE B-VII

MATERIALS WHICH DO NOT FIT ONE OF THE THREE FUNCTION CLASSIFICATIONS

Sedimentary Materials

Diatomaceous earth

Minerals

Magnetite

Barite

Gypsum

Quasi-Natural Material Fly ash 
fewer data are available. The data availability screen (Step 4) eliminated those materials for which data were judged inadequate (using university and company libraries, textbooks, scientific journals, and professional reports) to reliably evaluate the relevant properties within the time constraints of the testing program. For a material to pass this screen does not require that every property discussed under each function classification (Section B.6) be completely defined in the literature. Materials that are similar to other welldocumented materials, or materials that have well-documented properties and are similar to those discussed in the next section, are considered as having sufficient, available information to be able to assign attribute values on the basis of professional judgment or analogy (as discussed in Section B.6.2). However, those materials that lack sufficient, pertinent data on properties of concern (see section B.6) or lack well-documented analogs are eliminated by this screen. (See Section 3.3.4 for a more complete discussion of Step 4.)

The scale for assessing data availability is presented in Table B-VIII. In determining the ratings for individual materials, only the availability of data concerning the function(s) to be performed by the material (as specified in Section B.4) was considered. Thus, for example, only data on ion exchange capacity and sorption capacity were needed for materials that are to inhibit radionuclide migration. On the other hand, for a material that may provide structural integrity, it is necessary to have data on strength, creep characteristics, and thermal expansion.

Any material for which the relevant data base did not exist or could not be adequately determined within the time constraints of this study ( $i . e .$, receiving a rating of zero on the data 
TABLE B-VIII

DATA AVAILABILITY ATTR IBUTE ${ }^{a}$

\begin{tabular}{|c|c|c|}
\hline Attribute Name & Scale & Description \\
\hline \multirow[t]{3}{*}{$\begin{array}{l}\text { Availability of } \\
\text { relevant data }\end{array}$} & 0 & $\begin{array}{l}\text { Relevant data applicable } \\
\text { to program do not exist or } \\
\text { cannot be adequately } \\
\text { completed. }\end{array}$ \\
\hline & 1 & $\begin{array}{l}\text { Some data exist but must be } \\
\text { supplemented with estimates. }\end{array}$ \\
\hline & 2 & $\begin{array}{l}\text { Most data exist, and only a } \\
\text { few estimates are needed. }\end{array}$ \\
\hline
\end{tabular}

$a_{A}$ rating of zero was sufficient to eliminate a material from further consideration.

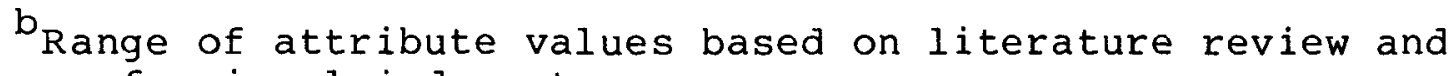
professional judgment. 
availability attribute) was eliminated from further consideration. Ratings are presented in Table B-IX; the list of surviving candidate materials is presented in Table $B-X$.

B.6 STEP 5: DETERMINATION OF MATERIAL PROPERTIES AND ATTRIBUTE LEVELS

During step 5 (discussed in this section) and step 6 (discussed in section B.7), the physical and chemical properties are evaluated for materials that were found in step 3 to be potentially usable for one or more of the three functions in a plug. Subsequently, in step 7 (discussed in Section B.8), the materials were further analyzed to select materials for preconceptual design that possess particular attributes indicating they should receive first priority for testing. The following questions are pertinent in developing the procedures used in Steps 5 and 6 of this selection process:

- What material properties should be considered?

- What attributes (evaluation measures) should be used to measure each important material property?

- How should the attribute levels be determined for each material?

- How should the different attributes be combined to arrive at a single overall evaluation of the physical and chemical properties of each material?

During Steps 5 and 6 of the materials selection process, it is not necessary to arrive at a specific ranking of the materials. Thus, a mathematical function that combines the 
TABLE B-IX

RESULTS OF DATA AVAILABILITY SCREENING

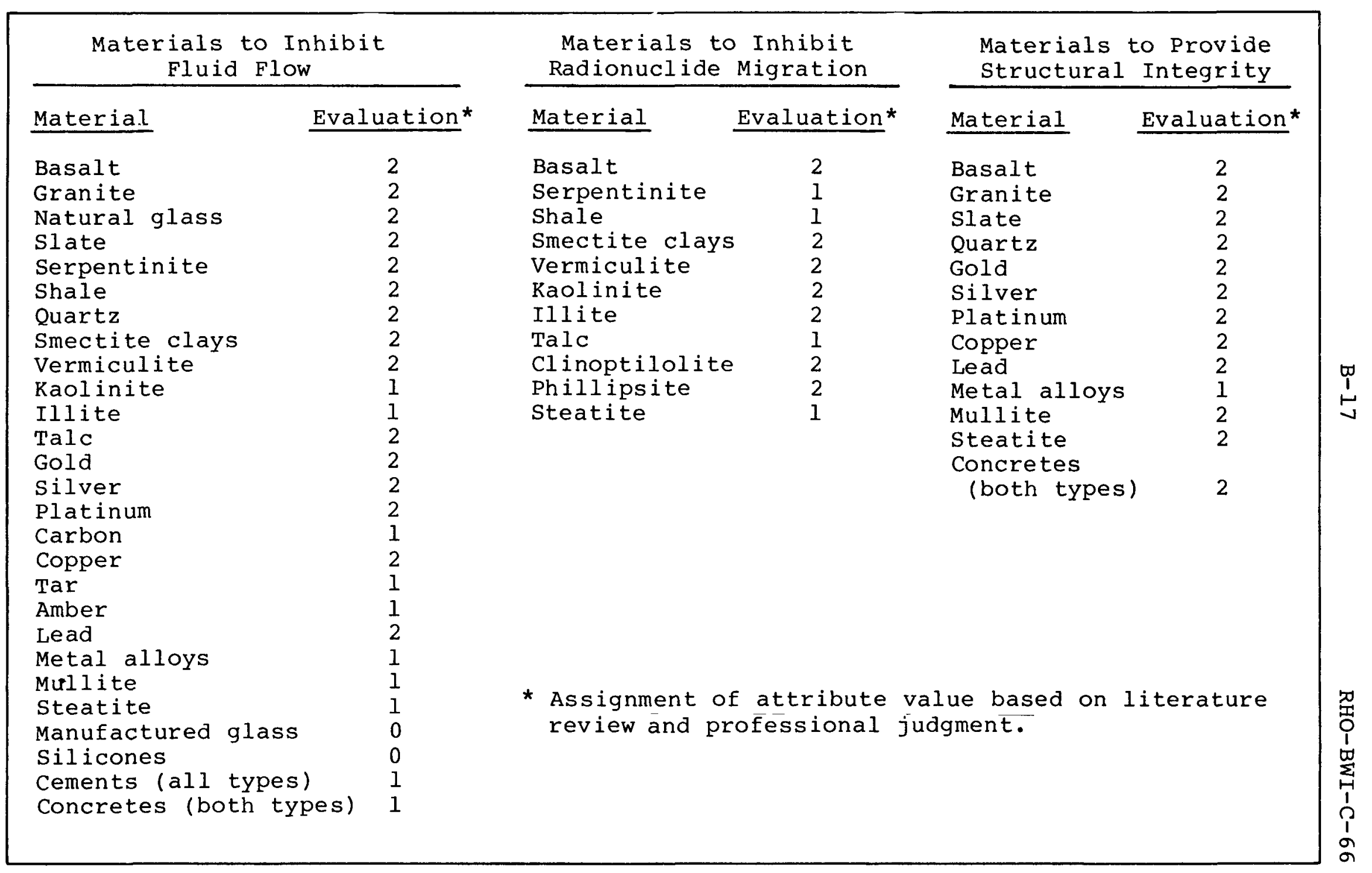


TABLE B-X

MATERIALS REMAINING AFTER DATA AVAILABILITY SCREENING

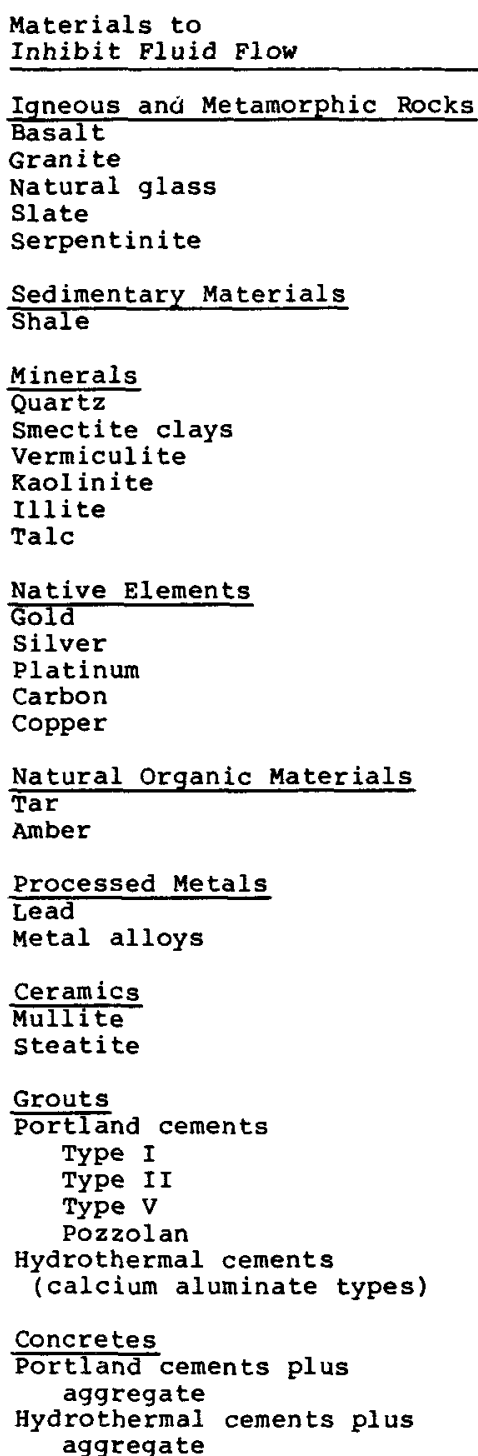

Materials to Inhibit Radionuclide Migration

Igneous and Metamorphic Rocks Basalt Serpentinite

Sedimentary Materials

Shale

Minerals

Smectite clays

Vermiculite

Kaolinite

Illite

Talc

Clinoptilolite

phillipsite

Ceramics

steatite
Materials to Provide Structural Integrity

Igneous and Metamorphic Rocks Basalt Granite

slate

Minerals Quartz

Native Elements

Gold

Silver

Platinum

Copper

Processed Metals

Lead

Metal alloys

Ceramics

Mullite

Steatite

Concretes

Portland cements plus aggregate

Hydrothermal cements plus aggregate 
various attributes into a single number summarizing the desirability of a material is not required. Such a mathematical function would require assignment of specific relative importance weights to the various material properties, which would involve judgments about the relative importance for plug design of the various properties. These judgments would have to be based on assumptions about potential plug configurations. Because the plug is yet to be designed, such assumptions would be speculative and were avoided at this stage of the investigation.

\section{B.6.1 Relevant Material Properties}

A wide variety of chemical and physical properties is potentially relevant for evaluating the desirability of a material for use in borehole, shaft, or tunnel plugs. Selecting the appropriate properties for use here requires that the purpose of the material selection process, which is to select materials for inclusion in programs for continued evaluation and testing, be kept clearly in mind. Note that the purpose is not to make a final selection of materials for use in plugs or to select a design for a plug. Many properties of a material will be important in deciding on a specific plug design that best utilizes that material. However, during the initial evaluation of whether a material should be considered for use in a plug, it is deemed appropriate to consider only a few critical material properties that will be important regardless of the plug's exact design.

Physical and chemical properties were selected for each function classification to help characterize the suitability of materials that could conceivably meet the requirements of the classification. In each case, the list of selected properties 
is based on parameters under each function classification for which adequate data exist in the literature and for which a direct evaluation can be made as to its impact on potential plug design.

Ambivalence surrounds the evaluation of certain properties as to their impact on the final performance of a plug. These properties were not used in the evaluation of materials under each function classification. Material properties used in the evaluation are discussed in the following sections. (In Chapter 3, Sections 3.3.5.1 to 3.3.5.3, the selection of material properties is discussed in more detail.)

B.6.1.1 Properties for Materials to Inhibit Fluid Flow

Permeability is the primary measure of the ability of a material to inhibit fluid flow. Many factors affect permeability, and a range of values for permeability is commonly cited in the literature for any given material. In addition, other physical properties of a material can directly affect the bulk permeability of a plug. One of these, thermal expansion, is included on the list of properties for materials to inhibit fluid flow which is shown in Table B-XI. Materials having coefficients of thermal expansion similar to basalt are considered more suitable for plugs than are materials with greatly different coefficients of thermal expansion because separation at the plug/wall rock interface and induced fracturing of the plug or basalt during the heating and cooling cycles of the containment period of a repository should be less likely if the plug has a coefficient of thermal expansion similar to basalt. Fracturing induced by materials having thermal expansion coefficients greatly different than basalt could drastically and adversely affect the bulk permeability of plugs. 
TABLE B-XI

ATTRIBUTE SCALES FOR MATERIALS TO INHIBIT FLUID FLOW

Attribute Name

Permeability*

Thermal Expansion*
Symbol

$\mathrm{F}_{1}$

$F_{2}$
Attribute Scale

1. High (more than $10^{-6} \mathrm{~cm} / \mathrm{sec}$ )

2. Moderate $\left(10^{-6}\right.$ to $\left.10^{-8} \mathrm{~cm} / \mathrm{sec}\right)$

3. Low; in the range of basalt or less (less than $10^{-8} \mathrm{~cm} / \mathrm{sec}$ )

1. Significantly lower or higher than basalt

2. In the range of basalt $\left(6.6 \times 10^{-6 / 10} \mathrm{C}\right)$

3. Slightly greater than basalt $\left(7 \times 10^{-6}\right.$ to $\left.10^{-4} /{ }^{\circ} \mathrm{C}\right)$

* Attribute ranges determined from data in Table A-I, Appendix $A$, of this report. 
Other potentially relevant factors, such as modulus of elasticity and plasticity index, were also considered, but the significance of these properties is difficult to determine unless a specific plug design is being evaluated. For instance, very high elasticity or plasticity can either be detrimental or beneficial in a plug material, depending on its proposed use. Both properties could influence the long-term ability of a plug to restrict fluid flow. However, because their impact is unclear (e.g., high plasticity may be desirable in some plug designs to maintain impermeability and undesirable in others), they are not used to evaluate materials at this time.

Thus, permeability and thermal expansion are the two factors that form the basis for determining the overall potential of a material for inhibiting fluid flow in this evaluation. The influence of thermal expansion on long-term permeability is reasonably direct and somewhat easier to infer than the effects of other factors, such as the modulus of elasticity and plasticity index. These latter factors have not been included here but should be considered once actual plug design is underway. Chemical stability and potential durability have already been assessed in step 2 .

B.6.1.2 Properties and Attributes of Materials for Inhibiting Radionuclide Migration

Under this function classification, the suitability of those materials that could inhibit the migration of radionuclides (although not necessarily a fluid containing them) was evaluated. In addition to low permeability, a large capacity to exchange ions with the environment is one important mechanism by which plug material can help control the migration of 
radionuclides in solution; ion exchange potential and sorption capacity are two primary indicators of this ability.

Ion exchange potential is a measure of the ability of a material to set free and replace ions in its structure with ions in solution in contact with the material. Materials with high ion-exchange potentials may have the capacity for setting free ions from their lattice structure and replacing them with (and thus immobilizing) radionuclides.

Sorption capacity is a measure of the general ability of a material to entrap ions migrating in solution; the actual sorption mechanism for any given material can reflect several phenomena including: van der Waals bonding, the filling of vacant lattice spaces in crystal structure, and the entrapment of ions by the host due to unsatisfied bonds along crystal edges (edge effects), as well as actual ion exchange (as described above). Generally, the distribution coefficient ( $\left.k_{d}\right)$ value, which gives a relative assessment of the sorption capacity of a material, is a collective, somewhat qualitative measure of these various phenomena.

Both ion exchange potential and sorption capacity are temperature dependent; for most materials, they decrease with increasing temperature. However, thermal stability is not included as a third attribute under this function classification because the temperature at plug seats is expected to be less than $100^{\circ} \mathrm{C}$ (see Table A-I, Appendix A). Within this temperature range, the ion exchange potentials and sorption capacities for most materials are not greatly affected, and thermally induced changes in the materials listed under this function classification are minor. Table B-XII lists the attribute scales applied to ion exchange potential 
TABLE B-XII

ATTR IBUTE SCALES FOR MATERIALS

TO INHIBIT RADIONUCLIDE MIGRATION

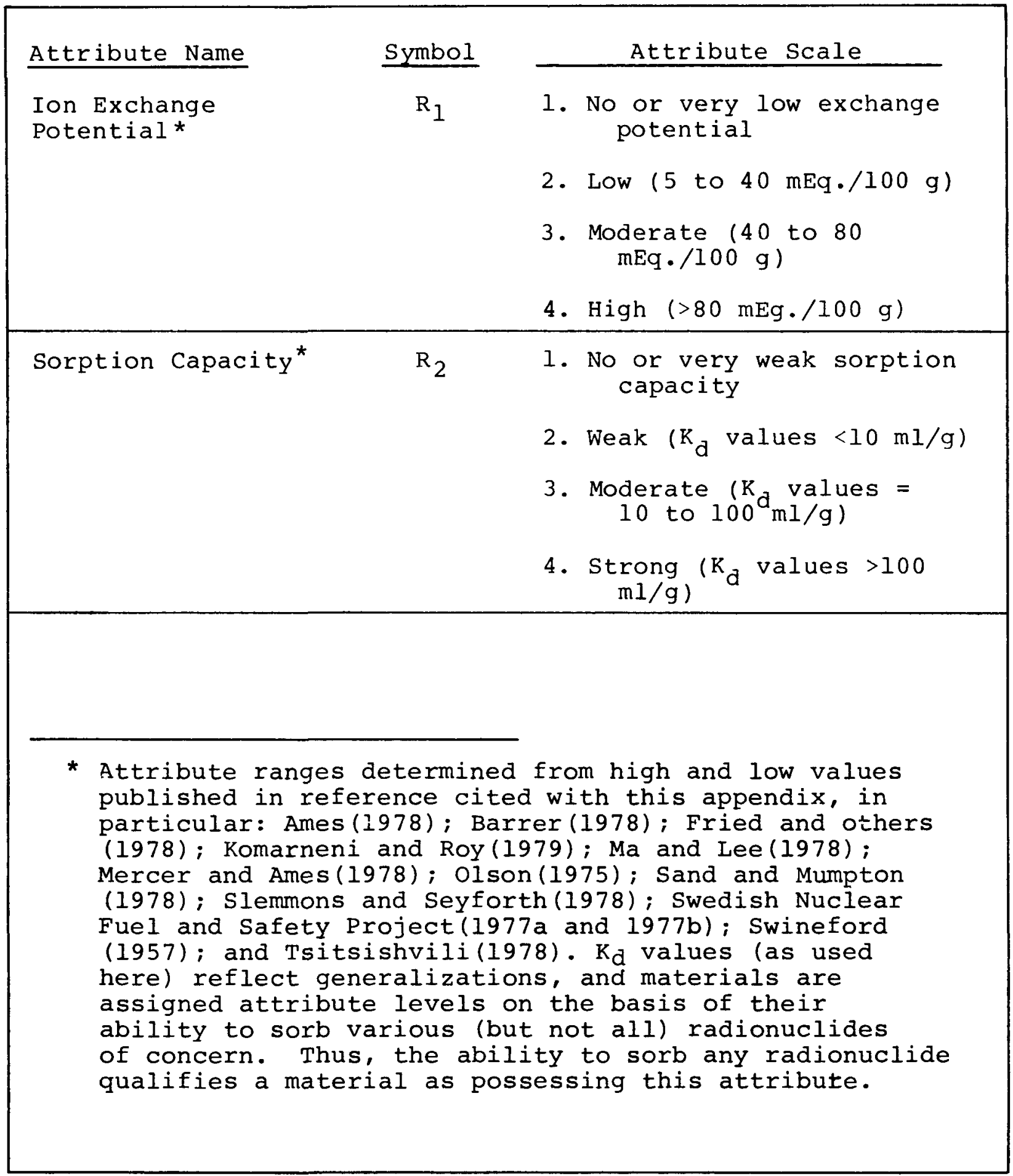


and sorption capacity, the two properties used to rank a material's ability to inhibit radionuclide migration in this selection process. Chemical stability has already been assessed in step 2 .

B.6.1.3 Properties of Materials for Providing Structural Integrity

Structural integrity of the plug will be provided primarily by its ability to resist or accommodate deformation over time due to tectonism, heating and cooling of the repository, lithostatic pressure, and hydrostatic pressure. Because of the possible easy deformation of materials that provide the other important functions of inhibiting fluid flow and radionuclide migration, it was deemed necessary to evaluate separately materials suitable for providing the plug with requisite strength during the containment period of the repository. While deformable, plastic materials will provide some physical continuity in large openings (shafts and tunnels); such materials may need to be buttressed by more rigid plug components capable of transmitting various loads that may be imposed on large plugs. Thus, the factors listed in Table B-XIII for evaluating the ability of a material to provide structural integrity include strength (in unconfined compression), creep (as a measure of a material's long-term behavior), and its coefficient of thermal expansion.

The last factor measures the compatibility of the candidate plug material with host rock and the natural environment. Materials that have thermal expansion properties similar to those of basalt are preferred. Chemical stability and potential durability have already been assessed in step 2 . 


\section{TABLE B-XIII}

ATTRIBUTE SCALES FOR MATERIALS

TO PROVIDE STRUCTURAL INTEGRITY






\section{B.6.2 Attribute Levels for Materials}

In order to determine and record material properties in a consistent and easily understandable way, numerical evaluation measures (attributes) were used to summarize the properties of each material. The assignment of attribute levels to materials 1 isted in Table B-XIV was based on three steps. The selection of appropriate ranges for the attribute scales, as listed in Tables B-XI to B-XIII, was the first step. These ranges reflect either information on the natural environment (taken from Table A-I in Appendix A of this report) or were selected using naturally occurring materials for which information is available (see references to this appendix) to help scale the attribute. For instance, the scaling of ion exchange potential reflects values published in the literature for materials with a notably high ion exchange potential as compared to materials with progressively lower ion exchange potentials.

The second step was to tabulate all readily available data concerning the various materials and respective properties. In most cases, ranges in published data for the properties of a given material fall within the range of a defined level for each of the various attribute scales. The references used in this step are listed with this appendix. The pertinent material properties for all the candidate plug materials are shown in Table B-XIV.

Because not every property listed as an attribute has been measured for every material listed in Table B-XIV (or because the pertinent data could not be located in the available time), the third step in determining attribute levels was, where necessary, to assign levels on the basis of analogy with 
TABLE B-XIV

PROPERTIES OF CANDIDATE MATERIALS

\section{Materials to Inhibit Fluid Flow}

Material

Igneous and Metamorphic Rocks

Basalt

Granite

Natural glass

Slate

Serpentinite

Sedimentary Materials

Shale

Minerals

Quartz

Smectite clays

Vermiculite

Kaolinite

Illite

Talc

Native Elements

Gold

Silver

Platinum

Carbon

Copper

Natural Organic Materials

Tar

Amber

Processed Metals

Lead

Metal alloys

Ceramics

Mullite

Steatite

Grouts (all types)

Concretes (both types)

\section{Permeability Thermal \\ Expansion}

$\begin{array}{ll}3 & 2 \\ 3 & 2 \\ 3 & 2 \\ 3 & 2 \\ 3 & 3\end{array}$

3

3

$\begin{array}{ll}3 & 3 \\ 3 & 3 \\ 3 & 3 \\ 3 & 2 \\ 2 & 2 \\ 3 & 3\end{array}$

$\begin{array}{ll}3 & 1 \\ 3 & 1 \\ 3 & 1 \\ 3 & 2 \\ 3 & 1\end{array}$

$\begin{array}{ll}3 & 1 \\ 3 & 1\end{array}$

$\begin{array}{ll}3 & 1 \\ 3 & 1\end{array}$

32

3

32

a Materials are assumed to be in a solid (crystalline), unmixed and uncrushed state.

b Assignment of attribute values are based on the following references cited for this appendix: Brewer (1967); Cedergren(1967); Colorado School of Mines $(1978 ; 1979)$; Eilers and Spangle (1973); Grim(1968); Holliday (1966); Laguros(1969); Lama and Vutukuri (1978); Lambe and Whitman(1969); Merritt(1976); Mitchell(1976); Neville(1971); Pusch(1979); Root and Calvert(1971); Swineford (1957); Weant (1976); and Young (1947). 


\section{TABLE B-XIV (continued)}

\section{Materials to Inhibit Radionuclide Migration}

Material

Ion Exchange
Potential*

Sorption Capacity*

Igneous and Metamorphic Rocks

Basalt

Serpentinite

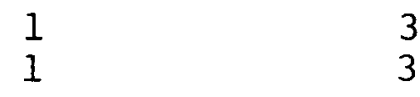

Sedimentary Materials

Shale

2

3

Minerals

Smectite clays

Vermiculite

Kaolinite

Illite

Talc

Clinoptilolite

Phillipsite

2

Ceramics

Steatite

$\begin{array}{ll}4 & 4 \\ 4 & 4 \\ 2 & 3 \\ 2 & 2 \\ 2 & 2 \\ 4 & 4 \\ 4 & 4\end{array}$

1

1

* Assignment of attribute value based on the following references cited for this appendix: Ames(1978); Barrer (1978); Fried and others(1978); Komarneni and Roy(1979); Ma and Lee(1978); Mercer and Ames (1978); Olson(1975); Sand and Mumpton(1978); Slemmons and Seyforth (1978); Swedish Nuclear Fuel and Safety Project(1977a and1977b); Swineford(1957); and Tsitsishvili(1978). 
TABLE B-XIV (continued)

Materials to Provide structural Integrity

Material $\underline{\text { Strength }}^{\mathrm{b}} \quad \begin{gathered}\text { Creep } \\ \text { Characteristics }\end{gathered}$

Igneous and

Metamorphic Rocks

Basalt

Granite

Slate

3

3

2

Minerals

Quartz

Native Elements

Gold

Silver

Platinum

Copper

Processed Metals

Lead

Metal alloys

Ceramics

Mullite

Steatite

Concretes

(both types)
3

3

3

3

3

2

3

3
3

2 $\begin{array}{ll}3 & 2 \\ 3 & 2 \\ 3 & 2\end{array}$

3

2

1

$\begin{array}{ll}1 & 1 \\ 1 & 1\end{array}$

11

$1 \quad 1$

1

$\begin{array}{ll}3 & 2 \\ 3 & 2\end{array}$

3

2

a Materials are assumed to be in a solid (crystalline), unmixed and uncrushed state.

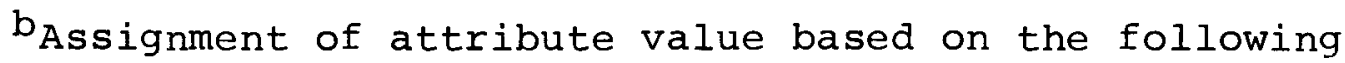
references cited for this appendix: Agapito and others (1977); Allirot and Boehler(1979); Barla and Innurato (1973); Boa (1978); Brewer(1967); Clark(1966); Colorado School of Mines and Geology(1978; 1979); Eilers and Spangle(1973); Farmer(1968); Hoadley(1964); Holliday (1966); Lama and Vutukuri(1978); Merritt(1976); Neville (1971); Root and Calvert(1971); Weant(1976); and Young (1947). 
similar materials for which data are available. In other cases, attributes were assigned on the basis of judgment and the expected behavior of a given material. Again, the primary objective of the materials selection process was to select preferred and promising materials for future study, and the judgmental assignments of attribute levels were considered accurate enough to meet this objective and to allow comparisons with attribute levels assigned on the basis of data collected during the second step. Because materials for which little data are available were screened out in step 4, determination of the attribute level for each material using the various attribute scales was relatively straightforward. Within the level of detail used in this evaluation, there was no significant uncertainty about what the attribute levels were for a particular material.

B.7 STEP 6: EVALUATION OF PHYSICAL AND CHEMICAL PROPERTIES OF MATERIALS

To evaluate the overall physical and chemical properties of a material, it is necessary to consider all of the relevant properties of the material together. To the extent possible, it is desirable to evaluate candidate plug materials without deciding on the relative importance of the various attributes. This is desirable because the importance of the different factors depends in part on features of plug design that have not yet been determined. For example, the importance that should be attached to having high ion exchange potential depends on the degree to which this mechanism will be used to trap radionuclides in the plug. This has not yet been determined. 
In order to avoid the subjective assignment of relative importance weights, a dominance analysis was carried out in Step 6. One material is said to dominate a second material if it has at least as high a rating as the second material on all relevant attributes (which numerically quantify a material's properties) and has a higher rating on at least one of the attributes. Because the attributes numerically summarize the material characteristics that are relevant for evaluation purposes, a material that dominates a second material is more preferable than the second material, regardless of what function is used to combine the attributes into a single measure of overall desirability.

The dominance analysis of the materials in each function classification had two steps: (1) The dominance relation (or lack of one) was identified between each pair of materials in each function classification (discussed in section B.4) using the definition of dominance presented in section B.7.1.1 (below); and (2) This information was used to determine a rank-ordering of the materials by applying an analysis method developed especially for this problem. In general, it is not possible to determine a complete ordering based only on dominance analysis. However, the analysis provided sufficient ranking for the evaluation in step 6 .

The basic idea of the analysis procedure can be illustrated by a simple example. Suppose five materials $M_{1}, M_{2}, M_{3}, M_{4}$, and $M_{5}$ are to be evaluated. Suppose that when the material property attributes are compared, it is found that $M_{1}$ dominates $M_{3}, M_{4}$, and $M_{5} ; M_{2}$ dominates $M_{3}, M_{4}$, and $M_{5} ; M_{3}$ dominates $M_{5}$; and $M_{4}$ dominates $M_{5}$. These dominance relations are shown graphically in Figure $B-2$ in which the convention is used that a material at the tail of any arrow dominates any material 


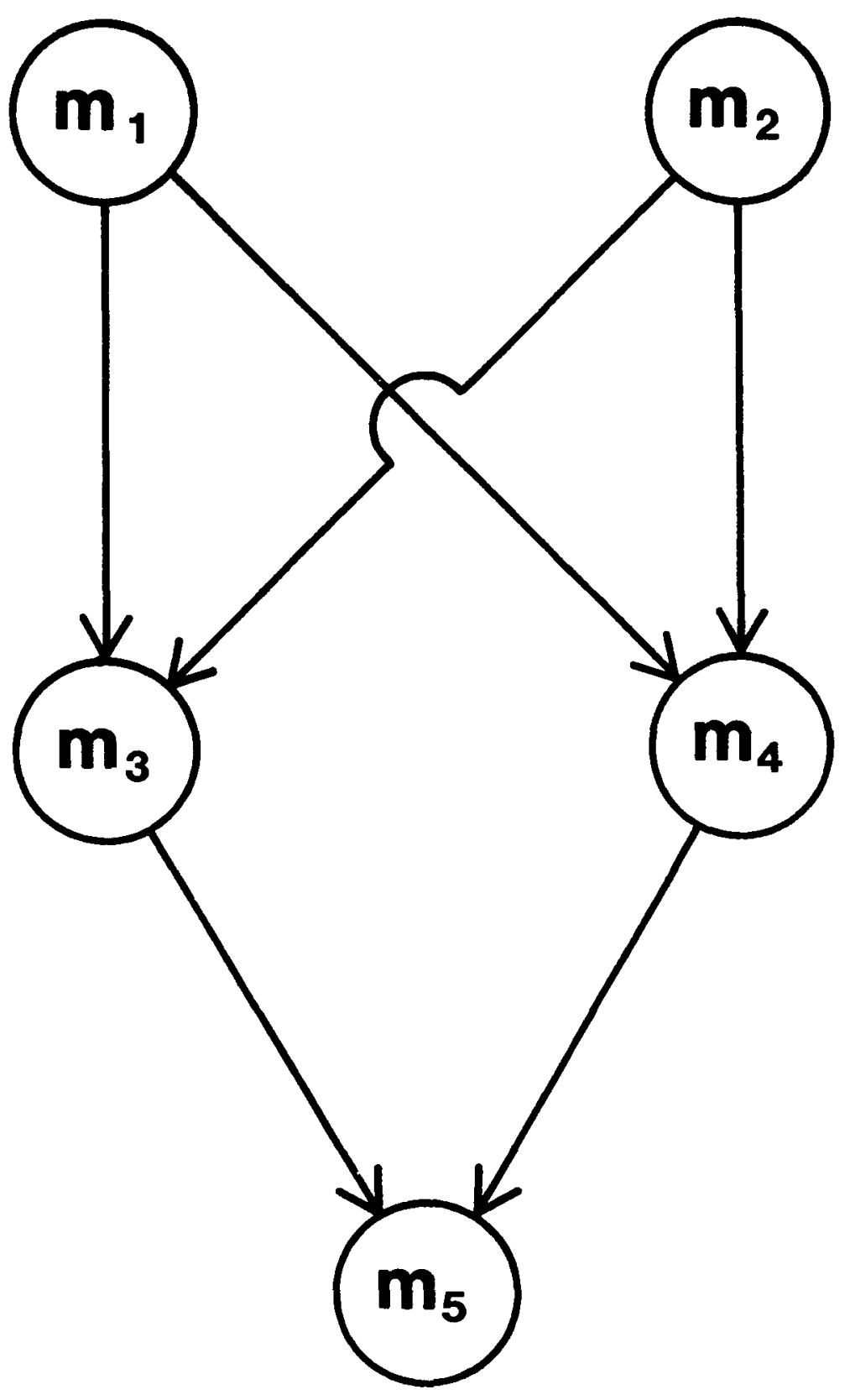

FIGURE B-2 
that can be reached by following a path in the direction of the arrows. Thus, for example, Figure B-2 shows that $M_{1}$ dominates $M_{5}$ because $M_{5}$ can be reached from $M_{1}$ by following the path $M_{1}$ to $M_{3}$ and $M_{3}$ to $M_{5}$ (or $M_{1}$ to $M_{4}$ and $M_{4}$ to $M_{5}$ ). Thus, Figure B 2 shows that the five materials can be categorized into three groups: $M_{1}$ and $M_{2}$ are more preferable than any of the other materials; $M_{3}$ and $M_{4}$ are less preferable than $M_{1}$ and $M_{2}$ but more preferable than $M_{5} ;$ and $M_{5}$ is least preferable of all the materials. Using only dominance, it is not possible to rank order $M_{1}$ and $M_{2}$, nor is it possible to rank order $M_{3}$ and $M_{4}$. Note, however, that this ranking does not necessarily mean that $M_{1}$ and $M_{2}$ are equally preferable or that $M_{3}$ and $M_{4}$ are equally preferable. Rather, the ordering of these pairs depends specifically on what function is used to combine their various attributes to determine their overall desirability.

Figure B-2 illustrates the basic idea underlying the dominance analysis used in step 6 of the materials selection process; however, it is time-consuming to draw such a figure when there are more materials. Furthermore, in a more complex case, it is difficult to identify the rank-ordering that is implied by the diagram. For these reasons, an alternative approach for identifying the rank-ordering was developed for the modified selection process described here. This approach is presented in section $B .7 .1$, and the results of applying it are given in Section B.7.2.

\section{B.7.1. Dominance Analysis Procedure}

In this section, $x_{i}$ will represent an attribute, and $x_{i}$ will represent a specific level of $x_{i}$. For this presentation, $i t$ will not be necessary to distinguish whether the attributes are 
being used to evaluate materials to inhibit fluid flow, inhibit radionuclide migration, or provide structural integrity.

B.7.1.1 Definition A-1 (Dominance)

Material $m$ dominates material $n$ if

$$
\begin{aligned}
& x_{i}(m) \gtrsim x_{i}(n), \text { for all } i, \text { and } \\
& x_{i}(m)>x_{i}(n), \text { for some } i
\end{aligned}
$$

where, $x_{i}(m)$ and $x_{i}(n)$, respectively are the ratings of the materials $m$ and $n$ on the $i^{\text {th }}$ attribute, and 2 means "at least as preferable as," while > means "preferable to."

Simply stated, dominance means that a material has at least as desirable levels on all attributes and has a more desirable level on at least one attribute. Clearly, the dominating material is more desirable than the dominated material.

\section{B.7.1.2 Definition A-2 (Set Dominance)}

For two subsets of materials $M$ and $N$, $M$ dominates $N$ if, for any $m$ in $M, n$ in $N$,

$$
\begin{aligned}
& x_{i}(m) \geq x_{i}(n), \text { for all } i \text {, and } \\
& x_{i}(m)>x_{i}(n), \text { for some } i \text {. }
\end{aligned}
$$

In other words, the set of materials $M$ is said to dominate the set $N$ only if every material in $M$ dominates every material in N. From the earlier discussion of dominance relaticns between pairs of materials it is clear that if $M$ dominates $N$, then any material in $M$ is more preferred than any material in $N$. 
Set dominance concepts permit the identification of subsets $M_{1}$, $M_{2}, \ldots, M_{n} ; M_{1}$ dominates all the other subsets, $M_{2}$ dominates all other subsets except $M_{1}, M_{3}$ dominates all the other subsets except $M_{1}$ and $M_{2}$, and so forth. From the discussion above, it follows that each material in $M_{1}$ will be more preferable than any material in the other subsets, each material in $M_{2}$ will be less preferable than any material in $M_{1}$ and will be more preferable than any material in $M_{3}, M_{4}, \ldots, M_{n}$, and so forth. Based only on dominance concepts, it is not possible to rank-order the materials in any $M_{i}$.

\section{B.7.1.3 Set Dominance Analysis Procedure}

The procedure below can be used to identify the subsets $M_{1}, M_{2}$, ..., $M_{n}$. An example showing how the procedure is carried out is shown in Table $B-X V$, and a proof that the procedure works is given in Section B.7.1.4.

(1) Using Definition A-l, identify all of the dominance relations between pairs of materials. Prepare a pairwise dominance relation table like Table B-XVa showing the pairwise dominance relation as follows:

a) List the materials in the same order down the left-hand side and across the top; and

b) Enter a 1 in a cell of the table if the row material dominates the column material; otherwise enter a 0 .

(2) Determine the total of each column and 1 ist it at the bottom of the column. This tells how many other materials dominate the material in that column. 
TABLE B-XV

SET DOMINANCE ANALYSIS EXAMPLE

(a) Pairwise Dominance Relations

$\begin{array}{ccccccc} & M_{1} & M_{2} & M_{3} & M_{4} & M_{5} & M_{6} \\ M_{1} & 0 & 0 & 1 & 1 & 1 & 1 \\ M_{2} & 0 & 0 & 1 & 1 & 1 & 1 \\ M_{3} & 0 & 0 & 0 & 0 & 1 & 1 \\ M_{4} & 0 & 0 & 0 & 0 & 0 & 1 \\ M_{5} & 0 & 0 & 0 & 0 & 0 & 1 \\ M_{6} & \underline{0} & \underline{0} & \underline{0} & \underline{0} & \underline{0} & \underline{0} \\ \text { Col umn Totals } & 0 & 0 & 2 & 2 & 3 & 5\end{array}$

(b) Set Dominance Analysis

Required

Number of

Materials

\begin{tabular}{lcc} 
Column & $\begin{array}{c}\text { Materials } \\
\text { with }\end{array}$ & $\begin{array}{c}\text { Number of } \\
\text { Materials with } \\
\text { Totals }\end{array}$ Column Totals \\
\hline
\end{tabular}

Cumulative Number of Materials with Column Totals

\begin{tabular}{llllr}
1 & 5 & $M_{6}$ & 1 & 1 \\
\hline 2 & 4 & - & 0 & 1 \\
3 & 3 & $M_{5}$ & 1 & 2 \\
4 & 2 & $M_{3}, M_{4}$ & 2 & 4 \\
\hdashline 5 & 1 & - & 0 & 4 \\
6 & 0 & $M_{1}, M_{2}$ & 2 & 6
\end{tabular}


(3) Prepare a set dominance analysis table like Table B-XVb as follows:

a) In the first column (Required Number of Materials), enter the numbers $1,2, \ldots, m$, where $m$ is the total number of materials.

b) In the second column (Column Total), enter the numbers $m-1, m-2, \ldots, 2,1,0$.

c) In the third column (Materials with Column Total), list next to each number in the second column all the materials with that "Column Total" on the pairwise dominance analysis table.

d) In the fourth column (Number of Materials with Column Total), enter next to each list of materials in the third column the number of materials in the list. (Note that the sum of all the entries in the fourth column is m.)

e) In each row of the fifth column (Cumulative Number of Materials with Column Total), enter the sum of the entries in the fourth column down to and including that row.

(4) Identify the dominance relations as follows:

a) Compare the entries in each row of the first and fifth columns of the set dominance analysis table. Draw a dashed line across the table under each row where the entries in the first and fifth columns are equal. 
b) From the third column of the table (Materials with Column Total), determine the sets of materials falling between successive pairs of dashed lines.

c) These sets of materials are successively more preferable in the course down the set dominance analysis table. Within each set, it is not possible to determine the order of preference using only dominance concepts.

This analysis procedure is somewhat cumbersome to write down but is straightforward to carry out. For the example in Table $B-X V$, material $m_{6}$ is the least preferable; materials $\mathrm{m}_{3}$ ' $\mathrm{m}_{4}$, and $\mathrm{m}_{5}$ are next nost preferable; and materials $\mathrm{m}_{1}$ and $\mathrm{m}_{2}$ are most preferable. Based only on dominance arguments, it is not possible to determine which of the materials $\mathrm{m}_{3}, \mathrm{~m}_{4}$, or $\mathrm{m}_{5}$ is most preferable or least preferable. Similarly, it is not possible to determine which of $m_{1}$ or $m_{2}$ is more preferable.

\section{B.7.1.4 Proof that Procedure Identifies $M_{1}, M_{2}, \ldots, M_{n}$}

The proof proceeds in two steps: (1) it is established that the subsets of materials between successive dashed lines are increasingly preferable as one works down the set dominance analysis table; and (2) it must be shown that the establishment of a complete preference order is not possible within the subset of materials between two successive dashed 1 ines.

To establish that the subsets of materials between successive dashed lines are successively more preferable, it is sufficient to show that any material below any particular dashed 1 ine is more preferable than any material above the dashed line. 
If there is a total of $m$ materials, then from the definitions of Column 1 (Required Number of Materials) and Column 2 (Column Total), the sum of the entries in these two columns for any row will be m. Thus, if the "Column Total" immediately above a dashed line is $n$, the "Required Number of Materials" corresponding to this must be $m-n$. Given this information, it follows from the procedure used to construct the dashed line that all materials above the line are dominated by at least $n$ materials, and there are exactly $\mathrm{m}-\mathrm{n}$ materials above the line (and hence, exactly $n$ materials below the line).

All materials below the line can be less preferable than at most $n-1$ other materials. The rationale for this is as follows: Suppose one of the materials below the line is less preferable than at least $n$ other materials. There must be exactly $n$ materials that are less preferable than at most $n-1$ other materials. Hence, one of the materials above the line would have to be less preferable than at most $n-1$ other materials if one of the materials below the line is less preferable than at least $n$ other materials. However, this is a contradiction because all materials above the line are dominated by at least $n$ other materials. Hence, all materials below the line can be less preferable than at most $n-1$ other materials.

Because of this, each of the materials below the line must be more preferable than any material above the line. The rationale for this is as follows: Suppose a material below the line were not more preferable than some specified material above the line. Then, because the specified material above the line is less preferable than at least $n$ other materials, the material below the line would also have to be less preferable 
than at least $n$ other materials. However, it has been shown above that each material below the line is less preferable than at most $n-1$ other materials. Hence, a contradiction has been established, and it must be true then that any material below the line is more preferable than any material above the line.

This establishes the first part of the proof. The remaining part to be established is that it is not possible to completely order the materials between any two dashed lines.

From the construction procedure, it follows that either there is only one material between a pair of successive dashed lines (in which case this part of the theorem is not applicable) or there must be at least two materials in the row immediately above the dashed line. However, it must be true then that none of the entries in this row dominates any other entry. The rationale for this is as follows: If one entry dominated another, then it would have a "Column Total" that was greater; hence, the two entries would not appear in the same row.

Because none of the entries in the row dominates another in the row, the preference order of the entries will depend on the particular preference structure used to evaluate the materials. Thus, the materials can not be ordered solely on the basis of set dominance analysis.

This establishes that the set dominance analysis procedure has the claimed properties. 


\section{B.7.2 Results of Evaluation of Physical and Chemical Properties of Materials}

The results of analyzing the dominance relations between all pairs of materials in each of the three functional categories are shown in Tables B-XVI, B-XVII, and B-XVIII. These tables were prepared by applying step 1 in the set dominance analysis procedure (discussed in Section B.7.1) to the data in Table BXIV. The materials grouped together as a set in each table have exactly the same levels of all the relevant attributes. Thus, regardless of what procedure was used to combine the various attributes to evaluate the overall physical and chemical properties of the materials, it would not be possible to distinguish between the materials in any one set. Thus, for example, the materials in the set containing basalt, granite, quartz, mullite, and steatite have identical structural integrity attribute levels.

The results of carrying out the set dominance analysis on the data in Tables B-XVI, B-XVII, and B-XVIII are shown in Tables $B-X I X, B-X X$, and $B-X X I$.

\section{B.8 STEP 7: CONSIDERATION OF OTHER FACTORS}

The relative desirability of materials from the list in Table B-XIV (as presented in Tables B-XIX, B-XX, and B-XXI) is based only on the attributes listed in Tables B-XI to B-XIII. Prior to compilation of Table B-XIV, other important attributes, such as durability through time and chemical stability in the natural environment, had already been evaluated in step 2 (discussed in section B.3) for the materials that appear in Tables B-XIX, B-XX, and B-XXI. Other significant factors are considered in this section to aid in selecting a final list of 


\section{PAIRWISE DOMINANCE ANALYSIS OF MATERIALS TO INHIBIT FLUID FLOW}

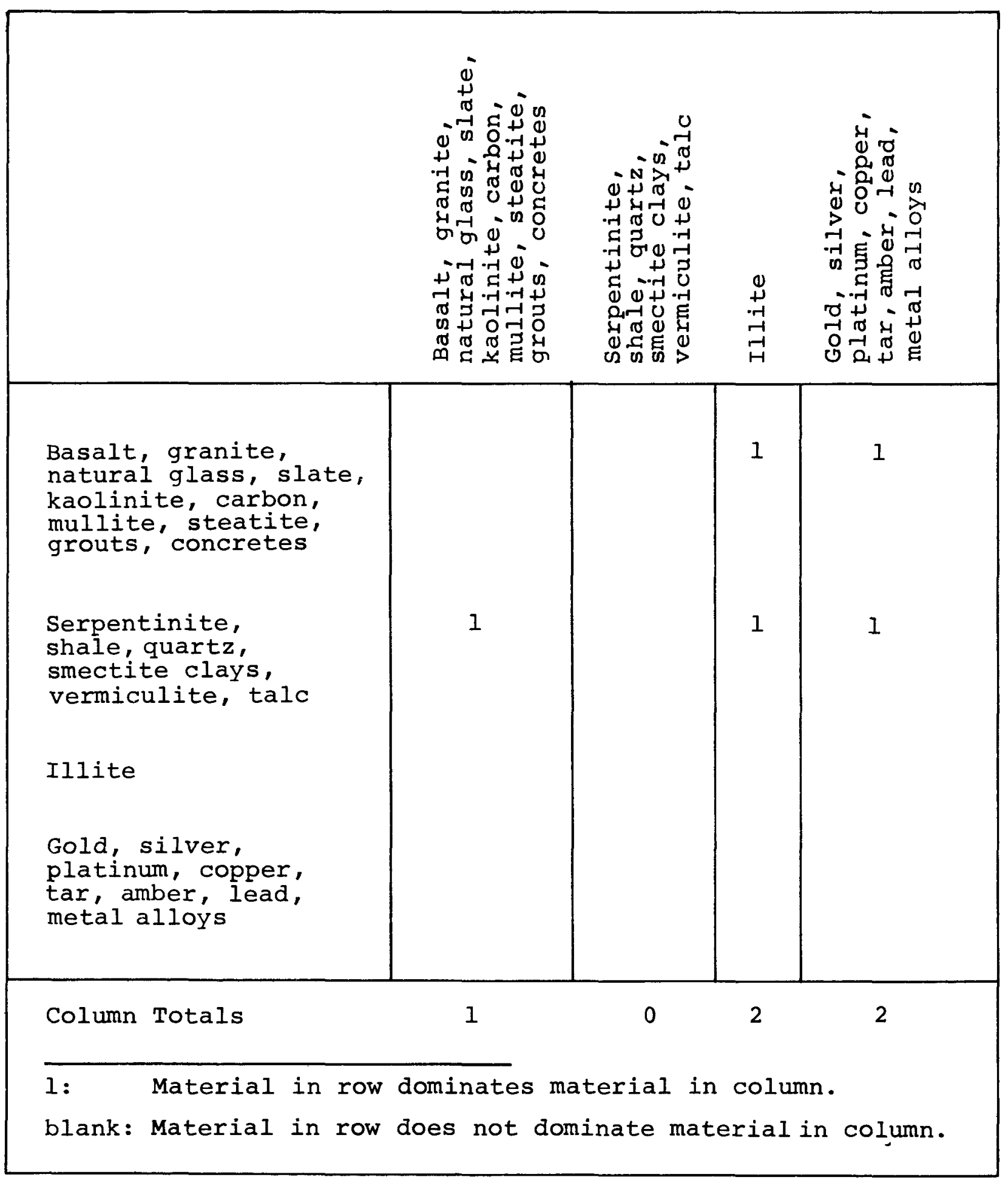


TABLE B-XVII

PAIRWISE DOMINANCE ANALYSIS OF MATERIALS

TO INHIBIT RADIONUCLIDE MIGRATION

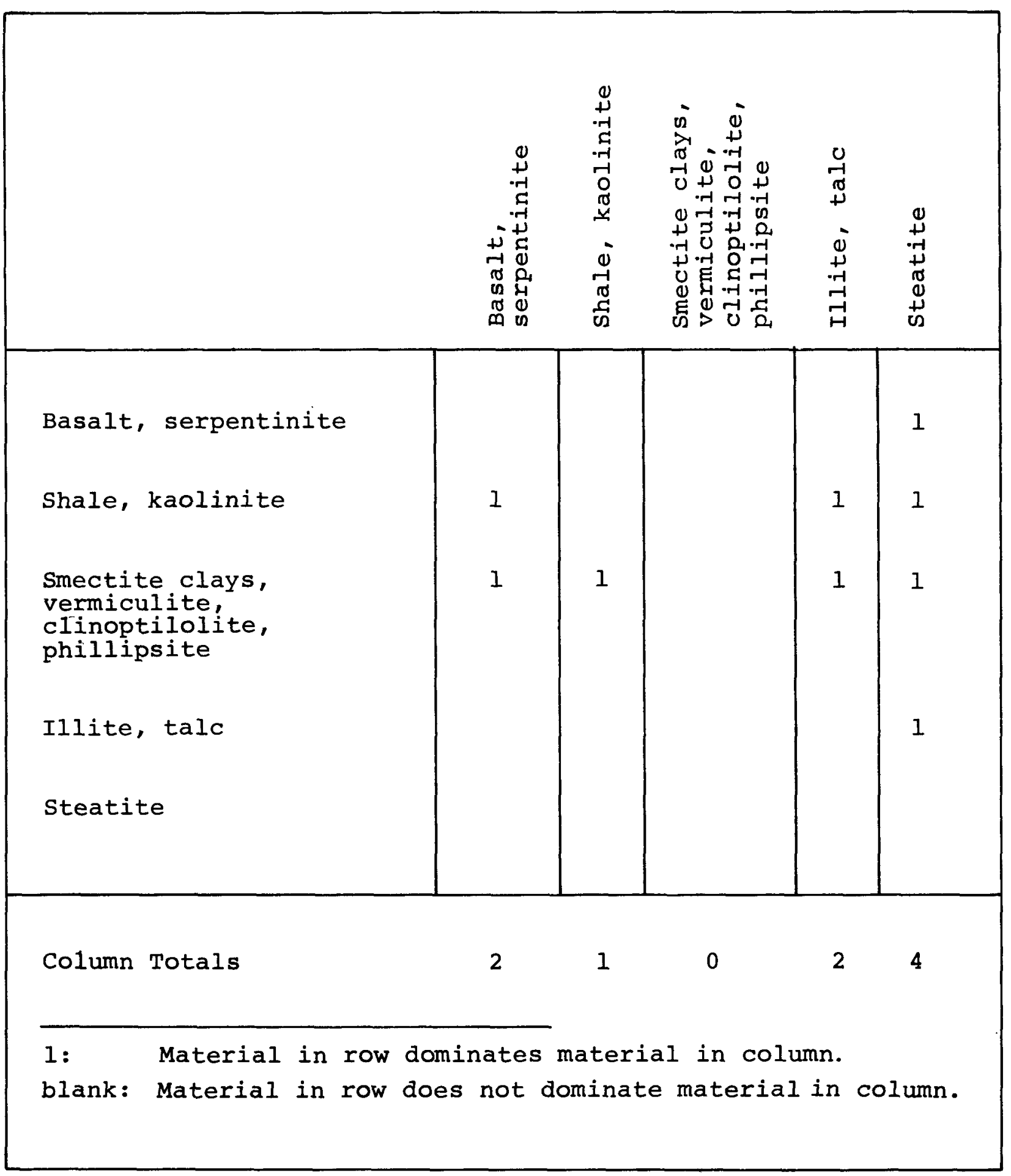


TABLE B-XVIII

PAIRWISE DOMINANCE ANALYSIS OF MATERIALS

TO PROVIDE STRUCTURAL INTEGRITY

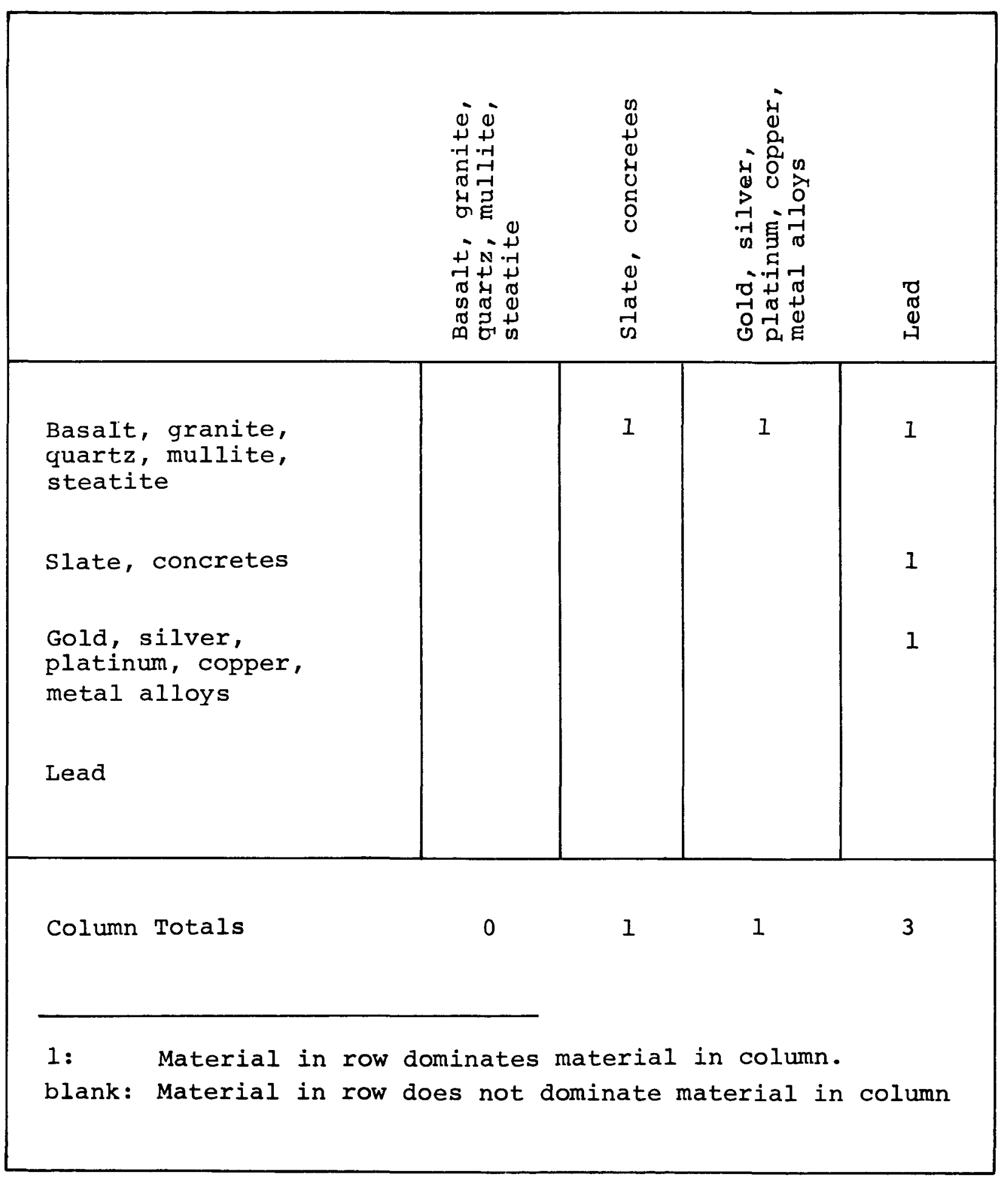


TABLE B-XIX

RESULTS OF SET DOMINANCE ANALYSIS OF

MATERIALS TO INHIBIT FLUID FLOW

Materials with most preferable physical and chemical properties

Materials with second most preferable physical and chemical properties

Materials with third most preferable physical and chemical properties
Serpentinite, shale, quartz, smectite clays, vermiculite, talc

Basalt, granite, natural glass, slate, kaolinite, carbon, mullite, steatite, grouts, concretes

Illite, gold, silver, platinum, copper, tar, amber, lead, metal alloys 
TABLE B-XX

RESULTS OF SET DOMINANCE ANALYSIS OF MATER IALS TO INHIBIT RADIONUCLIDE MIGRATION

Materials with most preferable physical and chemical properties
Smectite clays, vermiculite, clinoptilolite, phillipsite

Shale, kaolinite

Materials with second most preferable physical and chemical properties

Materials with third most preferable physical and chemical properties

Basalt, serpentine, illite, talc

Materials with fourth most preferable physical

Steatite and chemical properties 
TABLE B-XXI

RESULTS OF SET DOMINANCE ANALYSIS OF

MATERIALS TO PROVIDE STRUCTURE INTEGRITY

Materials with most preferable physical and chemical properties

Materials with second most preferable physical and chemical properties

Materials with third most preferable physical and chemical properties
Basalt, granite, quartz, mullite, steatite

Slate, concretes, gold, silver, platinum, copper, metal alloys

Lead 
preferred candidate materials for use in testing programs and preconceptual plug design.

The reasons that the various cost and availability issues considered in this step are evaluated after the physical and chemical properties of the materials are discussed in detail in Sections 3.2 .2 .4 and 3.3 .7 of Chapter 3 . The purpose of this step is primarily to determine whether cost and availability could change the order of the materials as shown in Tables B-XIX, B-XX, and B-XXI.

The factors considered in step 7 included relative cost, availability, and applicability to small openings (boreholes) and/or large openings (tunnels and shafts). The materials are reviewed in generic groups to facilitate discussion and comparison of like entities. Qualitative statements about the physical and chemical properties of the materials are made in several places. The reader may wish to refer to Tables B-XIX, $B-X X$, and $B-X X I$ to verify these statements.

\section{B.8.1 Consideration of Other Factors for the Generic Group--Rocks}

B.8.1.1 Basalt

Basalt mined from the repository and from access shafts and tunnels will supply a low cost, readily available material with low permeability, if used in solid machined plugs for small holes. It also has properties that make it desirable for use in functions requiring good strength to provide structural integrity for both solid plugs in small boreholes and, when crushed, for use in mixtures placed in tunnels and shafts. Basalt has a low ion exchange potential and sorption capacity 
when compared with other materials, but a greater ability to inhibit radionuclide migration than most other rock types considered here. For all these reasons, it is included as a preferred candidate material.

B.8.1.2 Granite and Slate

These rocks have properties similar to basalt as to permeability and application in engineered fills. However, they are less readily available and would undoubtedly cost more than basalt in actual plugging applications. Because basalt would fulfill the same functions at lower cost, they are not included on the preferred list.

B.8.1.3 Serpentinite, Shale, and Natural Glass

These materials, if properly selected and placed, could conceivably have somewhat lower permeabilities than basalt and ion exchange potentials and could have sorption capacities equal to or slightly higher than basalt. However, they rank lower than basalt as to properties that would provide structural integrity and strength for plugs, and rank considerably lower than other materials in inhibiting fluid flow and radionuclide migration. Because other materials excel them in each function classification they are not included as preferred candidate plug materials.

\section{B.8.2 Consideration of Other Factors for the Generic}

\section{Group -- Minerals}

\section{B.8.2.1 Quartz}

As can be seen in Tables $B-X I X, B-X X$, and $B-X X I$, a solid quartz plug machined to fit a small borehole has the property of low 
permeability and the potential for providing good structural integrity. It compares favorably with basalt in these aspects and may even be somewhat more stable than basalt in the potentially changing chemical environment of the repository and boreholes. Crushed and used as a plug component in large openings such as shafts and tunnels, quartz would have properties similar to crushed basalt. However, it has no ion exchange potential or sorption capacity and would be somewhat more expensive than the readily available basalt in this application. Quartz is placed on the preferred materials list as a potential solid plug material for use in small boreholes only.

B.8.2.2 Smectite Clays, Vermiculite, and Kaolinite

Sinectite clays and vermiculite both have excellent properties for inhibiting fluid flow and radionuclide migration. However, smectite clays (notable deposits of bentonite) are more readily available in the region surrouding the Hanford site, and for this reason are preferred over vermiculite, which would prove more costly and difficult to acquire for use in plugging. Kaolinite has a moderate ability to block radionuclide migration and a relatively low potential permeability. Kaolinite and vermiculite are not included with smectite clays as preferred candidate plug materials for the reasons given above. However, because of the ability of kaolinite to trap anions migrating in solution and vermiculite's high ranking in most respects, both should be considered for possible use in specialized requirements of future plug designs. 


\section{B.8.2.3 Clinoptilolite and Phillipsite}

Both of these zeolite minerals have very high ion exchange potentials and sorption capacities, and thus should excel in their ability to block radionuclides migrating in solution. Within several hundred kilometers of the Hanford site are naturally occurring deposits of clinoptilolite; therefore, it was chosen for inclusion as the preferred candidate plug material over phillipsite on a cost basis.

\section{B.8.2.4 Illite and Talc}

These two materials have some ion exchange potential and sorption capacity, and talc has the potential for relatively low permeability in certain plug designs. However, other materials are better able to inhibit fluid flow and radionuclide migration; therefore illite and talc are not included as preferred candidate plug materials.

B.8.3 Consideration of Other Factors for the Generic Group -- Native Elements and Metals

B.8.3.1 Gold, Silver, Platinum, Copper, Lead, and Metal Alloys

These materials have low permeability and relatively high strength, which at first glance would appear to make them viable candidates as solid plugs for small boreholes. However, problems with shrinkage upon cooling after placement in a molten form and a coefficient of thermal expansion considerably different from that of basalt could conceivably degrade the bulk permeability of the plug system with time. In addition, all are considerably more costly than other materials being considered for solid plugs, and some (notably silver and 
copper) may be somewhat unstable in the potentially changing chemical environment of repository boreholes and exploratory holes. Thus, none of the metals are included as preferred candidate plug materials.

\section{B.8.3.2 Carbon}

Very dense, pre-compacted carbon has potential use as a solid plug in a small hole. It would have relatively low permeability and possibly some ability to absorb migrating radionuclides. However, other materials in each function classification excel carbon in potential applications, and so it is not included as a preferred candidate plug material.

\section{B.8.4 Consideration of Other Factors for the Generic Group -- Natural Organic Material}

\section{B.8.4.1 Tar and Amber}

These organic materials, though impermeable, may become chemically unstable during the containment period of the repository and are not included as preferred candidate plug materials.

\section{B.8.5 Consideration of Other Factors for the Generic Group -- Ceramics}

B.8.5.1 Mullite and Steatite

Solid ceramic plugs manufactured to fit in small holes would have properties similar to solid basalt or quartz plugs with respect to their ability to inhibit fluid flow and provide structural integrity. Cost and availability would probably be 
similar to that for machining solid basalt or quartz plugs. Steatite has minor ion exchange potential and sorption capacity and because of its other properties is included as a representative of this group of materials in the list of preferred candidate plug materials while mullite is not included.

\section{B.8.6 Consideration of Other Factors for the Generic Group -- Grouts}

B.8.6.1 Portland Cements and Hydrothermal Cements

These manufactured materials have relatively low permeability when compared with other materials considered in Table B-XIX. Because of their versatility, low cost, and general availability, they are included as preferred candidate plug materials.

B.8.7 Consideration of Other Factors for the Generic Group -Concretes

B.8.7.1 Portland Cements plus Aggregate and Hydrothermal Cements plus Aggregate

When properly prepared and placed, concretes have relatively low permeability (and thus, some ability to block migrating fluids) and relatively high strength (to provide plugs with structural integrity). They appear to be potentially stable in the plug environment, and because of their low cost relative to other materials, versatility, and availability, concretes are included as preferred candidate plug materials. 


\section{B.8.8 Discussion}

The final list of preferred materials is shown in Table B-XXII. Those materials set aside at this time are shown in Table B-XXIII. Note in particular that the preferred candidate plug materials listed in Table B-XXII all ranked in the most preferable category in step 6 for at least one function classification, except grouts and concretes. These rank in the second most preferable category for at least one function classification, and were included because of various desirable cost and availability characteristics, as discussed in Sections B.8.6 and B.8.7.

Generally speaking, the materials set aside at this time (Table B-XXIII) ranked below the most desirable category in Step 6 in all function classifications. Exceptions to this are granite, serpentinite, shale, vermiculite, and mullite. These materials were set aside, even though they had desirable physical and chemical properties, because some other material included in the preferred candidate plug material list was judged to have at least as desirable properties and to be more practical or available, as discussed in the preceding sections.

\section{B.9. CONCLUDING REMARKS}

The seven-step materials selection process described in this appendix addresses the following questions:

Is there adequate assurance that each selected material will survive and continue to perform as desired for the required length of time? (addressed in step 2); 
TABLE B-XXII

PREFERRED CANDIDATE PLUG MATERIALS

\begin{tabular}{|c|c|}
\hline Material & Attributes \\
\hline Basalt & $\begin{array}{l}\text { Relatively impermeable as a } \\
\text { solid plug. } \\
\text { Good strength for engineering } \\
\text { purposes. } \\
\text { Low (but some) ion exchange } \\
\text { potential and moderate } \\
\text { sorption capacity. } \\
\text { Low cost, high availability. }\end{array}$ \\
\hline $\begin{array}{l}\text { Quartz (only as a } \\
\text { solid plug for } \\
\text { small br -aholes) }\end{array}$ & $\begin{array}{l}\text { Impermeable. } \\
\text { Good strength. } \\
\text { Chemically stable. } \\
\text { Low cost. }\end{array}$ \\
\hline Smectite clays & $\begin{array}{l}\text { Very impermeable. } \\
\text { High ion exchange potential } \\
\text { and sorption capacity. } \\
\text { Chemically stable. } \\
\text { Low cost, readily available }\end{array}$ \\
\hline Clinoptilolite & $\begin{array}{l}\text { High ion exchange potential } \\
\text { and sorption capacity. } \\
\text { Chemically stable. } \\
\text { Low cost, readily available. }\end{array}$ \\
\hline $\begin{array}{l}\text { Steatite (only as a } \\
\text { solid plug for } \\
\text { small boreholes) }\end{array}$ & $\begin{array}{l}\text { Low permeability. } \\
\text { Good strength. } \\
\text { Low cost. }\end{array}$ \\
\hline $\begin{array}{l}\text { Grouts } \\
\text { Portland cements } \\
\text { Hydrothermal cements }\end{array}$ & $\begin{array}{l}\text { Low permeability. } \\
\text { High adaptability. } \\
\text { Low cost, readily available. }\end{array}$ \\
\hline $\begin{array}{l}\text { Concretes } \\
\text { Portland cements plus } \\
\text { aggregate } \\
\text { Hydrothermal cements } \\
\text { plus aggregate }\end{array}$ & $\begin{array}{l}\text { Good strength. } \\
\text { Low permeability. } \\
\text { High adaptability. } \\
\text { Low cost, readily available. }\end{array}$ \\
\hline
\end{tabular}


TABLE B-XXIII

MATERIALS SET ASIDE AT THIS TIME

\begin{tabular}{|c|c|}
\hline Material & Reason for Setting Aside \\
\hline $\begin{array}{l}\text { Granite } \\
\text { Natural glass } \\
\text { Slate } \\
\text { Serpentinite } \\
\text { Shale }\end{array}$ & $\begin{array}{l}\text { Generally have the same properties } \\
\text { as basalt in similar applications } \\
\text { and would be less readily available. }\end{array}$ \\
\hline Vermiculite & $\begin{array}{l}\text { Same attributes as smectite clays but } \\
\text { somewhat less readily available in } \\
\text { comparison. }\end{array}$ \\
\hline Kaolinite & $\begin{array}{l}\text { Other clays have better ability to inhibit } \\
\text { radionuclide migration. (Moderate ability } \\
\text { to exchange anions in a solution--potential } \\
\text { future application.) }\end{array}$ \\
\hline $\begin{array}{l}\text { Illite } \\
\text { Talc }\end{array}$ & $\begin{array}{l}\text { Generally excelled by other rocks } \\
\text { and minerals in function classifications. }\end{array}$ \\
\hline $\begin{array}{l}\text { Gold } \\
\text { Silver } \\
\text { Platinum } \\
\text { Copper } \\
\text { Lead } \\
\text { Metal alloys } \\
\text { Carbon }\end{array}$ & $\begin{array}{l}\text { Generally excelled by other } \\
\text { materials in function classifications; } \\
\text { also, very high cost and low } \\
\text { availability for some. }\end{array}$ \\
\hline $\operatorname{Tar}$ & $\begin{array}{l}\text { Generally excelled by other } \\
\text { materials in function classification. }\end{array}$ \\
\hline Amber & $\begin{array}{l}\text { Potentially unstable in the repository and } \\
\text { plug environment. }\end{array}$ \\
\hline Mullite & $\begin{array}{l}\text { Similar to steatite but no ion exchange } \\
\text { potential. }\end{array}$ \\
\hline
\end{tabular}


- Are adequate data available for each candidate plug material so that it can be usefully studied within the time frame of current pre-conceptual design studies and testing programs? (addressed in step 4);

- What function or functions could each material perform in a plug? (addressed in Steps 1 and 3);
How well would each material perform these functions? (addressed in Steps 5 and 6 ); and

- Taking into account the resource and contractual requirements of the pre-conceptual design studies and testing programs, as well as the relative abilities of each material to perform the various required plug functions, which materials should receive highest priority for inclusion in pre-conceptual design studies and testing programs? (addressed in step 7).

The selection process handles these issues in a systematic manner and documents, in a quantitative form, answers to the five questions 1 isted above. Any evaluation of this type requires the incorporation of professional judgment. However, the procedure attempts to reduce the effects of subjective judgment where possible. In addition, because the selection mechanism is systematically documented, another investigator can determine how differences in judgments would affect the final results of the selection process.

Finally, because the process is clearly defined and systematic, it is possible to evaluate any proposed plug materials that may come to light in the future on a basis that is consistent with the evaluation presented here. 
In view of the large number of materials identified in step 1 as being potentially applicable in plugs, the final list of selected materials may appear short. However, the length of this list is somewhat deceptive. Some of the items, such as smectite clays and concretes, are actually categories of materials that have a variety of specific types to be investigated. In addition, there are various additives (not discussed here) to be investigated for use with some of the materials. Finally, a mixed component plug could combine two or more of the materials on the list in various proportions.

With all of these many possible variations available for investigation, the 1 ist of selected materials provides an anple group of materials and mixtures with potential promise for preconceptual design and testing. 


\section{APPENDIX B}

\section{REFERENCES}

Ayapito, J.F.T., Hardy, M.P., and St. Laurent, D.R., 1977, Geoengineering review and proposed program outline for the structural design of a radioactive waste repository in Columbia Plateau basalts: RHO-ST-6, Rockwell Hanford Operations, Richland, Washington, $95 \mathrm{p}$.

Allirot, D.A., and Boehler, J., 1979, Evolution of the mechanical properties of a stratified rock under confining pressure: Proceedings of the 4 th Congress of the International Society for Rock Mechanics, Part-l, Montreux, Switzerland, $8 \mathrm{p}$.

Ames, L.L., 1978, Radionuclide batch $K_{d}$ values on basalt, huelandite, and nontronite, in Basalt waste Isolation Prograin Annual Report - Fiscal Year 1978: RHO-BWI-78-100, Rockwell Hanford Operations, Richland, Washington, p. 136-144.

Barla, G., and Innurato, N., 1973, Indirect tensile testing of anisotropic rocks: Rock Mechanics, v. 5, p. 215-230.

Barrer, R.M., 1978, Cation-exchange equilibria in zeolites and feldspathoids, in Natural Zeolites-Occurrence, Properties, and Use, Sand, L.B. and Mumpton, F.A. (eds.): Pergamon Press, New York, p. 385-396. 
Benson, L.V., 1978, Secondary minerals, oxidation potentials, pressure and temperature gradients in the Pasco Basin of Washington State: RHO-BWI-C-34, Rockwell Hanford Operations, Richland, Washington, $21 \mathrm{p}$.

Boa, J.A., Jr., 1978, Borehole plugging program (waste disposal), Report 1 - Initial investigations and preliminary data: U.S. Army Engineer Waterways Experiment Station, Miscellaneous Paper C-78-1, Vicksburg, Mississippi, $16 \mathrm{p}$.

Brewer, H.W., 1967, General relation of heat flow factors to unit weight of concrete: Journal of the PCA (Portland Cement Association) Research and Development Laboratories, v. 9, no. 1 , p. 48-60.

Cedergren, H.R., 1967, Seepage, Drainage and Flow Nets: John Wiley and Sons, New York, New York, 489 p.

Clark, S.P., Jr., 1966, Handbook of physical constants: Geological Society of America Memoir 97, 587 p.

Colorado School of Mines and Geology, 1978, Physical and thermal properties of basalt cores: RHO-BWI-C-38, Rockwell Handford Operations, Richland, Washington, $76 \mathrm{p}$.

Colorado School of Mines and Geology, 1979, Determination of basalt physical and thermal properties at varying temperatures, pressures and moisture contents, First progress report - Fiscal Year 1974: RHO-BWI-C-50, Rockwell Hanford Operations, Richland, Washington, $77 \mathrm{p}$. 
Eilers, L.H., and Spangle, L.B., 1973, Borehole sealing: ORNL/Sub/15966-73/1, Union Carbide Corporation Nuclear Division, Oak Ridge, Tennessee, 110 p.

Farmer, I.W., 1968, Engineering Properties of Rocks: Spon, London, England, $180 \mathrm{p}$.

Fried, S., Fridman, A.M., Cohen, D., Hines, J.J., and Strickert, R.G., 1978, The migration of long-lived radioactive processing wastes in selected rocks: ANL-78-46, Argonne National Laboratory, Oakridge, Tennessee.

Garrels, K.M., and Christ, C.L., 1965, Solutions, Minerals, and Equilibria: Harper and Row, New York, New York, 450 p.

Grim, R.E., 1968, Applied Clay Mineralogy: McGraw-Hill, New York, New York, 596 p.

Hoadley, A., 1964, Essentials of structural design: John Wiley and Sons, New York, New York, $395 \mathrm{p}$.

Holliday, L., 1966, Composite Materials: Elsevier, Amsterdam, The Netherlands, $540 \mathrm{p}$.

Komarneni, S. and Roy, R., 1979, Superoverpack: Tailor-made mixtures of zeolites and clays: International symposium on Scientific Basis for Nuclear Waste Management, Materials Research Society, Cambridge, Massachusetts, Paper I4. 
Kracek, F.C., and Clark, S.P., Jr, 1966, Melting and transformation points in oxide and silicate systems at low pressure, in Handbook of Physical Constants: Geological Society of American Memoir 97, p. 301-322.

Krauskopf, K.B., 1967, Introduction to Geochemistry: McGrawHi11, New York, New York, 721 p.

Laguros, J.G., 1969, Effect of temperature on some engineering properties of clay soils: Highway Research Board Special Report 103, p. 186-193.

Lama, R.D., and Vutukuri, V.S., 1978, Handbook of Mechanical Properties of Rocks, Volume 2: Trans Tech Publications, Clausthal, Germany, 481 p.

Lambe, T.W., and Whitman, R.V., 1969, Soil Mechanics: John Wiley and Sons, New York, New York, 553 p.

Ma, Y.H., and Lee, T.Y., 1978, Sorption and diffusion properties of natural zeolites, in Natural Zeolites-Occurrence, Properties, and Use, Sand, L.B. and Mumpton, F.A. (eds.): Pergamon Press, New York, p. $373-383$.

Mercer, B.W., and Ames, L.L., 1978, Zeolite ion exchange in radioactive and municipal wastewater treatment, in Natural Zeolites-Occurrence, Properties, and Use, Sand, L.B. and Mumpton, F.A. (eds.): Pergamon Press, New York, p. 451-462. 
Merritt, F.S., (ed.), 1976, Standard Handbook for Civil Engineers: McGraw-Hill, New York, New York, various pages.

Mitchell, J.K., 1976, Fundamentals of Soil Behavior: John Wiley and Sons, New York, New York, 422 p.

Neville, A.M., 1971, Hardened concrete--Physical and mechanical properties: American Concrete Institute Monograph No. 6 , Detroit, Michigan, $206 \mathrm{p}$.

Olson, R.H., (ed.), 1975, Economic aspects of zeolites, in Industrial Minerals and Rocks: American Institute of Mining, Metalurgical and Petroleum Engineers,

Pusch, R., 1979, Highly compacted sodium bentonite for isolating rock-deposited radioactive waste products: Nuclear Technology, v. 45, p. 153-157.

Root, R.L., and Calvert, D.G., 1971, The real story of cement expansion: SPE-3346, Society of Petroleum Engineers of the American Institute of Mechanical Engineers, Dallas, Texas, $5 \mathrm{p}$.

Sand, L.B., and Mumpton, F.A., (eds.), 1978, Natural Zeolites-Occurrance, Properties, and Use: Pergamon Press, New York, New York, $546 \mathrm{p}$. 
Slemmons, M.J., and Seyforth, M., 1978, The selectivity of clinoptilolite for certain heavy metals, in Natural Zeolites--Occurrence, Properties, and Use, Sand, L.B. and Mumpton, F.A. (eds.): Pergamon Press, New York, p. 519-526.

Swedish Nuclear Fuel Safety Project, 1977a, A short review of the formation, stability, and cementing properties of natural zeolites: KBS-27, Karnbranslesakerhet, Stockholm, Sweden.

Swedish Nuclear Fuel Safety Project, 1977b, Retardation of escaping nuclides from a final repository: KBS-30, Karnbranslesakerhet, Stockholm, Sweden.

Swineford, A., (ed.), 1957, Clays and Clay Minerals: Pergamon Press, New York, New York, $411 \mathrm{p}$.

Taylor, C.L., O'Rourke, J.E., and Niccum, M.R., 1979, Borehole plugging of man-made accesses to a basalt repository: A preliminary study: RHO-BWI-C-49, Rockwell Hanford Operations, Richland, Washington, 157 p.

Tsitsishvili, G.V., 1978, Absorption and catalytic properties of some Soviet natural zeolites, in Natural Zeolites-Occurrence, Properties, and Use, Sand, L.B. and Mumpton, F.A. (eds.): Pergamon Press, New York, P. 397-402. 
Weant, R.C., (ed.), 1976, Handbook of Chemistry and Physics, 57 th edition: CRC Press, Inc., Cleveland, Ohio, various pages.

Young, J.F., 1947, Materials and Processes: John Wiley and Sons, New York, New York, 628 p. 
RHO-BWI-C-66

APPENDIX C

DETAILED DATA FROM GEOCHEMICAL TESTING PROGRAM 


\author{
APPENDIX C \\ DETAILED DATA FROM GEOCHEMICAL \\ TESTING PROGRAM \\ LIST OF TABLES
}

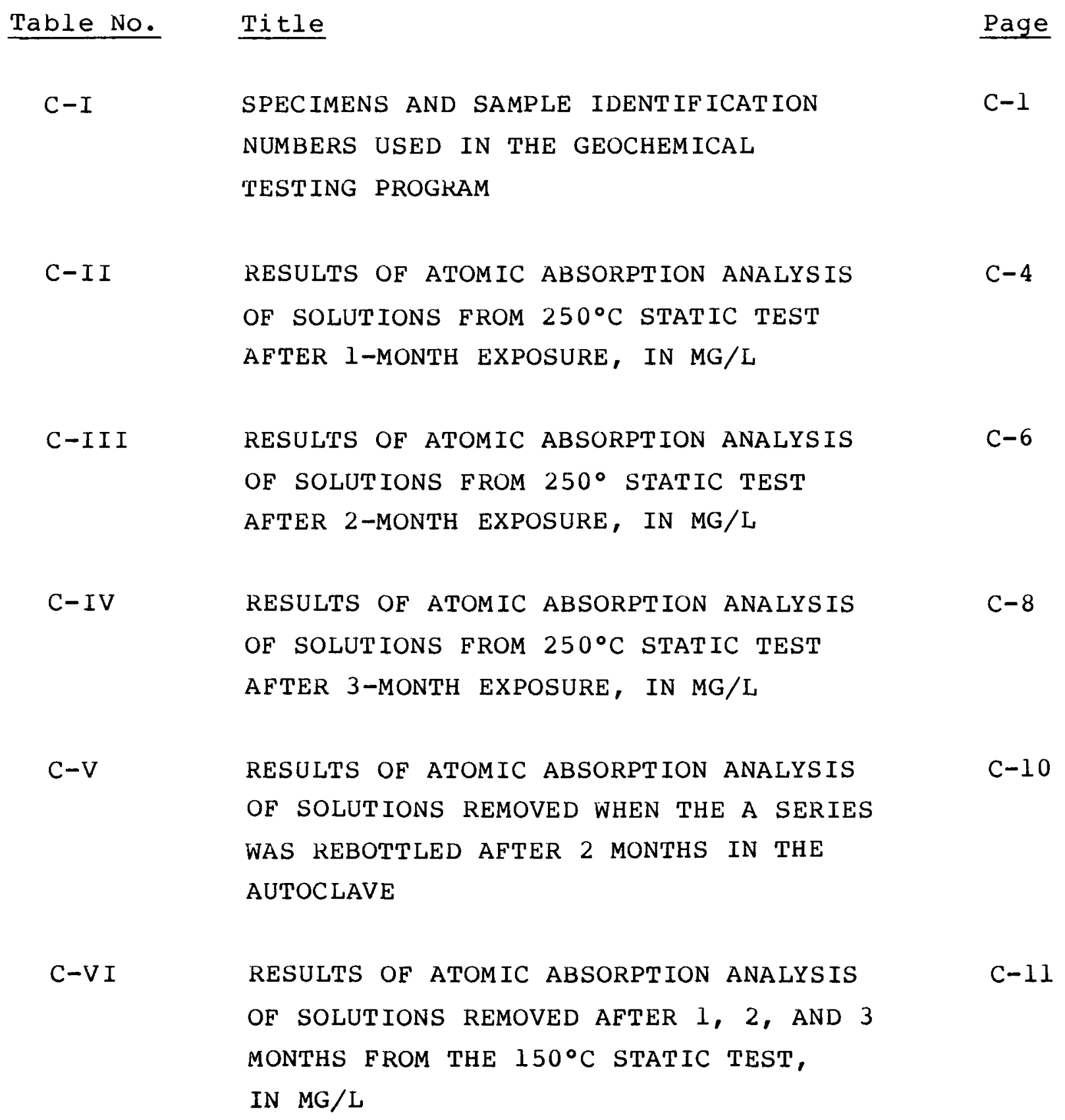




\begin{tabular}{|c|c|c|}
\hline$C-V I I$ & $\begin{array}{l}\text { RESULTS OF ATOMIC ABSORPTION ANALYSIS } \\
\text { OF SOLUTIONS FROM STIRRED AND } 34.5 \mathrm{MPa} \\
\text { STATIC TESTS, IN MG/L }\end{array}$ & $C-12$ \\
\hline $\mathrm{C}-\mathrm{VIII}$ & $\begin{array}{l}\text { RESULTS OF X-RAY DIFFRACTION ANALYSIS } \\
\text { OF SOLID SPECIMENS FROM STATIC, } 250^{\circ} \mathrm{C} \\
\text { TEST; SINGLE NATURAL MATERIALS }\end{array}$ & $c-13$ \\
\hline$C-I X$ & $\begin{array}{l}\text { X-RAY DIFFRACTION ANALYSIS OF PHASE } \\
\text { CHANGES IN SOLID SPECIMENS FROM } \\
\text { STATIC, } 250^{\circ} \mathrm{C} \text { TEST; MIXTURES OF } \\
\text { NATURAL MATERIALS }\end{array}$ & $C-14$ \\
\hline$C-x$ & $\begin{array}{l}\text { X-RAY DIFFRACTION ANALYSIS OF PHASE } \\
\text { CHANGES IN SOLID SPECIMENS FROM } \\
\text { STATIC, } 250^{\circ} \mathrm{C} \text { TEST; CEMENTITIOUS } \\
\text { MIXTURES }\end{array}$ & $c-15$ \\
\hline$C-X I$ & $\begin{array}{l}\text { PERCENTAGES OF SOLID MATERIAL } \\
\text { RECOVERED AFTER } 250^{\circ} \mathrm{C} \text { STATIC TESTS }\end{array}$ & $C-16$ \\
\hline$C-X I I$ & $\begin{array}{l}\text { FISHER PARTICLE SIZE ANALYSIS OF } \\
\text { SOLID SPECIMENS FROM STATIC, } \\
250^{\circ} \mathrm{C} \text { TEST, AFTER INDICATED EXPOSURE }\end{array}$ & $C-18$ \\
\hline$C-X I I I$ & $\begin{array}{l}\text { AVERAGE POROSITIES OF POWDER COMPACTS } \\
\text { FROM STATIC } 250^{\circ} \mathrm{C} \text { TEST, AFTER } \\
\text { INDICATED EXPOSURE }\end{array}$ & $C-20$ \\
\hline
\end{tabular}


TABLE C - I

SPECIMENS AND SAMPLE IDENTIFICATION NUMBERS

USED IN THE GEOCHEMICAL TESTING PROGRAM

Sample

ID No. ${ }^{a}$ Composition

\section{Basalt}

Basalt

Basalt

Basalt/Sand

Basalt/Oregon bentonite

Basalt/Wyoming bentonite

Basalt/Shurgel

Basalt/Aquagel

Basalt/Ringold clay d

Basalt/sand/Oregon bentonite

Basalt/sand/Wyoming bentonite

Basalt/sand/Ringold clay

Basalt/zeolite/Oregon bentonite

Basalt/zeolite/Wyoming bentonite

Basalt/zeolite/Ringold clay

oregon bentonite

Wyoming bentonite

Oregon bentonite/sand

Wyoming bentonite/sand $\underline{\text { Proportions }}^{\mathrm{b}} \quad$ Description ${ }^{\mathrm{C}}$

Single piece, polished face

$-10 /+40$ mesh

$1: 1$

$1: 1$

$1: 1$

$1: 1$

$1: 1$

$1: 1$

$1: 1: 1$

$1: 1: 1$

$1: 1: 1$

$1: 1: 1$

$1: 1: 1$

$1: 1: 1$

$1: 1$

$1: 1$

Bentonite -325 mesh

Shurgel -325 mesh

(processed bentonite)

Aquagel -325 mesh

(processed bentonite)

Clay -325 mesh

Bentonite -325 mesh

Bentonite -325 mesh

Clay -325 mesh

Zeolite, bentonite -325 mesh

zeolite, bentonite -325 mesh

Zeolite, clay -325 mesh

-325 mesh

-325 mesh

Bentonite -325 mesh

Bentonite -325 mesh 
TABLE C-I (continued)

\begin{tabular}{|c|c|c|c|}
\hline $\begin{array}{l}\text { Sample } \\
\text { ID No? }\end{array}$ & Composition & Proportions $^{b}$ & Description $^{\mathrm{C}}$ \\
\hline 20 & Oregon bentonite/zeolite & $1: 1$ & Both -325 mesh \\
\hline 21 & Wyoming bentonite/zeolite & $1: 1$ & Both -325 mesh \\
\hline 22 & Oregon zeolite & & -325 mesh \\
\hline 23 & Ringold clay & & -325 mesh \\
\hline 24 & Ringold clay/sand & $1: 1$ & Clay -325 mesh \\
\hline 25 & Fondu/sand/basalt & $1: 1: 1$ & $\begin{array}{l}\text { Fondu = hydrothermal cement } \\
\text { (brand name) }\end{array}$ \\
\hline 26 & Secar/sand/basalt & $1: 1: 1$ & $\begin{array}{l}\text { Secar = hydrothermal cement } \\
\text { (brand name) }\end{array}$ \\
\hline 27 & (Portland pozzolan cement + sand)/basalt & $1: 1$ & \\
\hline 28 & (Portland Type II cement + sand)/basalt & $1: 1$ & \\
\hline 29 & (Portland Type $V$ cement + sand)/basalt & $1: 1$ & \\
\hline 30 & $($ Fondu + zeolite) $/$ basalt & $1: 1$ & \\
\hline 31 & (Portland pozzolan cement + zeolite)/basalt & $1: 1$ & \\
\hline 32 & (Portland Type II cement + zeolite)/basalt & $1: 1$ & \\
\hline 33 & (Portland Type $V$ cement + zeolite)/basalt & $1: 1$ & \\
\hline 34 & (Portland Type $V$ cement + silica flour)/basalt & $1: 1$ & \\
\hline 35 & Basalt core + concrete & & $\begin{array}{l}\text { Bulk specimen supplied by } \\
\text { Rockwell }\end{array}$ \\
\hline
\end{tabular}


TABLE C-I (continued)

Sample

ID No. ${ }^{a}$ Composition

36

(TXI Chem Com cement + Lassenite)/sand

37

(Portland Type $V$ cement + silica flour +

Plastiment)/sand

38

39
(Portland pozzolan cement + silica flour)/sand

Proportions $^{\text {b }}$

$1: 1$

$1: 1$

$1: 1$

(Portland Type $\mathrm{V}$ cement + Lassenite)/sand

$1: 1$ $\underline{\text { Description }}^{\mathrm{C}}$

TXI Chem Com $=$ portland cement with shrinkage compensating agent (brand name);

Lassenite = natural pozzolan additive (brand name)

Plastiment $=$ organic water reducing retarder agent (brand name)

a Letter designations shown with Sample ID numbers on the following tables are as follows: A, B, and C refer to 3-month, 2-month, and 1 -month $250^{\circ} \mathrm{C}$ static tests, respectively; $\mathrm{D}, \mathrm{E}$, and $\mathrm{F}$ refer to 3-month, 2-month, and 1-month $150^{\circ} \mathrm{C}$ static tests, respectively

$b_{\text {All }}$ proportions are by weight to $\pm 0.001 \mathrm{~g}$.

${ }^{c}$ All materials ground to $-200+325$ mesh, unless specified otherwise.

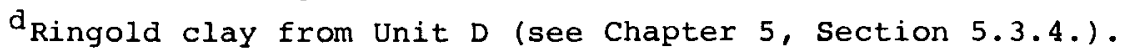


TABLE C-II

RESULTS OF ATOMIC ABSORPTION ANALYSIS OF SOLUTIONS FROM $250^{\circ} \mathrm{C}$ STATIC TEST AFTER 1-MONTH EXPOSURE, IN MG/L

\begin{tabular}{|c|c|c|c|c|c|c|c|}
\hline Sample & $\mathrm{Na}$ & $\mathrm{K}$ & $\mathrm{Mg}$ & $\mathrm{Fe}$ & $\mathrm{Ca}$ & $\mathrm{Al}$ & $S i$ \\
\hline $\begin{array}{l}\text { Ground } \\
\text { Watera }\end{array}$ & 26 & 10 & 1 & $<0.2$ & 7 & $\leq 0.01$ & 0.1 \\
\hline $\begin{array}{l}\text { Autoclave } \\
\text { Solutionb }\end{array}$ & 94 & 18 & U. 2 & 10 & 53 & 0.04 & 120 \\
\hline $1 c^{C}$ & 116 & 14 & 0.8 & $<0.2$ & 14 & 4 & 180 \\
\hline $2 C$ & 114 & 12 & 0.4 & $<0.2$ & 6 & 0.6 & 180 \\
\hline $3 C$ & 116 & 18 & 0.2 & $<0.2$ & 6 & $\leq 0.01$ & 60 \\
\hline $4 \mathrm{C}$ & 140 & 12 & 0.2 & $<0.2$ & 14 & 2 & 80 \\
\hline $5 C$ & 170 & 16 & 1.4 & $<0.2$ & 74 & 14 & 140 \\
\hline $6 C$ & 134 & 14 & $<0.01$ & $<0.2$ & 4 & 0.6 & 180 \\
\hline $7 \mathrm{C}$ & 146 & 12 & $<0.01$ & $<0.2$ & 2 & 1.2 & 220 \\
\hline $3 C$ & 695 & 18 & 0.7 & 2 & 9 & 6 & 60 \\
\hline $9 \mathrm{C}$ & 164 & 12 & $<0.01$ & $<0.2$ & 6 & 0.8 & 280 \\
\hline $10 \mathrm{C}$ & 136 & 6 & 0.2 & $<0.2$ & 50 & 1.2 & 120 \\
\hline $11 \mathrm{C}$ & 88 & 10 & 1 & 5 & 340 & 6 & 8 \\
\hline $12 \mathrm{C}$ & 108 & 8 & $<0.01$ & $<0.2$ & 12 & 0.8 & 40 \\
\hline $13 \mathrm{C}$ & 130 & 4 & $<0.01$ & $<0.2$ & 10 & 1.6 & 80 \\
\hline $14 \mathrm{C}$ & 112 & 10 & 0.2 & $<0.2$ & 4 & 1.6 & 200 \\
\hline $15 \mathrm{C}$ & 106 & 4 & 0.01 & $<0.2$ & 4 & 1.4 & 140 \\
\hline $16 \mathrm{C}$ & 17 & 2 & 0.2 & $<0.2$ & 256 & 1 & 6 \\
\hline \multicolumn{8}{|l|}{$17 \mathrm{C}$} \\
\hline $18 \mathrm{C}$ & 174 & 14 & 0.2 & $<0.2$ & 82 & $<0.01$ & 100 \\
\hline $19 \mathrm{C}$ & 114 & 8 & $<0.01$ & $<0.2$ & 3 & 0.8 & 160 \\
\hline $20 \mathrm{C}$ & 2 & $<0.05$ & $<0.01$ & $<0.2$ & 1 & $<0.01$ & 14 \\
\hline $21 \mathrm{C}$ & 132 & 22 & $<0.01$ & $<0.2$ & 10 & 23 & 80 \\
\hline $22 \mathrm{C}$ & 112 & 18 & 0.2 & 8 & 6 & 8 & 140 \\
\hline $23 C$ & 120 & 8 & $<0.01$ & $<0.2$ & 6 & 4 & 240 \\
\hline $24 \mathrm{C}$ & 142 & 6 & $<0.01$ & $<0.2$ & 14 & 0.2 & 40 \\
\hline
\end{tabular}

As prepared.

bAfter 1 month.

CLetter "C" denotes 1-month exposure $250^{\circ} \mathrm{C}$ static test. 
TABLE C-II (continued)

\begin{tabular}{|c|c|c|c|c|c|c|c|}
\hline Sample & $\underline{\mathrm{Na}}$ & $\underline{\mathrm{K}}$ & $\underline{\mathrm{Mg}}$ & $\mathrm{Fe}$ & $\mathrm{Ca}$ & $\mathrm{A} 1$ & Si \\
\hline $25 \mathrm{C}$ & 112 & 18 & $<0.01$ & $<0.2$ & 14 & 2 & 80 \\
\hline $26 \mathrm{C}$ & 110 & 16 & $<0.01$ & $<0.2$ & 10 & 0.6 & 120 \\
\hline $27 C$ & 122 & 10 & 100 & 52 & 144 & 76 & 80 \\
\hline $28 \mathrm{C}$ & 382 & 40 & 1 & 6 & 84 & 2 & 80 \\
\hline $29 \mathrm{C}$ & 2 & $<0.05$ & $<0.01$ & $<0.2$ & 1.4 & 0.2 & 80 \\
\hline $30 \mathrm{C}$ & 2 & $<0.05$ & $<0.01$ & $<0.2$ & $<0.05$ & 0.2 & 10 \\
\hline $31 \mathrm{C}$ & 2 & $<0.05$ & $<0.01$ & $<0.2$ & 2 & 2 & 8 \\
\hline $32 \mathrm{C}$ & 216 & 88 & $<0.01$ & $<0.2$ & 10 & 0.2 & 100 \\
\hline $33 \mathrm{C}$ & 135 & 11 & 1.1 & $<0.2$ & 177 & 2.1 & 64 \\
\hline $34 \mathrm{C}$ & 2 & $<0.05$ & $<0.01$ & $<0.2$ & 2 & 0.6 & 40 \\
\hline $36 \mathrm{C}$ & 2 & $<0.05$ & $<0.01$ & $<0.2$ & 1.2 & $<0.01$ & 40 \\
\hline $37 \mathrm{C}$ & 190 & 60 & $<0.01$ & $<0.2$ & 14 & 1.0 & 160 \\
\hline $38 \mathrm{C}$ & 176 & 16 & 1.4 & $<0.2$ & 226 & 1.6 & 120 \\
\hline $39 C$ & 206 & 14 & 4 & 12 & 260 & 6 & 100 \\
\hline
\end{tabular}


TABLE C-III

RESULTS OF ATOMIC ABSORPTION ANALYSIS OF SOLUTIONS FROM $250^{\circ} \mathrm{C}$ STATIC TEST AFTER 2-MONTH EXPOSURE, IN MG/L

\begin{tabular}{|c|c|c|c|c|c|c|c|}
\hline Sample $^{a}$ & $\underline{\mathrm{Na}}$ & $\underline{K}$ & $\underline{M g}$ & $\underline{\mathrm{Fe}}$ & Ca & $\underline{\mathrm{A} 1}$ & $\underline{\mathrm{Si}}$ \\
\hline $\begin{array}{l}\text { Autoclave } \\
\text { Solutionb }\end{array}$ & 52 & 10 & 0.2 & $<0.2$ & 6 & 1.2 & 100 \\
\hline $1 B^{C}$ & 120 & 3 & 0.4 & $<0.2$ & 4 & 1.4 & 160 \\
\hline $2 B$ & 314 & 6 & 0.4 & $<0.2$ & 6 & 2 & 120 \\
\hline $3 B$ & 360 & 14 & 1.6 & $<0.2$ & 10 & 4 & 80 \\
\hline $4 \mathrm{~B}$ & 92 & 6 & 0.8 & $<0.2$ & 10 & 2 & 80 \\
\hline $5 B$ & 146 & 8 & 14 & 32 & 124 & 2.40 & 100 \\
\hline $6 \mathrm{~B}$ & 76 & 8 & 2.8 & 3 & 8 & 10 & 80 \\
\hline $7 \mathrm{~B}$ & 92 & 10 & 0.6 & $<0.2$ & 6 & 4 & 160 \\
\hline $8 B$ & 116 & 12 & 4 & 12 & 3 & 2 & 100 \\
\hline $9 B$ & 94 & $\Delta$ & 0.4 & $<0.2$ & 3 & $<0.05$ & 140 \\
\hline $10 B$ & 360 & 6 & 2.6 & $<0.2$ & 142 & 1.2 & 100 \\
\hline $11 \mathrm{~B}$ & 94 & 4 & 2.2 & 4 & 3 & 4 & 120 \\
\hline $12 \mathrm{~B}$ & 54 & 2 & 0.4 & $<0.2$ & 4 & $<0.05$ & 140 \\
\hline $13 \mathrm{~B}$ & 174 & 20 & 0.3 & $<0.2$ & 34 & $<0.05$ & 80 \\
\hline $1 \leq \mathrm{B}$ & 46 & 4 & 0.4 & $<0.2$ & 2 & $<0.05$ & 120 \\
\hline $15 B$ & 252 & 64 & 18 & 4 & 33 & 134 & 160 \\
\hline $16 \mathrm{~B}$ & 156 & 14 & 1.2 & $<0.2$ & 242 & 4 & 20 \\
\hline $17 \mathrm{~B}$ & 50 & $\leq$ & 1.6 & $<0.2$ & 6 & 2 & 100 \\
\hline $18 \mathrm{~B}$ & 48 & 2 & 0.2 & $<0.2$ & 4 & $<0.05$ & 80 \\
\hline $19 \mathrm{~B}$ & 96 & 6 & 2.4 & 8 & 6 & 1.4 & 40 \\
\hline $20 B$ & 148 & 26 & 1.6 & 7 & 26 & 388 & $\Delta 40$ \\
\hline $21 B$ & 102 & 8 & 0.2 & $<0.2$ & 4 & 8 & 160 \\
\hline $22 \mathrm{~B}$ & 52 & 2 & 0.2 & $<0.2$ & 4 & 4 & 120 \\
\hline $23 B$ & 82 & 2 & 0.4 & $<0.2$ & 4 & 4 & 60 \\
\hline $24 B$ & 46 & 2 & 0.2 & $<0.2$ & 2 & 12 & 80 \\
\hline $25 B$ & 44 & 6 & 0.2 & $<0.2$ & 6 & 2 & 80 \\
\hline
\end{tabular}

a See Table C-I for description of sample. $b_{\text {After }} 1$ month.

C. Letter "B" denotes 2-month exposure $250^{\circ} \mathrm{C}$ static test. 
TABLE C-III (continued)

\begin{tabular}{|c|c|c|c|c|c|c|c|}
\hline Sample & $\underline{\mathrm{Na}}$ & $\underline{\mathrm{K}}$ & $\underline{M g}$ & $\underline{\mathrm{Fe}}$ & $\underline{\mathrm{Ca}}$ & $\mathrm{Al}$ & $\underline{\mathrm{Si}}$ \\
\hline $26 \mathrm{~B}$ & 48 & 8 & 0.2 & $<0.2$ & 4 & $<0.05$ & 80 \\
\hline $27 \mathrm{~B}$ & 54 & 4 & $<0.01$ & $<0.2$ & 3 & $<0.05$ & 100 \\
\hline $28 B$ & 58 & 2 & 0.2 & $<0.2$ & 10 & $<0.05$ & 80 \\
\hline $29 \mathrm{~B}$ & 54 & 2 & 0.2 & $<0.2$ & 10 & 1.6 & 30 \\
\hline $30 \mathrm{~B}$ & 50 & 10 & 0.2 & $<0.2$ & 6 & 1.4 & 80 \\
\hline $31 \mathrm{~B}$ & 62 & 6 & 3 & 8 & 116 & 8 & 80 \\
\hline $32 \mathrm{~B}$ & 42 & 2 & 0.2 & $<0.2$ & 10 & 1 & 30 \\
\hline $33 \mathrm{~B}$ & 52 & 2 & 0.2 & $<0.2$ & 8 & $<0.05$ & 100 \\
\hline $34 \mathrm{~B}$ & 64 & 2 & 0.2 & $<0.2$ & 3 & $<0.05$ & 100 \\
\hline $36 \mathrm{~B}$ & 42 & 2 & 0.2 & $<0.2$ & 14 & $<0.05$ & 120 \\
\hline $37 \mathrm{~B}$ & $\Delta 4$ & 2 & 0.2 & $<0.2$ & 12 & $\leq$ & 100 \\
\hline $33 \mathrm{~B}$ & 50 & 4 & 5 & 20 & 2.56 & 3 & 100 \\
\hline $39 B$ & 82 & 4 & 0.2 & $<0.2$ & 17 & 2 & 100 \\
\hline
\end{tabular}


TABLE C-IV

RESULTS OF ATOMIC ABSORPTION ANALYSIS OF SOLUTIONS FROM $250^{\circ} \mathrm{C}$ STATIC TEST AFTER 3-MONTH EXPOSURE, IN MG/L

\begin{tabular}{|c|c|c|c|c|c|c|c|}
\hline Sample & $\underline{\mathrm{Na}}$ & $\underline{\mathrm{K}}$ & $\underline{M g}$ & $\underline{\mathrm{Fe}}$ & Ca & $\mathrm{Al}$ & $\underline{\mathrm{Si}}$ \\
\hline $\begin{array}{l}\text { Autoclave } \\
\text { Solutionb }\end{array}$ & 34 & 12 & 0.2 & $<0.2$ & 6 & 2 & 40 \\
\hline $1 A^{C}$ & 96 & 8 & $<0.01$ & $<0.2$ & 2 & 2 & 240 \\
\hline $2 \mathrm{~A}$ & 92 & 4 & $<0.01$ & $<0.2$ & 4 & 20 & 180 \\
\hline $3 A$ & 80 & 12 & 0.2 & $<0.2$ & 4 & 12 & 140 \\
\hline $4 \mathrm{~A}$ & 108 & 10 & 0.4 & $<0.2$ & 40 & 60 & 140 \\
\hline $5 \mathrm{~A}$ & 592 & 52 & 2.2 & $<0.2$ & 194 & 2 & 100 \\
\hline $6 \mathrm{~A}$ & 102 & 8 & 1 & 6 & 2 & 6 & 180 \\
\hline $7 \AA$ & 96 & 10 & 1.6 & 8 & 10 & 20 & 180 \\
\hline $8 \mathrm{~A}$ & 102 & 16 & 0.8 & 4 & 2 & 14 & 2.40 \\
\hline $9 A$ & 70 & 6 & 0.2 & $<0.2$ & 2 & 2 & 140 \\
\hline $10 \mathrm{~A}$ & 76 & 4 & 1.4 & 6 & 30 & 6 & 100 \\
\hline $11 \mathrm{~A}$ & 104 & 8 & 0.3 & 4 & 4 & 23 & 140 \\
\hline $12 \mathrm{~A}$ & 73 & 4 & $<0.01$ & $<0.2$ & 2 & 12 & 140 \\
\hline $13 \mathrm{~A}$ & 130 & 34 & 0.4 & $<0.2$ & 10 & 18 & 60 \\
\hline $14 \mathrm{~A}$ & 138 & 18 & 0.4 & $<0.2$ & 20 & 16 & 100 \\
\hline $15 \mathrm{~A}$ & 44 & 6 & 0.2 & $<0.2$ & 2 & 8 & 100 \\
\hline $16 \mathrm{~A}$ & 730 & 64 & 2.6 & $<0.2$ & 262 & 6 & 12.0 \\
\hline $17 \mathrm{~A}$ & 120 & 6 & 0.3 & 4 & 2 & 13 & 160 \\
\hline $18 \mathrm{~A}$ & 236 & 14 & 0.6 & $<0.2$ & 154 & 33 & 120 \\
\hline $19 A$ & 72 & 8 & 0.6 & $<0.2$ & 4 & 28 & 60 \\
\hline $20 A$ & 238 & 28 & 0.2 & $<0.2$ & 46 & 12 & 120 \\
\hline $21 A$ & 122 & 24 & 1 & $<0.2$ & 44 & 12 & 100 \\
\hline $22 \mathrm{~A}$ & 114 & 34 & 1.6 & 16 & 30 & 14 & $1 \leq 0$ \\
\hline $23 A$ & 60 & 8 & 0.2 & 4 & $<0.05$ & 3 & 120 \\
\hline $24 \mathrm{~A}$ & 74 & 4 & 0.2 & $<0.2$ & 4 & 10 & 140 \\
\hline $25 A$ & 84 & 16 & 0.2 & $<0.2$ & 3 & 12 & 100 \\
\hline
\end{tabular}

a See Table c-1 for description.

$b_{\text {After }} 1$ month.

cletter "A" denotes 3-month exposure $250^{\circ} \mathrm{C}$ static test. 
C-9

RHO-BWI-C- 66

TABLE C-IV (continued)

\begin{tabular}{|cccccccc|}
\hline Sample & $\underline{\mathrm{Na}}$ & $\underline{\mathrm{K}}$ & $\underline{\underline{M g}}$ & $\underline{\mathrm{Fe}}$ & $\underline{\mathrm{Ca}}$ & $\frac{\mathrm{A} 1}{4}$ & $\frac{\mathrm{Si}}{60}$ \\
$26 \mathrm{~A}$ & 68 & 18 & 0.4 & $<0.2$ & 4 & 14 & 600 \\
$27 \mathrm{~A}$ & 48 & $\underline{4}$ & $<0.01$ & $<0.2$ & 10 & 6 & 100 \\
$23 \mathrm{~A}$ & 96 & 6 & $<0.01$ & $<0.2$ & 23 & 2 & 100 \\
$29 \mathrm{~A}$ & 60 & 4 & $<0.01$ & $<0.2$ & 14 & 2 & 120 \\
$30 \mathrm{~A}$ & 56 & 10 & $<0.01$ & $<0.2$ & 6 & 2 & 120 \\
$31 \mathrm{~A}$ & 53 & 4 & $<0.01$ & $<0.2$ & 12 & 2 & 100 \\
$32 \mathrm{~A}$ & 36 & 6 & 0.2 & $<0.2$ & 22 & $<0.1$ & 100 \\
$33 \mathrm{~A}$ & 36 & 6 & $<0.01$ & $<0.2$ & 26 & $<0.1$ & 100 \\
$34 \mathrm{~A}$ & 30 & 6 & 0.2 & $<0.2$ & 4.2 & 2 & 120 \\
$36 \mathrm{~A}$ & 46 & 6 & 0.6 & $<0.2$ & 76 & 14 & 100 \\
$37 \mathrm{~A}$ & 50 & 2 & 0.2 & $<0.2$ & 16 & 2 & 100 \\
$38 \mathrm{~A}$ & 76 & 4 & $<0.01$ & $<0.2$ & 20 & 4 & 100 \\
$39 \mathrm{~A}$ & 76 & 6 & $<0.01$ & $<0.2$ & 46 & 2 & 100 \\
\hline
\end{tabular}


TABLE $C-V$

RESULTS OF ATOMIC ABSORPTION ANALYSIS OF SOLUTIONS REMOVED WHEN THE A SERIES WAS REBOTTLED AFTER 2 MONTHS IN THE AUTOCLAVE

\begin{tabular}{|c|c|c|c|c|c|c|c|}
\hline$\underline{\text { Sample }}^{\mathrm{a}}$ & Na & $\underline{\mathrm{K}}$ & $\underline{\mathrm{Mg}}$ & Fe & Ca & Al & $\underline{\mathrm{Si}}$ \\
\hline $3 A$ & 68 & 12 & $<0.01$ & $\mathrm{~b}$ & 4 & 2 & $\overline{220}$ \\
\hline $8 \mathrm{~A}$ & 104 & 12 & 0.4 & $\mathrm{~b}$ & 2 & 8 & 120 \\
\hline $9 A$ & 86 & 6 & 0.4 & $\mathrm{~b}$ & 4 & 4 & 120 \\
\hline $11 \mathrm{~A}$ & 90 & 6 & 6.6 & $\mathrm{~b}$ & 4 & 2 & 160 \\
\hline $12 \mathrm{~A}$ & 76 & 2 & 2.8 & $\mathrm{~b}$ & 4 & 1.4 & 200 \\
\hline $14 \mathrm{~A}$ & 62 & 6 & 4 & $\mathrm{~b}$ & 2 & 1.6 & 180 \\
\hline $24 \mathrm{~A}$ & 82 & 2 & 0.2 & $\mathrm{~b}$ & 4 & 1.0 & 160 \\
\hline $28 \mathrm{~A}$ & 100 & 4 & 0.4 & $\mathrm{~b}$ & 24 & $<0.05$ & 120 \\
\hline $29 A$ & 56 & 10 & 3.6 & 14 & 74 & 60 & 320 \\
\hline $30 A$ & 60 & 4 & 0.8 & 6 & 20 & 4 & 220 \\
\hline $31 \mathrm{~A}$ & 62 & 2 & 0.4 & $\mathrm{~b}$ & 12 & $<0.05$ & 180 \\
\hline $32 \mathrm{~A}$ & 72 & 4 & 0.2 & $\mathrm{~b}$ & 20 & 1.8 & 220 \\
\hline $33 \mathrm{~A}$ & 72 & 4 & 0.4 & $\mathrm{~b}$ & 28 & $<0.05$ & 160 \\
\hline $34 \mathrm{~A}$ & 78 & 4 & 32 & $b$ & 30 & 4 & $1 \varepsilon 0$ \\
\hline $39 A$ & 76 & 4 & 0.4 & b & 48 & $<0.05$ & 140 \\
\hline
\end{tabular}

$a_{\text {see Table }}$ C-I for description.

$\left.\mathrm{b}_{\{\mathrm{Fe}}\right\}<0.2 \mathrm{ppm}$ 
TABLE C-VI

RESULTS OF ATOMIC ABSORPTION ANALYSIS OF SOLUTIONS REMOVED AFTER 1, 2, AND 3 MONTHS FROM THE $150^{\circ} \mathrm{C}$ STATIC TEST, IN MG/L

\begin{tabular}{|c|c|c|c|c|c|c|c|}
\hline Sample ${ }^{a}$ & $\underline{\mathrm{Na}}$ & $\underline{\underline{K}}$ & $\underline{M g}$ & $\underline{\underline{\mathrm{Fe}}}$ & $\underline{\mathrm{Ca}}$ & $\underline{A 1}$ & $\underline{\mathrm{Si}}$ \\
\hline \multicolumn{8}{|c|}{ I-Month Test } \\
\hline $12 \mathrm{~F}$ & 52 & 18 & $<0.01$ & $\mathrm{~b}$ & 12 & 5 & 80 \\
\hline $13 \mathrm{~F}$ & 376 & 94 & $<0.01$ & $\mathrm{~b}$ & 43 & $\leq 1$ & 80 \\
\hline $2 I F$ & 326 & 54 & 0.6 & $\mathrm{~b}$ & 48 & $\leq 1$ & 40 \\
\hline $25 \mathrm{~F}$ & 30 & 52 & 0.58 & 20 & 48 & 40 & 60 \\
\hline $27 F$ & 30 & 48 & $<0.01$ & $b$ & 26 & $<1$ & 80 \\
\hline $39 \mathrm{~F}$ & 86 & 42 & 0.4 & $\mathrm{~b}$ & 22 & 3 & 80 \\
\hline \multicolumn{8}{|c|}{ 2-Month Test } \\
\hline $12 \mathrm{~F}$ & 100 & 22 & 24 & $\mathrm{~b}$ & 8 & 2 & 120 \\
\hline $13 \mathrm{E}$ & 176 & 62 & 0.6 & $\mathrm{~b}$ & 22 & $<0.05$ & 40 \\
\hline $21 E$ & 706 & 140 & 1.0 & $\mathrm{~b}$ & 64 & 1.8 & 180 \\
\hline $25 E$ & 36 & 80 & 12 & 20 & 36 & 40 & 80 \\
\hline $27 E$ & 108 & 72 & 0.4 & $\mathrm{~b}$ & 16 & $<0.05$ & 120 \\
\hline $39 E$ & 112 & 66 & 0.6 & $\mathrm{~b}$ & 18 & 1.6 & 2.00 \\
\hline \multicolumn{8}{|c|}{ 3-Month Test } \\
\hline $12 \mathrm{D}$ & 70 & 42 & 0.4 & $\mathrm{~b}$ & 12 & 2 & 100 \\
\hline $13 D$ & 416 & 150 & 0.4 & $\mathrm{~b}$ & 56 & 2 & 300 \\
\hline $21 \mathrm{D}$ & 652 & 136 & 2 & $\mathrm{~b}$ & 140 & 0.08 & 100 \\
\hline $25 \mathrm{D}$ & 50 & 26 & 0.4 & $\mathrm{~b}$ & 10 & 0.3 & 8 \\
\hline $27 D$ & 156 & 94 & 66 & 138 & 136 & 64 & 80 \\
\hline 39D & 140 & 88 & 0.4 & $\mathrm{~b}$ & 14 & 8 & 100 \\
\hline
\end{tabular}

$a_{\text {See Table }}$ C-I for description.

$b_{\{F e}<0.2 \mathrm{ppm}$. 
TABLE C-VII

RESULTS OF ATOMIC ABSORPTION ANALYSIS OF SOLUTIONS FROM STIRRED AND $34.5 \mathrm{MPa}$ STATIC TESTS, TN MG/L

\begin{tabular}{|c|c|c|c|c|c|c|c|}
\hline Sample & $\mathrm{Na}$ & $\underline{\mathrm{K}}$ & $\underline{\mathrm{Mg}}$ & Fe & $\mathrm{Ca}$ & Al & $\underline{\mathrm{Si}}$ \\
\hline \multicolumn{8}{|l|}{ Stirred Vessel } \\
\hline \multicolumn{8}{|l|}{ 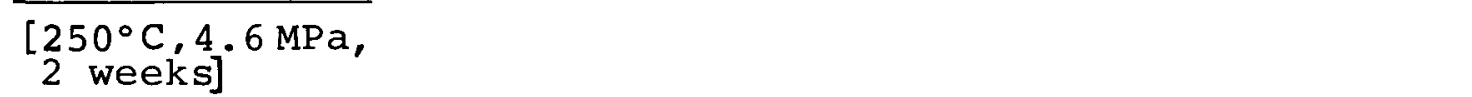 } \\
\hline Basalt & 154 & 56 & 72 & 142 & $1 \leq 0$ & 223 & 320 \\
\hline Zeolite & 1,640 & 1.008 & 34 & 42 & 456 & 736 & 540 \\
\hline $\begin{array}{l}\text { Bentonite plus } \\
\text { Zeolite }\end{array}$ & 1,456 & 552 & 52 & 32 & 1,134 & 298 & 580 \\
\hline \multicolumn{8}{|l|}{ Basalt plus } \\
\hline Bentonite & 608 & 19 & 0.2 & 0.3 & 16 & $<2$ & 6 \\
\hline \multicolumn{8}{|c|}{ High Pressure Vessel } \\
\hline \multicolumn{8}{|c|}{$\begin{array}{l}{\left[250^{\circ} \mathrm{C}, 34.5 \mathrm{MPa},\right.} \\
\text { static, } 2 \text { weeks] }\end{array}$} \\
\hline Basalt & 102 & 50 & 22 & 40 & 72 & 78 & 420 \\
\hline Zeolite & 458 & 40 & 0.2 & $<0.2$ & 12 & 100 & 320 \\
\hline $\begin{array}{l}\text { Bentonite plus } \\
\text { zeolite }\end{array}$ & 608 & 72 & 1.8 & $<0.2$ & 206 & 6 & 200 \\
\hline $\begin{array}{l}\text { Basalt plus } \\
\text { bentonite }\end{array}$ & 925 & 40 & $<0.2$ & $<0.2$ & 3 & 0.4 & 30 \\
\hline $\begin{array}{l}\text { Basalt plus } \\
\text { zeolite plus } \\
\text { bentonite }\end{array}$ & 412 & 134 & 30 & 40 & 140 & 8 & 260 \\
\hline
\end{tabular}




\section{TABLE C-VIII}

RESULTS OF X-RAY DIFFRACTION ANALYSIS OF SOLID SPECIMENS FROM STATIC, $250^{\circ} \mathrm{C}$ TEST; SINGLE NATURAL MATERIALS

Qualitative Dhase Analysis (VOl \%), After Indicated Exposure

Sample Starting

ID No* Material

$365 \mathrm{~L}-30 \mathrm{~A}-5 \mathrm{M}$

$1675 \mathrm{Mt}-250$

$$
\text { 1-Month }
$$

2-Month

3-Month

$17 \quad 75 \mathrm{Mt}-20 \mathrm{Q}-5 \mathrm{U}$

$59 L-27 A-4 M$

$-10 \mathrm{Mt}$

$59 \mathrm{~L}-27 \mathrm{~A}-4 \mathrm{M}$

$-10 \mathrm{Mt}$

$88 \mathrm{Mt}-12 \mathrm{Q}$

$75 \mathrm{Mt}-25 \mathrm{O}$

$55 \mathrm{~L}-26 \mathrm{~A}-4 \mathrm{M}$

$-15 \mathrm{Mt}$

$80 \mathrm{Mt}-20 \mathrm{Q}$

$90 M t-10 Q$

$2365 \mathrm{Mt}-10 \mathrm{I}-25 \mathrm{Q}$

$2290 \mathrm{C}-10 \mathrm{U}$

$59 M t-9 I-22 Q$

$-10 \mathrm{X}$

$65 \mathrm{Mt}-10 \mathrm{I}-25 \mathrm{Q}$

$100 \mathrm{C}$

$95 \mathrm{Mt}-5 \mathrm{Q}$
$60 \mathrm{Mt}-10 \mathrm{Q}-30 \mathrm{X}$
$52 \mathrm{Mt}-8 \mathrm{I}-20 \mathrm{Q}$
$100 \mathrm{C}^{-20 \mathrm{X}}$

* See Table C-I for description.

NOTES: $Q=$ Quartz $\left(\mathrm{SiO}_{2}\right) ; \mathrm{L}=$ Labradorite $\left(\{\mathrm{Ca}, \mathrm{Na}\} \mathrm{Si}_{2} \mathrm{Al}_{2} \mathrm{O}_{8}\right) ;$

$A=$ Augite $\left(\{\mathrm{Ca}, \mathrm{Mg}, \mathrm{Fe}\} \cdot \mathrm{SiO}_{2}\right) ; \mathrm{M}=$ Magnetite $\left(\mathrm{Fe}_{3} \mathrm{O}_{4}\right) ;$

Mt = Montmorillonite; $I=$ Illite; $C=$ Clinoptilolite $\left(\{\mathrm{Ca}, \mathrm{Na}, \mathrm{K}\} \mathrm{Al}_{2} \mathrm{Si}_{7} \mathrm{O}_{18} \cdot 6 \mathrm{H}_{2} \mathrm{O}\right), \mathrm{X}=$ Unknown phase giving single large peak; $U=$ Unidentified 
TABLE C-IX

X-RAY DIFFRACTION ANALYSIS OF PHASE CHANGES IN SOLID

SPECIMENS FROM STATIC, $250^{\circ} \mathrm{C}$ TEST;

MIXTURES OF NATURAL MATERIALS

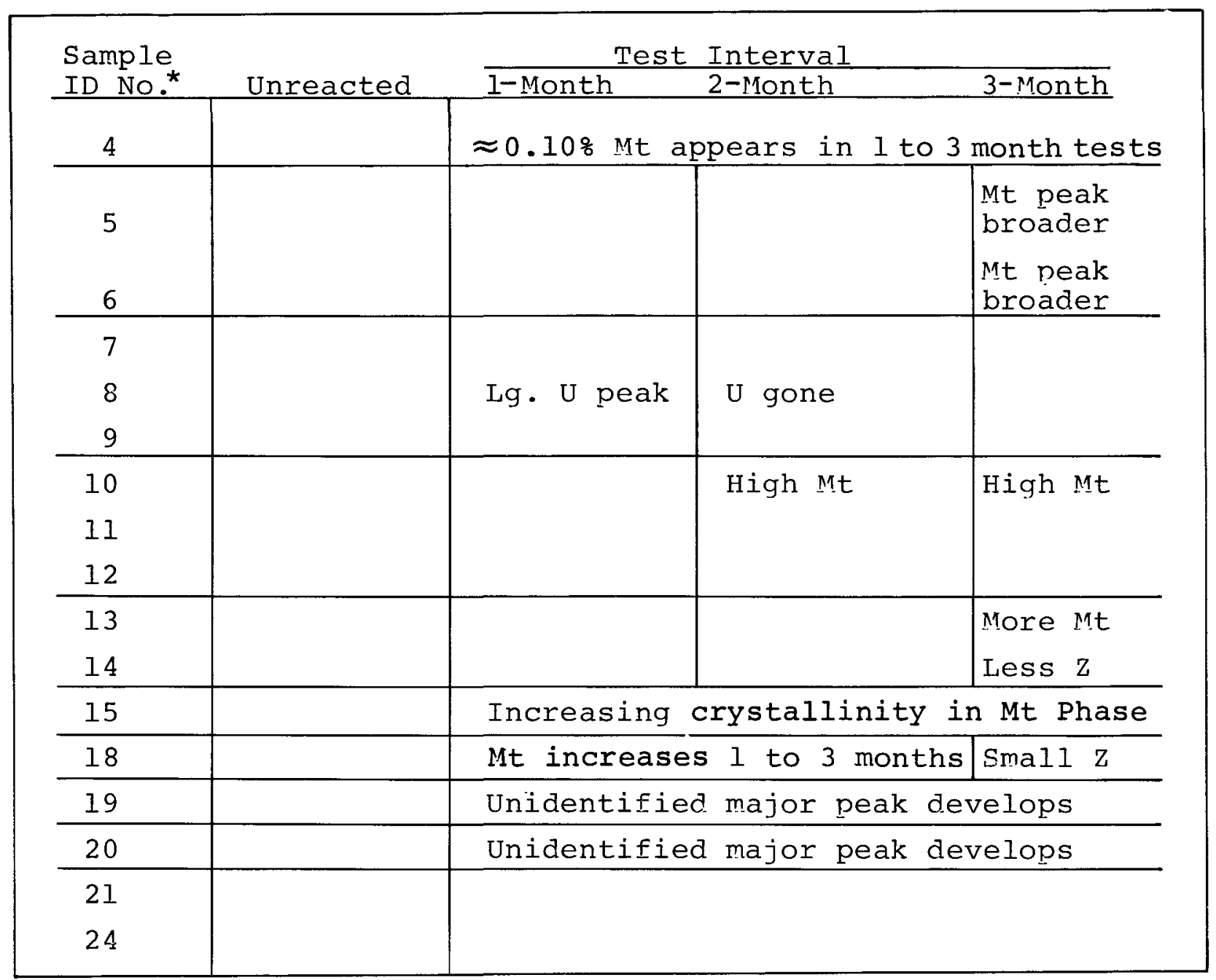

* See Table C-l for description.

NOTES: Unless otherwise indicated, y-ray spectra are superpositions of those from original, unreacted single components. Mt = Montmorillonite, $U$ = Unidentified peak, $\mathbf{z}=$ Zeolite 
TABLE $C-\mathrm{X}$

$X$-RAY DIFFRACTION ANALYSIS OF PHASE CHANGES IN SOLID SPECIMENS FROM STATIC, $250^{\circ} \mathrm{C}$ TEST; CEMENTITIOUS MIXTURES

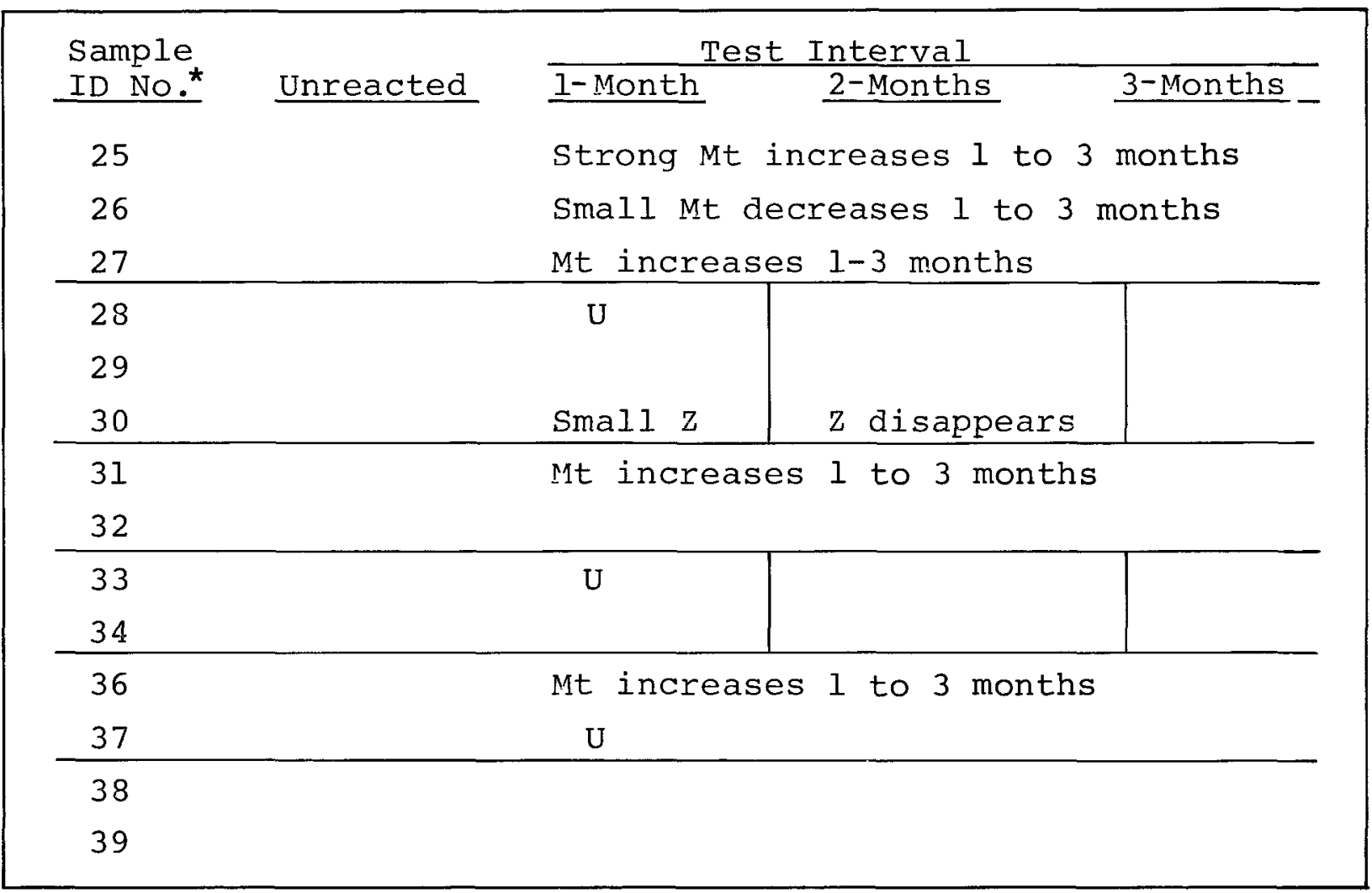

* See Table C-I for description.

NOTES: No entry means spectra unchanged from ,tarting material.

Mt = Montmorillonite, $U$ = Unidentified Phase, $\mathrm{z}=$ Zeolite 
TABLE C-XI

PERCENTAGES OF SOLID MATERIAL RECOVERED AFTER $250^{\circ} \mathrm{C}$ STATIC TESTS

\begin{tabular}{|c|c|c|c|c|c|}
\hline \multirow{2}{*}{\multicolumn{2}{|c|}{ Sample ID }} & \multirow[b]{2}{*}{ Number $^{a}$} & \multicolumn{3}{|c|}{ Recovered Sample Weight (percent) } \\
\hline & & & 1 Month & 2 Months & 3 Months \\
\hline & 1 & & 95.2 & 93.6 & 94.5 \\
\hline & 2 & & 91.0 & 91.9 & 89.8 \\
\hline & 3 & & 94.2 & 94.7 & 93.3 \\
\hline & 4 & & 95.2 & 94.8 & 95.1 \\
\hline & 5 & & $86.9(B)^{b}$ & 86.4 & 94.7 \\
\hline & 6 & & 89.3 & $92.8(\mathrm{~B})$ & 94.8 \\
\hline & 7 & & 91.5 & 94.3 & 91.4 \\
\hline & 8 & & 93.2 & 96.0 & 95.0 \\
\hline & 9 & & 96.1 & 93.7 & 96.2 \\
\hline & 10 & & $89.6(\mathrm{~B})$ & 91.2 & 89.8 \\
\hline & 11 & & 95.6 & 93.6 & 95.0 \\
\hline & 12 & & 95.3 & 93.6 & 95.5 \\
\hline & 13 & & 89.6 & 94.2 & 99.7 \\
\hline & 14 & & 91.9 & 87.2 & 93.9 \\
\hline & 15 & & 91.6 & 89.4 & 77.5 \\
\hline & 16 & & 92.8 & 79.9 & $93.2(\mathrm{~B})$ \\
\hline & 17 & & $92.8(\mathrm{~B})$ & $76.5(B)$ & $98.0(\mathrm{~B})$ \\
\hline & 18 & & 91.2 & 83.9 & 90.1 \\
\hline & 19 & & $87.5(B)$ & 96.0 & $95.2(\mathrm{~B})$ \\
\hline & 20 & & 96.3 & $86.8(B)$ & 92.7 \\
\hline & 21 & & 88.4 & 94.5 & $89.8(\mathrm{~B})$ \\
\hline & 22 & & 84.4 & 84.1 & 82.0 \\
\hline & 23 & & 96.6 & 95.4 & 96.2 \\
\hline & 24 & & 95.5 & 91.1 & 94.9 \\
\hline & 25 & & 97.2 & $95.5(\mathrm{~B})$ & $96.1(\mathrm{~B})$ \\
\hline & 26 & & 95.5 & 93.8 & 94.7 \\
\hline & 27 & & 95.9 & 96.9 & 96.0 \\
\hline
\end{tabular}

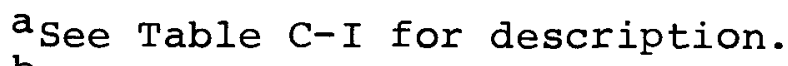
$\mathrm{b}_{\mathrm{B}}=$ broken bag. 
TABLE C-XI (continued)

\begin{tabular}{|c|c|c|c|c|c|}
\hline \multirow[b]{2}{*}{ Sample } & \multirow[b]{2}{*}{ ID } & \multirow[b]{2}{*}{ Number ${ }^{a}$} & \multicolumn{2}{|c|}{ Recovered Sample Weight } & $t$ (percent) \\
\hline & & & 1 Month & 2 Months & 3 Months \\
\hline & 28 & & 98.7 & 97.8 & 95.9 \\
\hline & 29 & & 98.7 & 97.3 & 97.3 \\
\hline & 30 & & 96.0 & 91.4 & 90.2 \\
\hline & 31 & & 92.2 & 90.2 & 89.3 \\
\hline & 32 & & 93.9 & 86.4 & 91.8 \\
\hline & 33 & & 92.8 & 84.3 & 90.9 \\
\hline & 34 & & 96.1 & 93.7 & 94.7 \\
\hline & 36 & & 97.7 & $96.4(\mathrm{~B})^{\mathrm{b}}$ & 94.7 \\
\hline & 37 & & 99.1 & $93.6(\mathrm{~B})$ & 93.2 \\
\hline & 38 & & 96.8 & 93.0 & $95.4(\mathrm{~B})$ \\
\hline & 39 & & 96.1 & 95.3 & 94.3 \\
\hline
\end{tabular}

a See Table C-I for description. $\mathrm{b}_{\mathrm{B}}=$ broken bag. 
TABLE C-XII

FISHER PARTICLE SIZE ANALYSIS OF SOLID SPECIMENS FROM STATIC, $250^{\circ} \mathrm{C}$ TEST, AFTER INDICATED EXPOSURE

\begin{tabular}{|c|c|c|c|c|}
\hline $\begin{array}{l}\text { Sample } \\
\text { ID No.* }\end{array}$ & $\begin{array}{c}\text { Starting } \\
\text { Material } \\
\text { Avg Dia ( } \mathrm{m}) \\
\end{array}$ & $\begin{array}{c}\text { 1-Month } \\
\text { Avg Dia(m) }\end{array}$ & $\begin{array}{r}\text { 2-Months } \\
\text { Avg Dia }(\mu \mathrm{m}) \\
\end{array}$ & $\begin{array}{c}\text { 3-Months } \\
\text { Avg Dia ( } \mathrm{km})\end{array}$ \\
\hline 3 & 32.34 & 4.77 & 3.78 & 3.86 \\
\hline 16 & 2.94 & 4.17 & 3.62 & 4.11 \\
\hline 17 & 7.34 & 9.67 & 6.82 & 12.38 \\
\hline 23 & 2.56 & 3.46 & 2.28 & 3.92 \\
\hline 22 & 2.58 & 3.90 & 2.76 & 3.06 \\
\hline 4 & - & 3.87 & 3.01 & 3.84 \\
\hline 5 & - & 3.49 & 2.66 & 3.55 \\
\hline 6 & - & 4.08 & 5.93 & 4.98 \\
\hline 9 & - & 3.10 & 2.01 & 3.14 \\
\hline 18 & - & 3.72 & 2.69 & 2.84 \\
\hline 19 & - & 4.65 & 5.01 & 3.66 \\
\hline 24 & - & 4.42 & 2.65 & 2.99 \\
\hline 20 & - & 2.97 & 3.38 & 2.00 \\
\hline 21 & - & 3.58 & 2.72 & 2.60 \\
\hline 10 & - & 3.34 & 2.93 & $2 . \pm 4$ \\
\hline 11 & - & 3.72 & 3.21 & 2.88 \\
\hline 12 & - & 3.19 & 2.96 & 2.25 \\
\hline 13 & - & 2.88 & 2.29 & 2.35 \\
\hline 14 & - & 3.46 & 2.67 & 2.12 \\
\hline 15 & - & 2.76 & 2.27 & 1.91 \\
\hline 25 & - & 3.20 & 2.87 & 1.90 \\
\hline 26 & - & 2.16 & 1.98 & 1.76 \\
\hline 27 & - & 4.57 & 2.23 & 2.28 \\
\hline 28 & - & 1.76 & 1.79 & 1.97 \\
\hline
\end{tabular}


TABLE C-XII (continued)

\begin{tabular}{|c|c|c|c|c|}
\hline $\begin{array}{l}\text { Sample } \\
\text { ID No. }\end{array}$ & $\begin{array}{c}\text { Starting } \\
\text { Material } \\
\text { Avg. Dia ( } \mathrm{m}) \\
\end{array}$ & $\begin{array}{c}1 \text { Month } \\
\text { Avg Dia ( } \mathrm{m})\end{array}$ & $\begin{array}{r}2 \text { Months } \\
\text { Avg Dia }(\mu \mathrm{m}) \\
\end{array}$ & $\begin{array}{c}3 \text { Months } \\
\text { Avg Dia }(\mu \mathrm{m})\end{array}$ \\
\hline 29 & - & 1.77 & 1.62 & 1.53 \\
\hline 30 & - & 2.26 & 3.50 & 2.12 \\
\hline 31 & - & 1.93 & 1.34 & 0.90 \\
\hline 32 & - & 2.28 & 1.81 & 1.23 \\
\hline 33 & - & 2.16 & 1.35 & 1.01 \\
\hline 34 & - & 1.28 & 0.60 & 0.75 \\
\hline 36 & - & 1.76 & 1.80 & 1.18 \\
\hline 37 & - & 2.91 & 1.46 & 1.44 \\
\hline 38 & - & 1.35 & 0.68 & 0.79 \\
\hline 39 & - & 1.64 & 0.47 & 0.61 \\
\hline
\end{tabular}


TABLE C-XIII

AVERAGE POROSITIES OF POWDER COMPACTS FROM STATIC $250^{\circ} \mathrm{C}$ TEST, AFTER INDICATED EXPOSURE

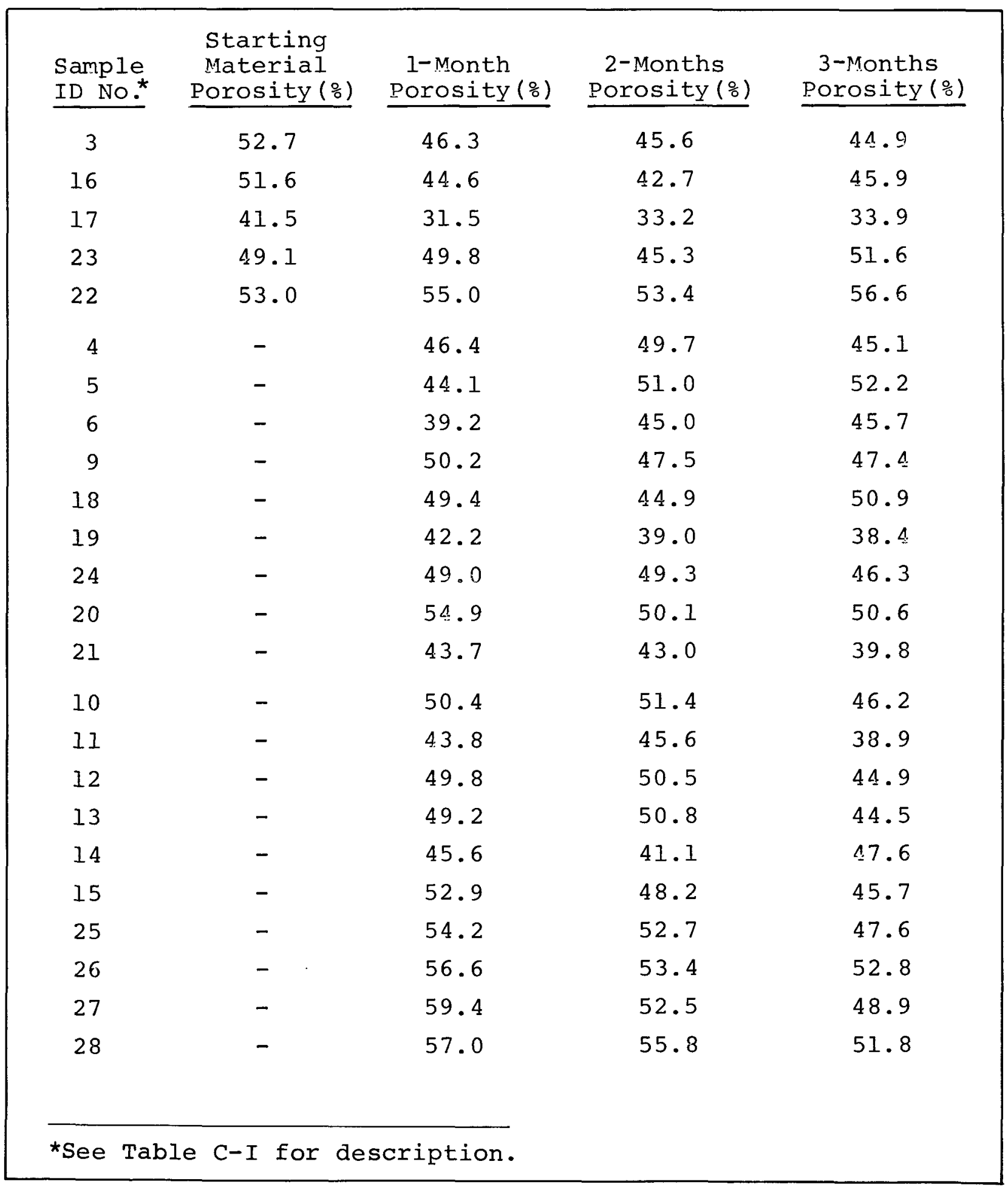


TABLE C-XII (continued)

\begin{tabular}{|c|c|c|c|c|}
\hline $\begin{array}{l}\text { Sample } \\
\text { ID No. }\end{array}$ & $\begin{array}{c}\text { Starting } \\
\text { Material } \\
\text { Avg. Dia ( }(\mathrm{m})\end{array}$ & $\begin{array}{c}1 \text { Month } \\
\text { Avg Dia }(\mu \mathrm{m})\end{array}$ & $\begin{array}{c}2 \text { Months } \\
\text { Avg Dia }(\mu \mathrm{m})\end{array}$ & $\begin{array}{c}3 \text { Months } \\
\text { Avg Dia }(\mu \mathrm{m})\end{array}$ \\
\hline 29 & - & 1.77 & 1.62 & 1.53 \\
\hline 30 & - & 2.26 & 3.50 & 2.12 \\
\hline 31 & - & 1.93 & 1.34 & 0.90 \\
\hline 32 & - & 2.28 & 1.81 & 1.23 \\
\hline 33 & - & 2.16 & 1.35 & 1.01 \\
\hline 34 & - & 1.28 & 0.60 & 0.75 \\
\hline 36 & - & 1.76 & 1.80 & 1.18 \\
\hline 37 & - & 2.91 & 1.46 & 1.44 \\
\hline 38 & - & 1.35 & 0.68 & 0.79 \\
\hline 39 & - & 1.64 & 0.47 & 0.61 \\
\hline
\end{tabular}


TABLE C-XIII

AVERAGE POROSITIES OF POWDER COMPACTS FROM STATIC $250^{\circ} \mathrm{C}$ TEST, AFTER INDICATED EXPOSURE

\begin{tabular}{|c|c|c|c|c|}
\hline $\begin{array}{l}\text { Sample } \\
\text { ID No.* }\end{array}$ & $\begin{array}{c}\text { Starting } \\
\text { Material } \\
\text { Porosity }(\%) \\
\end{array}$ & $\begin{array}{c}\text { I-Month } \\
\text { Porosity }(\%) \\
\end{array}$ & $\begin{array}{c}2 \text {-Months } \\
\text { Porosity }\left(\frac{8}{6}\right) \\
\end{array}$ & $\begin{array}{c}\text { 3-Months } \\
\text { Porosity (\%) } \\
\end{array}$ \\
\hline 3 & 52.7 & 46.3 & 45.6 & 44.9 \\
\hline 16 & 51.6 & 44.6 & 42.7 & 45.9 \\
\hline 17 & 41.5 & 31.5 & 33.2 & 33.9 \\
\hline 23 & 49.1 & 49.8 & 45.3 & 51.6 \\
\hline 22 & 53.0 & 55.0 & 53.4 & 56.6 \\
\hline 4 & - & 46.4 & 49.7 & 45.1 \\
\hline 5 & - & 44.1 & 51.0 & 52.2 \\
\hline 6 & - & 39.2 & 45.0 & 45.7 \\
\hline 9 & - & 50.2 & 47.5 & 47.4 \\
\hline 18 & - & 49.4 & 44.9 & 50.9 \\
\hline 19 & - & 42.2 & 39.0 & 38.4 \\
\hline 24 & - & 49.0 & 49.3 & 46.3 \\
\hline 20 & - & 54.9 & 50.1 & 50.6 \\
\hline 21 & - & 43.7 & 43.0 & 39.8 \\
\hline 10 & - & 50.4 & 51.4 & 46.2 \\
\hline 11 & - & 43.8 & 45.6 & 38.9 \\
\hline 12 & - & 49.8 & 50.5 & 44.9 \\
\hline 13 & - & 49.2 & 50.8 & 44.5 \\
\hline 14 & - & 45.6 & 41.1 & 47.6 \\
\hline 15 & - & 52.9 & 48.2 & 45.7 \\
\hline 25 & - & 54.2 & 52.7 & 47.6 \\
\hline 26 & - & 56.6 & 53.4 & 52.8 \\
\hline 27 & - & 59.4 & 52.5 & 48.9 \\
\hline 28 & - & 57.0 & 55.8 & 51.8 \\
\hline
\end{tabular}


TABLE C-XIII (continued)

\begin{tabular}{|ccccc}
\hline $\begin{array}{c}\text { Sample } \\
\text { ID No. }\end{array}$ & $\begin{array}{c}\text { Starting } \\
\text { Material } \\
\text { Porosity(\%) }\end{array}$ & $\begin{array}{c}\text { 1-Month } \\
\text { Porosity (\%) }\end{array}$ & $\begin{array}{c}\text { 2-Months } \\
\text { Porosity(\%) }\end{array}$ & $\begin{array}{c}\text { 3-Months } \\
\text { Porosity }(\%)\end{array}$ \\
\cline { 1 - 2 } 29 & - & 55.4 & 52.1 & 52.3 \\
30 & - & 53.1 & 50.9 & 47.8 \\
31 & - & 59.1 & 54.9 & 54.6 \\
32 & - & 58.0 & 56.4 & 55.5 \\
33 & - & 59.6 & 56.9 & 55.8 \\
34 & - & 63.3 & 59.0 & 57.7 \\
36 & - & 59.2 & 52.2 & 57.7 \\
37 & - & 59.0 & 56.8 & 56.7 \\
38 & - & 63.3 & 59.4 & 56.7 \\
39 & - & 60.5 & 59.2 & 60.6 \\
\hline
\end{tabular}

